\title{
Conceptual and Preliminary Design of a Stowable Ruggedized Micro Air Vehicle
}

\author{
Shanti D. Hamburg \\ West Virginia University
}

Follow this and additional works at: https://researchrepository.wvu.edu/etd

\section{Recommended Citation}

Hamburg, Shanti D., "Conceptual and Preliminary Design of a Stowable Ruggedized Micro Air Vehicle" (2010). Graduate Theses, Dissertations, and Problem Reports. 4600.

https://researchrepository.wvu.edu/etd/4600

This Thesis is protected by copyright and/or related rights. It has been brought to you by the The Research Repository @ WVU with permission from the rights-holder(s). You are free to use this Thesis in any way that is permitted by the copyright and related rights legislation that applies to your use. For other uses you must obtain permission from the rights-holder(s) directly, unless additional rights are indicated by a Creative Commons license in the record and/ or on the work itself. This Thesis has been accepted for inclusion in WVU Graduate Theses, Dissertations, and Problem Reports collection by an authorized administrator of The Research Repository @ WVU. For more information, please contact researchrepository@mail.wvu.edu. 


\title{
Conceptual and Preliminary Design of a Stowable Ruggedized Micro Air Vehicle
}

\author{
Shanti D. Hamburg
}

Thesis submitted to the College of Engineering and Mineral Resources

at West Virginia University

in partial fulfillment of the requirements for the degree of

\author{
Master of Science \\ In \\ Aerospace Engineering
}

\author{
Wade W. Huebsch, Ph.D., Chair \\ Mridul Gautam, Ph.D. \\ John M. Kuhlman, Ph.D.
}

Department of Mechanical and Aerospace Engineering

Morgantown, West Virginia

2010

Keywords: Micro Air Vehicle; Unmanned Air Vehicle; Low Reynolds Number Flight; Stowable Aircraft;

Numerical Simulation; Aircraft Design; Fluent; Gambit; TGrid; Computational Fluid Dynamics

Copyright 2010 Shanti D. Hamburg 


\title{
Abstract \\ Conceptual and Preliminary Design of a Stowable Ruggedized Micro Air Vehicle
}

\begin{abstract}
Shanti D. Hamburg
This study presents both feasibility and preliminary design studies of a ruggedized, stowable, ballistically launched Micro Air Vehicle (MAV). A vehicle capable of being stored within a $40 \mathrm{~mm}$ diameter, $133 \mathrm{~mm}$ long cylinder and able to withstand a significantly rough environment when stowed was desired. Minimum performance specifications were a $20 \%$ range increase from a $450 \mathrm{~m}$ range, $45^{\circ}$ launch angle ballistic trajectory and a gliding time of $30 \mathrm{~s}$ from the apex of said trajectory. To this end, a study of comparable MAV systems, available control and communication electronics, low Reynolds number flight, ballistic flight, and advanced projectiles was conducted. It was found that the concept was possible using current electronics, however, these would require a large majority of the available volume necessitating the novel, compact, wing stowage systems discussed within. While aerodynamically feasible the transition between ballistic and aircraft flight will necessitate significant sensor and control logic design. The small scales of this project necessitated consideration of the vagaries of low Reynolds number flight. Despite the final design proposals maintaining chordwise Reynolds numbers greater than 100,000 several key trends were found to be significantly different than those encountered in classical aerodynamic theory; particularly the existence of an optimum aspect ratio for maximum lift to drag ratio of the wing alone. For a fixed wing area and velocity increasing the aspect ratio, thereby reducing induced drag, also reduced the chordwise Reynolds number which reduced the efficiency of the airfoil. At the optimum benefits from reducing induced drag balanced with the penalties of reduced airfoil performance. The feasibility study focused primarily on volumetric concerns; minimizing stowed wing volume was the main goal. Several design iterations were constructed in SolidWorks prior to the development of two concepts ready for prototyping and testing. Design optimization was performed with both classical semiempirical methods using Missile DATCOM and a custom in-house Matlab code as well as the Fluent CFD package. Significant work was done to find a suite of solver settings and mesh generation parameters capable of predicting 2D and 3D low Reynolds number airfoil performance with sufficient quality for preliminary design work. Optimization studies found that achieving both initial performance goals with a single aircraft would be highly inefficient. This effort concluded with a pair of designs, one high-speed cruise-to-target version capable of $700 \mathrm{~m}$ range and $9 s$ gliding time optimized for rapidresponse, and a long-endurance glider with a flight time greater than $60 \mathrm{~s}$ optimized for surveillance purposes.
\end{abstract}




\section{Acknowledgements}

To my mother and father for giving me the freedom, confidence, and encouragement to follow and begin to fulfill my childhood dream. To both of you and Aunt Diane for supporting my hobbies and harebrained schemes, and for being there when things did not go as planned.

To my brother for keeping me grounded. Seriously, thank you for "Design-Build-Crash \& Burn".

To Doctors John Loth and Richard Guiler for their advice and support in Design/Build/Fly. Thank you both for the opportunity to learn so much of design, management, and responsibility.

To my committee, Dr. Mridul Gautam, Dr. John Kuhlman, and especially Dr. Wade Huebsch for the incredible confidence and trust that was placed in me. New masters students do not often get the opportunity to lay the groundwork for such an important project.

Sincerely;

Shanti D. Hamburg 


\section{Table of Contents}

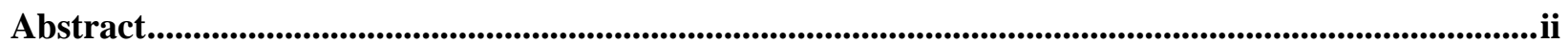

Acknowledgements .................................................................................................................................iii

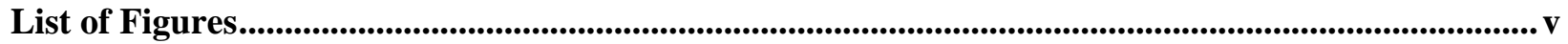

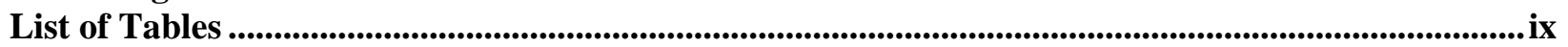

Chapter 1 Problem Statement.........................................................................................1

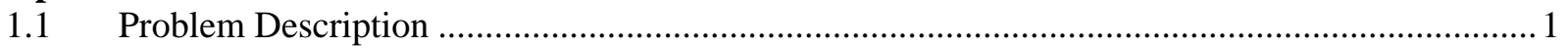

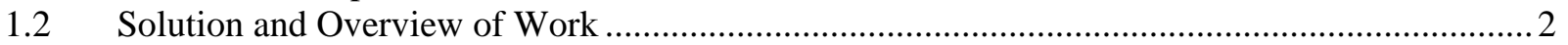

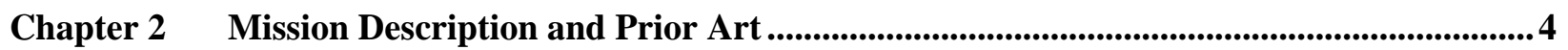

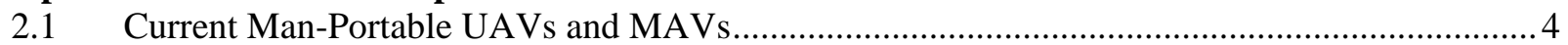

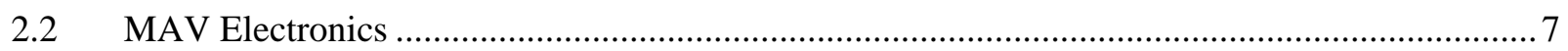

2.3 Low Reynolds Number Aerodynamics ................................................................. 11

2.3.1 Two Dimensional Flow: Separation Bubbles and Transition........................................ 12

2.3.2 Three Dimensional Low Aspect Ratio Aerodynamics .................................................. 14

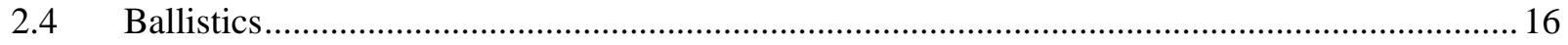

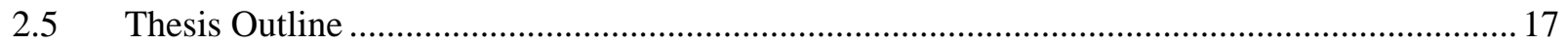

Chapter 3 Concept Development ..................................................................................................... 19

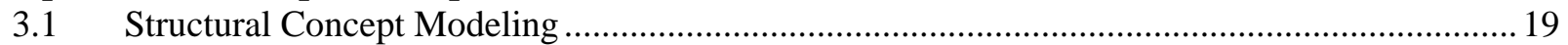

3.1.1 Cargo Stowage Concepts ........................................................................................... 22

3.1.2 Wrapped Membrane Structure Detail ........................................................................ 25

3.1.3 Transformer Stowage Concepts ................................................................................ 30

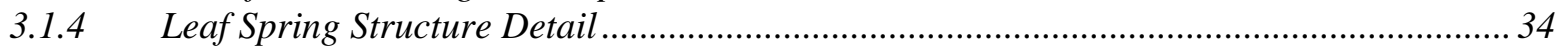

Control Surface Actuation Concepts............................................................................. 37

3.2.1 Torsion Rod System......................................................................................... 37

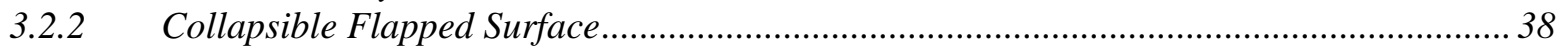

3.3 De-Spin and Orientation Methods ............................................................................. 39

Chapter 4 Initial Surface Sizing Calculations ....................................................................................43

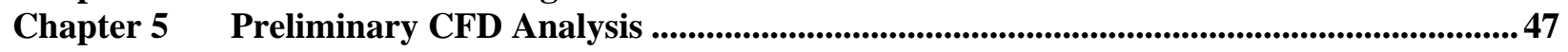

$5.1 \quad$ Stowed Geometry Mesh Generation .......................................................................... 47

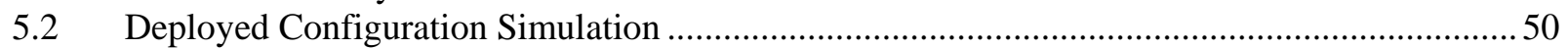

Chapter 6 Classical Aerodynamic Optimization Analysis ..............................................................52

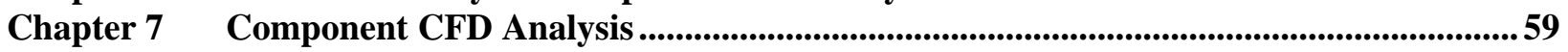

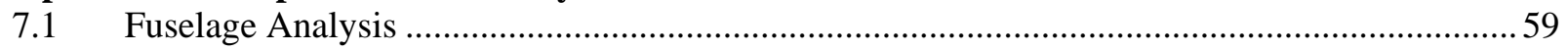

7.2 Two Dimensional Low Reynolds Number Airfoil Analysis.................................................61

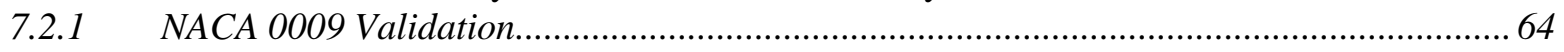

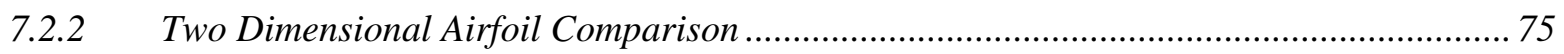

7.3 Preliminary Three Dimensional Main Wing Analysis ................................................... 79

Chapter 8 Recommended Preliminary Designs.................................................................85

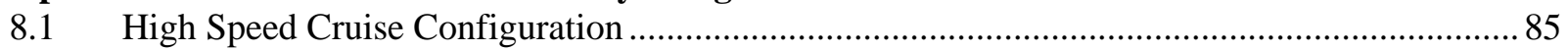

Long Endurance Configuration................................................................................. 88

Chapter 9 Summary and Recommendations ..............................................................................92

References............................................................................................................................95

Appendix A Missile DATCOM Input and Output Files.................................................................. 97

Appendix B Grid Generation Details .............................................................................................. 102

Appendix C Analysis Program Code ................................................................................................. 105

Appendix D Fluent Configuration Details .................................................................................... 120

Appendix E Curriculum Vitae ..................................................................................................... 123 


\section{List of Figures}

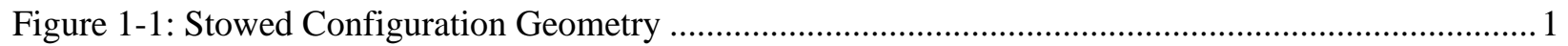

Figure 1-2: Ballistic Launch Trajectory with Minimum Range Increase Specified .................................2

Figure 2-1: Collage of Current UAV and MAVs, Number and Sources as Listed in Table 2-1 ................ 5

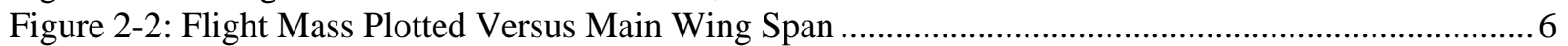

Figure 2-3: Cruise Velocity Plotted Versus Main Wing Span .................................................................... 6

Figure 2-4: Image from $100 \mathrm{~m}$ Altitude at $45^{\circ}$ Angle from Aircraft, $40^{\circ} \times 40^{\circ}$ Field of View, 1,000x 1,000

Pixel Camera(Davis, Kosicki, Boroson, \& Kostishack, 1996) ..................................................... 7

Figure 2-5: Effect of Pitch Oscillation on Camera View (Morris, Design of Micro Air Vehicles and Flight

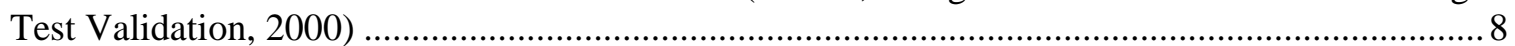

Figure 2-6: Twin Camera System from AeroVironment's Wasp MAV(Grabowsky, 2007) ...................... 8

Figure 2-7: $20 \mathrm{~cm}$ Trochoid Planform MAV from MLB Company (Morris, Design of Micro Air Vehicles

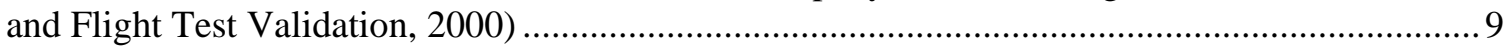

Figure 2-8: Micro Video Camera and Transmitter (Torres \& Mueller, 2001)......................................... 9

Figure 2-9: Circuitry Required for Optical Flow Velocity and Altitude Measurement System (Ruffier,

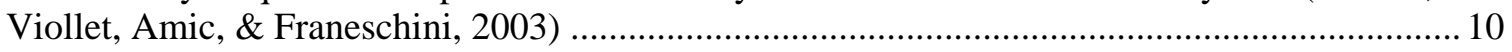

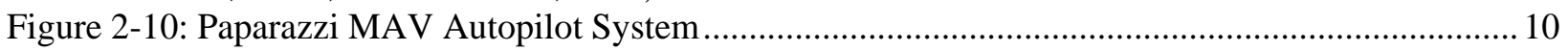

Figure 2-11: Ground Stations for MLB Bat MAV System (Morris, Design of Micro Air Vehicles and

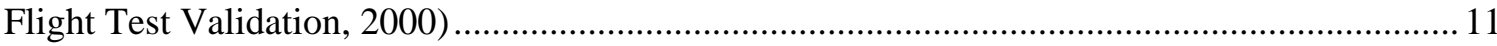

Figure 2-12: Reduction in Smooth Airfoil Performance with Falling Reynolds Number (Lissman, 1983)12

Figure 2-13: Schematic of Low Re Separation Bubble Transition (Roberts, 1980) ................................ 12

Figure 2-14: Hysteresis Behavior of a Wing at Low Reynolds Number (Simons, 1999)........................ 13

Figure 2-15: Drag Polars of an Eppler E374 Airfoil at Low Reynolds Numbers (Shyy, Lian, Tang, Viieru,

\& Liu, 2008) …................................................................................................................ 14

Figure 2-16: Lift Coefficient Versus Angle of Attack for Low Aspect Ratio Rectangular Planforms at

$\mathrm{Re}=10^{5}$ (Mueller, Torres, \& Srull, Elements of Aerodynamics, Propulsion, and Design, 2006) .. 15

Figure 2-17: Characteristic Gyroscopically Stabilized Body Showing CG Location and Axis for Polar and

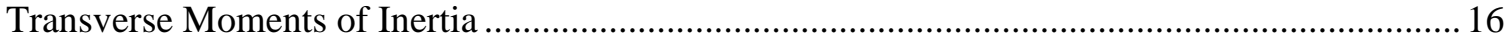

Figure 2-18: Increasing Dispersion and Developing Instability of a Slowly De-Spinning Round (Carlucci

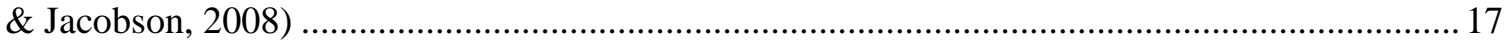

Figure 3-1: Cargo Type Design: Draper Lab's Flyer (Martorana, et al., 2003) ...................................... 19

Figure 3-2: Design Progression of WVU Cargo Work and Opening Sequence ...................................... 20

Figure 3-3: Transformer Type Sonotube, Missile Tube, and Naval Gun Designs (Woodland, 2000)

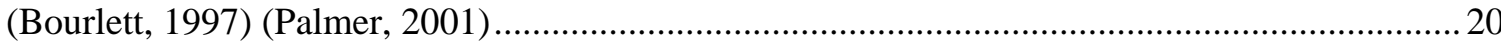

Figure 3-4: WVU Transformer Design Progression and Transformer Deployment Process..................... 21

Figure 3-5: Membrane Wings Concepts, a) WVU Wrapped, b) WVU Leaf Spring, c) Batten Reinforced

(Stanford, Abdulrahim, Lind, \& Ifju, 2007), d) Titanium-Mylar Insect Scale (Pornsin-sirirak, Tai,

\& Ho, 2001), e) Small Scale Batten Reinforced (Fleming, Bartram, Waszak, \& Jenkins, 2001) . 21

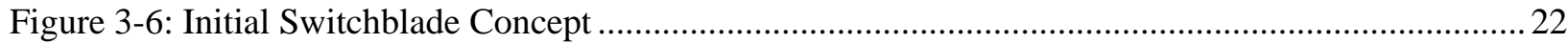

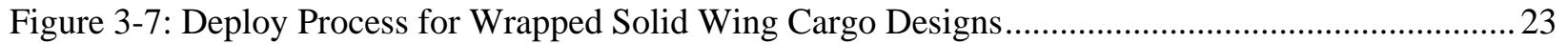

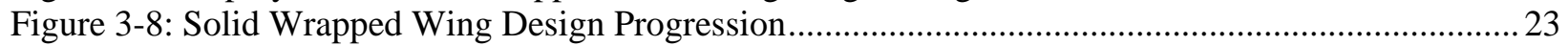

Figure 3-9: Wrapped Membrane Wing Concept............................................................................... 24

Figure 3-10: Cambered Plate MAV With Wrappable Wings (Shyy, Ifju, \& Vieru, Membrane Wing-based

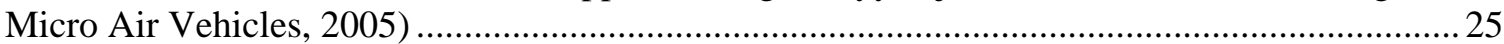

Figure 3-11: Slot For Inner Wrapped Wing Pass-Through................................................................... 26

Figure 3-12: Inflatable or Expandable Lower Surface Profile on Membrane Wing ................................ 26

Figure 3-13: Batten Reinforcement and Adaptive Washout Detail (Stanford, Abdulrahim, Lind, \& Ifju,

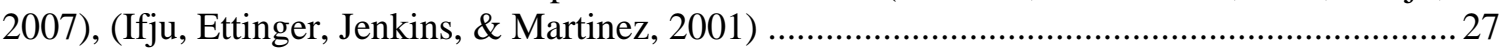

Figure 3-14: "Feathered" Wing Morphing System for WVU Horten Flying Wing (Guiler, 2007) ............ 28 
Figure 3-15: Potential Biomemetic Membrane Wing Configuration Diversity (Sachs, 2007) 29

Figure 3-16: Correlation Mass and Required Yaw Stability with Behavior of a Clean Swept Biomemetic

Planform(Sachs, 2007)

Figure 3-17: Sponsor Telescopic Transformer Concept, (dimensions in $\mathrm{cm}$ )...................................... 30

Figure 3-18: Switchblade Transformer Structural Concept, (dimensions in $\mathrm{mm}$ ) .................................. 31

Figure 3-19: Telescopic Transformer Structural Concept, (dimensions in $\mathrm{mm}$ ) ...................................... 32

Figure 3-20: Leaf Spring Transformer Structural Concept................................................................. 33

Figure 3-21: Inverse Relationship Between Span and Tip Chord Length of Leaf Spring Structure for

Wings with Equal Length Leading Edge Leaves ........................................................................ 34

Figure 3-22: Method for Varying Leaf Spring Angle of Attack Relative to Fuselage; Gray) Fuselage With

Slot for Membrane and Leaves, Blue) Rotating Mount for Leaves, Yellow) Leaf Spring Elements,

Tan) Membrane Bonded to Leaf Upper and Lower Surfaces .................................................... 35

Figure 3-23: Rotated Leaves for Control Surface Actuation and Camber Modifications; Fixed Leaves and

Fuselage (Gray), Outboard Surface Rotation Point and Leaves (Red), Inboard Rotation Point and

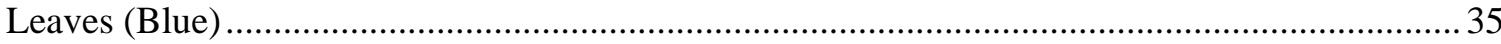

Figure 3-24: Staged Wing Deployment for Stabilization and De-spin; Red) Initial Deployment for De-

spin and Orientation, Blue) Secondary Deployment of Main Wings ............................................ 36

Figure 3-25: Illustration of Bounding Flight for Increased Cruising Speed (Morris, Design and Flight Test

Results for Micro-Sized Fixed-Wing and VTOL Aircraft, 1997)............................................... 36

Figure 3-26: Torsion Rod Control System on Batten Reinforced Wing, Multiple Actuation Point

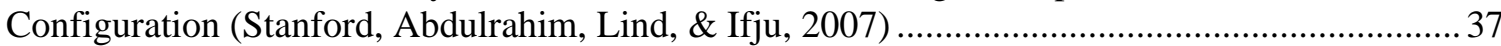

Figure 3-27: Effective Flapped Control Surface for Membrane Wings; Black) Carbon Laminate Structure,

Tan) Membrane Surface, Dark Gray) Rigid Elements Bonded to Membrane, Light Gray) Control

Horns and Cables for Pull-Pull Control ........................................................................................ 38

Figure 3-28: Instability and Dispersion Caused by Slowly Decreasing Spin Rate(Carlucci \& Jacobson, 2008)

Figure 3-29: Paparazzi Autopilot Infrared Aerodynamic Angle Sensor System for Spin Orientation

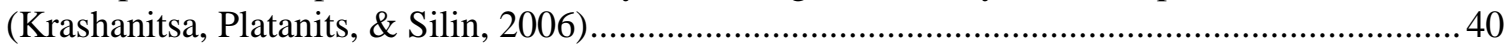

Figure 3-30: Cruciform Planform and Tri Planforms for Active Control Surface De-spin ....................... 40

Figure 3-31: Multi-Stage Fin Deployment Schematic; a) Stabilizer Fins Deploy Further as Lifting

Surfaces, b) Additional Lifting Surface Deploy, c) Stabilizers Deploy, De-Spin, and Discard Prior

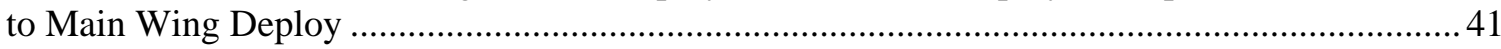

Figure 3-32: Casing Ejection in Spin Direction with High Rotation Rate to Reduce MAV Rotation Rate 42

Figure 4-1: Fuselage and Tail Configuration Studied with MDCOM, Dimensions in $\mathrm{mm}$...................... 44

Figure 4-2: Tail Sizing Sensitivity Study with Three CG Locations ......................................................45

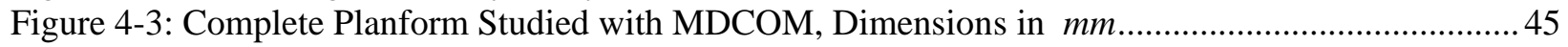

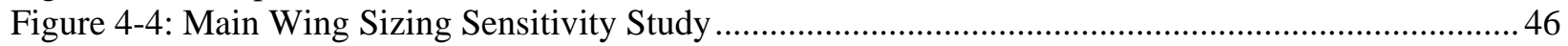

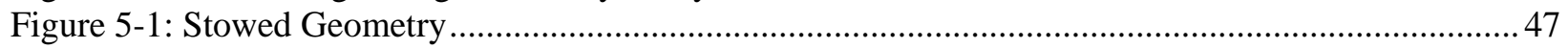

Figure 5-2: Solution Domain, Sliced on Longitudinal Centerline ..........................................................49

Figure 5-3: Convergence Plot for Stowed Geometry, Mesh Converged at 2.7x10 ${ }^{6}$ Cells ......................... 49

Figure 5-4: Initial Deployed Geometry Surface Meshes, Identical Vertical Tail Area and Main Wing

Area, Identical Fuselages ..................................................................................................... 50

Figure 5-5: Comparison of Flow at Tails of Conventional and Delta Planforms, Pathlines Colored by

Velocity, $(\mathrm{m} / \mathrm{s})$, Jagged Black Lines Are Artifacts From Geometry Contour Display ...................51

Figure 6-1: Effect of Varying Launch Angle for AR $=2$ Wing on Cruise Velocity and Initial Gliding

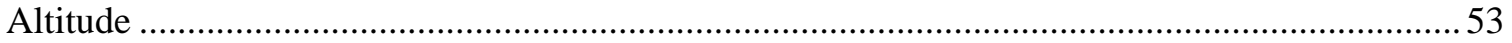

Figure 6-2: Optimization Code Flowchart ....................................................................................... 54

Figure 6-3: Comparison of High Speed, Low Angle Launch and Low Speed, High Angle Launch

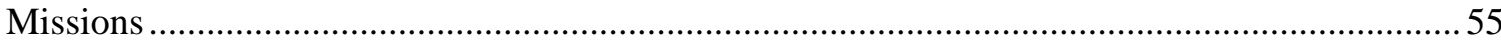

Figure 6-4: Comparison of Alternate Mission Plan Required Wing Areas, Dimensions in $\mathrm{mm}$...............56 
Figure 6-5: Comparison of Required Wing Area for High-Speed Cruise ( Wing Loading $(W / S)=700$

$\mathrm{N} / \mathrm{m}^{2}, V_{c r}=48 \mathrm{~m} / \mathrm{s}, S=2,523 \mathrm{~mm}^{2}$ ) and Long Endurance Missions (Wing Loading $(\mathrm{W} / \mathrm{S})=150$

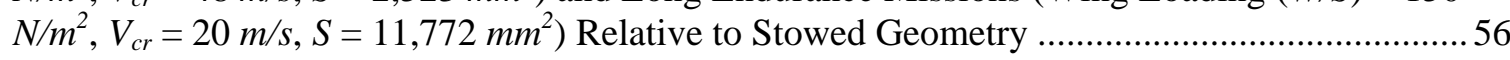

Figure 6-6: Comparison of WVU Stowable UAV Flight Regimes for High-Speed and Long-Endurance

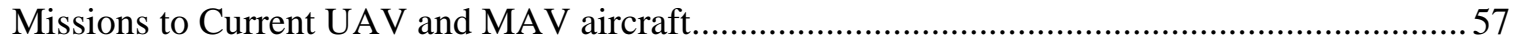

Figure 6-7: Lift-to-drag Ratio Sensitivity to Fuselage Drag Coefficient .................................................58

Figure 7-1: Various Ogive Tail Cones Applied to Stowed Geometry for Fuselage Study, Dimensions in mm

Figure 7-2: Mesh Independence Study for 45 mm Center Body Fuselage............................................ 60

Figure 7-3: Component Mesh For Fuselage Analysis, 45 mm Center Body .............................................. 60

Figure 7-4: Correlation Between Fuselage Volume and Fuselage Drag Coefficient, Stowed Geometry is

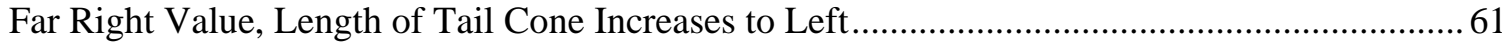

Figure 7-5: Smoke Visualization of Transition Bubble on a Smooth Airfoil at Re - 40,000 (Mueller \&

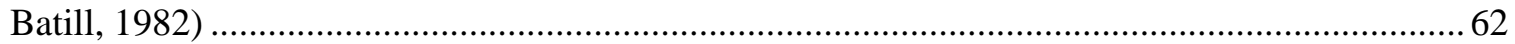

Figure 7-6: Turbulent Boundary Layer Measurements at Reynolds Numbers Under $0.5 \times 10^{5}$, Airfoil Chord

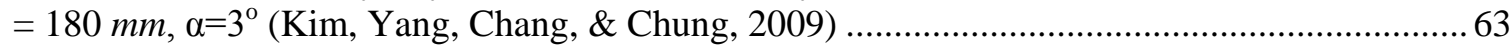

Figure 7-7: Comparison Between y+>30 Mesh Results and Experimental Data for a NACA 0009 Airfoil at $\mathrm{Re}=1.5 \times 10^{5}$. NACA 0009 Experimental Data, (Selig, Donovan, \& Fraser, 1989) ..................... 64

Figure 7-8: Mesh Regions for 2D Airfoil Studies, Labels as in Table 7-1 .......................................... 65

Figure 7-9: Lift and Drag Coefficient Plot Showing Mesh Independence for NACA 0009 2D Airfoil,

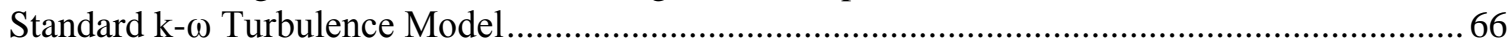

Figure 7-10: Comparison of Blunt and Sharp Trailing Edge Mesh Geometries, Dimensions in $m$............ 67

Figure 7-11: Comparison of Blunt and Sharp Trailing Edge Mesh Results, Standard k- $\omega$ Turbulence

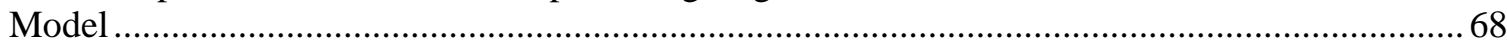

Figure 7-12: Lift-to-drag Ratios for Selected Turbulence Models at a Reynolds Number of $3 \times 10^{5} \ldots \ldots \ldots . . .70$

Figure 7-13: Lift-to-drag Ratios for Final Turbulence Model Down-Select at Reynolds Number of 0.6x10

Figure 7-14: Drag Polar Using K- $\omega$ SST Turbulence Model for a NACA 0009 at a Reynolds Number of

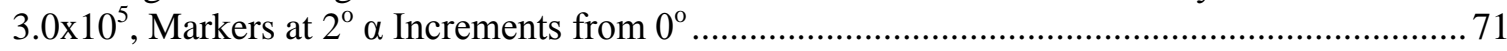

Figure 7-15: Drag Polar Using K- $\omega$ SST Turbulence Model for a NACA 0009 at a Reynolds Number of

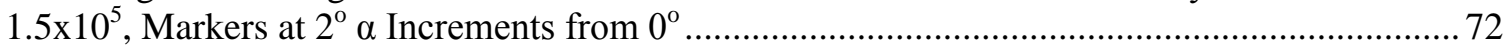

Figure 7-16: Drag Polar Using K- $\omega$ SST Turbulence Model for a NACA 0009 at a Reynolds Number of

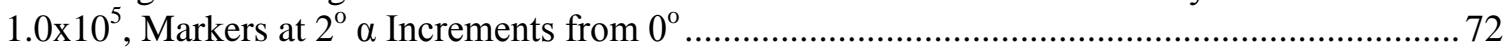

Figure 7-17: Drag Polar Using K- $\omega$ SST Turbulence Model for a NACA 0009 at a Reynolds Number of

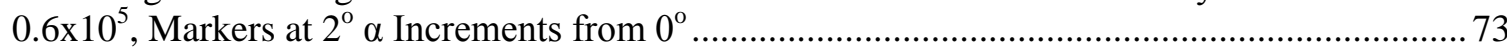

Figure 7-18: Velocity Pathlines $\left(\mathrm{m} / \mathrm{s}\right.$ ) Showing Prediction of Recirculating Separation Bubble, $6^{\circ} \alpha$,

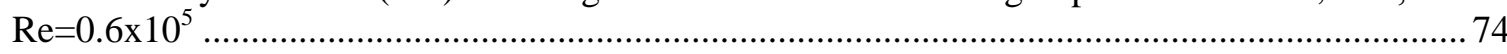

Figure 7-19: Pressure Coefficient Around NACA 0009 Showing Separation Bubble "plateau", $6^{\circ} \alpha$,

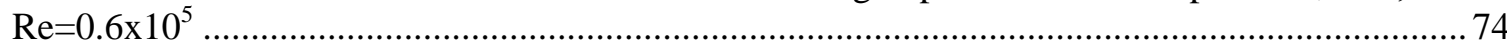

Figure 7-20: MA 409 Drag Polar with Experimental and CFD Data .................................................. 76

Figure 7-21: S 2048Drag Polar with Experimental and CFD Data ........................................................ 76

Figure 7-22: DF 102 Drag Polar with Experimental and CFD Data....................................................... 77

Figure 7-23: NACA 0009 Drag Polar with Experimental and CFD Data .............................................. 77

Figure 7-24: S 3010 Drag Polar with Experimental and CFD Data ...................................................... 78

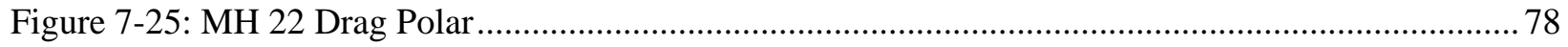

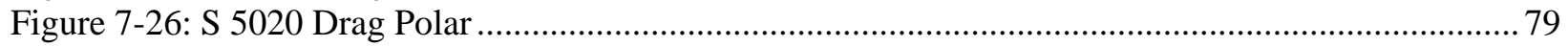

Figure 7-27: Surface and Centerline Volume Mesh for Initial 3D Wing Modeling ................................. 80

Figure 7-28: Mesh Independence Plot for Initial 3D Wing Modeling .................................................... 80

Figure 7-29: Pathlines Colored by Velocity $\left(\mathrm{m} / \mathrm{s}\right.$ ) Around Reference Wing (Angle of Attack $=4^{\circ}$ ) ......... 81

Figure 7-30: Inverse Correlation Between Aspect Ratio and Lift-to-drag Ratio and Direct Correlation Between Lift-to-drag Ratio and Mean Aerodynamic Chord Reynolds Number ........................... 82 
Figure 7-31: Lift-to-drag Ratio Improving Towards Optimum As Wing Loading Increases in Initial Study

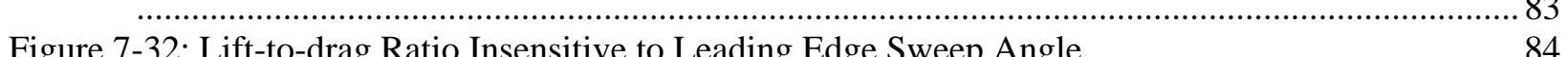

Figure 7-32: Lift-to-drag Ratio Insensitive to Leading Edge Sweep Angle ……….............................. 84

Figure 7-33: Inverse Correlation Between Taper Ratio and Lift-to-drag Ratio....................................... 84

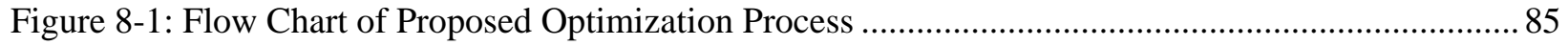

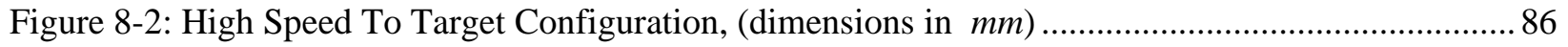

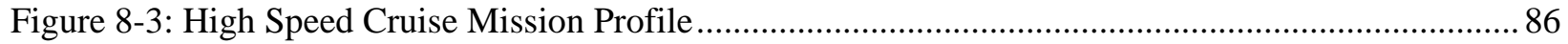

Figure 8-4: High Speed Leaf Spring Structure Concept, Partially Deployed (Left) and Fully Deployed

(Right)... 87

Figure 8-5: High Speed Membrane Wing Structure Concept, Partially Deployed (Left) and Fully

Deployed (Right) 87

Figure 8-6: Long Endurance Concept, Dimensions in mm. 89

Figure 8-7: Long Endurance Configuration Leaf Spring Structure, Top Left Front Quarter (Left), Bottom

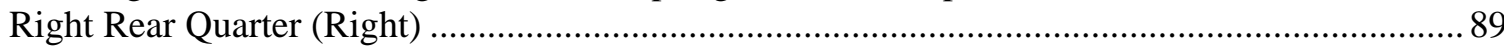

Figure 8-8: Long Endurance Configuration Wrapped Membrane Structure ..........................................90

Figure 8-9: Schematic of Long Endurance Mission Profile.................................................................. 91 


\section{List of Tables}

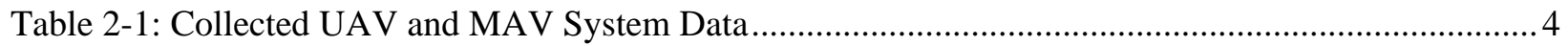

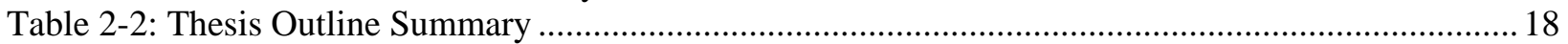

Table 5-1: Sponsor Recommended Solver Settings and Domain Sizes With WVU Selected Solver Settings 48

Table 6-1: Given Stowed Trajectory Data and Calculated Launch Velocity...........................................52

Table 6-2: Results of Optimization Code for an Array of Launch Angles ................................................54

Table 7-1 Mesh Region Specifications for Figure 7-8, C=Chord Length, $0.1 \mathrm{~m}$ for this Study ................ 65

Table 7-2: Summary of Fluent 12 Turbulence Models Applied to NACA 0009 at $6^{\circ}$ Angle of Attack and

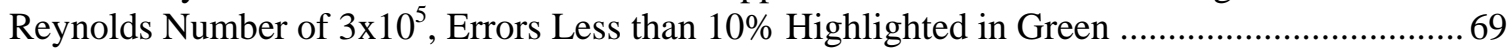

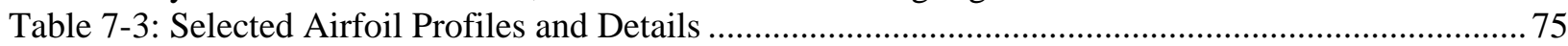

Table 7-4: Flow Parameters, Lift Coefficient, and Geometric Parameters Varied for Three Dimensional

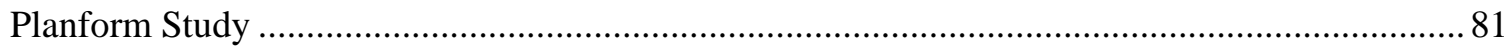

Table 8-1: Sizes and Expected Performance of High Speed MAV ................................................. 88

Table 8-2: Sizes and Expected Performance of Long Endurance MAV ................................................. 91 


\section{Chapter 1 Problem Statement}

\subsection{Problem Description}

A micro aerial vehicle (MAV) was to be deployed from a compact, rugged, stowed configuration. This aircraft was intended to launch on a ballistic trajectory in a cylindrical stowed configuration and deploy aerodynamic surfaces to increase range and provide maneuvering and guidance capability. This document discusses the conceptual and preliminary design, paying particular attention to the problems created by the transition between ballistic and aircraft flight. The proposed size of the stowed configuration imposed significant geometric constraints that required a thorough modeling process and forced the design into unusual flight regimes.

The stowed configuration was specified as a $40 \mathrm{~mm}$ diameter cylindrical body with a hemispherical nose $133 \mathrm{~mm}$ in total length, as shown in Figure 1-1. The center of gravity was fixed at $50 \%$ along the body length in the stowed configuration. Launch conditions were specified as a ballistic trajectory with $450 \mathrm{~m}$ range on the ballistic arc with a $40 \mathrm{~m} / \mathrm{s}$ apex velocity at a launch angle of $45^{\circ}$ (Figure 1-2). A minimum $20 \%$ range increase was specified, as well as a fight mass of $180 \mathrm{~g}$. Note that the flight profiles sketched in Figure 1-2 are for illustration only and do not represent the actual profile. In reality the flight plan would form a ballistic arc up to apex and a straight-line gliding decent afterwards.

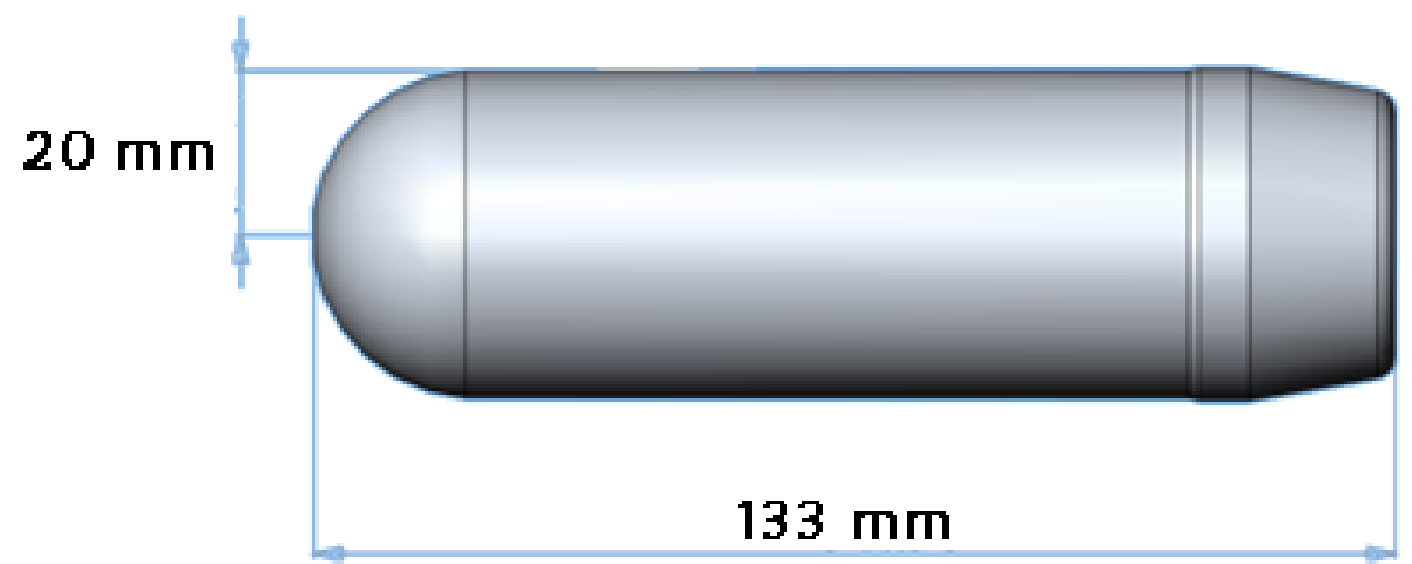

Figure 1-1: Stowed Configuration Geometry 


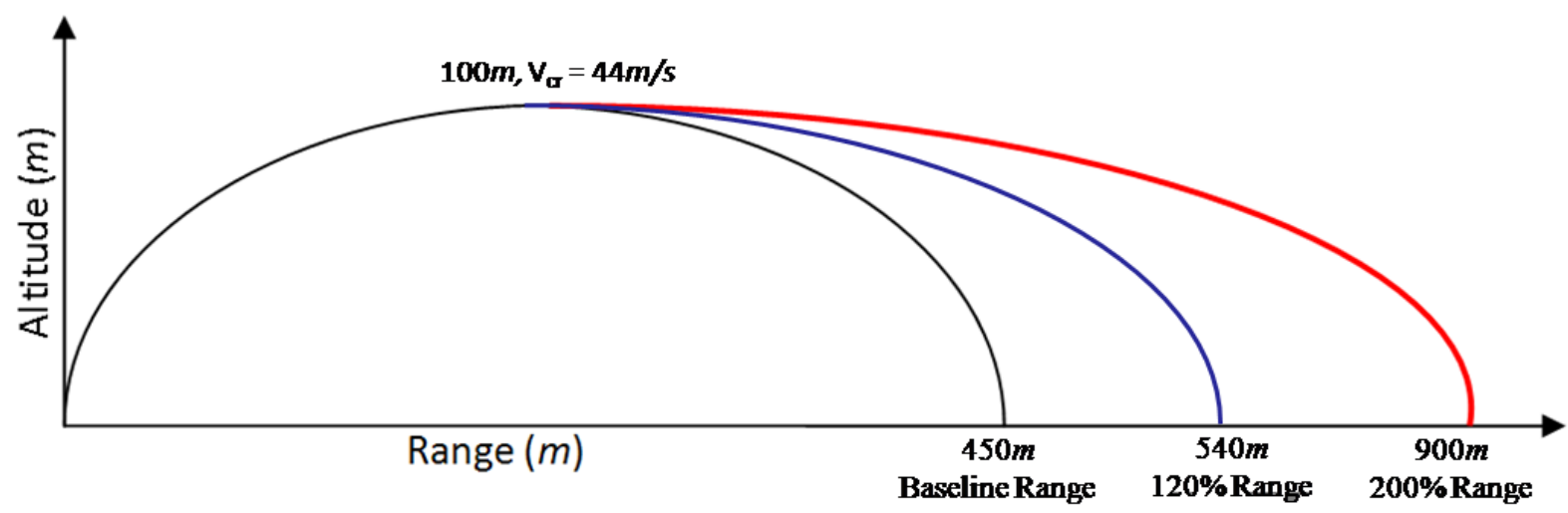

Figure 1-2: Ballistic Launch Trajectory with Minimum Range Increase Specified

Concepts for lifting and stabilizing surface planforms as well as stowable structures were required. The primary goal was to prove the aerodynamic feasibility of this stowed MAV concept. This included preliminary recommendation on lifting and stabilizing surface sizing and location for acceptable gliding range and stable flight. Proving volumetric feasibility was also a major consideration. Stowed aerodynamic surfaces had to leave sufficient volume for future sensor, control, and payload systems.

Due to International Traffic in Arms Regulations and other security considerations some work done on this project has been omitted from this document. These omissions do not seriously impact the new information presented here as they deal with a specific application rather than the general preliminary design work which is the primary focus of this document.

\subsection{Solution and Overview of Work}

Few options exist to extend the range of an object on a ballistic trajectory. Drag can be reduced by modifying external geometry, but work in this document will show that body drag can only be reduced by approximately $1 / 3$ at a significant loss of useful volume. The most effective way to extend the range of a ballistic object was to increase its lift-to-drag ratio by the addition of lifting surfaces. This placed concept development in the region between ballistics and micro aerial vehicle design.

Design work began with brainstorming stowable wing structure concepts. Development of these concepts provided maximum area and extreme fore and aft location limits for the wings and tails. A semiempirical code was used to generate first-cut wing and tail sizes within these limits. According to these semi-empirical methods performance goals were surprisingly easy to meet.

With initial sizing completed the stowed geometry was simulated in Fluent to verify prediction capability and develop flexible, accurate solution settings. Two basic deployed planforms were then studied, a high aspect ratio conventional design, and a clipped-delta layout. At the low Reynolds numbers of this flight regime the clipped delta wing had twice the lift-to-drag ratio of the conventional layout. With such a clear and significant result all work was then focused on optimizing a delta, or other low aspect ratio, configuration. 
Classical aerodynamic analysis methods were applied again in an optimization analysis of the main wing and launch angle. As expected, optimum wing loading varied significantly with the apex/cruise velocity. This led to two divergent designs; one focused on the specified range increase, the other on a longer, slower flight better suited to a surveillance mission. Long endurance missions required a wing area in the neighborhood of $10,000 \mathrm{~mm}^{2}$ while the extended range mission only required 2,500 $\mathrm{mm}^{2}$.

A numerical study of airfoils and planforms at low Reynolds numbers was then conducted to check classical theory predictions and converge on optimums. This led to the two final designs; a high wing-loading, high-speed, range-extended version, and a low-speed, long-endurance reconnaissance design. 


\section{Chapter 2 Mission Description and Prior Art}

The project required combining the field of MAV design with basic ballistics as well as a preliminary study of available miniaturized electronics. While the deployed configuration is meant to function purely as a MAV with all associated ground equipment the launch concept required some basic knowledge of gyroscopically stabilized flight. Blending these two flight regimes necessitated a study of current unmanned aerial vehicles, micro air vehicles, gyroscopically stabilized ballistics, advanced projectiles, miniaturized electronics, and low speed aerodynamics.

\subsection{Current Man-Portable UAVs and MAVs}

A survey of current MAV and small UAV systems was conducted. Data collected included mass, size, velocity, and ground station type information. Table 2-1 presents this data and Figure 2-1 shows a collage of the vehicles. Unfortunately complete information was not available for all aircraft. Wing loadings would have been the preferred point of comparison rather than wing span and flight mass. Unfortunately wing area data was not available for the majority of the comparable aircraft.

Table 2-1: Collected UAV and MAV System Data

\begin{tabular}{|c|c|c|c|c|c|c|}
\hline & Designation & Classification & \begin{tabular}{|c|} 
Wing Span \\
$(m)$
\end{tabular} & $\begin{array}{l}\text { Maximum } \\
\text { Mass }(k g)\end{array}$ & $\begin{array}{c}\text { Cruise Speed } \\
(\mathrm{m} / \mathrm{s})\end{array}$ & Source \\
\hline 1 & MLB $15 \mathrm{~cm}$ Trochoid & $\mathrm{MAV}^{1}$ & 0.150 & & 13.400 & Design of MAVs (MLB Co.) \\
\hline 2 & University of Floridia MAV & MAV & 0.152 & 0.055 & 11.170 & Composite Materials for MAVs \\
\hline 3 & Black Widow & MAV & 0.152 & 0.050 & 12.630 & defense-update.com \\
\hline 4 & MLB $20 \mathrm{~cm}$ Trochoid & MAV & 0.200 & & 13.400 & Design of MAVs (MLB Co.) \\
\hline 5 & Mosquito & MAV & 0.300 & 0.250 & 16.450 & defense-update.com \\
\hline 6 & NRL MITE 2 & MAV & 0.368 & 0.213 & 13.400 & The NRL MITE Air Vehicle \\
\hline 7 & MLB Bat & MPUAV $^{2}$ & 0.600 & & 13.400 & Design of MAVs (MLB Co.) \\
\hline 8 & Wasp Block III & MPUAV & 0.723 & 6.530 & 13.410 & USAF Fact Sheet \\
\hline 9 & BirdEye 100 & MPUAV & 0.850 & 1.300 & & Israeli Aerospace Industries \\
\hline 10 & RQ-14B Dragon Eyes & MPUAV & 1.100 & 2.800 & 9.719 & defense-update.com \\
\hline 11 & Desert Hawk & MPUAV & 1.320 & 3.200 & 16.662 & defense-update.com \\
\hline 12 & RQ-11B Raven & MPUAV & 1.370 & 7.700 & 13.950 & designation-systems.net \\
\hline 13 & BirdEye 500 & $U A V^{3}$ & 2.000 & 5.000 & 18.000 & defense-update.com \\
\hline 14 & Finder & UAV & 2.620 & 27.200 & 19.439 & defense-update.com \\
\hline 15 & ScanEagle & UAV & 3.100 & 18.000 & 30.170 & USAF Fact Sheet \\
\hline 16 & MQ-1 Predator & UCAV $^{4}$ & 14.800 & 1020.000 & 44.700 & USAF Fact Sheet \\
\hline 17 & MP-9 Reaper & UCAV & 20.000 & 4750.000 & 102.800 & USAF Fact Sheet \\
\hline 18 & RQ-4B Global Hawk & HALE UAV ${ }^{5}$ & 39.800 & 14628.000 & 159.570 & USAF Fact Sheet \\
\hline AV: Mic & $\begin{array}{l}\text { o Air Vehicle, }{ }^{2} \text { MPUAV: } \\
{ }^{5} \text { HALE UAV: High-Altitu }\end{array}$ & Portable & $\begin{array}{l}\text { ehicle, } \\
\text { UAV }\end{array}$ & & - & e, UCAV: Unmanne \\
\hline
\end{tabular}




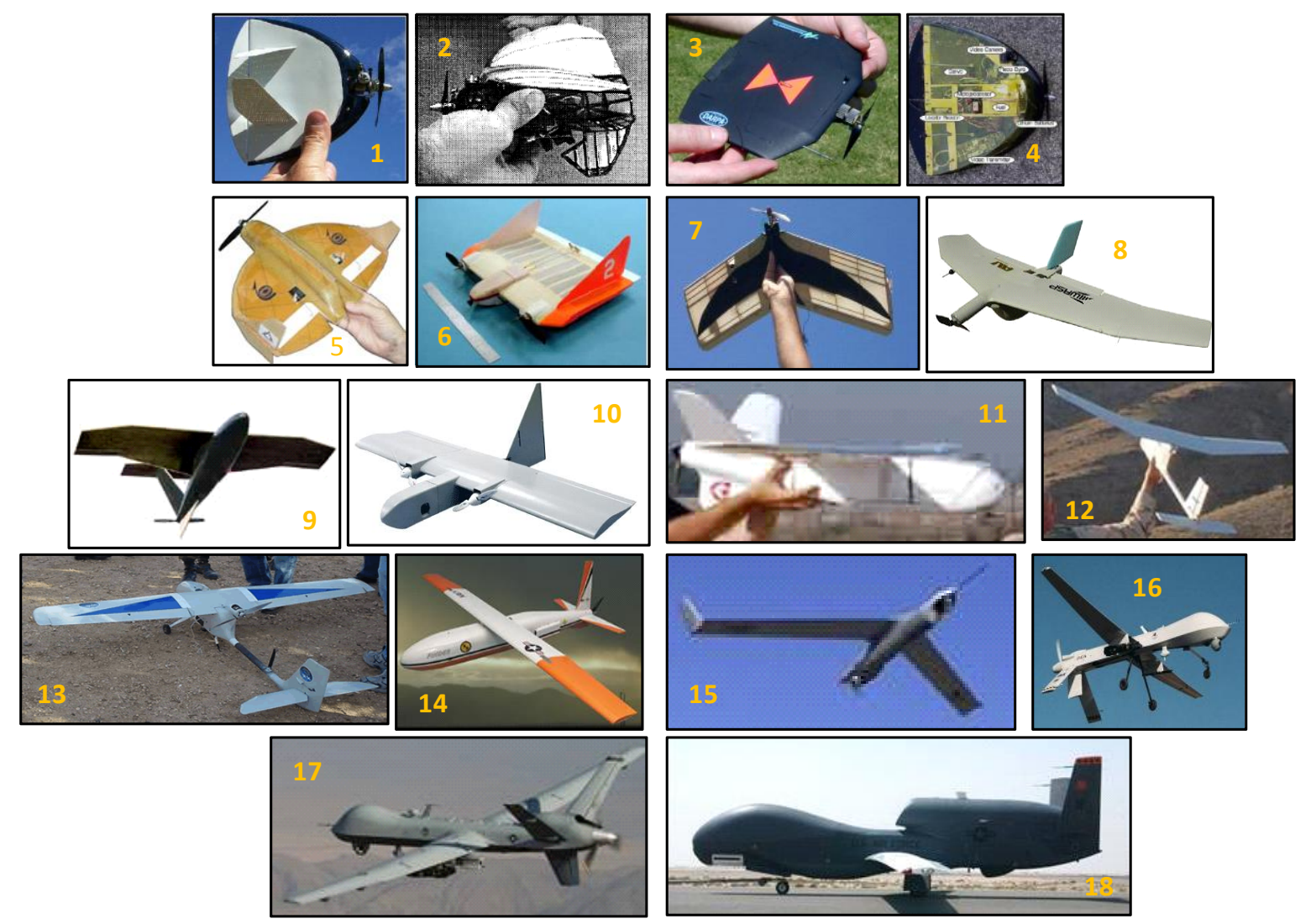

Figure 2-1: Collage of Current UAV and MAVs, Number and Sources as Listed in Table 2-1

Plotting flight mass and cruise velocity as a function of main wing span shows surprisingly strong correlations as seen in Figure 2-2 and Figure 2-3. Note that some of the UAVs listed in Table 2-1 have been omitted from the figures for the sake of clarity. The flight wing span to flight mass correlation was very nearly linear across the entire size range, an excellent guideline for preliminary design work. Cruise velocity also displayed a strong correlation with wing span, though with more complex behavior. Velocity was seen to decrease with smaller size to a minimum of $10 \mathrm{~m} / \mathrm{s}$. At the very smallest sizes aircraft operated within a band between $10 \mathrm{~m} / \mathrm{s}$ and $18 \mathrm{~m} / \mathrm{s}$. The lower limit was probably forced by the desire to avoid extremely low chordwise Reynolds numbers while maximum velocity was thought to be driven by mission constraints. For example, quality video reconnaissance from approximately $100 \mathrm{~m}$ altitude depends on a relatively slow moving platform ${ }^{1}$. Both Figure 2-2 and Figure 2-3 provide an initial estimate of the operating regime for the WVU stowable MAV (shaded red geometries) designs. Both designs were entirely outside the conventional regions. Innovative and application specific solutions were required.

${ }^{1}$ (Davis, Kosicki, Boroson, \& Kostishack, 1996) 


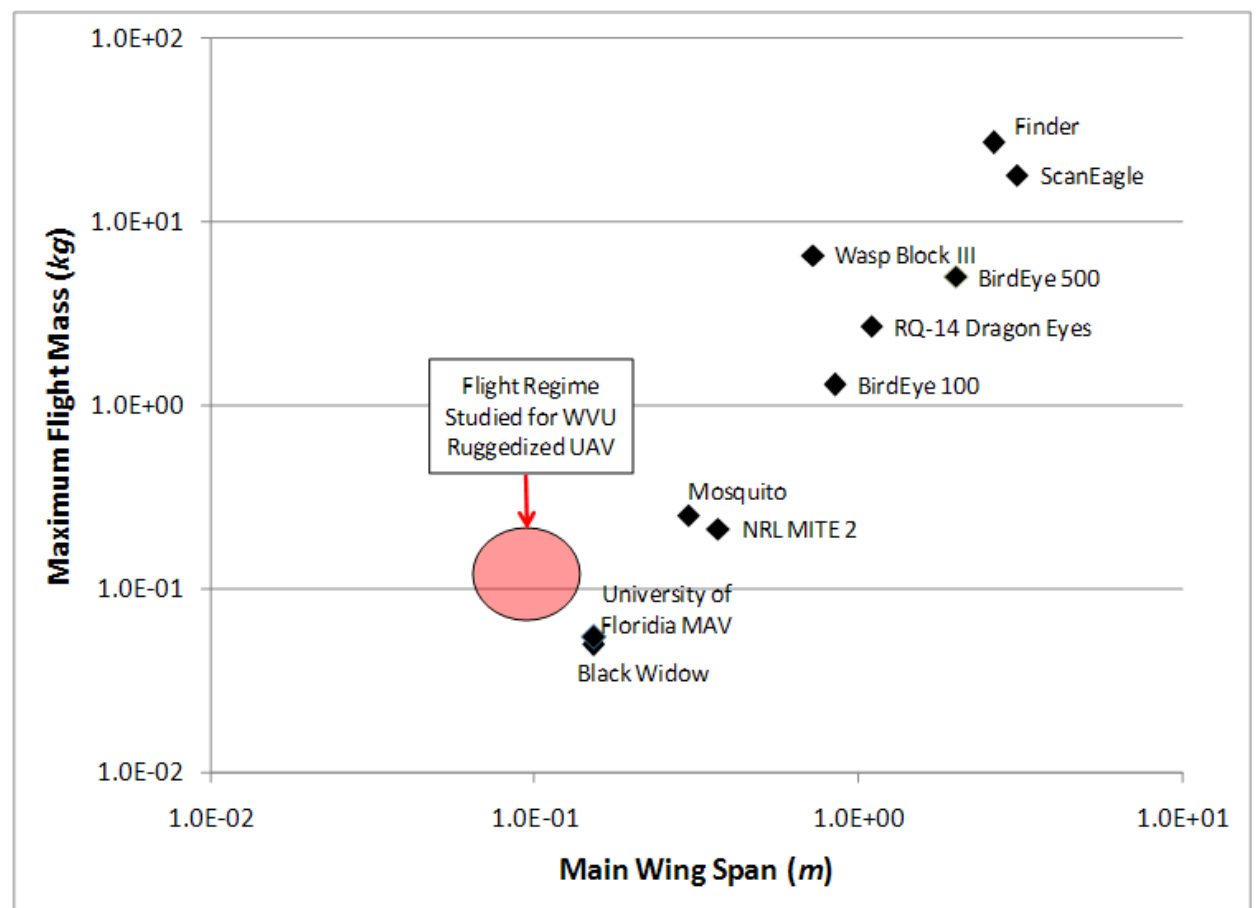

Figure 2-2: Flight Mass Plotted Versus Main Wing Span

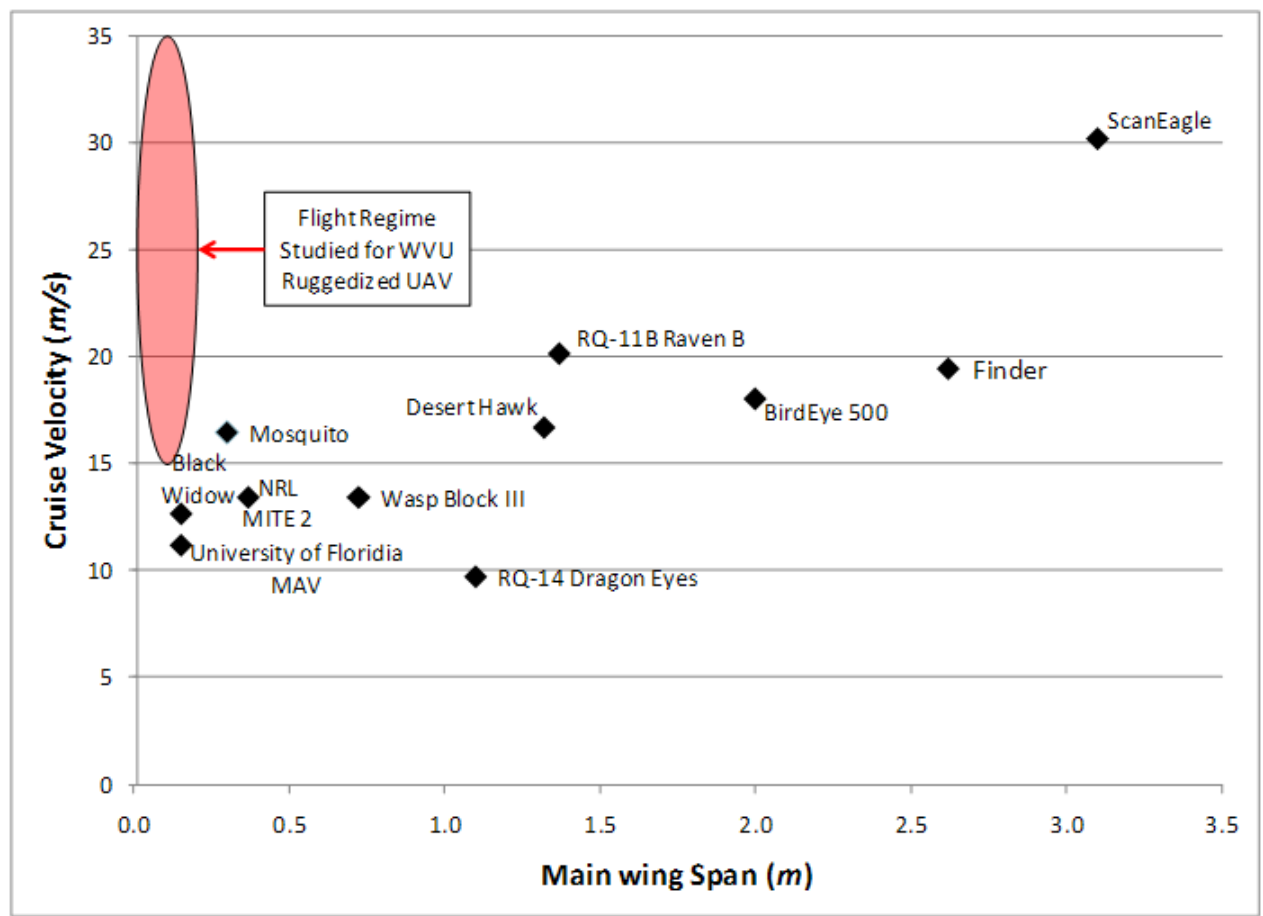

Figure 2-3: Cruise Velocity Plotted Versus Main Wing Span 


\subsection{MAV Electronics}

This project has not yet progressed to full systems integration. However, having information on current camera, sensor, control, and communication systems available was useful when considering the practicality of structural and volumetric designs and for directing future work. Information presented here provided minimum limits and goals for available useable fuselage volume throughout the design process. This also provides a brief overview of the currently available technologies.

Figure 2-4 shows an image taken from a MAV flying at $100 \mathrm{~m}$ above ground level with the camera mounted at a $45^{\circ}$ downward angle from horizontal and a 1,000x1,000 pixel resolution and a 40x40 degree field of view. Even with images from such a high resolution micro camera, identifying intentions of personnel on the ground could be difficult. Image stabilization systems are almost required in addition to the high resolution due to the oscillations of the MAV about all axes. The effects of pitch oscillation on the camera target are shown in Figure 2-5. AeroVironment's Wasp vehicle, $72.3 \mathrm{~cm}$ span, incorporated the twin-camera system shown in Figure 2-6. Image stabilization and view steering were both incorporated by April $2007^{2}$.

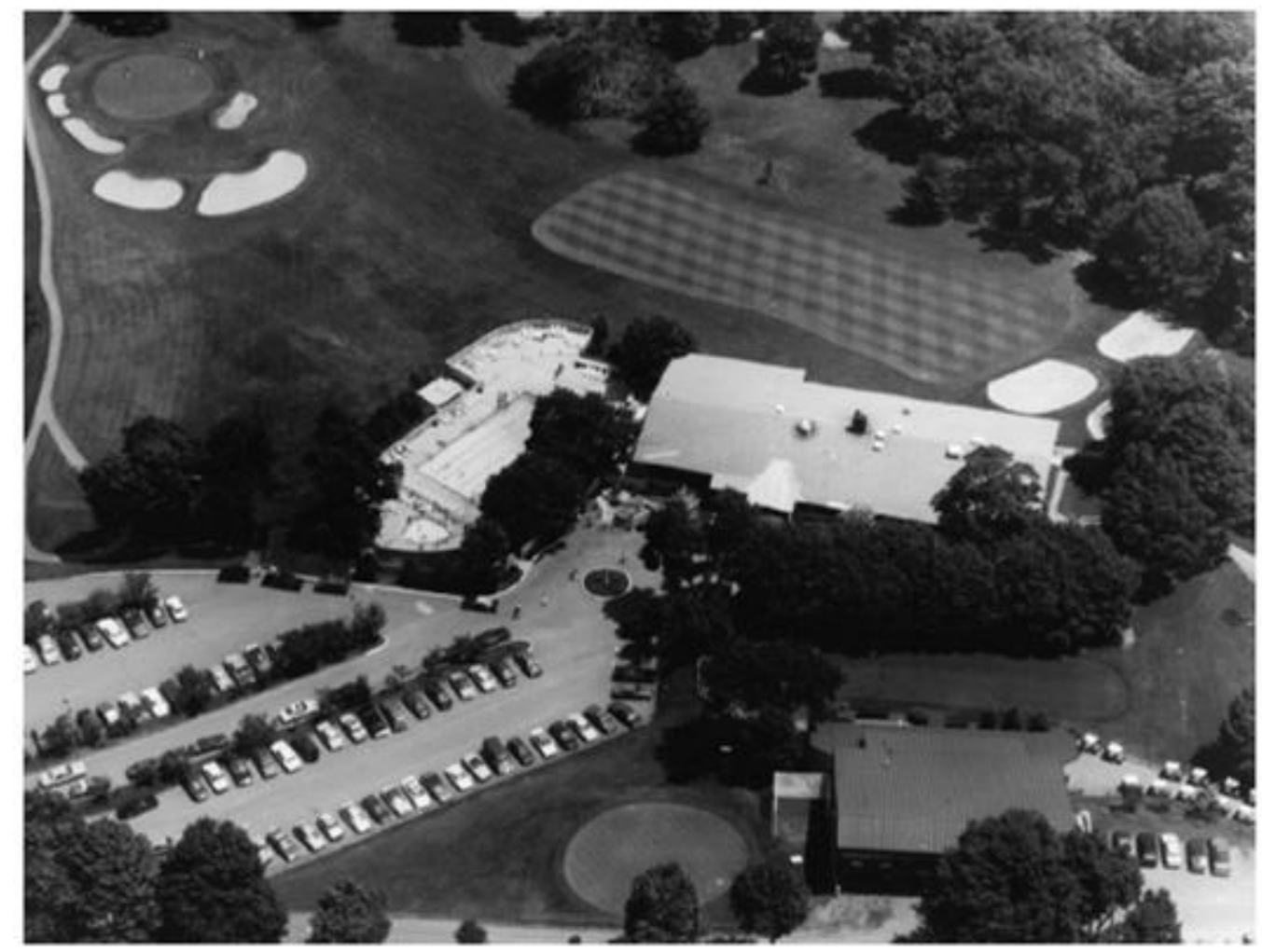

Figure 2-4: Image from $100 \mathrm{~m}$ Altitude at $45^{\circ}$ Angle from Aircraft, $40^{\circ} \times 40^{\circ}$ Field of View, 1,000x1,000 Pixel Camera(Davis, Kosicki, Boroson, \& Kostishack, 1996)

${ }^{2}$ (Grabowsky, 2007) 


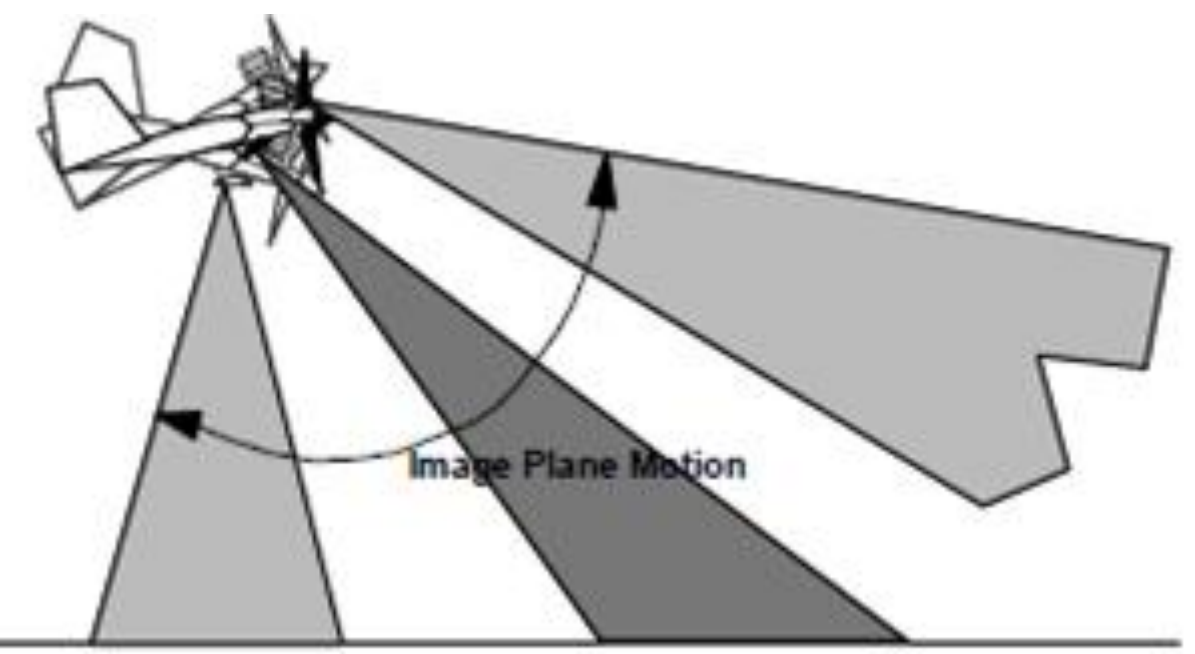

Figure 2-5: Effect of Pitch Oscillation on Camera View (Morris, Design of Micro Air Vehicles and Flight Test Validation, 2000)

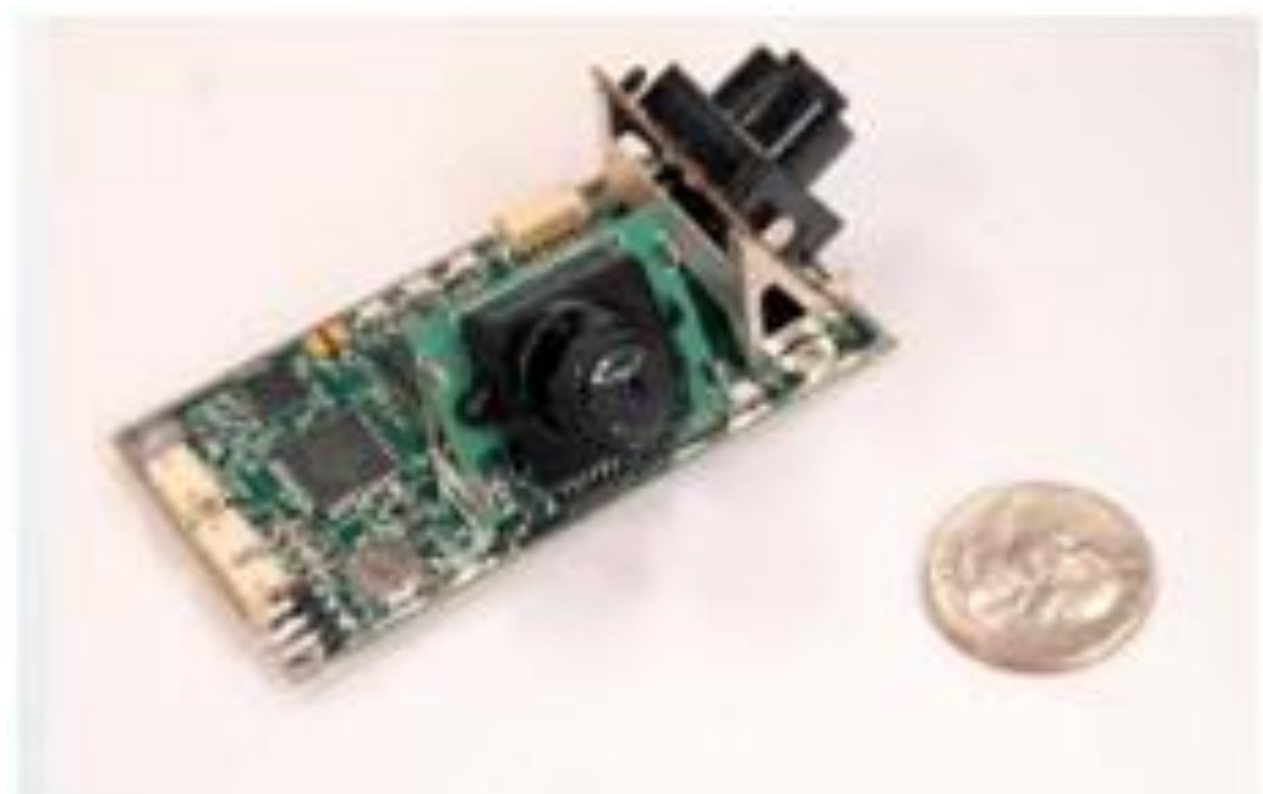

Figure 2-6: Twin Camera System from AeroVironment's Wasp MAV(Grabowsky, 2007)

Onboard electronics have been miniaturized sufficiently to make this type of project feasible. Figure 2-7 provides details of a small flying-wing MAV produced by MLB Company with major internal components visible through a transparent skin ${ }^{3}$. This design, developed by Morris et al., incorporated all control and communication systems in addition to propulsion. Focusing exclusively on gliding flight in the current project has freed a large amount of volume for wing stowage and more powerful transmitter systems.

${ }^{3}$ (Morris, Design and Flight Test Results for Micro-Sized Fixed-Wing and VTOL Aircraft, 1997) 


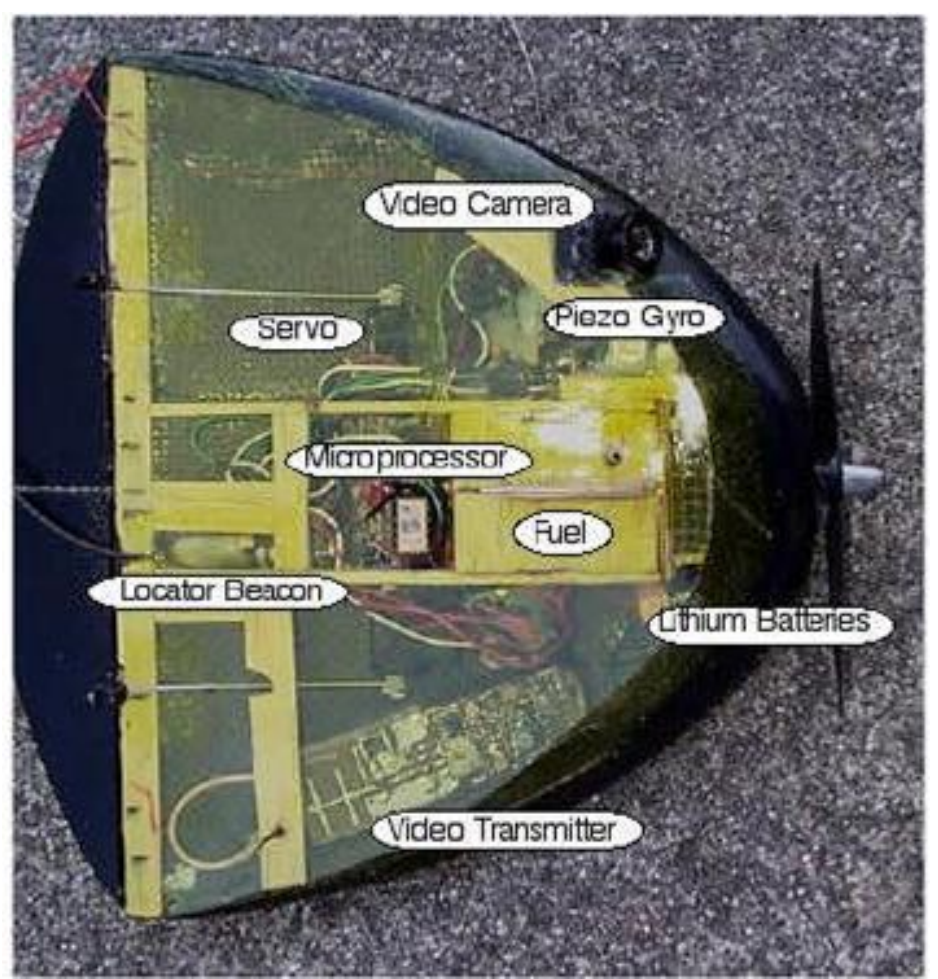

Figure 2-7: $20 \mathrm{~cm}$ Trochoid Planform MAV from MLB Company (Morris, Design of Micro Air Vehicles and Flight Test Validation, 2000)

In addition to the micro video cameras and transmitters such as those shown in Figure 2-8 several novel micro attitude sensors have been developed. An "optical flow" circuit designed by Ruffier, et al. can be used to determine both altitude and velocity. Rates of dilation and translation of separate objects in the video feed were used to collect velocity and climb rate information. The greatest advantage of this system was that it used the surveillance camera as a major component of the flight sensors and thus reduced system weight. An example is provided in Figure 2-9 ${ }^{4}$.
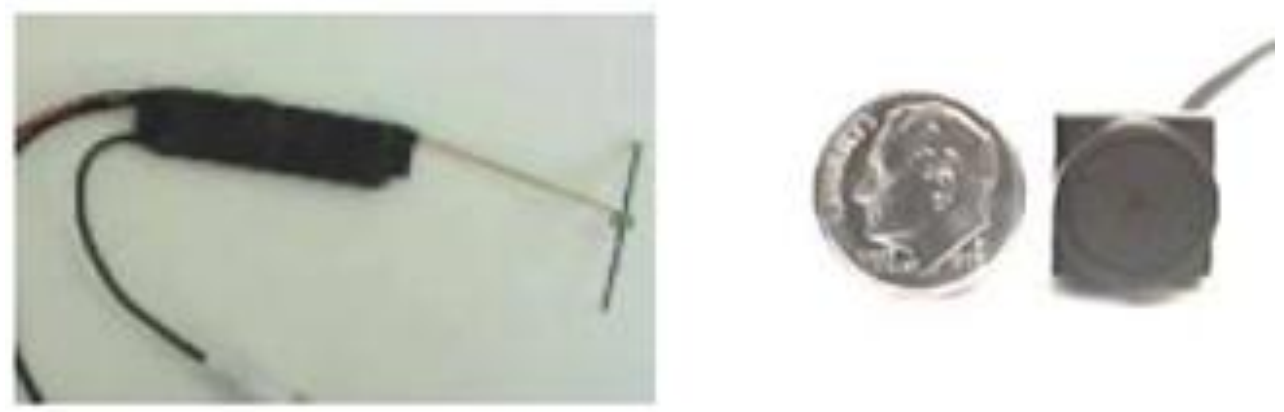

Figure 2-8: Micro Video Camera and Transmitter (Torres \& Mueller, 2001)

\footnotetext{
${ }^{4}$ (Ruffier, Viollet, Amic, \& Franeschini, 2003)
} 


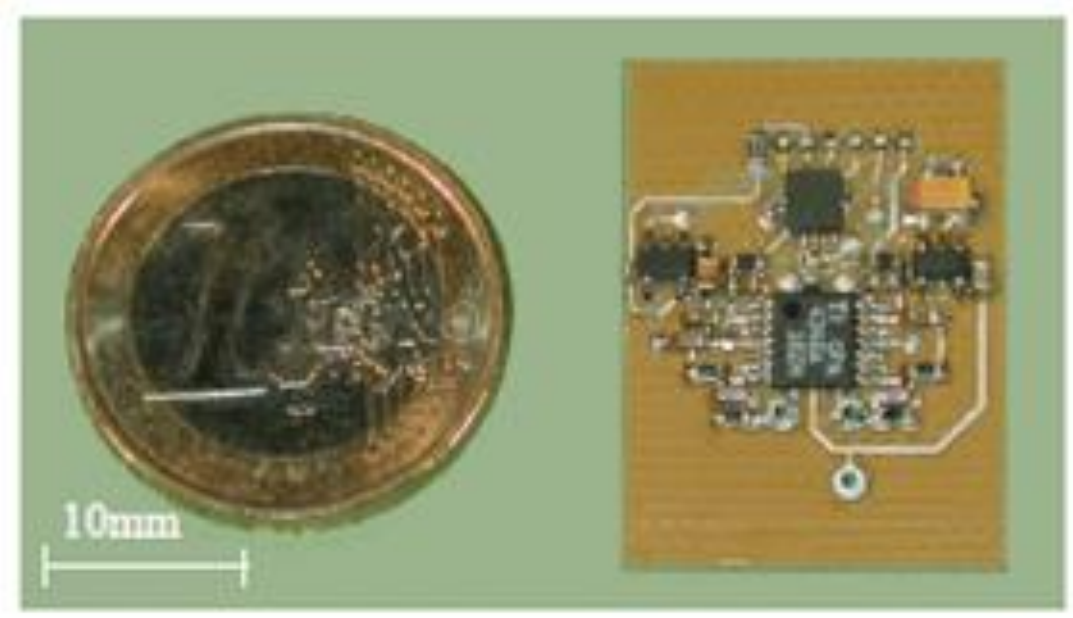

Figure 2-9: Circuitry Required for Optical Flow Velocity and Altitude Measurement System (Ruffier, Viollet, Amic, \& Franeschini, 2003)

A MAV scale onboard autopilot has been created by Krashanitsa, et al., (2006) for use in the $180 \mathrm{~g} 30 \mathrm{~cm}$ span Dragonfly MAV ${ }^{5}$. The Paparazzi system, shown in Figure 2-10, used a GPS receiver to obtain heading and altitude while a set of four infrared sensors collected pitch, roll, and yaw angles. The autopilot computer and sensor system weighed a mere $30 \mathrm{~g}$ in 2006. Modern equipment would likely be capable of bringing this weight down even further.

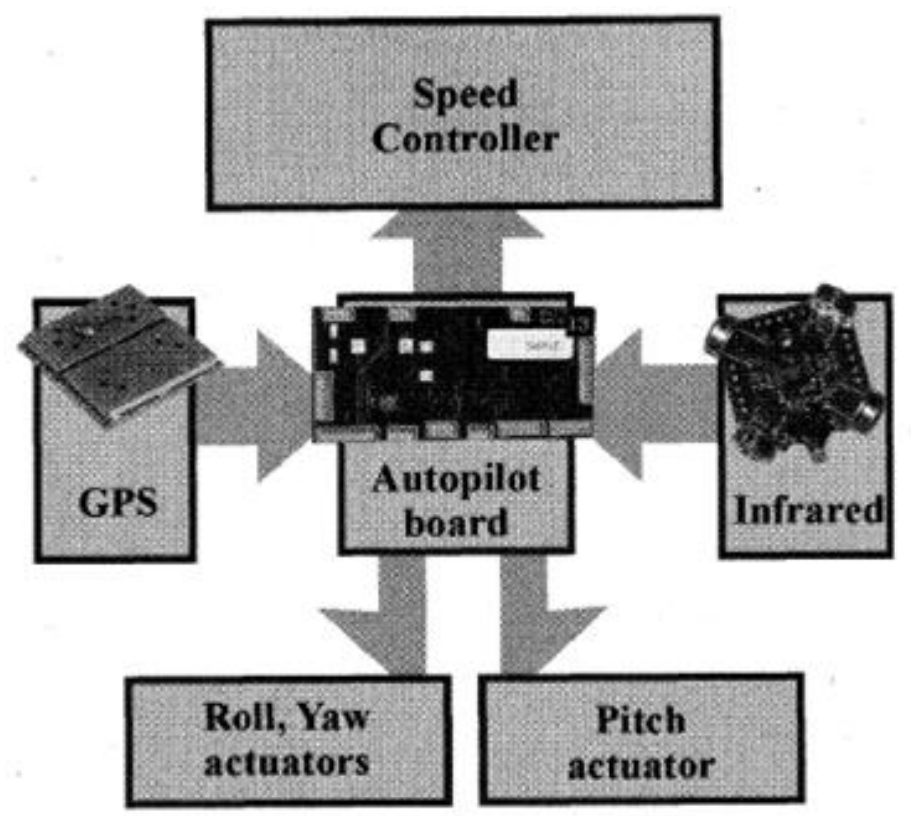

Figure 2-10: Paparazzi MAV Autopilot System

${ }^{5}$ (Krashanitsa, Platanits, \& Silin, 2006) 
Unfortunately the Achilles heel of all the small MAV/UAV designs has been the size of the ground station. Ground stations for the MLB Bat and AeroVironment's Switchblade are shown in Figure 2-11. Video display, manual controls, and high-power omnidirectional or gimbaled dish unidirectional transmitters and high-sensitivity gimbaled dish receivers have been required ${ }^{6}$. To achieve maximum potential the ground equipment for the current project would need to be significantly reduced in size.

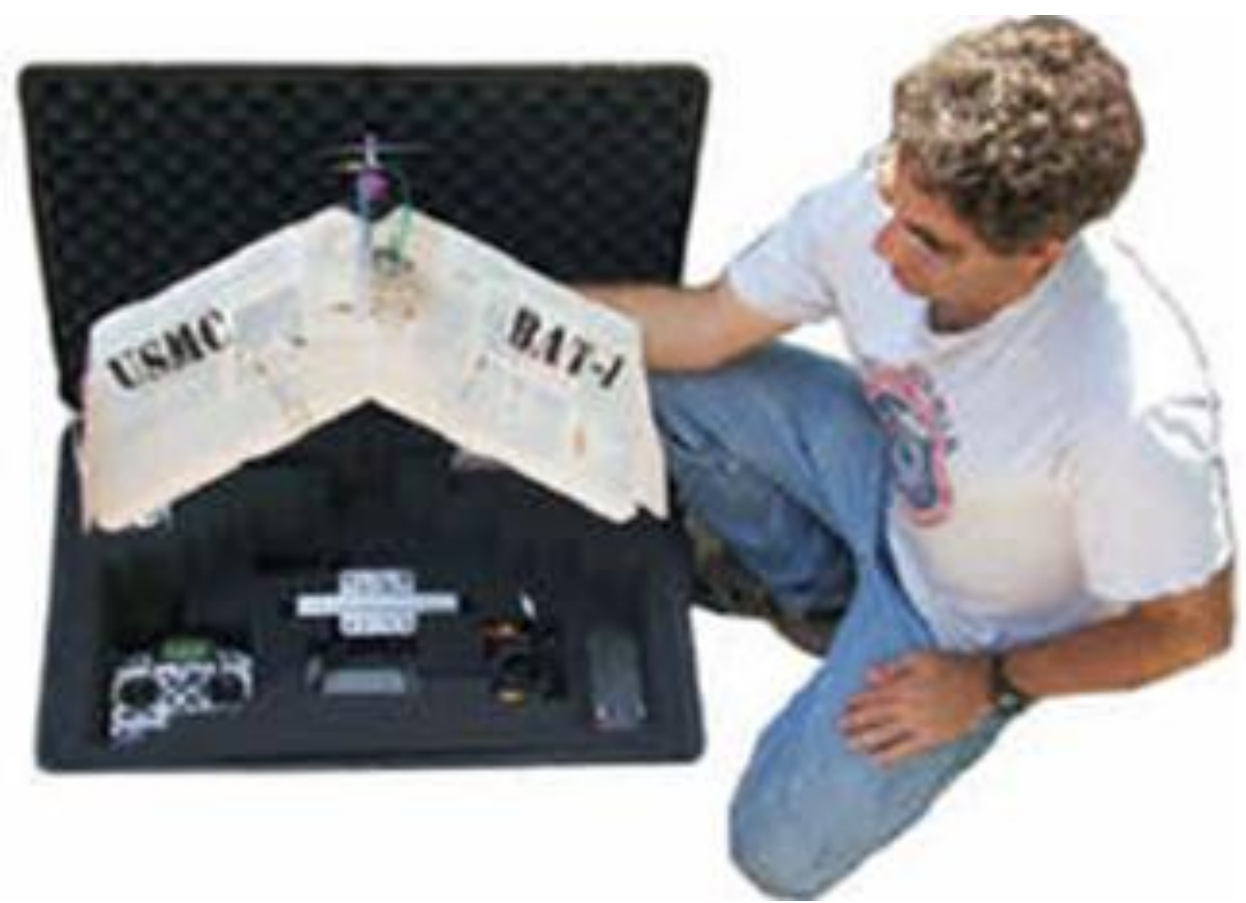

Figure 2-11: Ground Stations for MLB Bat MAV System (Morris, Design of Micro Air Vehicles and Flight Test Validation, 2000)

\subsection{Low Reynolds Number Aerodynamics}

Initial study of the small scales and low velocities, $130 \mathrm{~mm}$ body length and $40 \mathrm{~m} / \mathrm{s}$ maximum cruise speed, indicated that the aircraft would likely operate in a low Reynolds number $(\mathrm{Re})$ regime, under 300,000 based on main wing chord. This required attention since flow behavior begins to change in significant and nonlinear manners as the Reynolds number is reduced. Such effects become more extreme as Re drops toward 75,000.

\footnotetext{
${ }^{6}$ (Davis, Kosicki, Boroson, \& Kostishack, 1996)
} 


\subsubsection{Two Dimensional Flow: Separation Bubbles and Transition}

At chordwise Re under approximately 150,000 the performance of smooth a airfoil section begins to degrade rapidly, as shown in Figure $2-12^{7}$. This is caused by the variable laminar/turbulent nature of the boundary layer. When operating at low angles of attack both upper and lower surfaces maintain attached laminar flow. As angle of attack increases a leading edge separation bubble forms on the upper surface and flow trips to turbulent ${ }^{8}$. The chordwise length of this separation bubble can vary from a few percent near the point of maximum velocity at the surface to more than $40 \%$ of the upper surface. A schematic of the transition is shown in Figure 2-13 along with approximate outlines of the upper and lower surface pressure distributions.

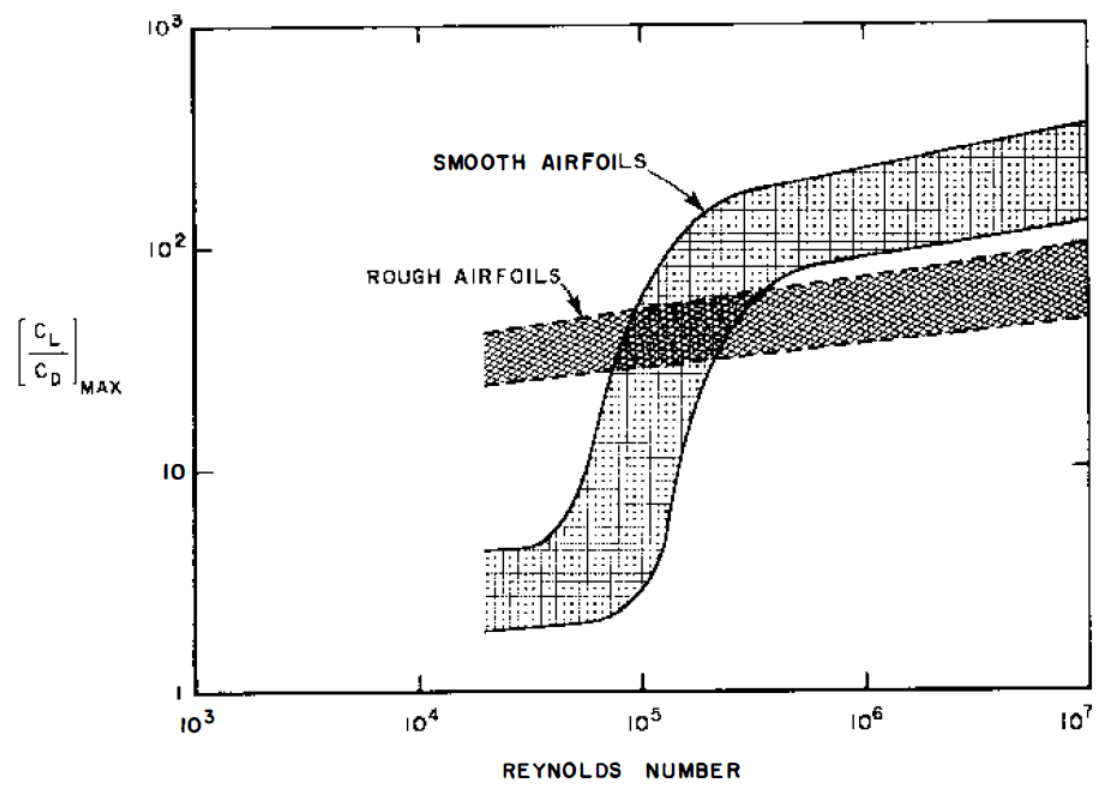

Figure 2-12: Reduction in Smooth Airfoil Performance with Falling Reynolds Number (Lissman, 1983)

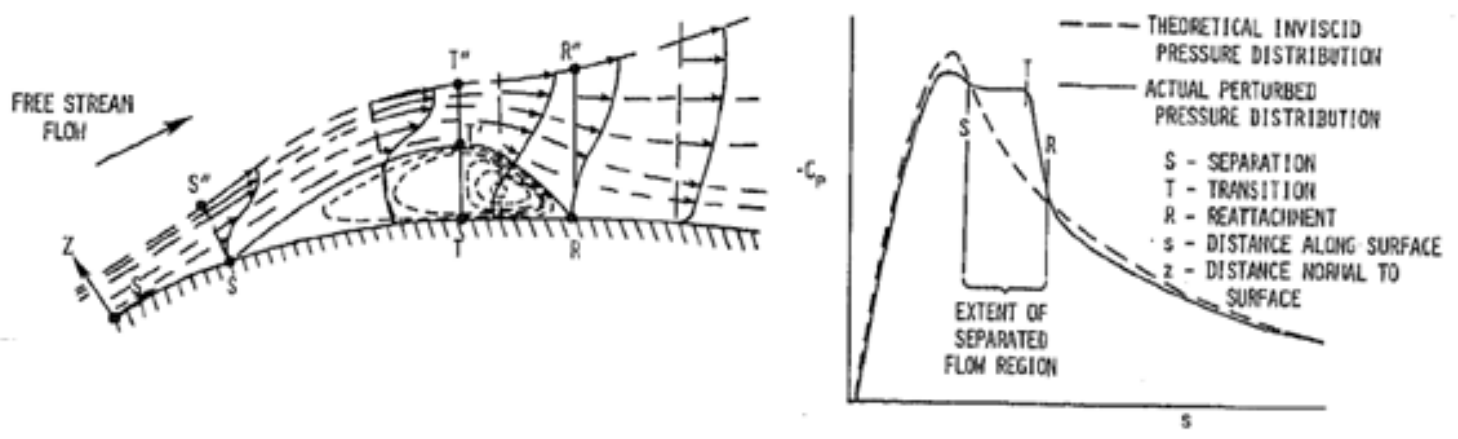

Figure 2-13: Schematic of Low Re Separation Bubble Transition (Roberts, 1980)

${ }^{7}$ (Lissman, 1983)

${ }^{8}$ (Mueller, Aerodynamic Measurments at Low Reynolds Numbers for Fixed Wing Micro Air Vehicles, 1999) 
Hysteresis behavior is also encountered at these low Reynolds numbers ${ }^{9}$. Flow detaches from the wing at a high angle stall but does not re-attach until a much lower angle of attack is achieved as illustrated in Figure 2-14. This effect can make stall recovery difficult for MAVs but is fortunately uncommon for most airfoils above Reynolds numbers of 100,000 where flow reattaches at approximately the same angle of attack at which it separated.

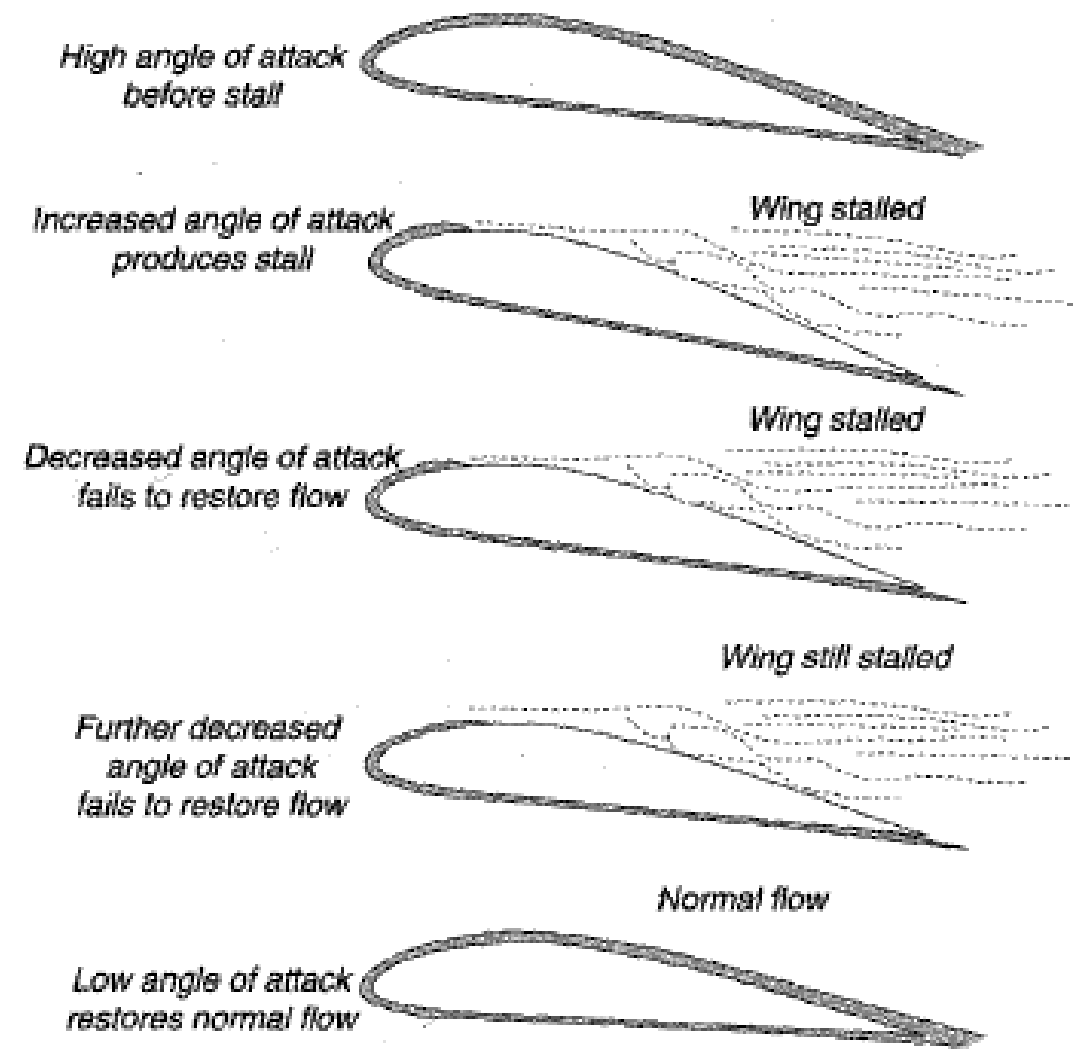

Hysteresis. At low Reynolds numbers, near the crtitical figure for the wing profile, a stall produced by increasing the angle of attack tends to persist until the angle of attack is much reduced. The normal expectation of a constant stalling angle tends to break down

Figure 2-14: Hysteresis Behavior of a Wing at Low Reynolds Number (Simons, 1999)

Due to these effects drag polars and moment coefficients become highly nonlinear and abnormal $^{10}$. Figure 2-15 clearly illustrates this behavior; the lift-to-drag ratio increases with increasing lift coefficient to near the stall point for Reynolds numbers below 200,000 on this thick profile. Such behavior is highly dependent on the profile studied ${ }^{11}$.

${ }^{9}$ (Simons, 1999)

${ }^{10}$ (Shyy, Lian, Tang, Viieru, \& Liu, 2008)

${ }^{11}$ (Selig, Donovan, \& Fraser, 1989) 


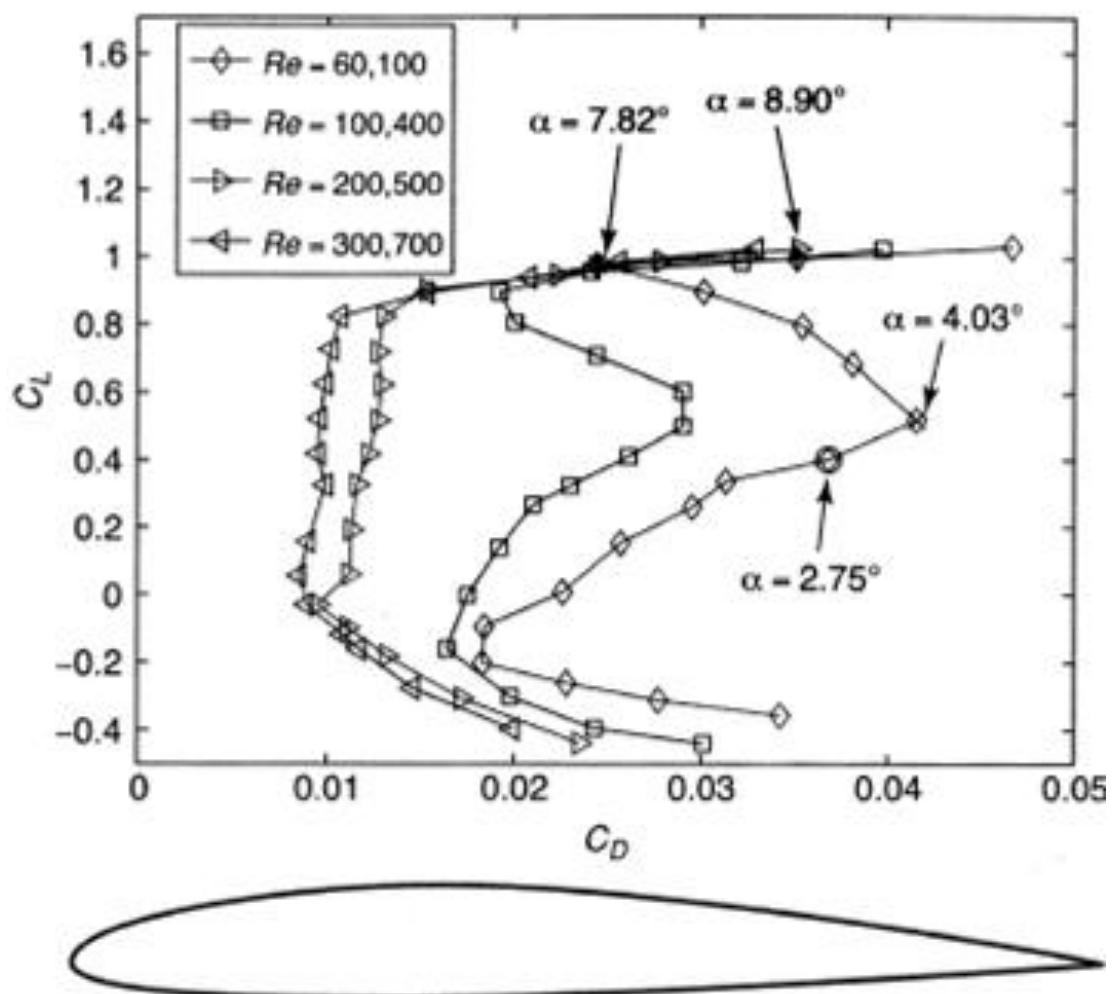

Figure 2-15: Drag Polars of an Eppler E374 Airfoil at Low Reynolds Numbers (Shyy, Lian, Tang, Viieru, \& Liu, 2008)

\subsubsection{Three Dimensional Low Aspect Ratio Aerodynamics}

The large performance benefits to be gained by increasing Reynolds number above 75,000 suggested that reducing aspect ratio and increasing chord could provide performance benefits in this unique case. According to classical aerodynamics increasing main wing aspect ratio $\left(\mathrm{b}^{2} / \mathrm{s}\right)$ increases efficiency by reducing induced drag. However, with poor airfoil performance at low Reynolds number and extreme sensitivity to increasing Reynolds number it appeared that an optimum balance would exist. Kellog, et al. (2001) working on the NRL MITE MAV derived an expression, Equation 2-1, for optimum rectangular planform chord length ${ }^{12}$. This would provide minimum wing drag at a given velocity and wing span. Since Equation 2-1 has a Reynolds number dependence in the calculation of $K_{l}$ based on two dimensional zero lift drag coefficient the solution is iterative.

12 (Kellogg, et al., 2001) 


$$
c=\left[\frac{\frac{3}{\pi \times e \times b}}{K_{1}\left(\frac{\mu}{\rho V}\right)^{\frac{1}{3}}}\right]^{\frac{3}{4}}, K_{1}=\mathrm{C}_{\mathrm{d}_{\mathrm{o}}}(\mathrm{Re})^{\frac{1}{3}}
$$

Low aspect ratios also produce non-standard effects. Extremely low aspect rations can postpone stall to higher angles of attack. Rectangular planforms can maintain attached flow up to $35^{\circ}$ as seen in Figure 2-16. This work was done with $2 \%$ thick $4 \%$ circular cambered flat plate airfoils ${ }^{13}$. Significant differences in performance would be realized by using other airfoil profiles and planforms.

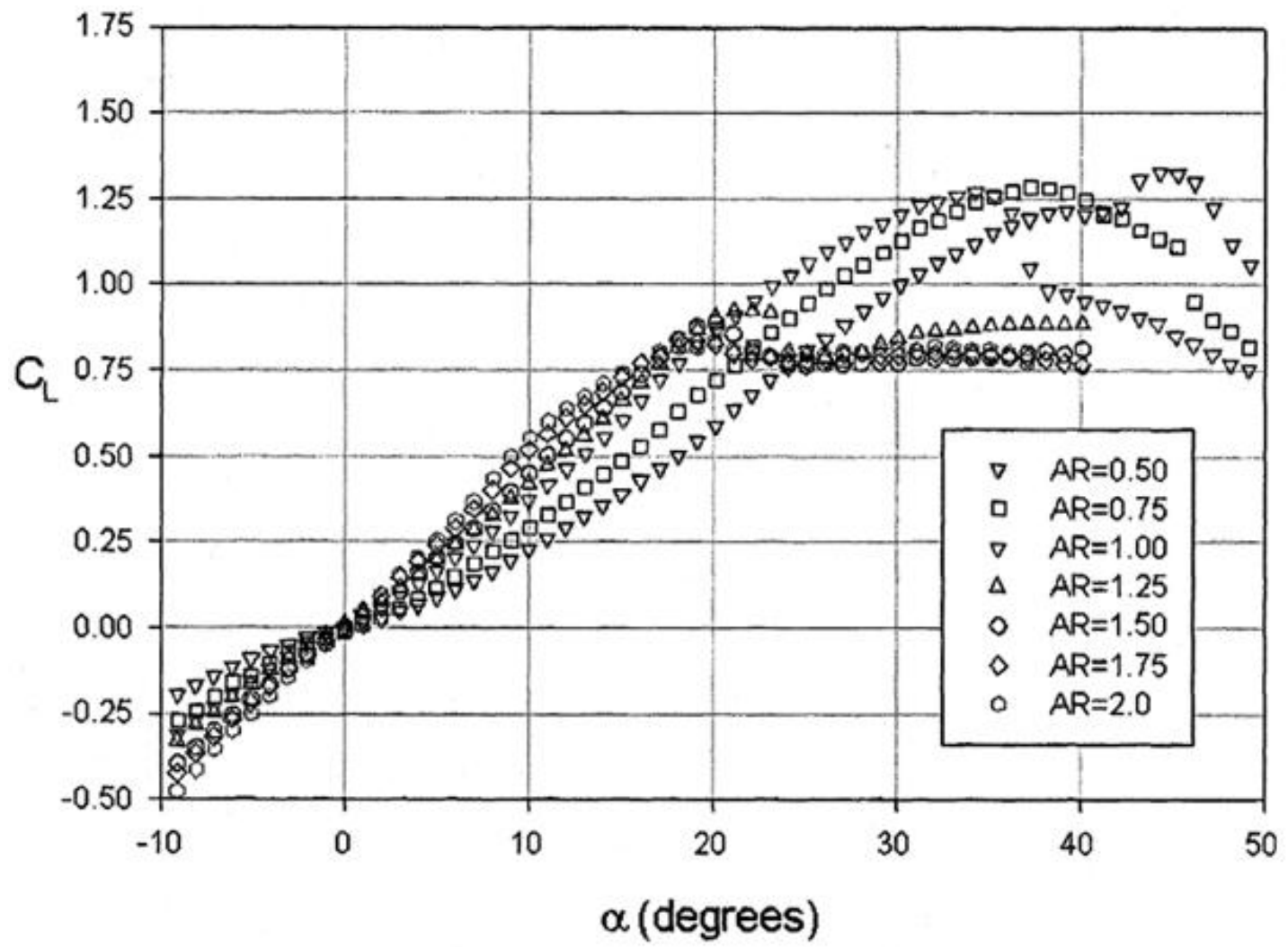

Figure 2-16: Lift Coefficient Versus Angle of Attack for Low Aspect Ratio Rectangular Planforms at $\operatorname{Re}=10^{5}$ (Mueller, Torres, \& Srull, Elements of Aerodynamics, Propulsion, and Design, 2006)

It is possible that the efficiency benefits from increased chordwise Reynolds number could outweigh the penalties incurred by a lower aspect ratio in these flight regimes. In addition, the increased angle of attack attainable before stall should make these aircraft more controllable since atmospheric gusts on the order of their flight speed would be less likely to stall the main wing.

\footnotetext{
${ }^{13}$ (Mueller, Torres, \& Srull, Elements of Aerodynamics, Propulsion, and Design, 2006)
} 


\subsection{Ballistics}

Due to the ballistic trajectory of launch and the necessity of gyroscopically stabilizing the stowed geometry some basic ballistics knowledge was required. Fin stabilized projectiles conveniently have a negative pitching moment coefficient. However, a gyroscopically stabilized body frequently has a positive pitching moment coefficient. This is due to the combination of a tapered nose and blunt aft body, characterized in Figure 2-17 and a near uniform density distribution forcing the center of gravity aft of the center of pressure.

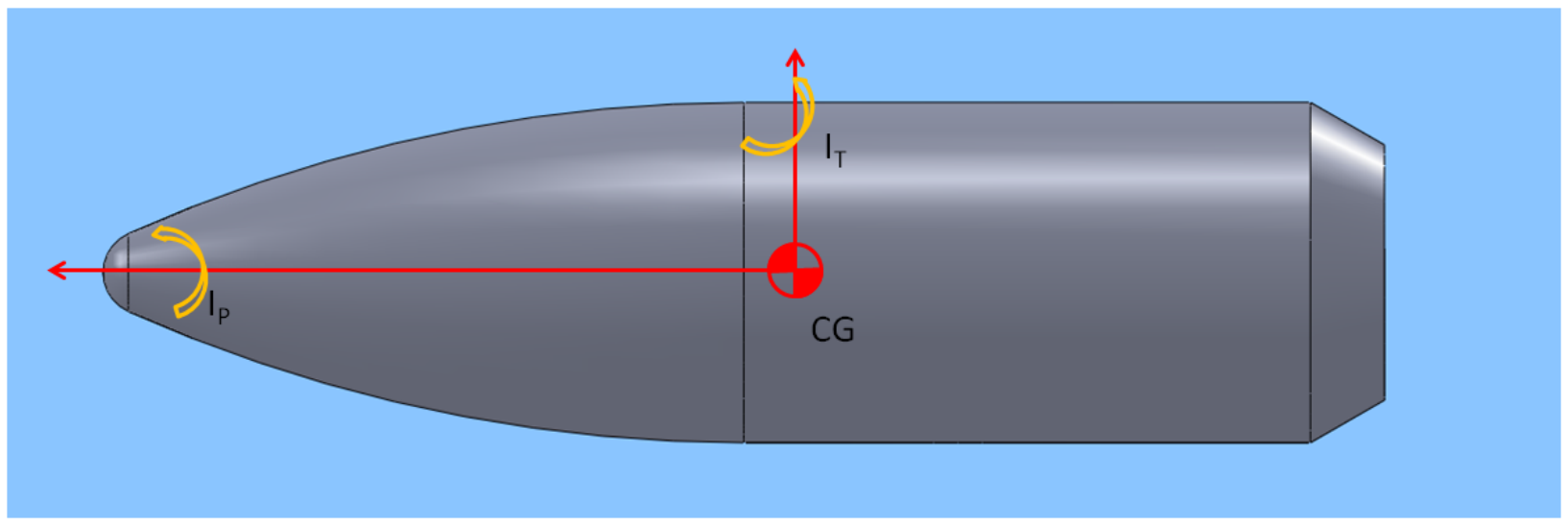

Figure 2-17: Characteristic Gyroscopically Stabilized Body Showing CG Location and Axis for Polar and Transverse Moments of Inertia

Information in Ballistics: Theory and Design of Guns and Ammunition ${ }^{14}$, presents the static stability criterion for a gyroscopically stabilized projectile. Note that the pitching moment coefficient is the only value dependent on the relative locations of the center of pressure and center of mass. If this value is insufficiently negative then the projectile would be statically unstable. To compensate for an insufficient restoring moment a spin rate would be required. However, to deploy lifting wings and directly enter gliding equilibrium the spin must be stopped and the aircraft oriented within less than $90^{\circ}$ of upright. A slowly decreasing spin rate can cause tumbling as the spin rate approaches and drops below the threshold for stability. This is due to dynamic effects discussed in detail in Carlucci and Jacobson's text. To avoid the tumbling issue, illustrated in Figure 2-18, the stowed MAV must "jump" down in spin rate and rapidly transfer to aerodynamic stability.

${ }^{14}$ (Carlucci \& Jacobson, 2008) 

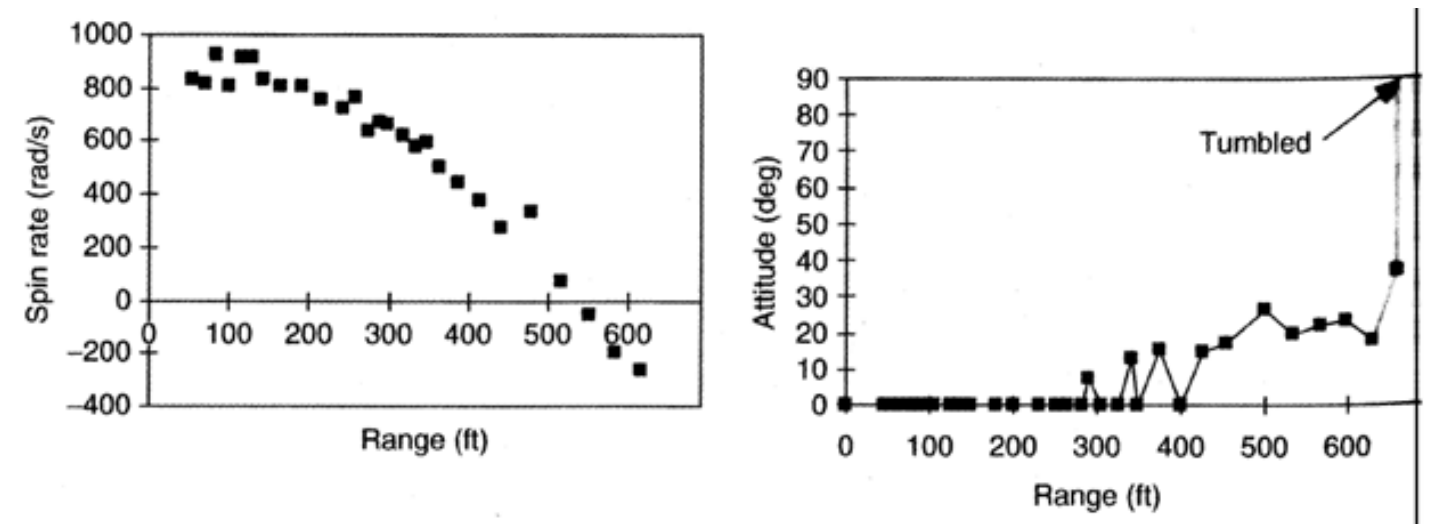

Figure 2-18: Increasing Dispersion and Developing Instability of a Slowly De-Spinning Round (Carlucci \& Jacobson, 2008)

Non-rigid internal components can also cause significant problems with ballistic flight. Harmonics induced by any launch shocks and the high spin rates can cause large trajectory dispersion or even structural failure. The lag time to bring these components into equilibrium can be problematic even if the steady-state flight analysis proves acceptable ${ }^{15}$.Significant structural analysis work will be required to characterize these effects.

\subsection{Thesis Outline}

While any design process is necessarily recursive a general trend was followed with this project and this thesis reflects the same order. Work began with structural stowage concepts. This provided the maximum aerodynamic surface limits and available fuselage volumes. Within these limits Missile DATCOM, discussed further in Chapter 4, was used to obtain initial main wing and tail sizes for a $200 \%$ range extension. This long-range capability dictated a moderate wing area and speed, $60 \mathrm{~cm}^{2}$ and $33 \mathrm{~m} / \mathrm{s}$.

Preliminary computational work was then possible. CFD simulations of the stowed geometry were conducted since experimental results for a simple blunt cylinder were available. This experimental data was used to generate a suite of mesh and Fluent solver settings which were flexible enough to support the inclusion of wings. Two deployed geometries were considered, a conventional high aspect ratio layout and a truncated delta planform. The delta wing proved to have nearly twice the lift-to-drag ratio of the conventional layout. As discussed in Section 2.3 the benefits of increasing chordwise Reynolds number outweighed the benefits of increased aspect ratio. Therefore the delta wing was selected for all future work.

${ }^{15}$ (US Army Armament Ballistic Research Laboratory, 1984) 
With the delta planform selected an optimization analysis was conducted using classical aerodynamic theory. Initially a range of launch angles was studied to see how wing area and range varied with apex/cruise velocity and apex altitude. This analysis showed that initial performance goals of both a flight time greater than thirty seconds and a 30\% range increase were driving the design in opposite directions and a compromise would not perform well at either. A 30\% range extension was possible with a direct, high-speed glide straight to the location at a high wing loading. However the surveillance option required a much lower flight velocity and greater range. Therefore the research was split to follow two tracks: one a small wing high-speed version for extended range to target, and the other a large wing, low speed, long endurance variant for surveillance purposes.

Parametric CFD studies were conducted in Fluent on all components with the goal of finding clear optimums or tradeoffs. An array of fuselages, airfoils, and wing planforms was studied. With this mass of data two final configurations were proposed. A summary of the process is provided in Table 2-2.

Table 2-2: Thesis Outline Summary

1) Structural Concept Modeling

2) Control Surface Actuation Concepts

3) De-Spin and Orientation Methods

4) Initial Surface Sizing Calculations

5) Stowed Geometry Mesh Generation

6) Deployed Configuration Simulation

7) Classical Aerodynamic Optimization Analysis

8) Fuselage Analysis

9) Two Dimensional Low Reynolds Number Airfoil Analysis

10) Preliminary Three Dimensional Main Wing Analysis

11) Recommended Preliminary Designs

12) Summary and Recommendations 


\section{Chapter 3 Concept Development}

Initial work began with developing wing storage concepts. The entire project depended on developing a method to collapse sufficient wing and tail area into the stowed geometry leaving sufficient volume for sensors, controls, and other mission equipment. Multiple different methods were considered including completely encased MAVs and shells which transformed their exterior surface using either rigid structures or flexible components.

\subsection{Structural Concept Modeling}

Two fundamental stowage systems were proposed in the initial concepts provided by our research sponsors. "Cargo" type designs, as presented in Figure 3-1, shed a casing which fully surrounds the UAV and provides some support and cushioning from launch loads. These also permit flexibility of the fuselage shape within the limits of the discarded shroud. Figure 3-2 provides and outline of the progression of the Cargo designs developed at WVU and a schematic of their deployment sequence.

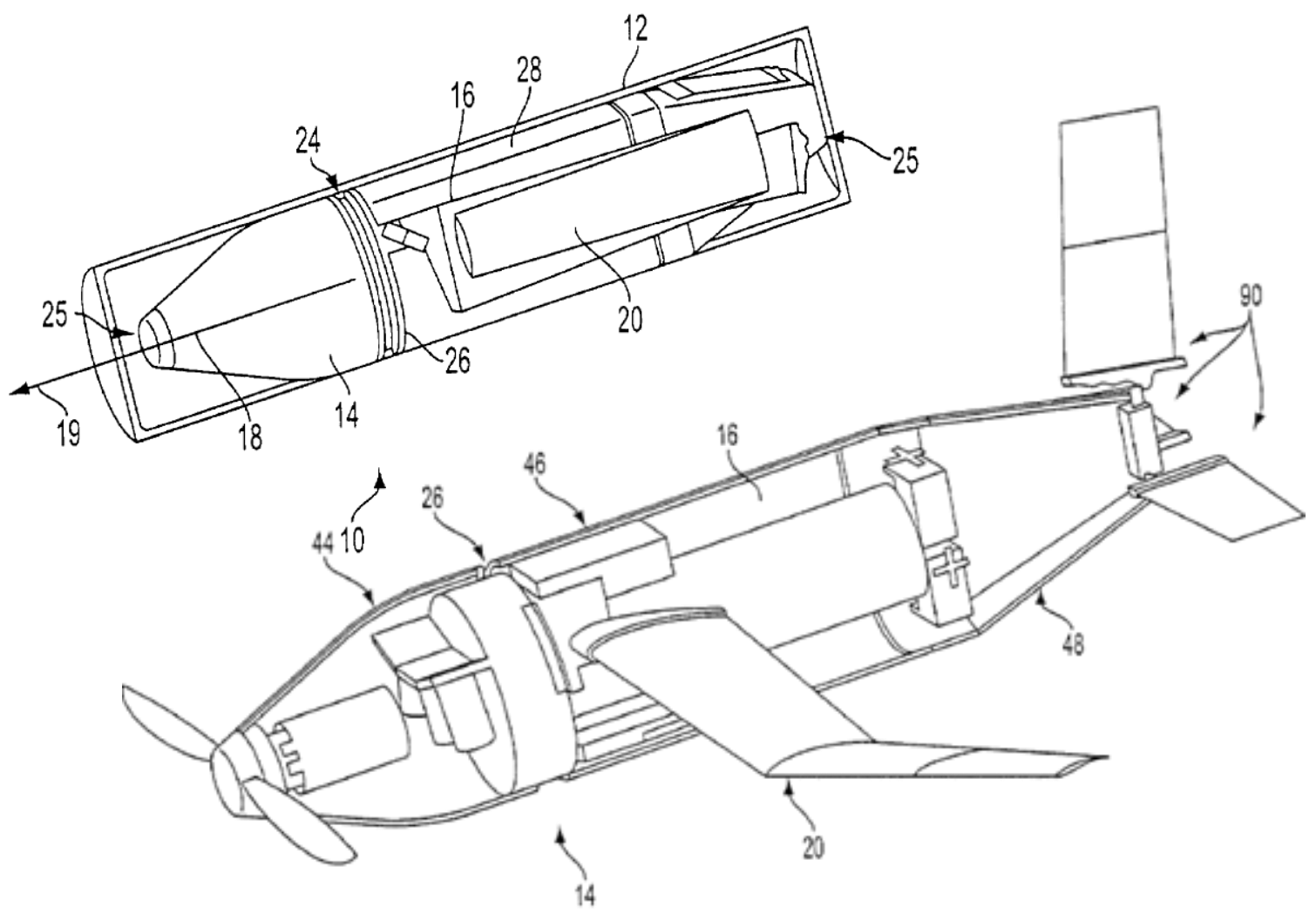

Figure 3-1: Cargo Type Design: Draper Lab's Flyer (Martorana, et al., 2003) 


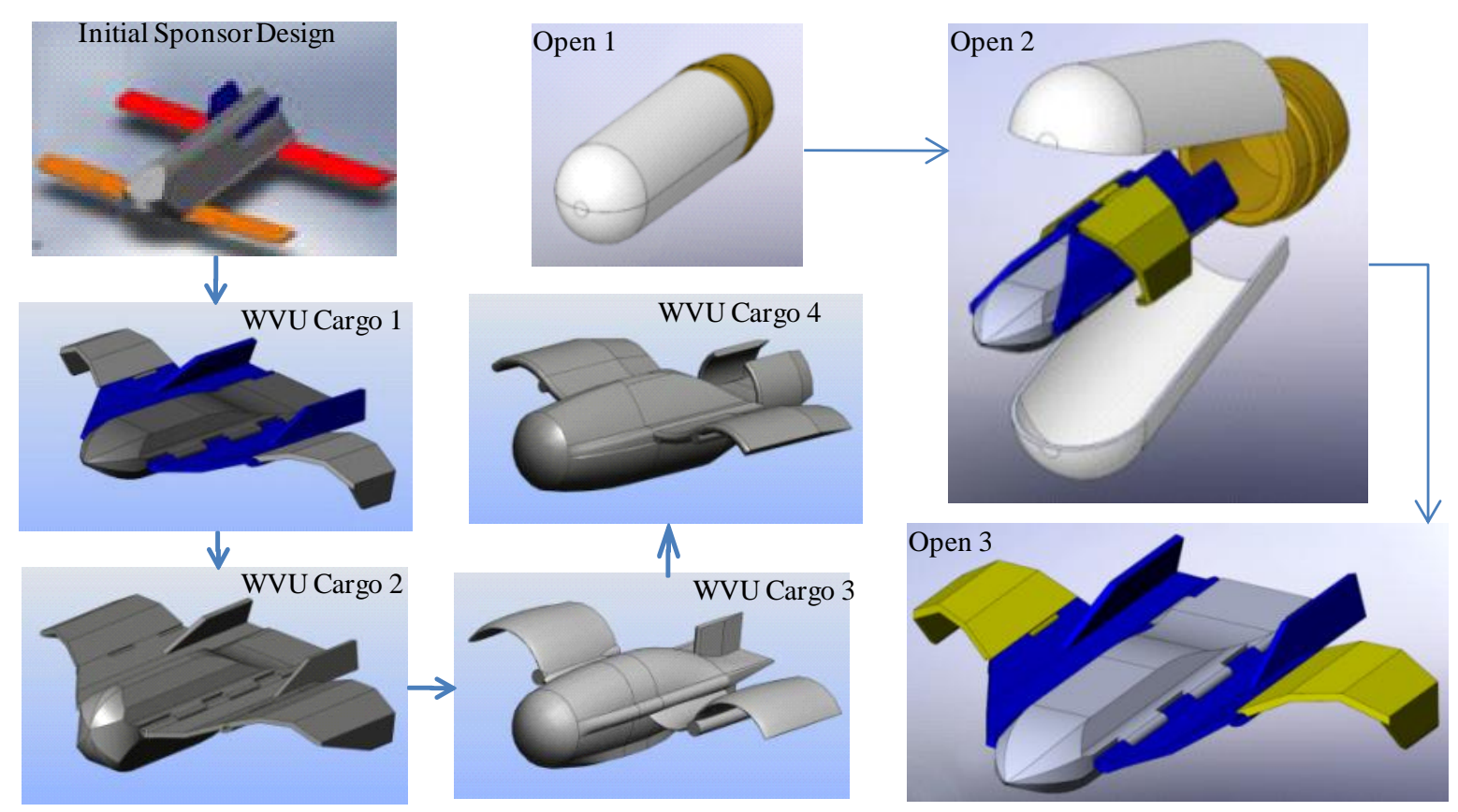

Figure 3-2: Design Progression of WVU Cargo Work and Opening Sequence

Alternately a "transformer" type configuration, Figure 3-3, could be used to increase the useable volume fraction of the stowed configuration. Only a thin shield or base support would be discarded, leaving the maximum possible volume available for the MAV. However, the fuselage design was far more constrained. Figure 3-4 provides a brief overview of the transformer type design progression and the deployment process of a transformer system.
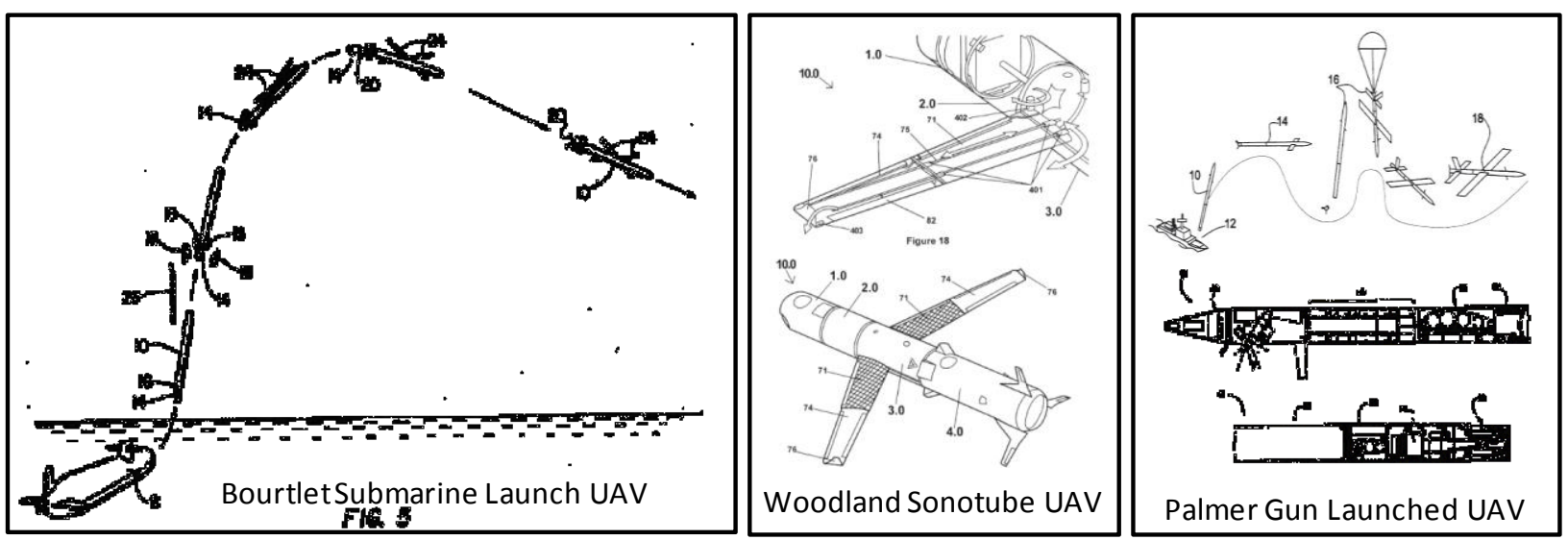

Figure 3-3: Transformer Type Sonotube, Missile Tube, and Naval Gun Designs (Woodland, 2000) (Bourlett, 1997) (Palmer, 2001) 


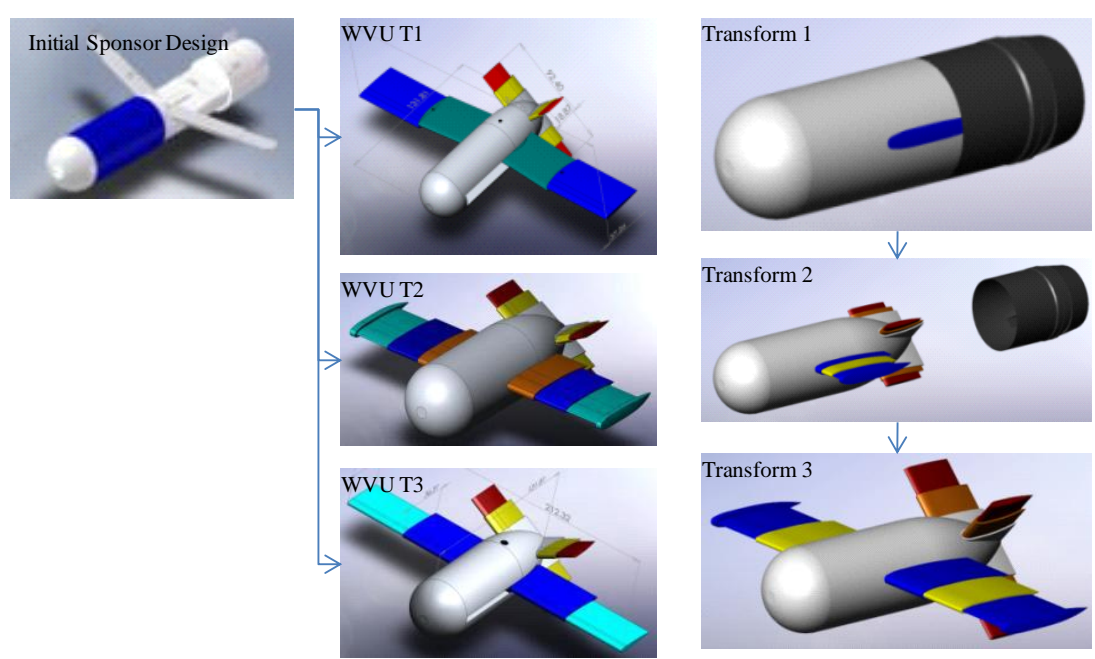

Figure 3-4: WVU Transformer Design Progression and Transformer Deployment Process

Two fundamental wing structures were also examined; solid segments which would swing or fold out to position, and membrane or other flexible segments which would un-wrap or expand. Figure 3-1 and Figure 3-3 illustrate the solid wing configurations while Figure 3-5 provides some examples of the flexible wings. Flexible wings included both composite thin plate airfoils and inflatable envelopes or durable, compressible foam to provide thick airfoil profiles.

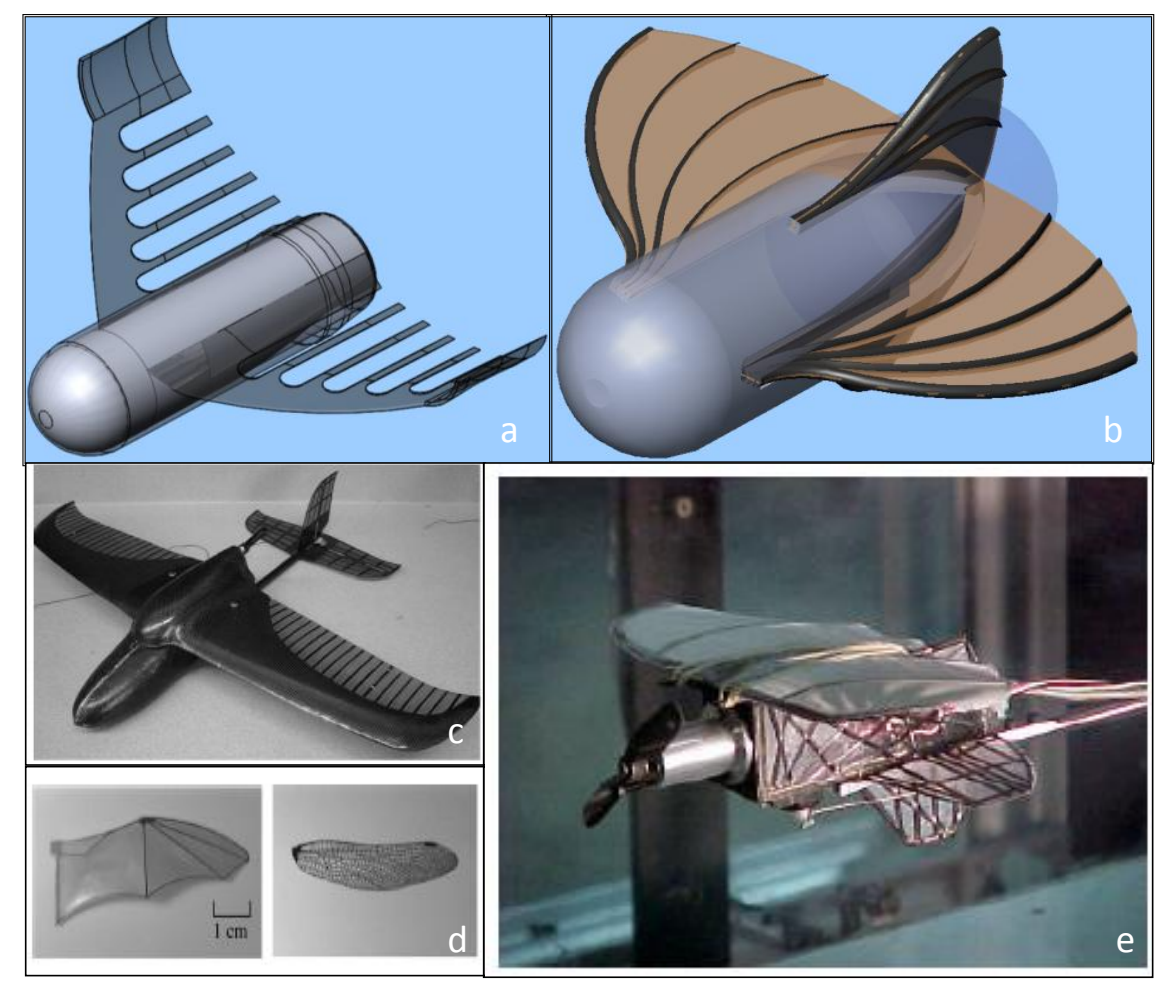

Figure 3-5: Membrane Wings Concepts, a) WVU Wrapped, b) WVU Leaf Spring, c) Batten Reinforced (Stanford, Abdulrahim, Lind, \& Ifju, 2007), d) Titanium-Mylar Insect Scale (Pornsin-sirirak, Tai, \& Ho, 2001), e) Small Scale Batten Reinforced (Fleming, Bartram, Waszak, \& Jenkins, 2001) 


\subsubsection{Cargo Stowage Concepts}

Cargo concepts are characterized by shedding a complete shell or casing from the stowed geometry and deploying a small MAV of arbitrary external geometry. This provides significant design freedom in both wing planform and fuselage shape but can waste large amounts of the available stowed volume.

\subsubsection{Switchblade}

The initial cargo concept was a "switchblade" configuration, very similar to a scaled version of AeroVironment's SOAR, which was provided by the research sponsors (Figure 3-6). This configuration was quickly discarded for two reasons. First, the thin wings would have operated at a chordwise Reynolds number under 50,000, severely compromising their efficiency. Second, the fuselage kept less than 22,000 $\mathrm{mm}^{3}$ useable volume of the initial $160,000 \mathrm{~mm}^{3}$ available in the stowed configuration, barely an eighth of the useable capacity. Note that for all cases only the fuselage volume was considered useable. The wing structures were all far too thin to contain anything but the smallest actuators and certainly no mission payload.

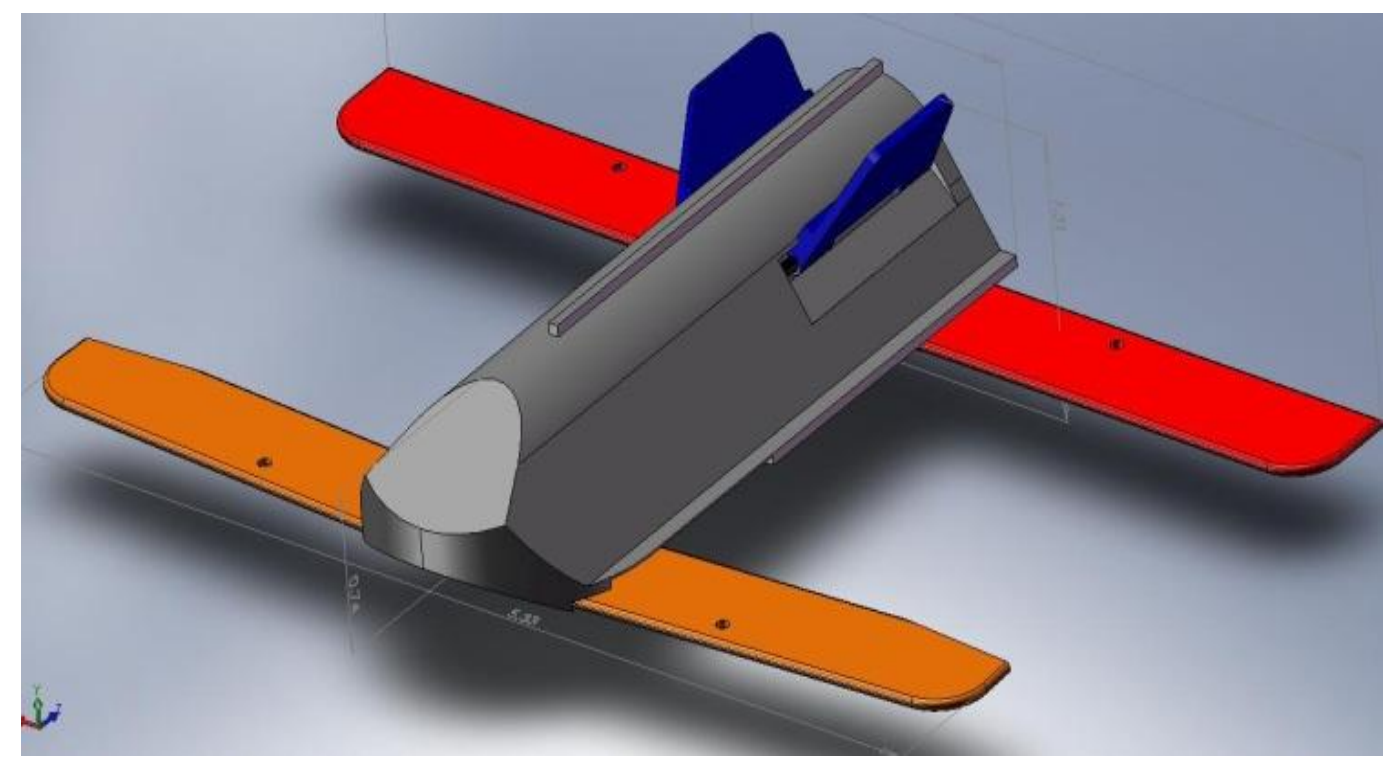

Figure 3-6: Initial Switchblade Concept

\subsubsection{Wrapped Solid Wing}

One of the first methods studied was a folding solid wing. A highly contoured wing with multiple chordwise hinge points modeled to "wrap" around the fuselage as shown in Figure 3-7. 


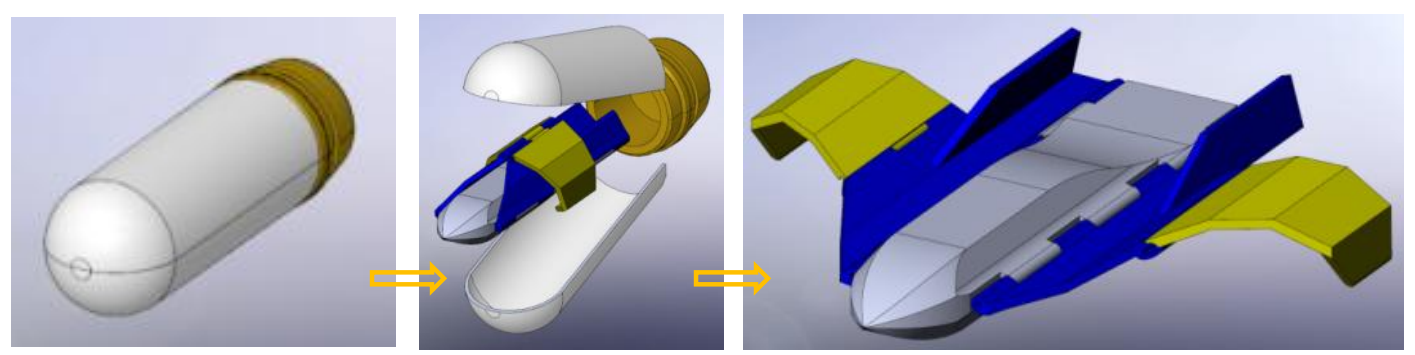

Figure 3-7: Deploy Process for Wrapped Solid Wing Cargo Designs

This permitted both a much higher chordwise Reynolds number, up to 100,000, and maintained far larger fractions of the useable capacity. Both the initial design and the four succeeding improvements of the solid structure configuration are shown in Figure 3-8. Available fuselage volume increased from $25,000 \mathrm{~mm}^{3}$ to $57,000 \mathrm{~mm}^{3}$.

Pros:

- Full airfoil profiles possible

- Simpler designs could use molded, cast, or "rolled" manufacturing to keep costs down Cons:

- Complex wing stowage system

- Full discarded casing may interfere with deployment or de-stabilize MAV during opening

- Poor volumetric efficiency when compared to later WVU solutions

- Complex transformation process

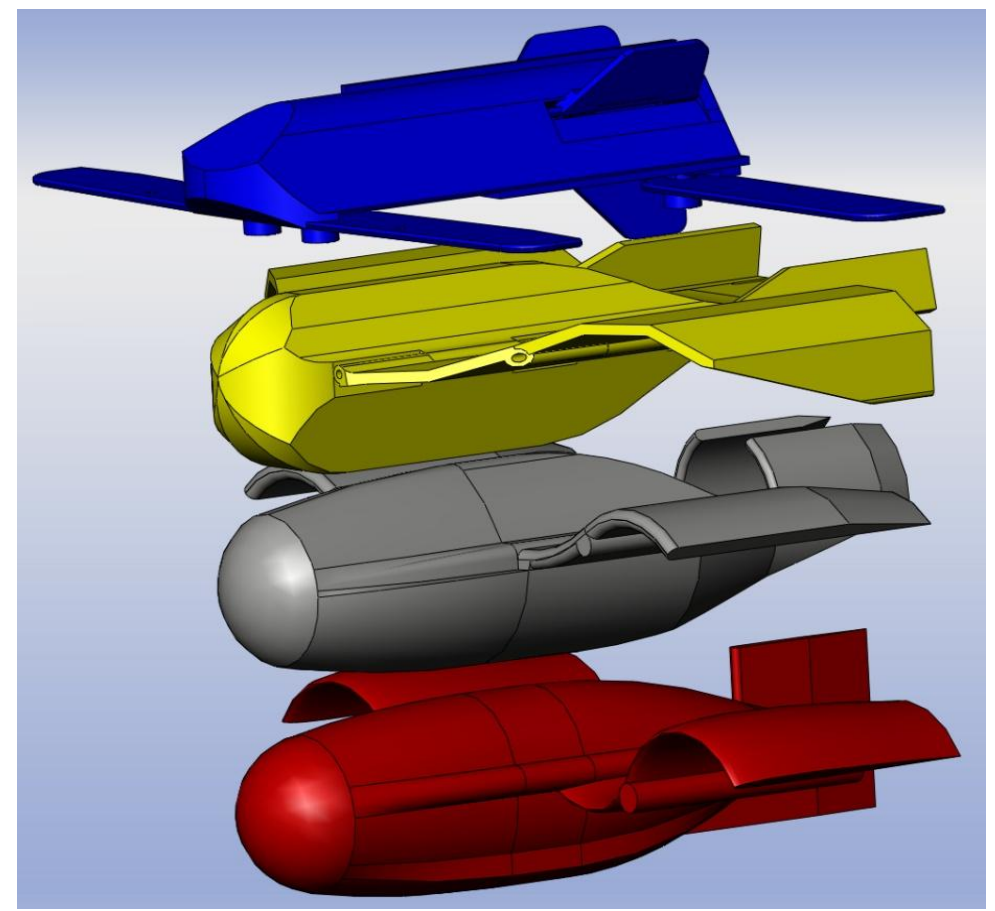

Figure 3-8: Solid Wrapped Wing Design Progression 


\subsubsection{Wrapped Membrane Wing}

Initially it was thought that membrane wings would be impossible on this configuration for designs requiring wing half-spans greater than three fourths to seven eighths of the circumference of the fuselage. This was due to the fact that one wing would have to wrap under the other and would conflict with the fuselage-wing junction of its twin. A slot through the fuselage, or an off-set mounting, combined with a moderate rearward leading edge sweep near the root chord solved the problem as shown in the top right of Figure 3-9 and covered in more detail in Section 3.1.2. With this design the inner-wrapped wing could pass freely under the root chord of the outer wrap. Only the composite substructure of the membrane wing has been shown in the figures. Either a rubber or fabric skin would be stretched over the surface to provide the final airfoil shape.

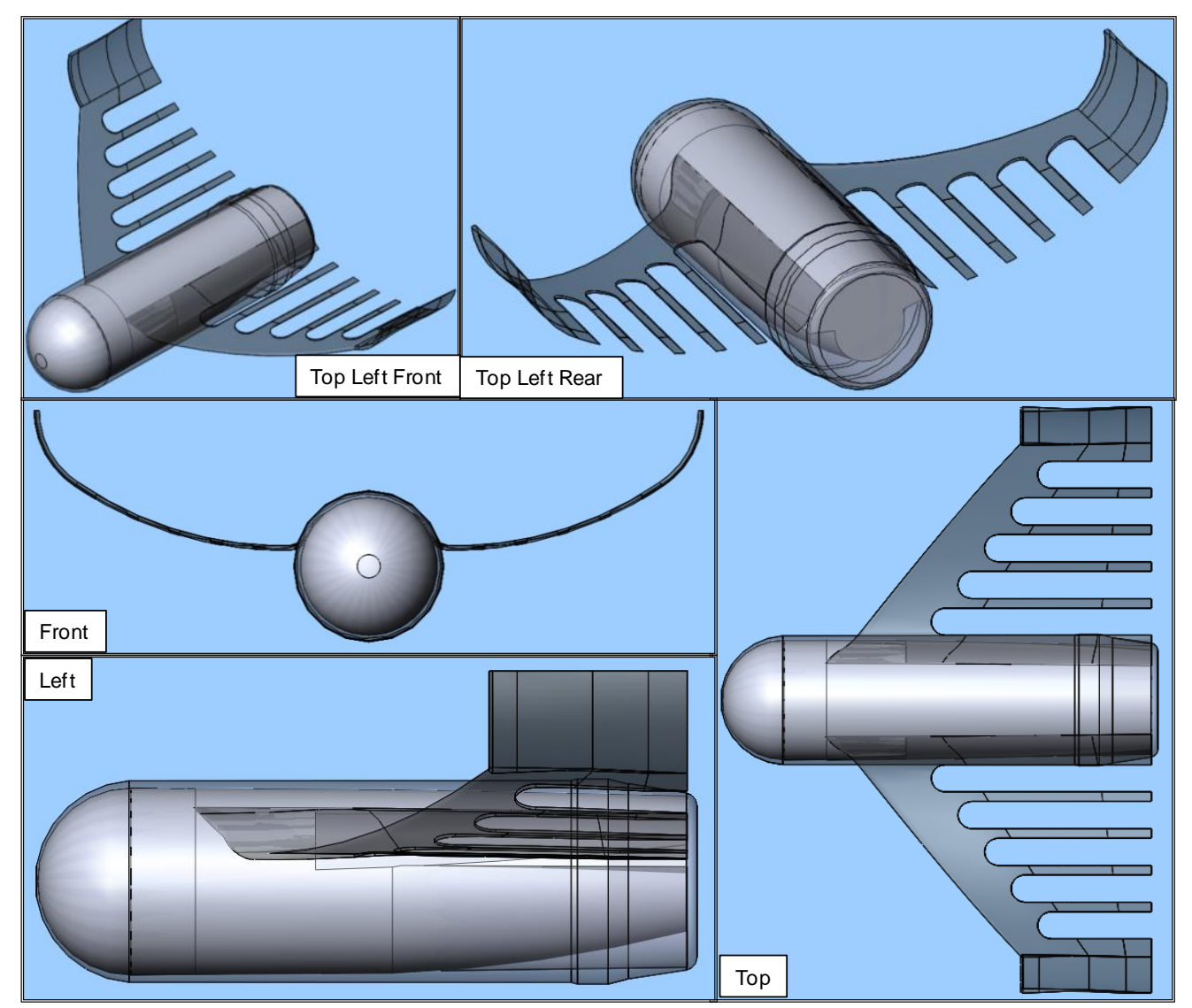

Figure 3-9: Wrapped Membrane Wing Concept

As Figure 3-9 shows, the wrapped membrane structure kept a far larger fraction of usable volume than any solid wing configuration, on the order of $100,000 \mathrm{~mm}^{3}$. This design was also far more flexible in terms of planform and multi-purpose components. Further discussion of this design is presented in Section 3.1.2 since it was the first of two structural systems that showed the most promise for implementation. 
Pros:

- Excellent volumetric efficiency

- Can provide thin-plate to full depth airfoil profiles as detailed in Section 3.1.2

- Design lends itself to dynamic wing morphing techniques such as adaptive washout

- Can imitate bird wing shapes to provide stealthier operation through misdirection

Cons:

- Wings may be difficult to deploy symmetrically

\subsubsection{Wrapped Membrane Structure Detail}

Composite membrane structure designs have been informed by the significant work done at the University of Florida. Figure 3-10 shows a MAV using a curved flat plate airfoil which relies on the cambered composite leading edge for spanwise rigidity. A more highly cambered wing could likely be made of a thinner, more flexible laminate as its cross-sectional moment of inertia would be greater.
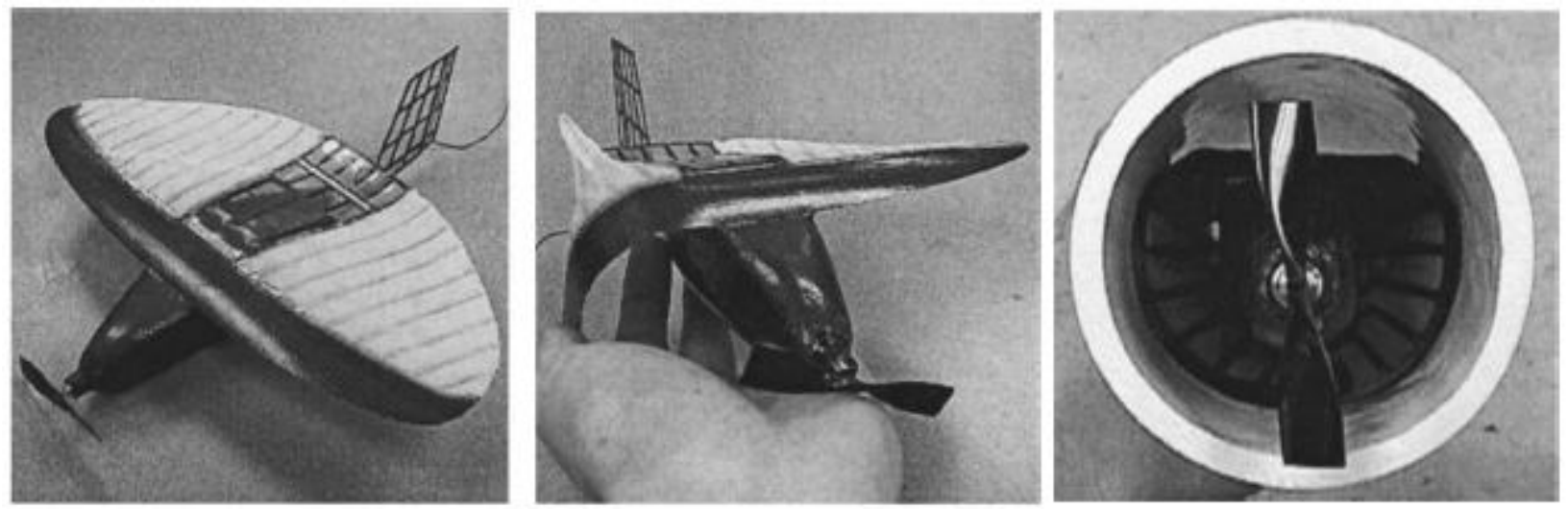

Figure 3-10: Cambered Plate MAV With Wrappable Wings (Shyy, Ifju, \& Vieru, Membrane Wing-based Micro Air Vehicles, 2005)

Span limitation was an early concern with the wrapped wing designs. Since both wings would have to wrap down around the fuselage initial designs were limited to the arc length between one main wing root chord and the other. This was overcome, as shown in Figure 3-11, by incorporating a slot which first wrapped one wing through a slot under the main wing root. The second wing would then wrap around the outside. With this modification spans were limited only by the ability of the system to un-coil from the stowed configuration. 


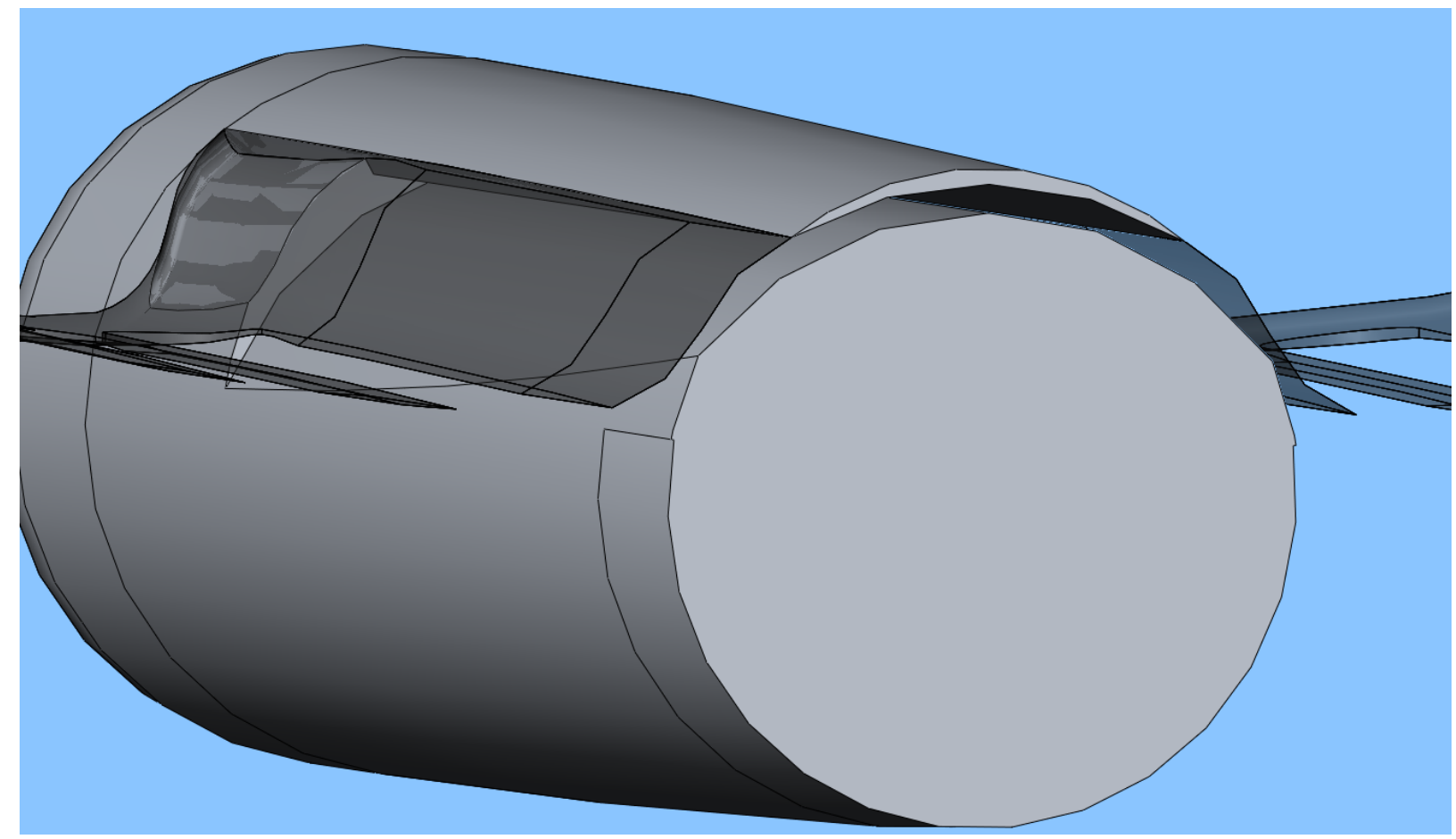

Figure 3-11: Slot For Inner Wrapped Wing Pass-Through

Full airfoil profiles could be created by using either highly compressible open cell foam rubber or inflatable envelopes as shown in Figure 3-12. A full airfoil profile could both increase efficiency and rigidity with the inclusion of tension fibers on the lower surface.

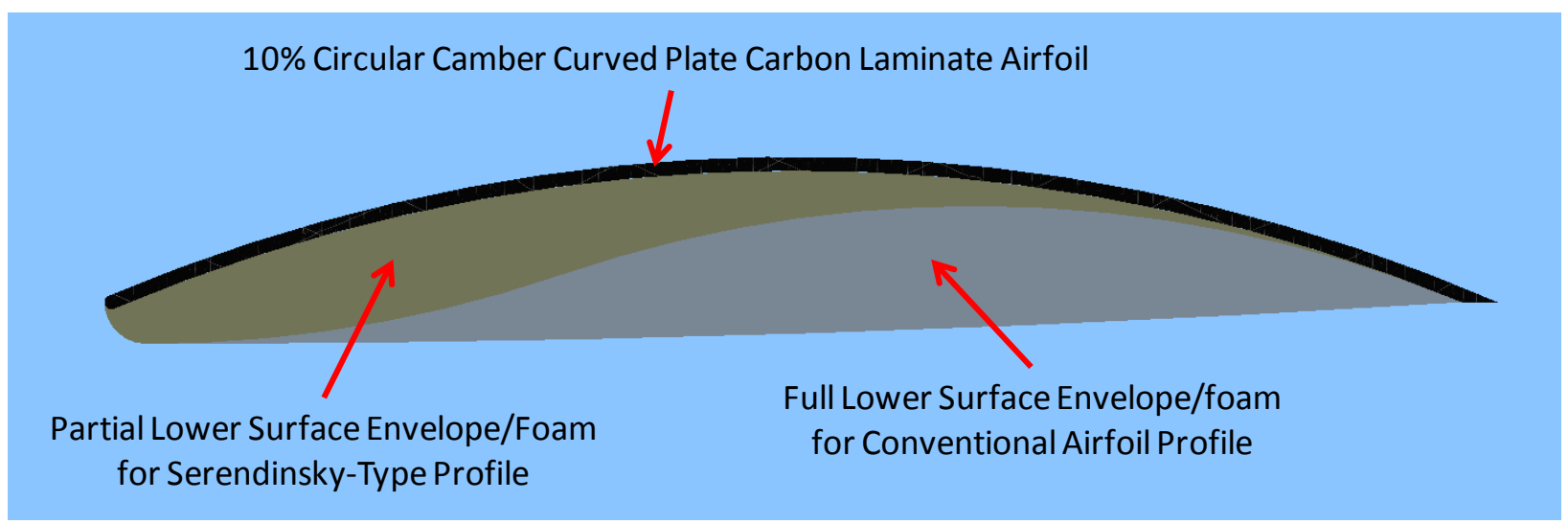

Figure 3-12: Inflatable or Expandable Lower Surface Profile on Membrane Wing 
Each of these methods can be combined with a "batten reinforced" wing. Battens, in the terminology of Ifju, et al, are the composite ribs extending aft from the wing leading edge as shown in Figure 3-9. They allow the trailing edge of the wing to deflect into oncoming gusts and reduce the change in lift caused by atmospheric disturbances thereby enhancing stability. ${ }^{16}$ Figure 3-13 shows a pair of batten reinforced structures. The left image is a high aspect ratio wing incorporating both adaptive washout and a torque rod for control purposes; the right is a much smaller MAV using only adaptive washout.
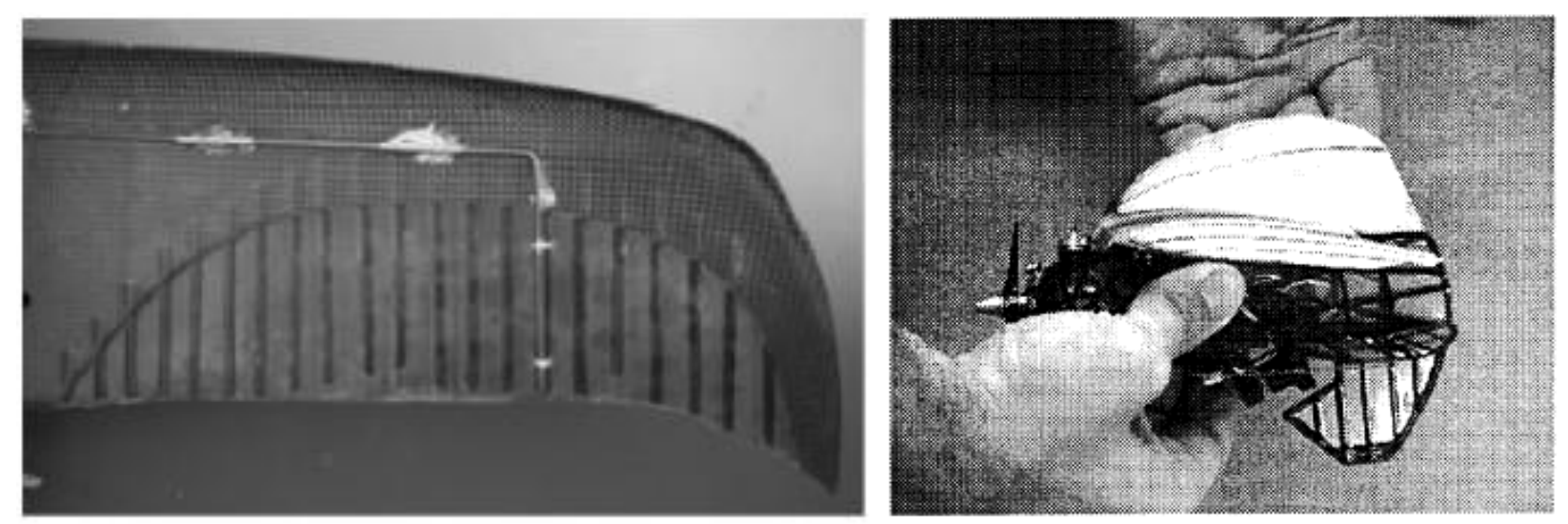

Figure 3-13: Batten Reinforcement and Adaptive Washout Detail (Stanford, Abdulrahim, Lind, \& Ifju, 2007), (Ifju, Ettinger, Jenkins, \& Martinez, 2001)

The usual method for creating a MAV wing with adaptive washout has been to create a composite laminate with a stiff leading edge structure and several trailing battens of unidirectional carbon fiber. A flexible, usually elastic, membrane is then bonded over the upper surface. This structure permits the wing chord to deform into an oncoming gust. Gust tolerance has been extremely important as flight speeds of MAVs are on the order of atmospheric gust velocities.

A previous wing morphing system developed at West Virginia University for the control of a tailless flying wing could be adapted for use on a membrane wing. The combination of a curved actuator rod, free-floating "feathers" and a common hinge line (Figure 3-14) allowed the creation of a continuous, smooth change in wingtip angle of attack. A latex and polypropylene skin has been omitted from the figure for additional clarity. Modifications to this system could incorporate more flexible feathers and multiple actuator rods to enable far more dynamic control input incorporating both angle of attack and camber changes.

${ }^{16}$ (Ifju, Ettinger, Jenkins, \& Martinez, 2001) 


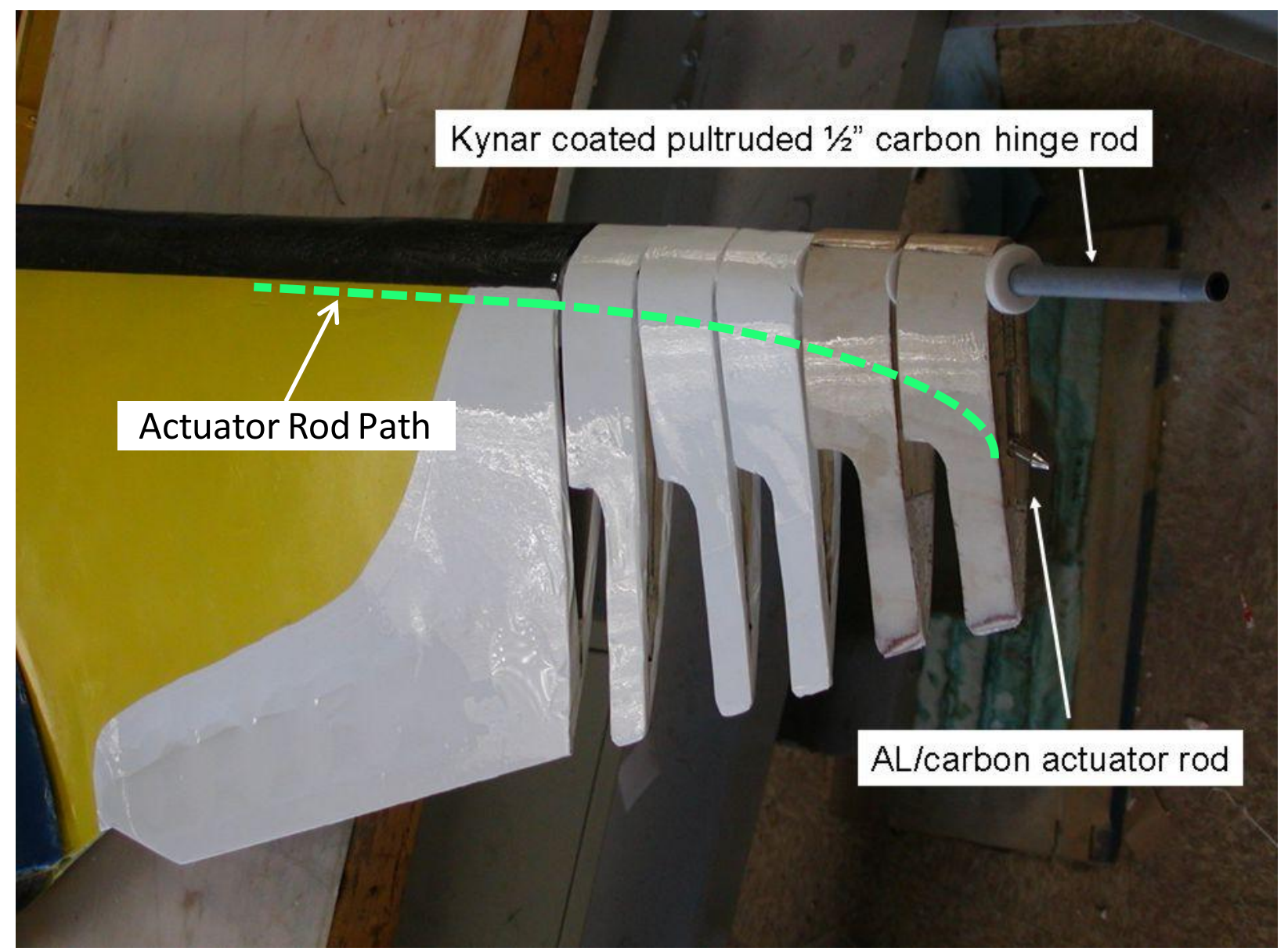

Figure 3-14: "Feathered" Wing Morphing System for WVU Horten Flying Wing (Guiler, 2007)

Membrane wings would give the maximum planform diversity. Blended vertical surfaces could be incorporated at the wing tips, or a biomimetic planform could be used. Figure 3-15 shows an array of possible layouts. Bird like planforms can provide stability without vertical surfaces at these scales as shown by Sachs, 2007. The rearward swept tips generate an induced drag imbalance when encountering a side-gust. Focusing attention on the Frigatebird in Figure 3-15 it can be seen that a side-gust from the right will increase lift and drag on the outboard right wing and inboard left wing while reducing both on the outboard left and inboard right wings. The forward swept inboard wing keeps the total amount of lift nearly constant while the reduced drag on the left tip and increased drag on the right tip act to rotate the bird into the oncoming gust. 


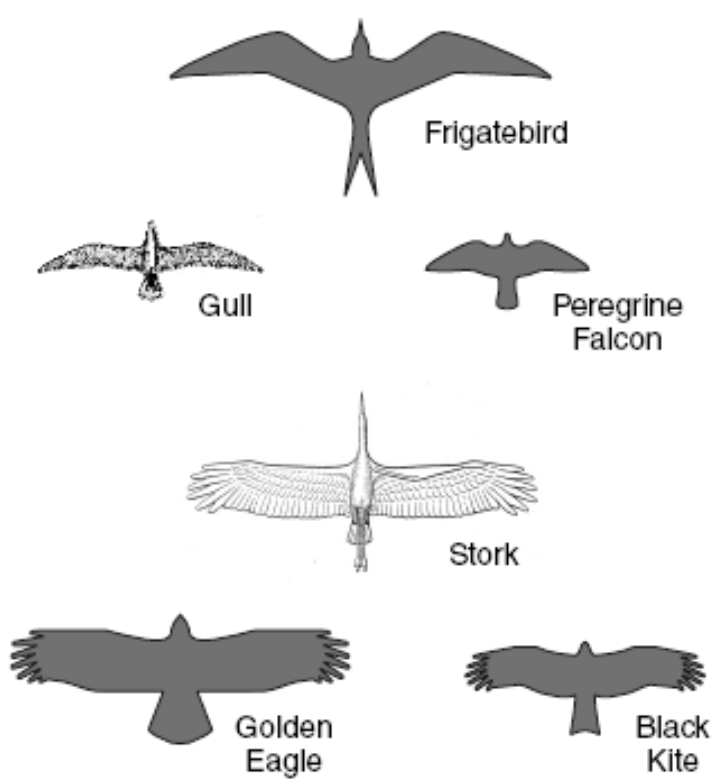

Figure 3-15: Potential Biomemetic Membrane Wing Configuration Diversity (Sachs, 2007)

Figure 3-16 provides Sach's scale analysis showing a reduced required yawing moment for stability as mass is reduced. Smaller birds require a proportionally smaller restoring moment and their planforms can therefore be simpler. It appears that these same planforms should provide acceptable performance for the MAVs designed in this project. The hawk-like swept wings which provide these acceptable stability characteristics would be easy to manufacture with the methods discussed in this section. Using a cylindrical body, a biomemetic wing, and no vertical surfaces the visual signature of the MAV would be quickly discounted by observers.

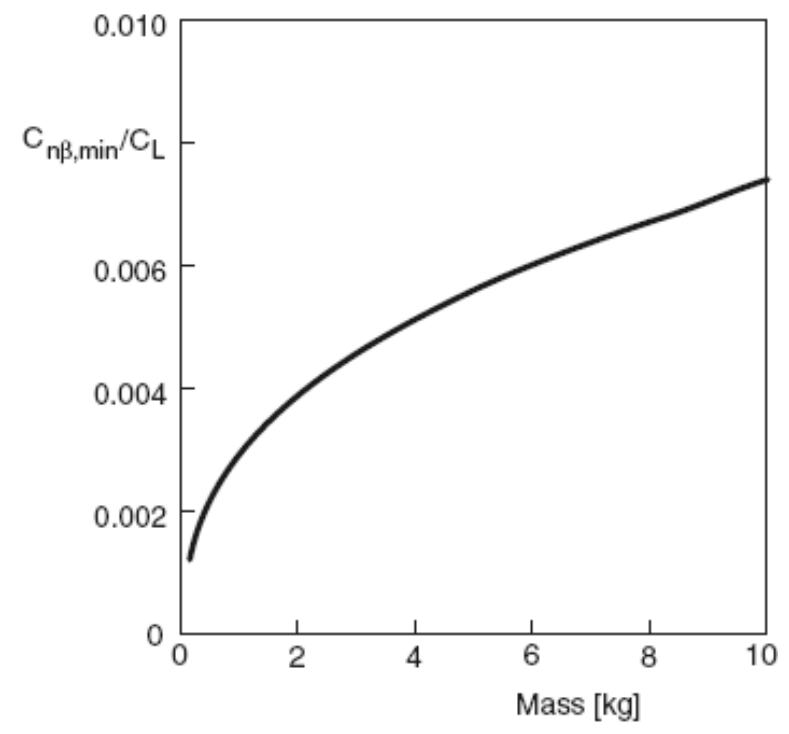

Figure 3-16: Correlation Mass and Required Yaw Stability with Behavior of a Clean Swept Biomemetic Planform(Sachs, 2007) 


\subsubsection{Transformer Stowage Concepts}

Three transformer concepts were developed. The first two incorporated solid wing and tail structures. A novel "leaf-spring" system was conceived third. Transformer designs, initially stemming from the "telescopic" system (Figure 3-17) developed by the sponsor, quickly proved to be more than worth the additional design difficulty. Initial designs kept $100,000 \mathrm{~mm}^{3}$ of useable fuselage volume, nearly $66 \%$ of the stowed configuration. The best solid-wing cargo designs kept barely $25 \%$.

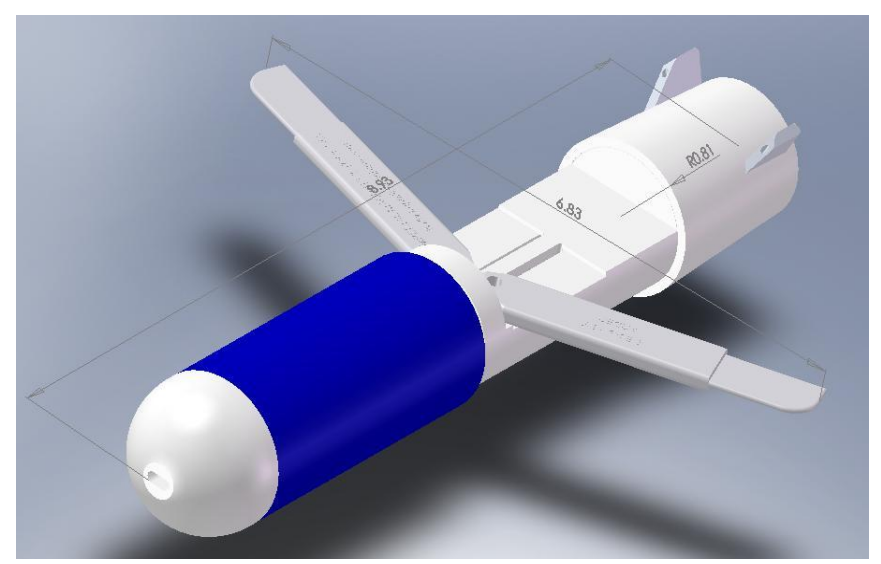

Figure 3-17: Sponsor Telescopic Transformer Concept, (dimensions in $\mathrm{cm}$ )

\subsubsection{WVU Switchblade Transformer}

All WVU transformer concepts significantly reduced the complexity of the sponsor's initial work. In all cases the fuselage was a monolithic volume rather than the multiple sliding elements shown in Figure 3-17.

The switchblade transformer system was the simplest system. Sets of single or multiple "fan" blade elements would be mounted on torsion springs as shown in Figure 3-18. These simple solid components could be easily and cheaply rolled or stamped for low cost. However, to conserve space only thin airfoils or cambered flat plates would be practical. An advantage of multiple wing elements was that they could be deployed at separate times to de-spin, stabilize, and orient prior to deploying lifting surfaces. This could be done by having multiple, staged wing deployments with separate sets of fins or fins which deploy further at a later point in the flight. 


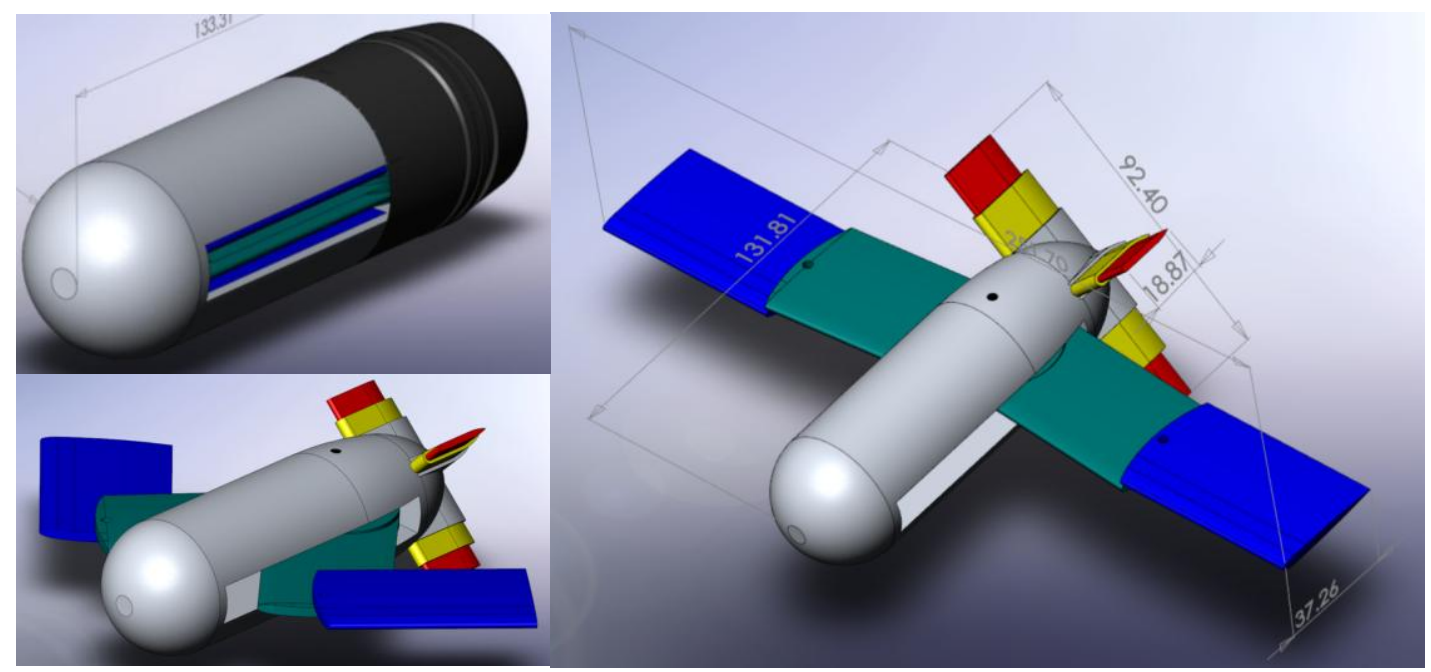

Figure 3-18: Switchblade Transformer Structural Concept, (dimensions in $\mathbf{m m}$ )

Unfortunately this design sacrificed large blocks of volume extending into the center of the fuselage. It is anticipated that there will be difficulty in the miniaturization of the electronics and payload without the structural design sub-dividing the available volume. In addition, most useful configurations opened slots through the center of the body. Air bleed through these gaps could cause significant instabilities which would be extremely hard to model and predict. ${ }^{17}$

Pros:

- Simple design

- Rugged torsion springs

- Full thin airfoil profile possible

- Can provide thin plate airfoil profiles

Cons:

- Open slot through center of fuselage

- Large block of central fuselage volume sacrificed

\subsubsection{Telescopic Transformer}

The telescopic transformer system increased complexity of both design and construction, but was able to increase both planform diversity and available internal volume. Figure 3-19 shows how a set of wing elements could telescope into one another creating both a small stowage volume and a complex planform. Note that there is no particular significance to the different colors in the figure other than ease of viewing.

${ }^{17}$ (Appich \& Wittmeyer, 2001) 


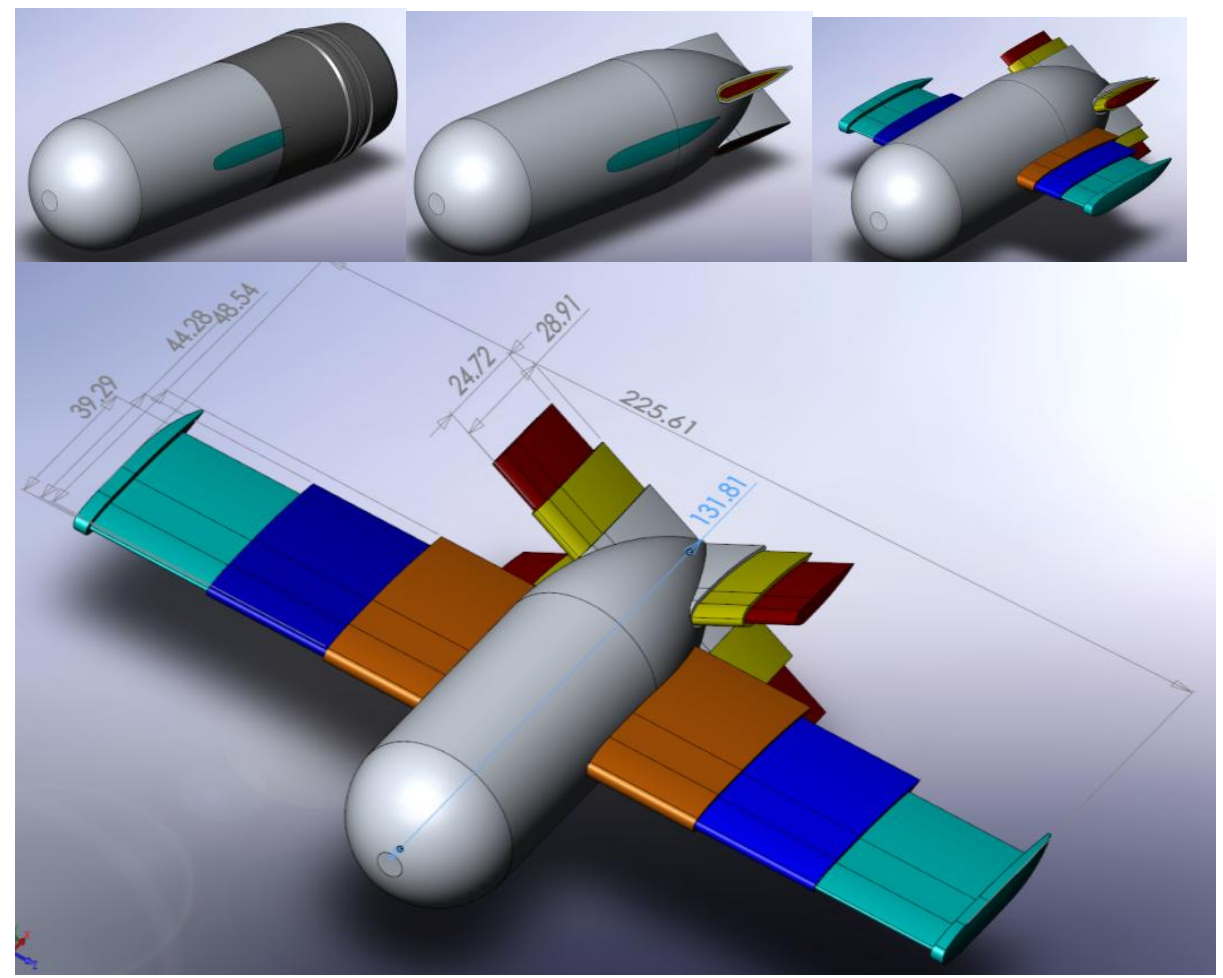

Figure 3-19: Telescopic Transformer Structural Concept, (dimensions in $\mathrm{mm}$ )

The large blocks on the wing tips served as both the surface seal of the stowed configuration and masses to increase the MAV's rolling moment of inertia. This was an important consideration in all designs since the extremely small moments of inertia of standard MAVs produce responses similar to fighter aircraft instead of the more desirable general aviation or transport aircraft dynamic characteristics. $^{18}$

Again, like the Switchblade transformer, a large block of fuselage volume would be sacrificed. In addition, manufacturing and g-load problems may be encountered with the thin shell structures the wing requires.

Pros:

- High AR possible

- Sacrifices less volume than WVU switchblade

- Full thin airfoil profile possible

Cons:

- Sacrifices large block of useful volume

- Delicate manufacturing process for "shell" wing segments, prone to deformation

${ }^{18}$ (Morris, Design and Flight Test Results for Micro-Sized Fixed-Wing and VTOL Aircraft, 1997) 
- Cannot provide curved plate airfoil profiles

- Cannot provide thick airfoil profiles

\subsubsection{Leaf Spring Transformer}

An elegant structural solution for a stowed-wing MAV was finally developed with the Leaf Spring system, shown in Figure 3-20. Elastic elements would be pinned together at the leading edge root and spread out in a fan when in the relaxed, deployed state. A membrane, either elastic rubber or taut fabric, would be stretched over at least the upper surface. When properly contoured, and with a taut membrane skin the leaf elements could support any thick airfoil contour by covering both upper and lower surfaces.

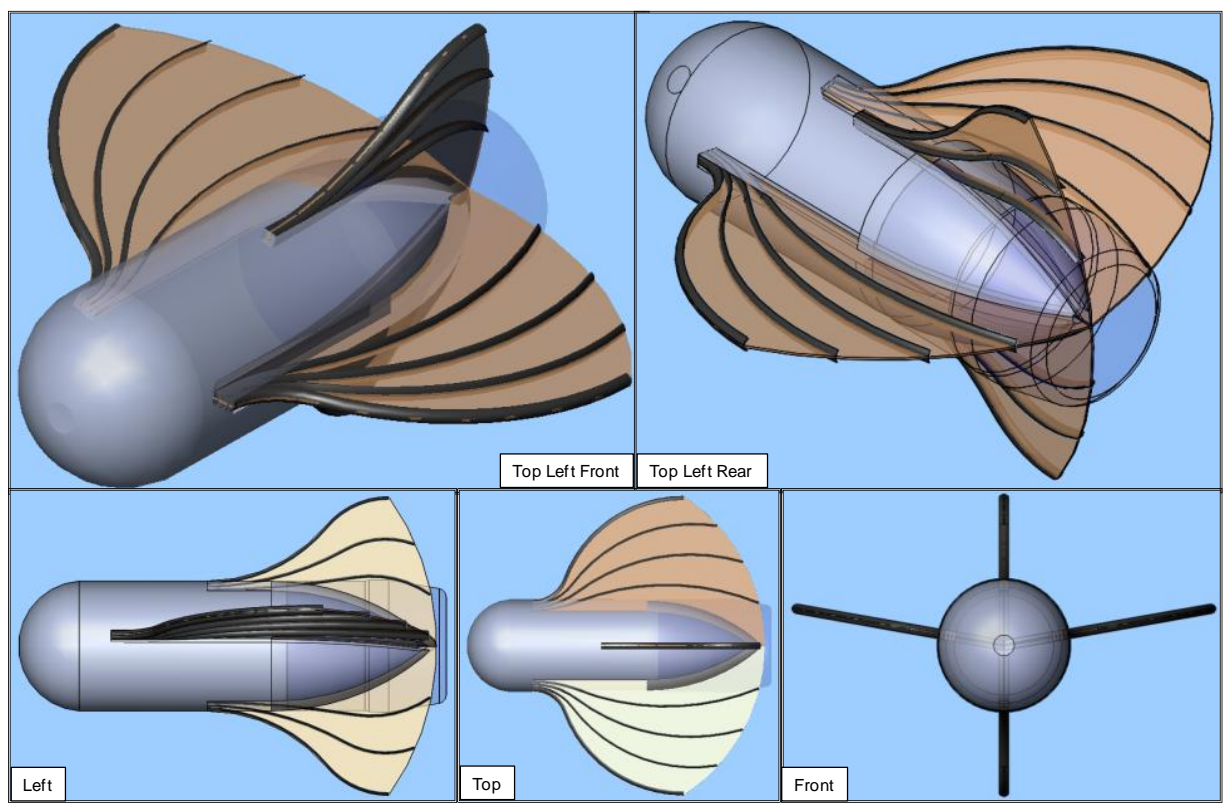

Figure 3-20: Leaf Spring Transformer Structural Concept

Volumetrically this system seemed to be by far the most efficient. With the leaves being the only solid components of the wing an extremely large area could be compacted into a much smaller volume than any other option, with the possible exception of the Wrapped Membrane system. Both methods left the central fuselage volume free for payload and electronics.

Problems this system could encounter include a somewhat difficult design of the leaves for a desired airfoil and planform shape, and difficulty in obtaining completely symmetrical wing deployment in both the transient phase and the final gliding shape. The aerodynamic analysis would also have to account for potential deformation of the membrane surface during flight. Unfortunately the span is limited by the mounting location, and the leaves may be forced to wrap around the fuselage tail for large spans. Span and tip chord are also cross-linked by the leading edge spar/tip rib leaf element as shown in Figure $3-21$. 

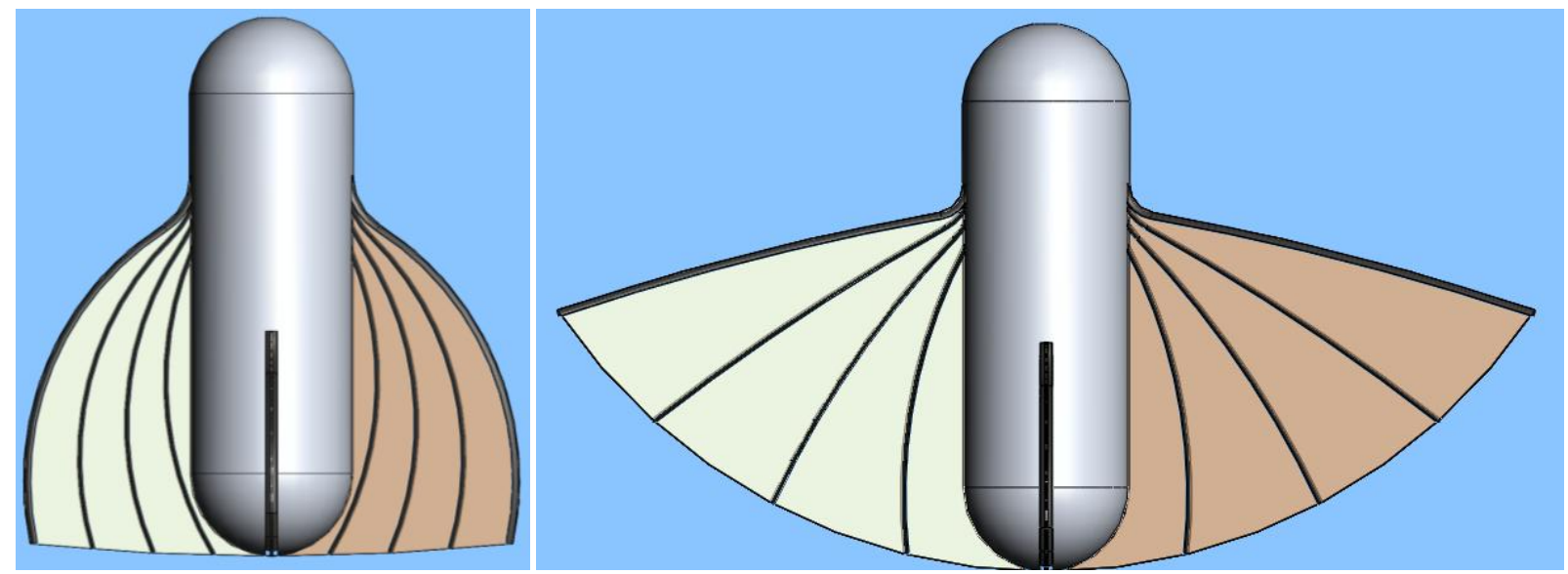

Figure 3-21: Inverse Relationship Between Span and Tip Chord Length of Leaf Spring Structure for Wings with Equal Length Leading Edge Leaves

Pros:

- Full airfoil profile possible

- Can support thin plate airfoil profiles

- Extremely small stowed volume

- Leaves center of fuselage available for payload and system components

Cons:

- Difficult design of leaf-spring element contours for desired airfoil shape

- Membrane covering will deform from desired shape

- Span-chord are cross-linked by leading edge spar/tip rib element

- Asymmetric deployment possible

\subsubsection{Leaf Spring Structure Detail}

Both thick, $10 \%$ thickness to chord ratio or greater, wing profiles and cambered plate airfoils could be coupled with a dynamic, morphing structure in the Leaf Spring concept. The minimal number of simple components move towards a rugged design with small stowage volume, and great planform and control diversity. Figure 3-22 illustrates how the relative angle between the fuselage centerline and the wing chord could be changed. All leaves would be mounted to a single rotating base point. This would remove the necessity to self-right. A tri or quad symmetry setup could be used. While requiring a control system able to re-orient for the rotated body reference frame the aerodynamic simplification may make this worthwhile. 


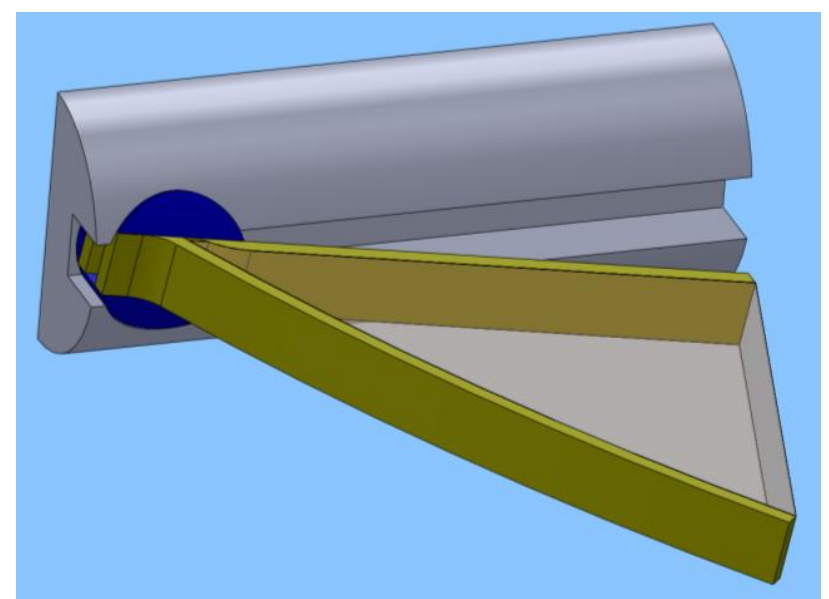

Figure 3-22: Method for Varying Leaf Spring Angle of Attack Relative to Fuselage; Gray) Fuselage With Slot for Membrane and Leaves, Blue) Rotating Mount for Leaves, Yellow) Leaf Spring Elements, Tan) Membrane Bonded to Leaf Upper and Lower Surfaces

Alternately some inboard leaves could be attached to an aft-mounted rotating base. This would form an effective control surface by altering wing camber around the rotated leaves as in Figure 3-23. It may be possible to couple this control system with the previous angle of attack alteration but more design work is required to prove this out.

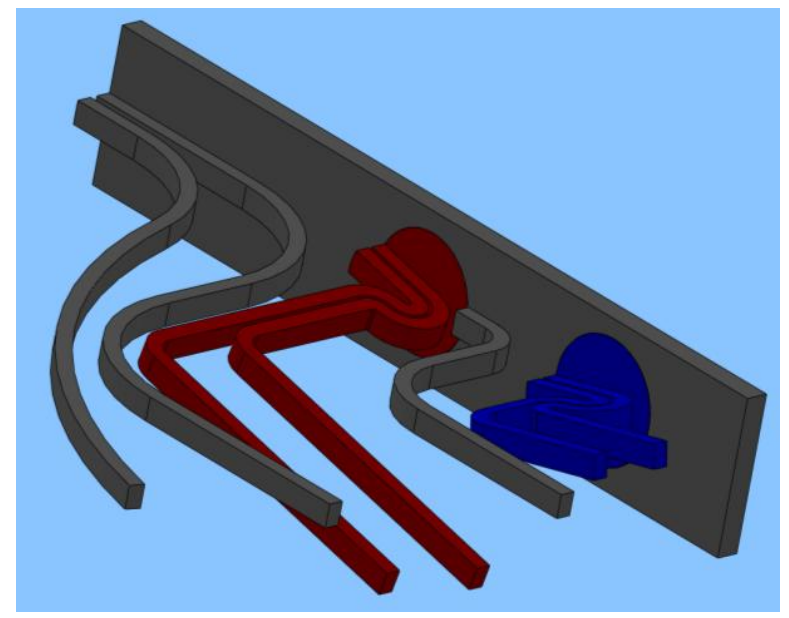

Figure 3-23: Rotated Leaves for Control Surface Actuation and Camber Modifications; Fixed Leaves and Fuselage (Gray), Outboard Surface Rotation Point and Leaves (Red), Inboard Rotation Point and Leaves (Blue)

Later powered versions may incorporate a method to actively change the amount the wings deploy, either through a winch system or active leaves of some variety. This system could be used to stage wing deployment as shown in Figure 3-24. Such a method would require an elastic membrane for the two-stage deployed main wings so that the appropriate airfoil shape would be maintained when not fully deployed during the de-spin and orientation phase. 


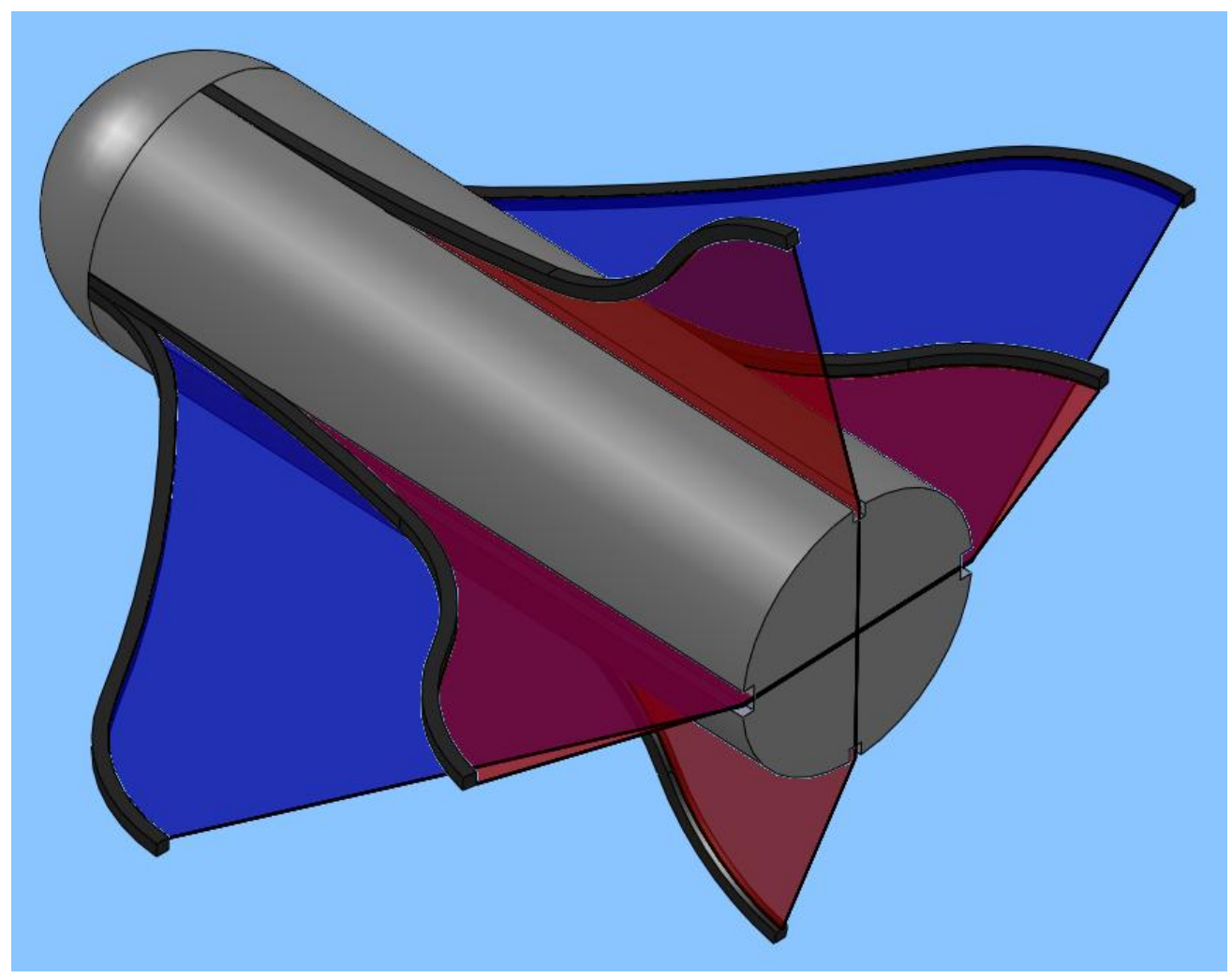

Figure 3-24: Staged Wing Deployment for Stabilization and De-spin; Red) Initial Deployment for De-spin and Orientation, Blue) Secondary Deployment of Main Wings

In addition, the ability to change wing area during flight could enable advanced maneuvers such as "bounding" flight described in Design and Flight Test Results for Micro-Sized Fixed-Wing and VTOL Aircraft (Morris, 1997) and shown in Figure 3-25. This shows how a bird, or an aircraft with variable wing area, can alternate between a ballistic trajectory and high-g pull-ups. This mode of flight could enable a powered aircraft to cruise at twice its optimum lift-to-drag velocity while operating near its maximum lift-to-drag ratio.

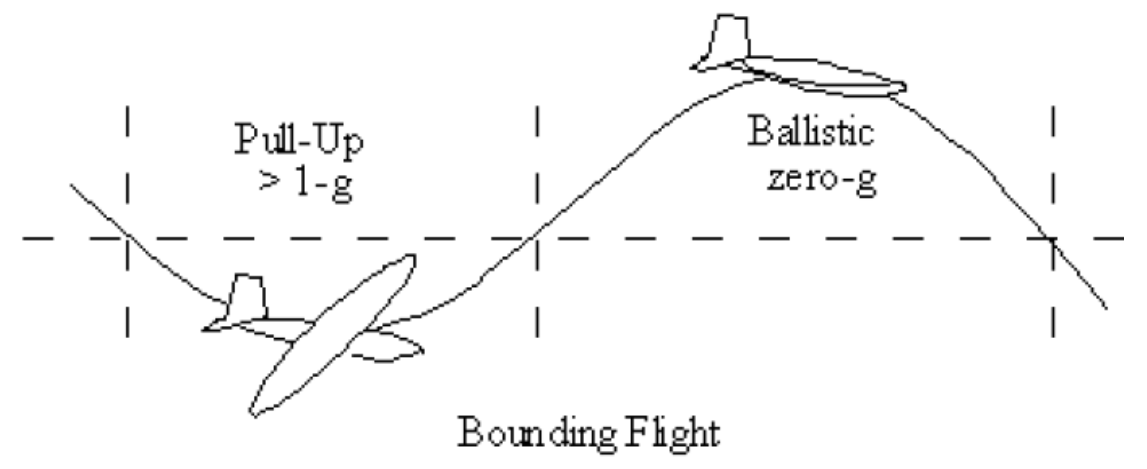

Figure 3-25: Illustration of Bounding Flight for Increased Cruising Speed (Morris, Design and Flight Test Results for Micro-Sized Fixed-Wing and VTOL Aircraft, 1997) 


\subsection{Control Surface Actuation Concepts}

While future work may enable the use of advanced morphing control systems the present designs focused on incorporating simple, standard control surface systems into the collapsible wing structures discussed previously. This was an interesting problem requiring hinge lines capable of collapsing down in a plane perpendicular to their rotation axis. Several concepts were developed.

\subsubsection{Torsion Rod System}

Torsion rods for actuation of flexible wing surface deflection have been used by several previous small UAVS, and have been studied in detail at the University of Florida on a high aspect ratio batten reinforced wing ${ }^{19}$. Their work proved that, on a batten reinforced MAV wing, excellent roll control could be achieved using a system similar to that shown in Figure 3-26. A servo was used to apply torque to the horizontal rod along the quarter chord line. This rotated the two chordwise rods in the batten reinforced section of the wing to twist the wing structure in that region and provide an effective aileron control.

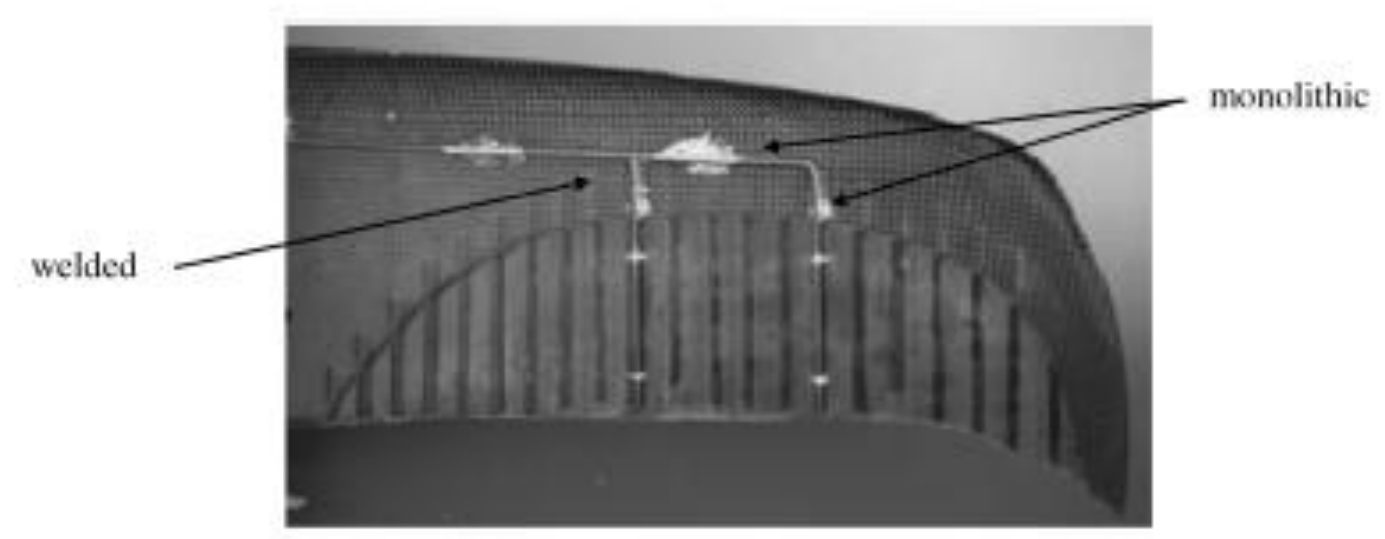

Figure 3-26: Torsion Rod Control System on Batten Reinforced Wing, Multiple Actuation Point Configuration (Stanford, Abdulrahim, Lind, \& Ifju, 2007)

This work recommended locating the torsion rod in the weakest spanwise location to maximize the amount of deformation gained for the power applied. Unfortunately serious drag penalties were discovered when compared to conventional rigid wings and control surfaces. Control authority was comparable to conventional systems up to the point tip stall was encountered on the outboard wing. This may be a poor choice for a high wing loading design as tip stalls could be encountered when twisting the wing leading edge up.

${ }^{19}$ (Stanford, Abdulrahim, Lind, \& Ifju, 2007) 


\subsubsection{Collapsible Flapped Surface}

A control surface similar to a conventional hinged flap system was desired since it would provide a more known quantity. Unfortunately a simple hinged system could not be incorporated into the selected flexible wings without creating serious problems for either the hinge or stowage method. A compromise system, Figure 3-27, was developed. A more defined hinge line could be created by using a second set of rigid segments just forward of the control surface elements with a small gap between the two sets. The gap between the two sets of plates would then act as a defined living hinge. Alternately a high-tension spanwise line could be run just in front of the control surface elements between two adjoining battens and then be bonded to the membrane surface. This would also act as a defined hinge line for a living hinge. The rigid elements could be constructed from either a one-way flexible composite or plastic, or smaller completely rigid components. A pull-pull system would actuate control horns mounted to the central rigid control surface element. While the system would compromise the flexibility of the structure somewhat, the stowage system would still function and the system should operate nearly as a standard flapped system. For the leaf spring structure a compressible foam could be used to provide a trailing edge shape and compatibility with this system. Some efficiency improvements may even be gained since control surface gaps would be eliminated and the airfoil profile would not be modified to the extent a torsion rod system could generate.

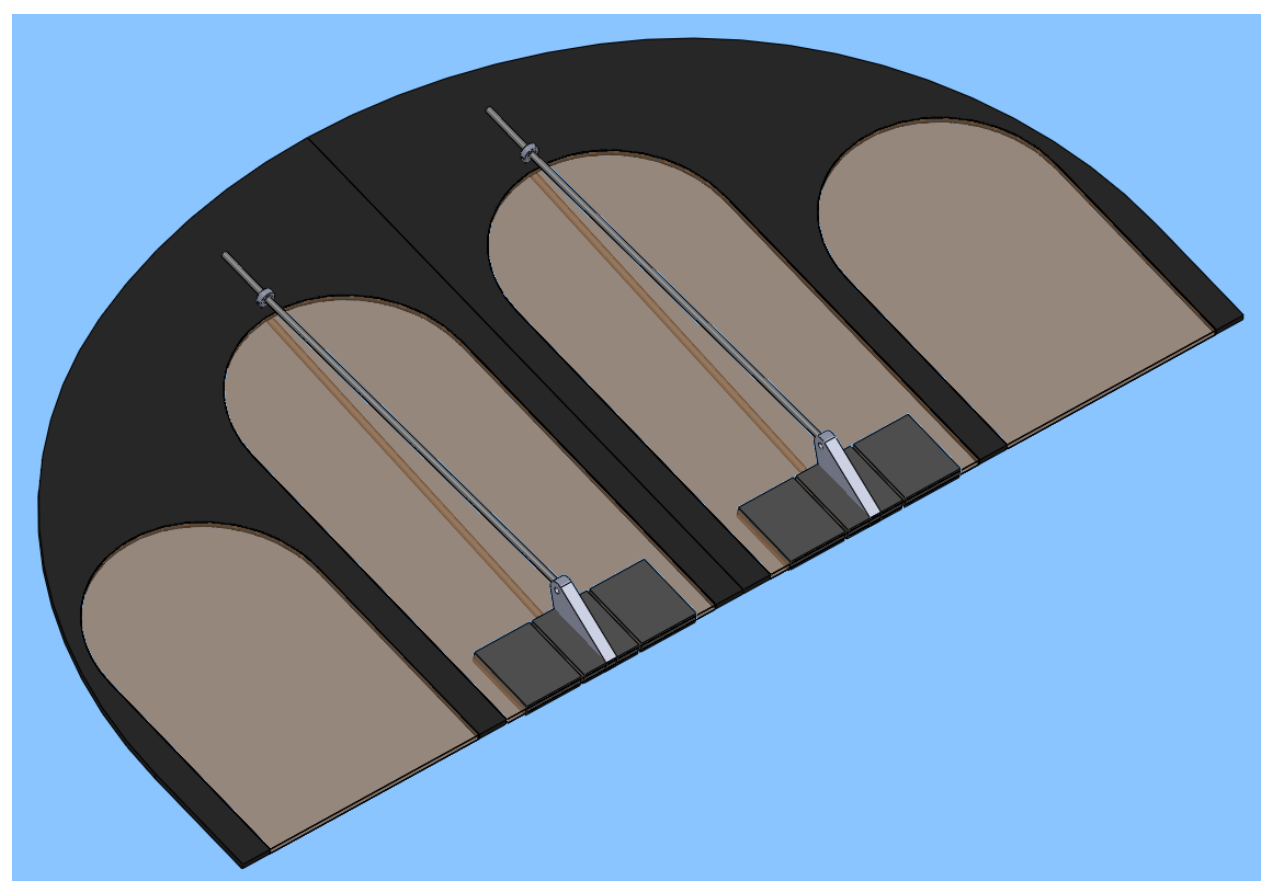

Figure 3-27: Effective Flapped Control Surface for Membrane Wings; Black) Carbon Laminate Structure, Tan) Membrane Surface, Dark Gray) Rigid Elements Bonded to Membrane, Light Gray) Control Horns and Cables for Pull-Pull Control 


\subsection{De-Spin and Orientation Methods}

The gyroscopically stabilized shell must be de-spun prior to fully deploying any lift generating surfaces to avoid a massive recovery oscillation which may end with the MAV traveling in a random direction. With the specified center of gravity a high spin rate was required for gyroscopic stability. Slowly reducing this rate can permit Magnus instabilities to tumble the round. These instabilities are caused by asymmetric circulation lift generated by the round's axial rotation when at a sideslip or pitch angle of attack. High spin rates cause gyroscopic stability effects to override these destabilizing lift components, but as spin rate drops the round begins to diverge from its intended trajectory and eventually tumbles. Figure 3-28 shows an explosively formed penetrator shell encountering just this effect. While deployed fins may make a round aerodynamically stable the de-spin action could cause an instability similar to that shown in Figure 3-28. Therefore it would be desirable to shorten this de-spin behavior as much as possible using over-sized fins or other active methods to reduce the spin rate.
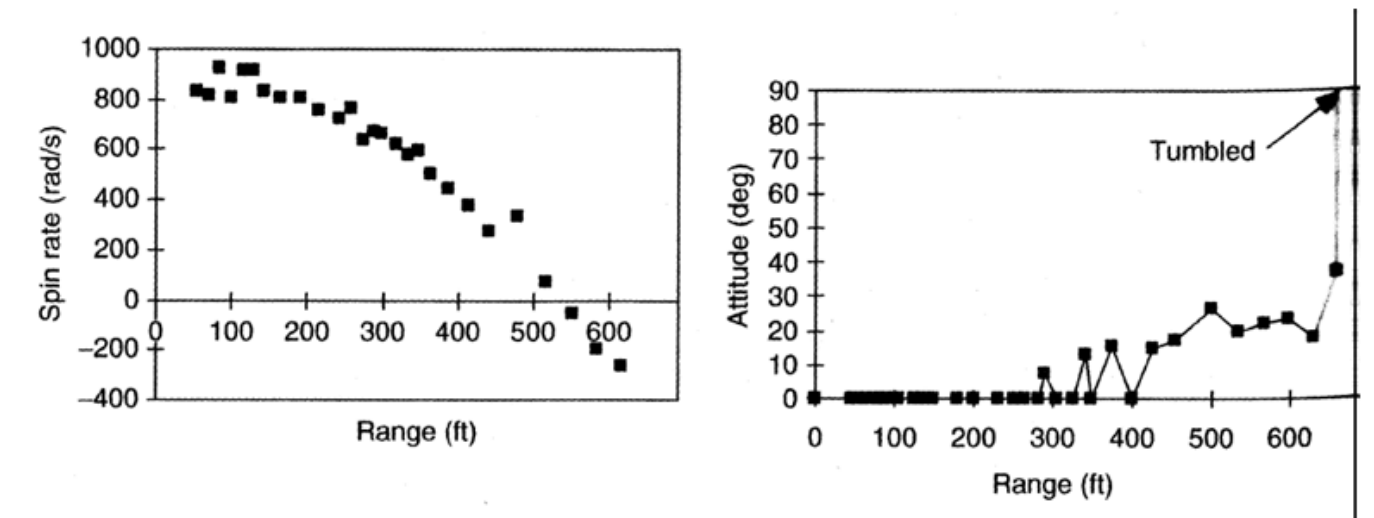

Figure 3-28: Instability and Dispersion Caused by Slowly Decreasing Spin Rate(Carlucci \& Jacobson, 2008)

Unfortunately no passive de-spin system could be developed which would also guarantee a specified orientation within an acceptable time span. The correction to gliding condition must be achieved within a very few seconds to insure the round stays on-target and does not lose so much altitude that it could not reach its intended goal. All systems required an orientation sensor and control system. The Paparazzi autopilot system, created by Krashanitsa, et al., (2006) would be ideally suited to determine the spin rate and angle, as well as selecting the appropriate time to activate the de-spin mechanism. Paparazzi's suite of four IR sensors mounted around the radius of the round could directly collect spin rate information and provide bank angle data. Figure 3-29 shows the autopilot with the four infrared sensors as they would be arranged around the circumference of the fuselage. 


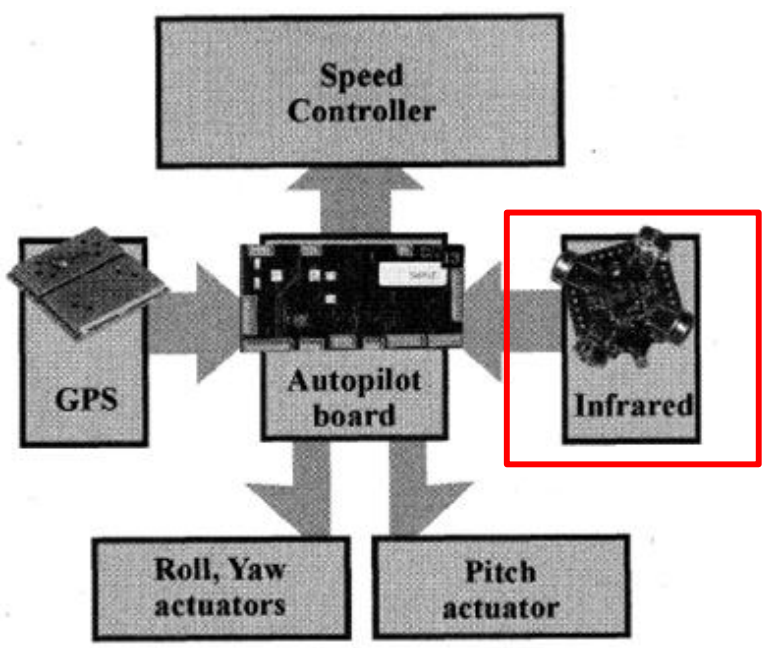

Figure 3-29: Paparazzi Autopilot Infrared Aerodynamic Angle Sensor System for Spin Orientation (Krashanitsa, Platanits, \& Silin, 2006)

Simplest of the methods would to be to deploy three or four large, symmetric, delta wings around the body. These wings would be sized to provide lift for cruise flight and use active control surfaces on some or all as a mix of elevons and rudders as illustrated in Figure 3-30. The drag penalty incurred by the redundant wings would not act over much time and would therefore not impact range to a large degree. In addition, the lack of a preferred orientation means less time would be wasted while the aircraft seeks its upright position and pitches for lift. Finally, if the deployed configuration is lower drag than the stowed configuration the casing could be ejected and the wings deployed shortly after launch to gain an even greater range extension.

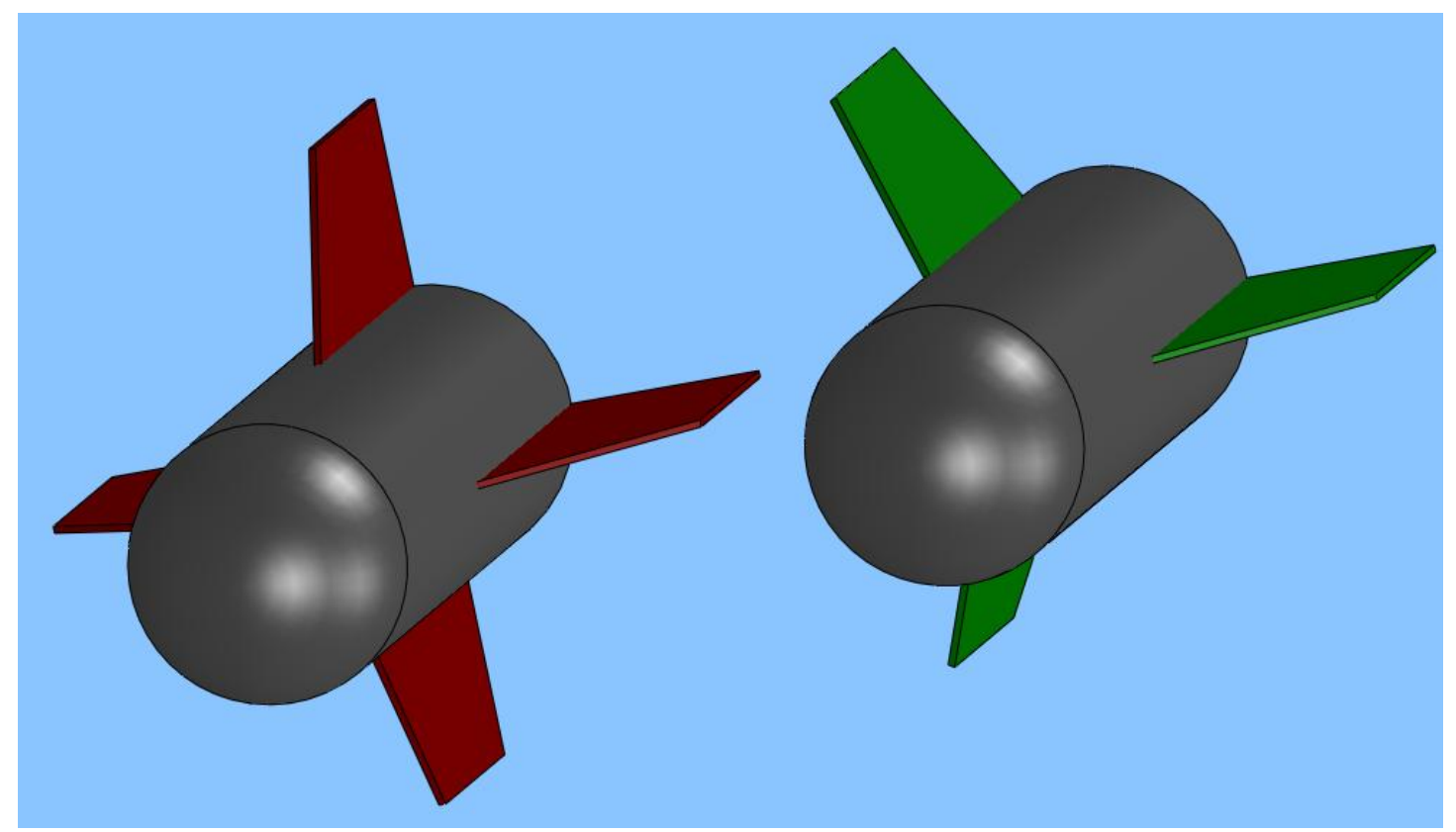

Figure 3-30: Cruciform Planform and Tri Planforms for Active Control Surface De-spin 
Utilizing cambered airfoils, which significantly enhance performance, was a much more difficult problem. A cambered wing, with its single functional orientation, must be within a tight range of attitudes when deployed. Therefore the de-spin mechanism control and timing must be much more precise. A two stage process is recommended. Several options are shown in Figure 3-31. First, as discussed earlier, the main wing could have variable deployment: an initial opening identical to the vertical surfaces, followed by the full opening when the MAV has de-spun and the correct orientation has been reached. Second, a set of main wings would be deployed in addition to the de-spin tail fins. Third, a set of symmetrical despin fins would be deployed from the aft casing. Once the spin rate has dropped to the point that one halfrevolution of the fully deployed main wings would damp out the rotation the casing, and de-spin fins, would be ejected and the main wings deployed. Strong dihedral stability would then complete the selfrighting process. Rotating the main wings up about the longitudinal axis (dihedral) creates a vertical lift component imbalance when the aircraft is at a bank angle. The wing on the side the craft has rotated to has a larger vertical lift component than the one on the other side which creates a restoring roll moment. With careful design this method could also be applied to the wrapped membrane structure.

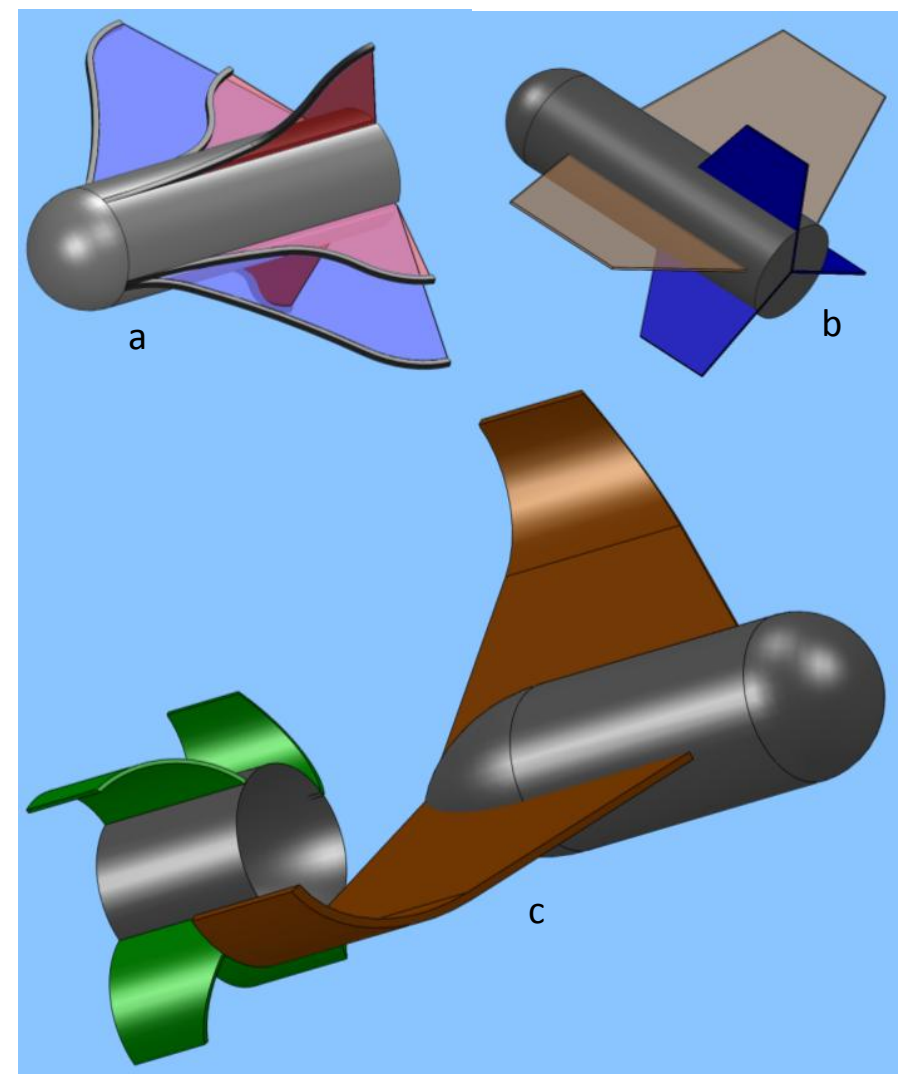

Figure 3-31: Multi-Stage Fin Deployment Schematic; a) Stabilizer Fins Deploy Further as Lifting Surfaces, b) Additional Lifting Surface Deploy, c) Stabilizers Deploy, De-Spin, and Discard Prior to Main Wing Deploy 
Finally, as shown in Figure 3-32, the casing components could be ejected with high tangential velocity in the direction of spin. This would carry significant rotational momentum since the rear casing must be somewhat massive to withstand explosive launch forces. Fortunately this idea would be compatible with all structural concepts.

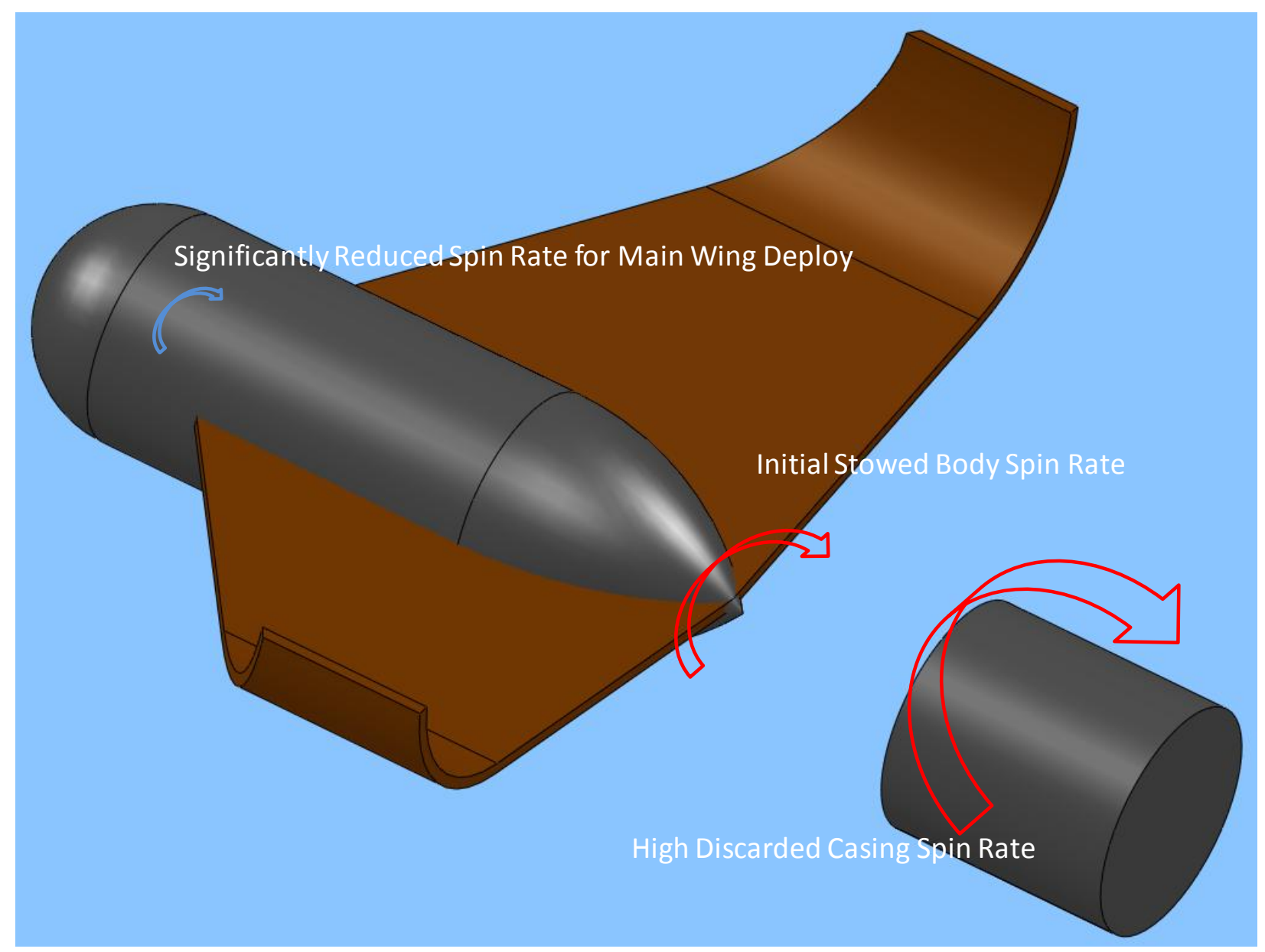

Figure 3-32: Casing Ejection in Spin Direction with High Rotation Rate to Reduce MAV Rotation Rate 


\section{Chapter 4 Initial Surface Sizing Calculations}

The US Air Force Air Vehicles Research Directorate has been developing and improving Missile DATCOM (MDCOM), a semi-empirical code for the analysis of finned projectiles, for several decades. MDCOM was used to quickly test a large assortment of fins and wings applied to a generic fuselage. An initial survey of this type was necessary to begin restricting the design space. The code requires a text input file listing fuselage, wing, tail, and protuberance geometry parameters as well as flight conditions. A sample code used for this project incorporating both main wing and tails has been included in Appendix A with the associated output. The 1997 Fortran 90 version user's manual was a necessity due to the blackbox nature of the executable file ${ }^{20}$

This semi-empirical code has been developed by the US Air Force to provide a first-cut estimation of aerodynamic coefficients for both gyroscopically and fin stabilized projectiles. Since access to this convenient program was available it was used to perform all initial sizing calculations. While not built for low Reynolds number work analytic and empirical relationships are exactly the classical aerodynamic theory used by all MAV design teams on their initial work ${ }^{21}$.

Initial work assumed a constant $29 \mathrm{~mm}$ chord cruciform tail with trailing edges coincident with the aft end of the fuselage. Tail fin span was incremented from zero to $125 \mathrm{~mm}$ by $25 \mathrm{~mm}$ increments to find the optimum. A $50 \mathrm{~mm}$ long Ogive tail cone was imposed in addition to the hemispherical nose on the $40 \mathrm{~mm}$ diameter body as in Figure 4-1. An Ogive tail was imposed in an initial attempt to reduce the massive drag producing recirculation region behind the blunt tail of the stowed geometry. Three different locations for the center of gravity (CG) were examined, beginning $32.5 \mathrm{~mm}$ aft of the nose and moving to $66.5 \mathrm{~mm}$ aft, $50 \%$ body length. Additional information from the research sponsors fixed the CG location at the rearmost of the locations examined. Flight velocity was assumed to be the apex velocity of the given $45^{\circ}$ launch trajectory, $44 \mathrm{~m} / \mathrm{s}$.

${ }^{20}$ (Blake, Missile DATCOM User's Manual - 1997 FORTRAN 90 Revision, 1998)

${ }^{21}$ (Mueller, Torres, \& Srull, Elements of Aerodynamics, Propulsion, and Design, 2006) 


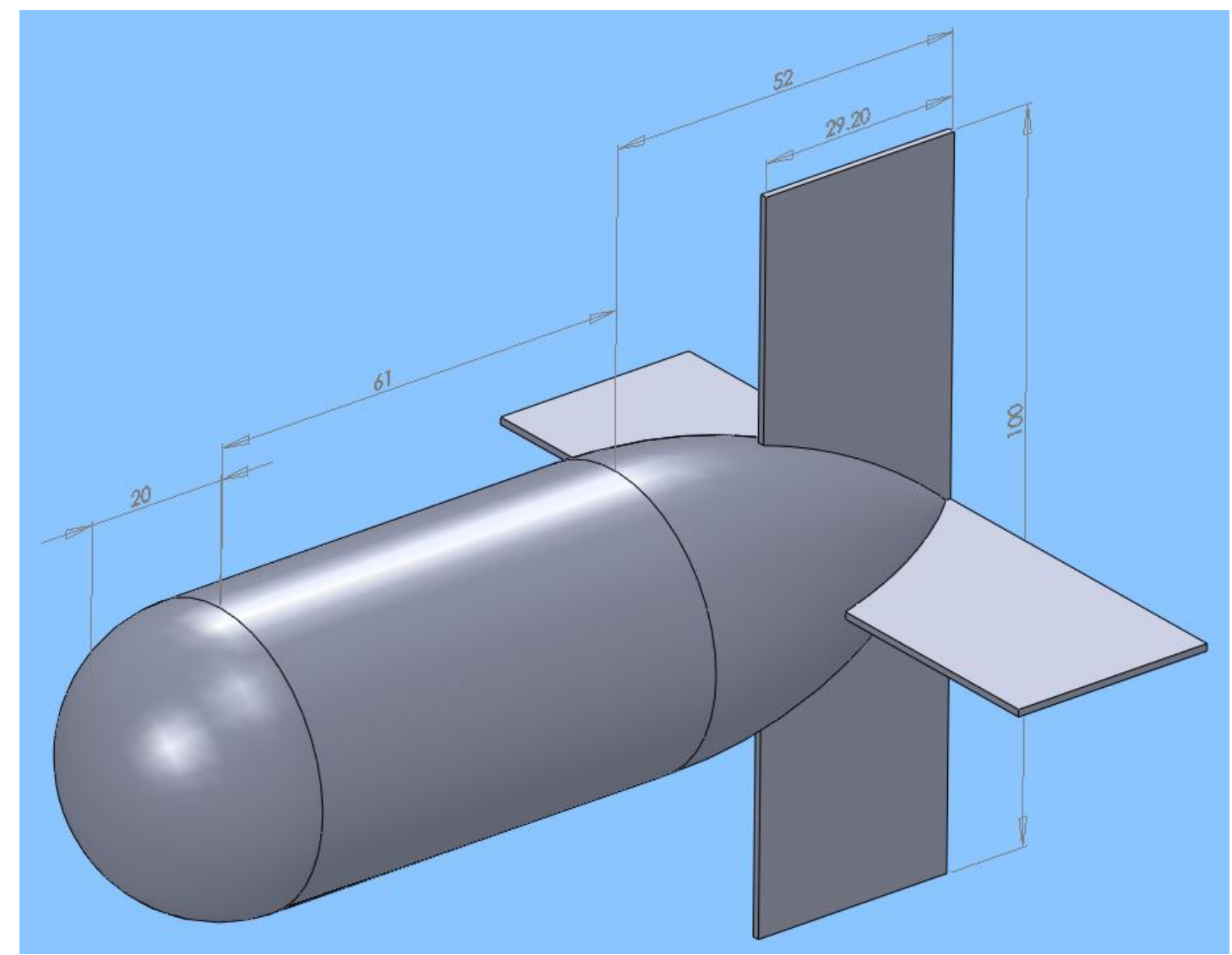

Figure 4-1: Fuselage and Tail Configuration Studied with MDCOM, Dimensions in $\mathbf{m m}$

Figure 4-2 presents the results of this study showing a near linear reduction in pitching moment coefficient with angle of attack when tail span exceeded $50 \mathrm{~mm}$. Linear interpolation between these points for a center of gravity conservatively located far aft, at $50 \%$ of the stowed geometry body length, provided sufficient information to estimate a stable tail surface area. A tail span of $60 \mathrm{~mm}$, not including the fuselage diameter, was calculated to give a pitching moment coefficient of -0.017 per degree as recommended in Aircraft Design: A Conceptual Approach ${ }^{22}$. Since an extremely stable platform was desired values recommended for transport aircraft seemed a good starting point. Smaller surfaces would not pose a design problem as the span could simply be truncated. This was not true for enlarging the surfaces. For all future work the projected tail area, not including the fuselage as customary in projectile design, was fixed at $1,740 \mathrm{~mm}^{3}$ for both horizontal and vertical surfaces. Work then moved to initial main wing sizing.

${ }^{22}$ (Raymer, 2006) 


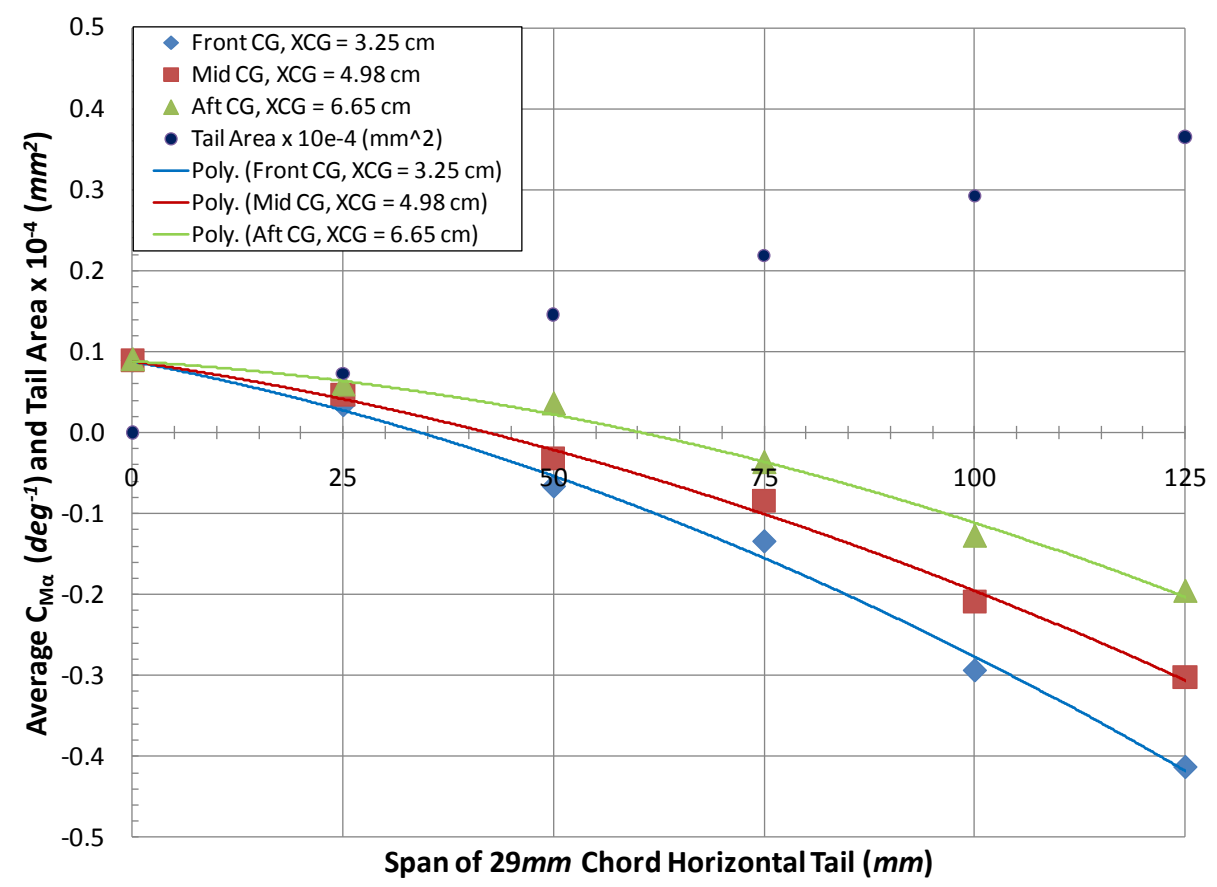

Figure 4-2: Tail Sizing Sensitivity Study with Three CG Locations

Wing sizing was done in a similar manner to tail sizing. A $36.5 \mathrm{~mm}$ chord main wing of varying span was placed with its quarter chord at the center of gravity, $62.5 \mathrm{~mm}$ aft of the nose. The tail was then rotated by $45^{\circ}$ to reduce interference issues, as shown in Figure 4-3. An extreme rearward location was required due to the fixed far aft CG location. A NACA 0008 airfoil was selected and simulations were done with the body at four angles of attack. Figure 4-4 presents the results of the analysis.

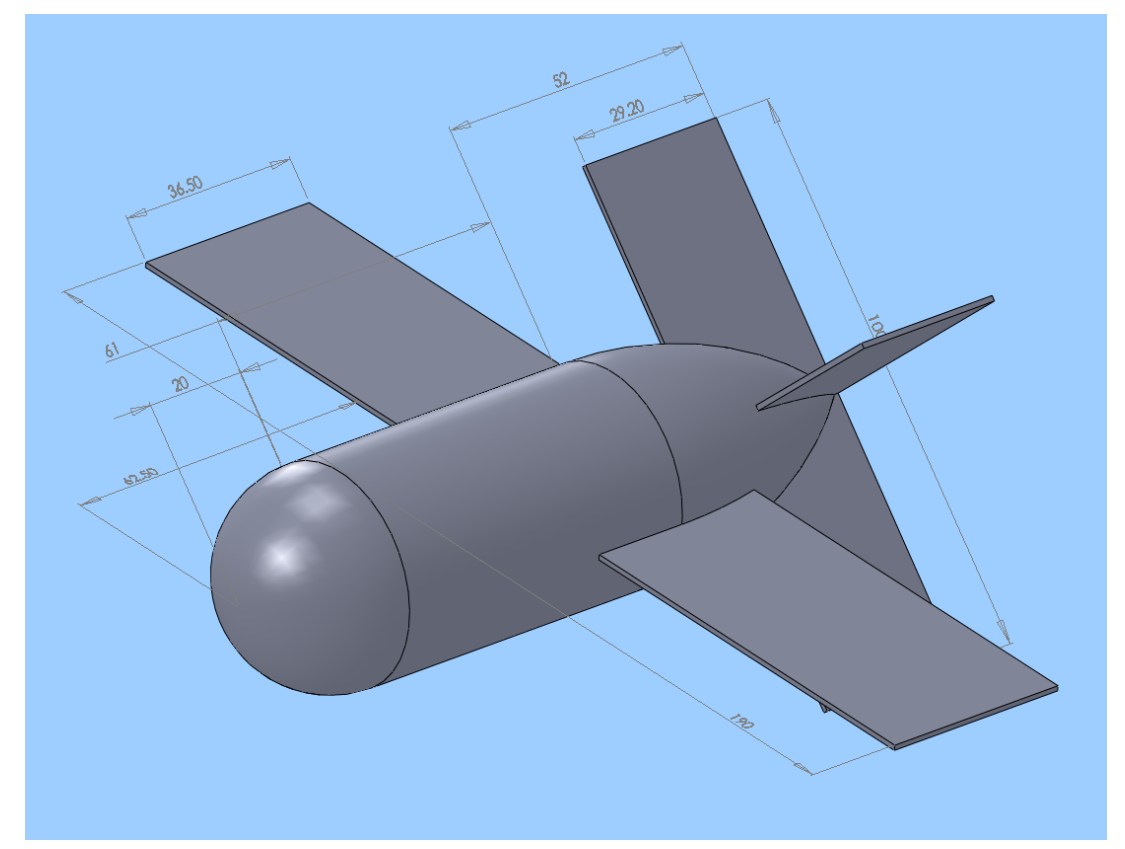

Figure 4-3: Complete Planform Studied with MDCOM, Dimensions in $\mathrm{mm}$ 


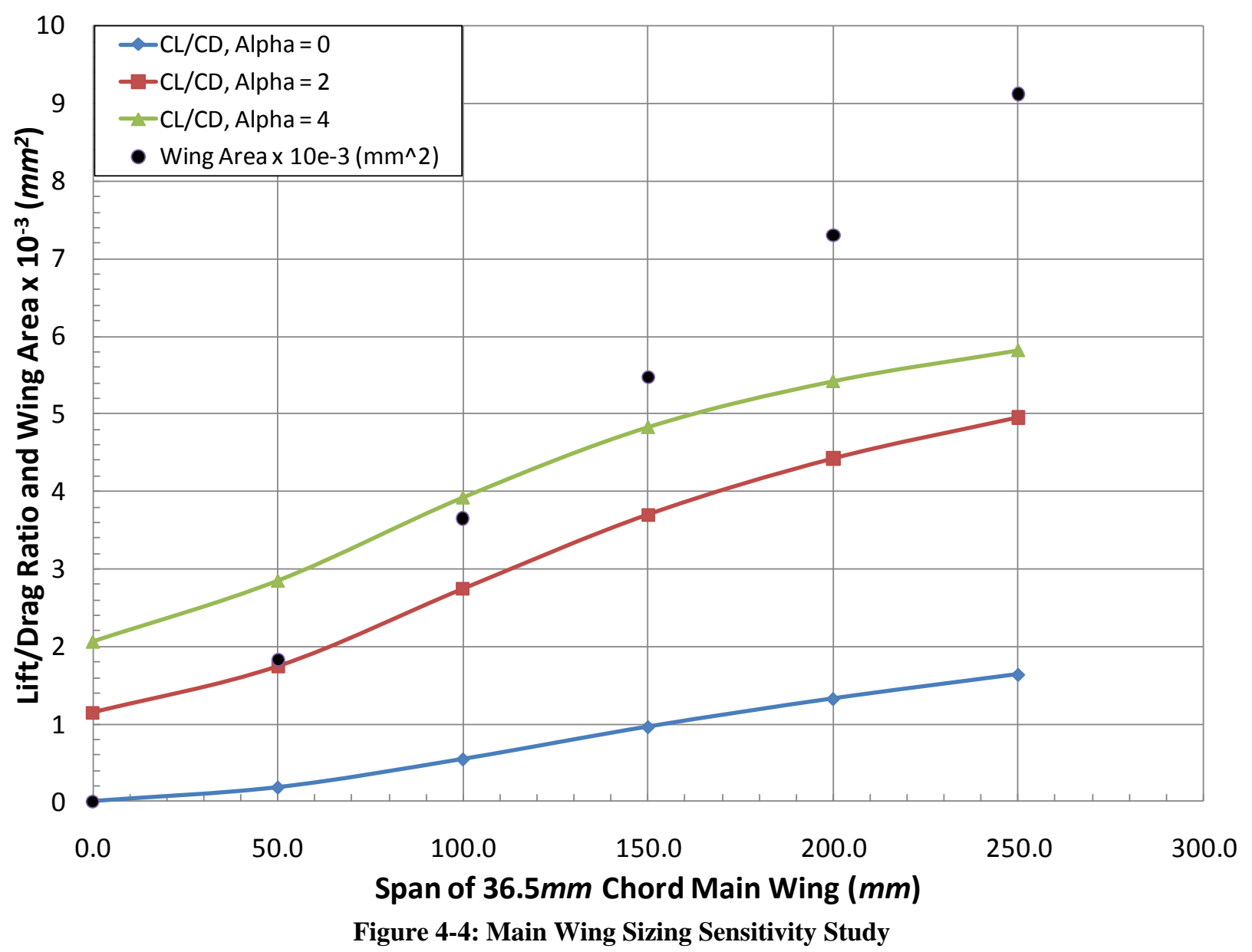

Figure 4-4 shows the near linear increase in lift-to-drag ratio with increasing wing area for a NACA 0008 airfoil mounted to the fuselage at $1^{\circ}$ angle of attack relative to the body. Data for the wingbody-tail combination is presented for three different angles of attack. Based on this information a wing area of 5,500 $\mathrm{mm}^{3}$ was selected, corresponding to a span of $150 \mathrm{~mm}$. This more than satisfied performance requirements with a 5:1 predicted lift-to-drag ratio. Structural stowage concepts were checked to insure that this wing was feasible. 


\section{Chapter 5 Preliminary CFD Analysis}

Initial CFD work began with studying the stowed, or baseline, geometry, presented in Figure 5-1. This was done to insure that the baseline experimental data for the geometry could be reproduced, and to provide a starting point for the selection of optimal solver settings and mesh parameters as work progressed to more complex geometry. Both conventional high aspect ratio and truncated delta wing concepts were then analyzed for the first planform down-select.

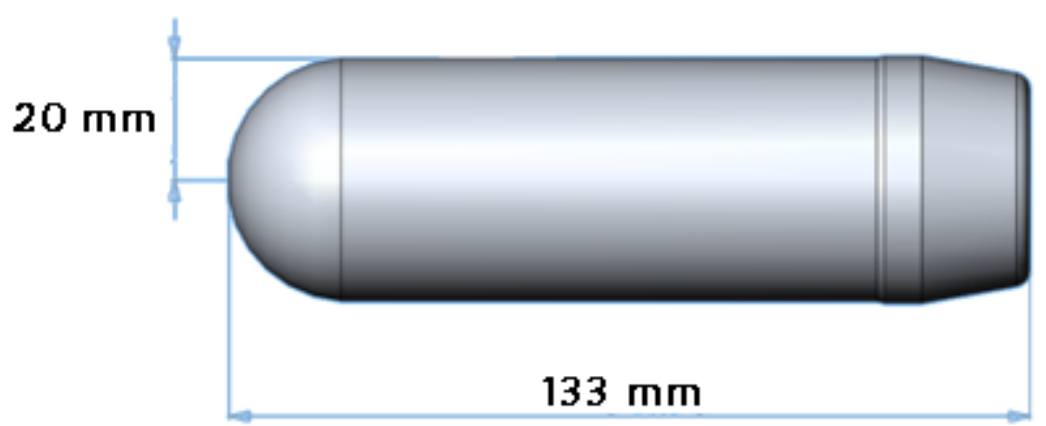

Figure 5-1: Stowed Geometry

\subsection{Stowed Geometry Mesh Generation}

The sponsors were familiar with the aerodynamics of the baseline configuration, and the associated CFD simulation of such geometries. A suite of recommended solver settings was provided as shown in Table 5-1 along with recommended domain sizes based on the cylindrical stowed body diameter. With these settings and the domain shown in Figure 5-2 the drag coefficient was predicted to within from the CFD simulation. Main body axial, dx, cell lengths of $2.0 \mathrm{~mm}$ were used, with a step down to $0.5 \mathrm{~mm}$ spacing at the tail. Five prismatic cell layers were grown up from the wall with a first height of $0.5 \mathrm{~mm}$ and a growth rate of 1.2. Outside the prismatic region a tetrahedral domain was created, again with a cell growth rate of 1.2. Specific details on the mesh generation parameters are provided in Appendix B. 
Table 5-1: Sponsor Recommended Solver Settings and Domain Sizes With WVU Selected Solver Settings

\begin{tabular}{|c|c|c|}
\hline \multicolumn{2}{|l|}{ Domain Geometry: } & \\
\hline Characteristic Length: & Body Diameter $\left(\mathrm{d}_{0}=40 \mathrm{~mm}\right)$ & \\
\hline Domain Shape: & Truncated Cone & \\
\hline Reference Location: & Body Nose & \\
\hline Upstream Length: & $50 \mathrm{~d}_{0}=2,000 \mathrm{~mm}$ & \\
\hline Upstream Diameter: & $25 \mathrm{~d}_{0}=1,000 \mathrm{~mm}$ & \\
\hline Downstream Length: & $100 \mathrm{~d}_{0}=4,000 \mathrm{~mm}$ & \\
\hline Downstream Diameter: & $50 \mathrm{~d}_{0}=2,000 \mathrm{~mm}$ & \\
\hline \multicolumn{3}{|l|}{ Boundary Conditions } \\
\hline & High Mach & Low Mach (WVU Developed) \\
\hline Inlet & Pressure - Far Field & Velocity Inlet \\
\hline Outlet & Pressure - Far Field & Pressure Outlet \\
\hline Body Surface & Wall & Wall \\
\hline \multicolumn{3}{|l|}{ Solver Settings } \\
\hline & High Mach & Low Mach (WVU Developed) \\
\hline Time & Steady & Steady \\
\hline Type & Pressure-Based & Pressure Based \\
\hline Velocity Formulation & Absolute & Absolute \\
\hline Turbulence Model & Standard k- $\omega$ & Standard k- $\omega$ \\
\hline Energy Equation & On & Off \\
\hline Discretization & Second Order & Second Order \\
\hline Gradient & Green-Gauss Node Based & Green-Gauss Node Based \\
\hline Precision & Double Precision & Double Precision \\
\hline Reference Location & $49 \mathrm{~d}_{0}$ upstream $=-1,960 \mathrm{~mm}$ & $49 \mathrm{~d}_{\circ}$ upstream $=-1,960 \mathrm{~mm}$ \\
\hline Initialization & Velocity $=0 \mathrm{~m} / \mathrm{s}$, Pressure $=1 \mathrm{~atm}$ & Velocity $=0 \mathrm{~m} / \mathrm{s}$, Pressure $=1 \mathrm{~atm}$ \\
\hline
\end{tabular}




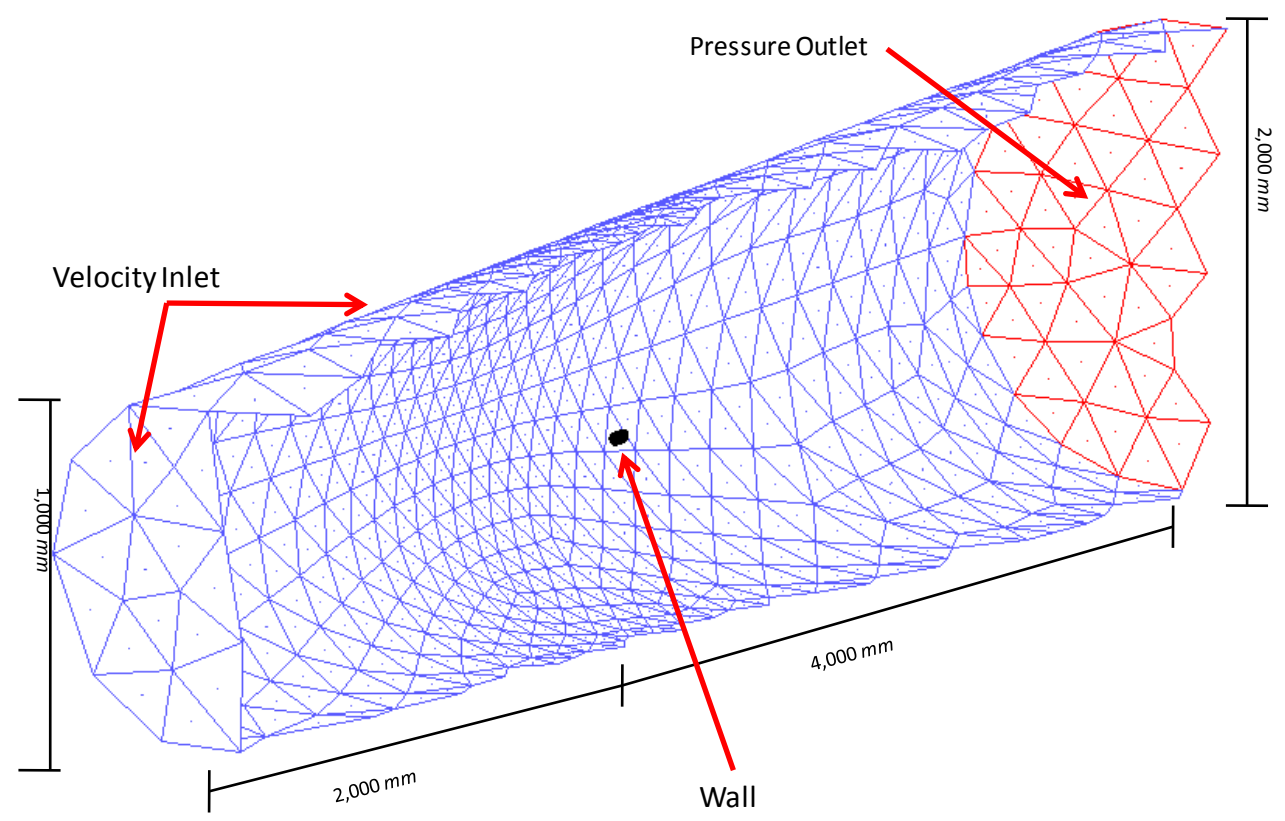

Figure 5-2: Solution Domain, Sliced on Longitudinal Centerline

Figure 5-3 shows the convergence obtained for the standard k- $\omega$ turbulence model which consistently under-predicted the drag value within acceptable limits, -7\%. As seen in Figure 5-3 grid independence was reached with $2.7 \times 10^{6}$ cells. A second run with the same mesh was conducted using the SST k- $\omega$ model. This shifted the error to $+8 \%$, still within acceptable limits for preliminary design work.

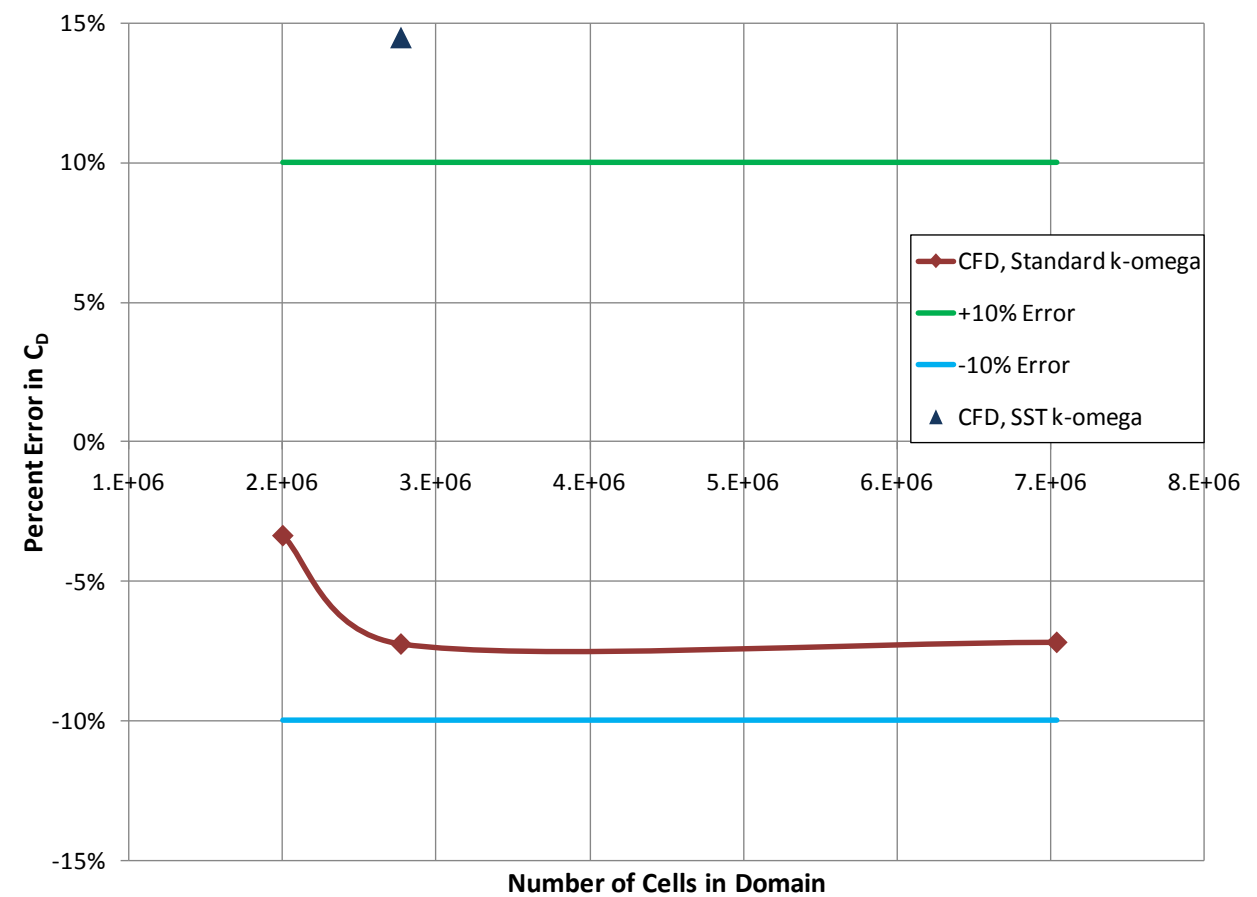

Figure 5-3: Convergence Plot for Stowed Geometry, Mesh Converged at 2.7x10 ${ }^{6}$ Cells 


\subsection{Deployed Configuration Simulation}

Once functional mesh and solver settings had been developed for the stowed configuration work moved to simulating the deployed configurations. Settings developed in the previous section were used as starting points for simulating the MAV geometry. Ogive tail cone fuselages, as detailed in Chapter 4, were used for the simulation of two configurations. Both a conventional planform based on the WVU Telescopic transformer, and a delta wing configuration were studied. Surface meshes were $1.5 \mathrm{~mm}$ spacing in large, low curvature regions, and condensed to $0.5 \mathrm{~mm}$ in complex regions such as the wing leading and trailing edges and wing-body junctions. This was done to match the on the stowed geometry discussed in Section 5.1, which provided an acceptable match to experimental data. All other mesh and solver parameters were defined similarly. Figure 5-4 shows the surface meshes of both geometries.
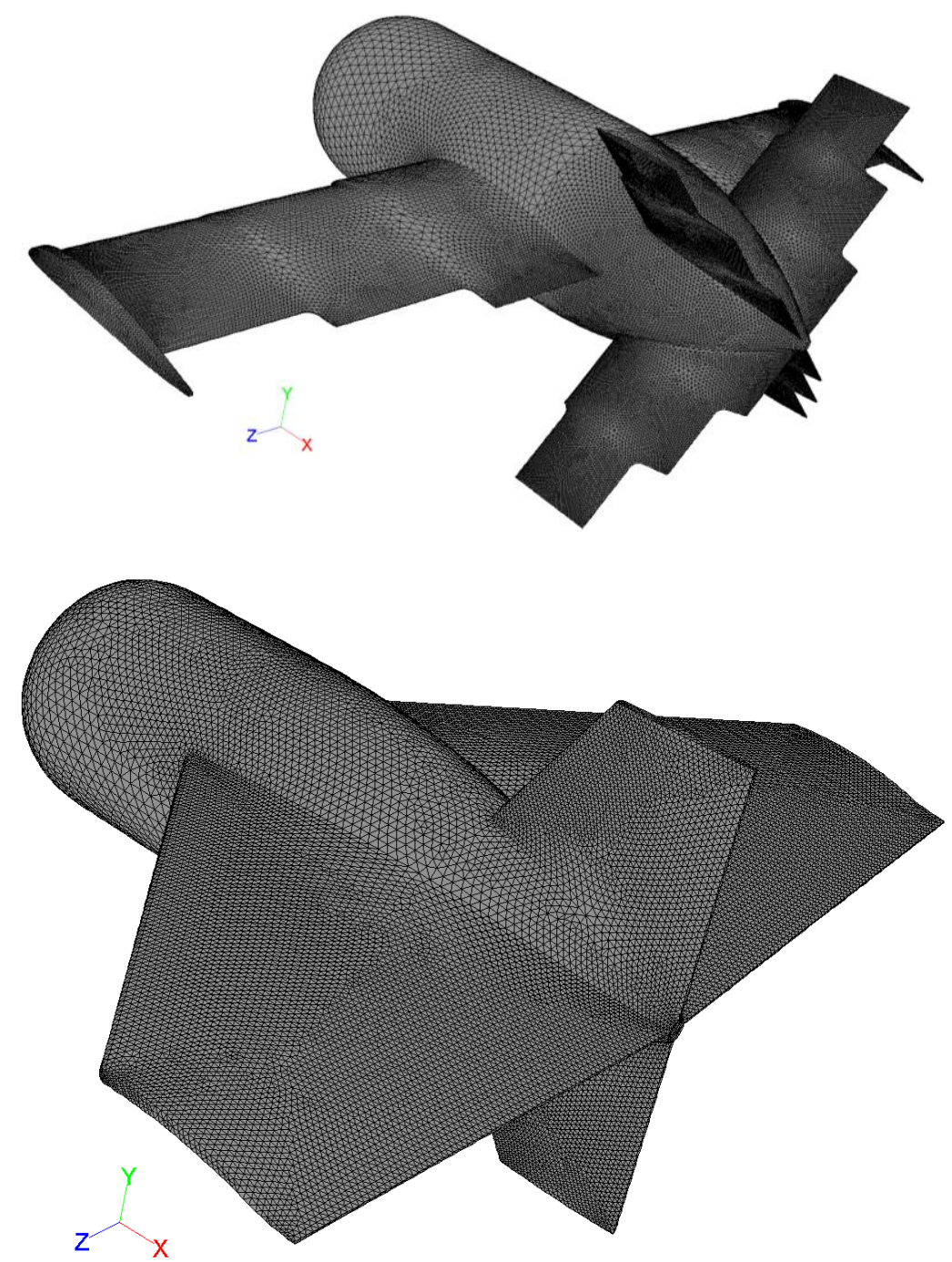

Figure 5-4: Initial Deployed Geometry Surface Meshes, Identical Vertical Tail Area and Main Wing Area, Identical Fuselages 
While the conventional planform produced an acceptable lift-to-drag ratio of 4:1, the delta planform exceeded it by $100 \%$ with a L/D of 8:1. Both had the same wing area, angle of attack, and vertical tail area, mounted to identical fuselages. This huge difference was caused by two phenomena. First the interference between the main wing and tail on the conventional layout as clearly seen in Figure 5-5. The complex vortical structures starting aft of the main wings and becoming denser at the tail significantly increase drag on the MAV. While some of these structures still exist on the delta wing configuration they are smaller and fewer, therefore generating less drag. Second, as discussed in Section 2.3.2, the increased chordwise Reynolds number of the delta planform increased the performance of its airfoil far in excess of the induced drag penalty incurred by a low aspect ratio. Therefore delta planforms were selected for all optimization work. This down-select was also fortuitous from a structural standpoint. The delta wing would be far easier to create than the conventional layout primarily due to the elimination of two wing surfaces by removing a horizontal tail. In addition, at these small scales the larger structures will likely be easier to build.

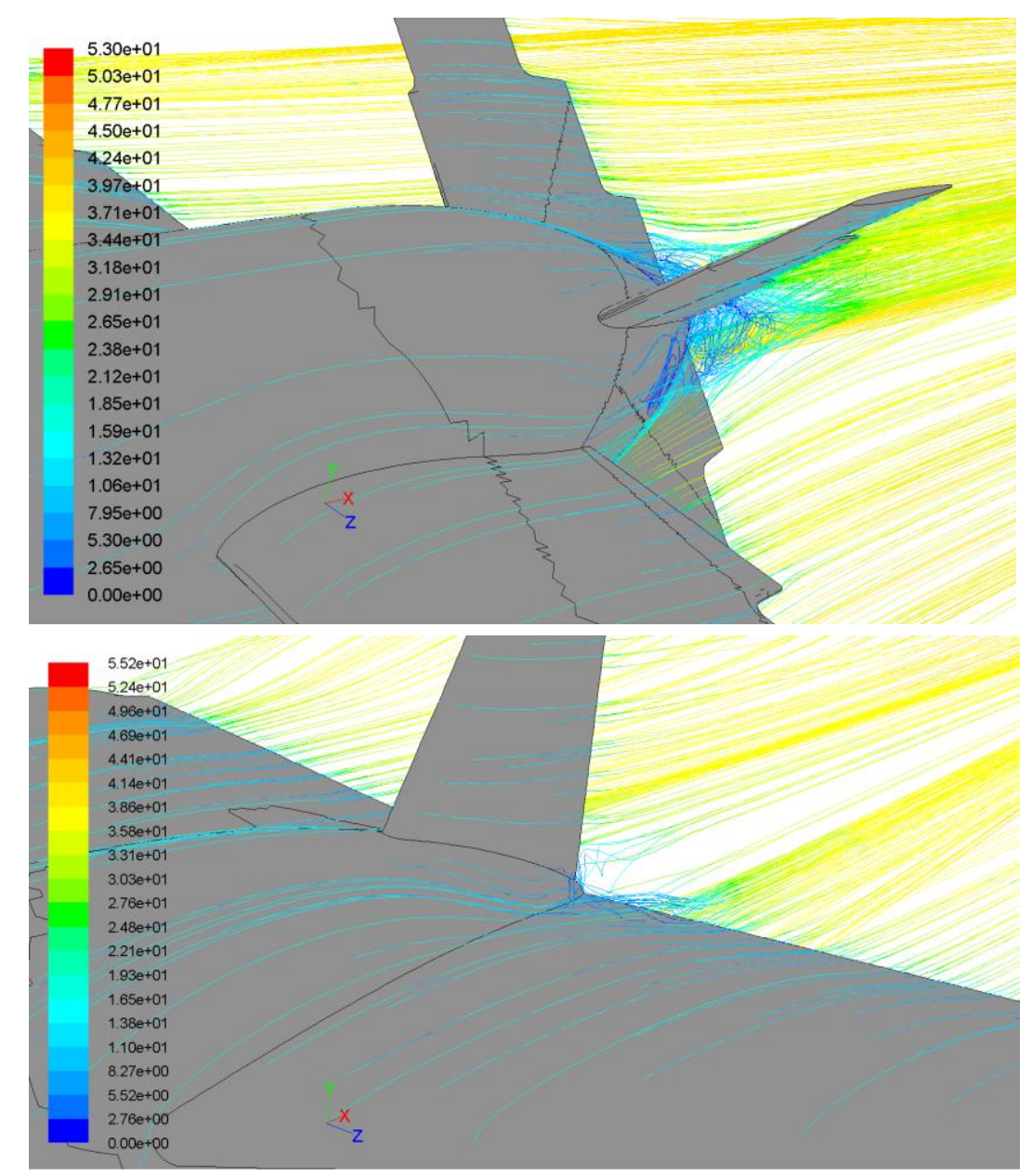

Figure 5-5: Comparison of Flow at Tails of Conventional and Delta Planforms, Pathlines Colored by Velocity, $(\mathrm{m} / \mathrm{s})$, Jagged Black Lines Are Artifacts From Geometry Contour Display 


\section{Chapter 6 Classical Aerodynamic Optimization Analysis}

It was possible that more optimal MAV designs or other missions could be discovered by using a launch angle other than the initially specified $45^{\circ}$. Therefore, a basic optimization analysis was performed using classical ballistics and aerodynamics. A simple MATLAB code was written to calculate launch velocity from the known data presented in Table 6-1. Once the launch velocity was known an array of apex altitudes and velocities were determined using a second in-house program. This study was conducted to provide initial gliding altitudes an velocities (apex altitude and velocity) as a starting point to optimize for maximum range. An increased lift-to-drag ratio at a lower velocity could provide a greater range by starting from a significantly higher altitude. All codes discussed in Chapter 6 have been included in Appendix C.

Table 6-1: Given Stowed Trajectory Data and Calculated Launch Velocity

\begin{tabular}{|c|c|c|c|}
\hline \multicolumn{3}{|c|}{ Given Trajectory Data } & \\
\hline \begin{tabular}{|l|} 
Drag Coefficient \\
\end{tabular} & 0.133 & & \\
\hline Range & 450 & $m$ & \\
\hline Launch Angle & 45 & $\operatorname{deg}$ & \\
\hline Apex Velocity & 40 & $\mathrm{~m} / \mathrm{s}$ & \\
\hline Flight Mass & 180 & $g$ & \\
\hline \multicolumn{3}{|l|}{ Calculated Data } & \\
\hline Laucnh Velocity & 71.32 & $\mathrm{~m} / \mathrm{s}$ & \\
\hline \multicolumn{4}{|c|}{ Calculated Apex Information } \\
\hline $\begin{array}{c}\text { Launch Angle } \\
\text { (deg) }\end{array}$ & $\begin{array}{c}\text { Apex Altitude } \\
(\mathrm{m})\end{array}$ & \begin{tabular}{|c|}
$\begin{array}{c}\text { Apex Velocity } \\
(\mathrm{m} / \mathrm{s})\end{array}$ \\
\end{tabular} & $\begin{array}{c}\text { Apex Range } \\
(m)\end{array}$ \\
\hline 45 & 124.2 & 45 & 233.9 \\
\hline 55 & 162.5 & 37 & 222.9 \\
\hline 65 & 193.8 & 28 & 181.2 \\
\hline 75 & 215.3 & 18 & 118.4 \\
\hline 85 & 116 & 6 & 41.2 \\
\hline
\end{tabular}

Results of the trajectory program for launch angles, $\Lambda_{\text {launch }}$, of 40,60, 70, and 80 degrees are presented in Figure 6-1. From this point on apex velocity, $V_{A}$, and optimum MAV glide velocity are considered to be identical. In addition, note that increasing launch angle reduces cruise velocity, increases starting glide altitude, and, by basic aerodynamics, increases optimum cruising wing area. 

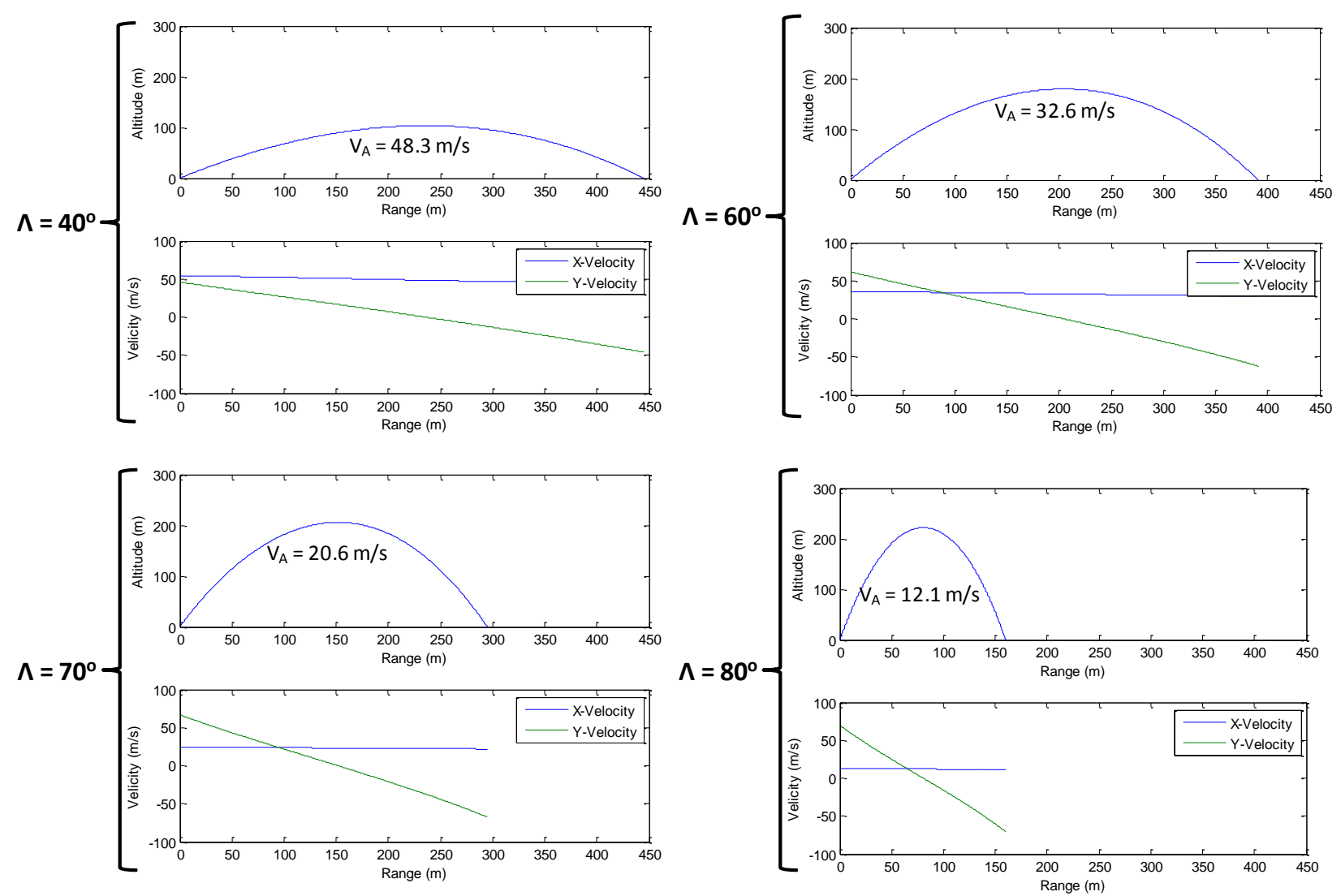

Figure 6-1: Effect of Varying Launch Angle for $A R=2$ Wing on Cruise Velocity and Initial Gliding Altitude

Once the precise effects of launch angle on cruise velocity and apex altitude were known a third code was written. This algorithm calculated an optimum main wing area of specified planform, located the wing on the fuselage such that no horizontal tail was necessary, and proceeded to calculate expected range and flight time. In the cases detailed in Table 6-2 the main wing was fixed at an aspect ratio of 2 with a taper ratio of 0.5 . Similar sets of data were generated for aspect ratios from 1 to 4 . All other values were calculated as illustrated by the program flowchart provided in Figure 6-2. 
Table 6-2: Results of Optimization Code for an Array of Launch Angles

\begin{tabular}{|c|c|c|c|c|c|c|c|c|c|c|}
\hline Launch Angle & (deg) & 40 & 45 & 50 & 55 & 60 & 65 & \multicolumn{2}{|c|}{ AR } & 2 \\
\hline Apex Altitude & $(m)$ & 103.8 & 124.2 & 143.9 & 162.5 & 179.2 & 193.8 & $\Lambda_{\mathrm{LE}}$ & $(\operatorname{deg})$ & 30 \\
\hline Apex Velocity & $(\mathrm{m} / \mathrm{s})$ & 48 & 45 & 41 & 37 & 33 & 28 & \multicolumn{2}{|r|}{$\lambda$} & 0.5 \\
\hline Apex Range & $(m)$ & 236 & 238.3 & 233.9 & 222.6 & 204.9 & 181.2 & \multicolumn{2}{|c|}{$t / c$} & 0.1 \\
\hline Total Range & $(m)$ & 659 & 798 & 1,004 & 1,256 & 1,498 & 1,914 & \multicolumn{2}{|c|}{$c_{t / c}$} & 0.4 \\
\hline$\%+$ Range & & $146 \%$ & $177 \%$ & $223 \%$ & $279 \%$ & $333 \%$ & $425 \%$ & & & \\
\hline$w / s$ & $\left(\mathrm{~N} / \mathrm{m}^{2}\right)$ & 700 & 600 & 450 & 325 & 250 & 150 & \multicolumn{2}{|c|}{$\mathrm{X}_{\mathrm{CG}}(\mathrm{mm})$} & 80 \\
\hline Wing Area & $\left(\mathrm{cm}^{2}\right)$ & 25.23 & 29.43 & 39.24 & 54.33 & 70.63 & 117.72 & & & \\
\hline L/D & & 4.07 & 4.51 & 5.36 & 6.35 & 7.2 & 8.94 & & & \\
\hline $\operatorname{Re}_{\text {MAC }}$ & & 121,020 & 122,550 & 128,930 & 136,910 & 143,450 & 152,510 & & & \\
\hline $\mathrm{X}_{\mathrm{CR} \perp \mathrm{F}}$ & $(m m)$ & 68.4 & 67.5 & 65.6 & 63 & 60.6 & 55 & & & \\
\hline$C_{R}$ & $(m m)$ & 47.4 & 51.1 & 59.1 & 69.5 & 79.2 & 102.3 & & & \\
\hline$c_{T}$ & $(m m)$ & 23.7 & 25.55 & 29.55 & 34.7 & 39.6 & 51.15 & & & \\
\hline b & $(\mathrm{mm})$ & 71 & 76.7 & 88.6 & 104.2 & 118.9 & 153.4 & & & \\
\hline$\alpha_{\text {trim }}$ & (deg) & 7.4 & 7.14 & 6.17 & 5.14 & 4.41 & 3.56 & & & \\
\hline L/D Wing & & 7.04 & 7.64 & 8.99 & 10.43 & 11.14 & 13.05 & & & \\
\hline
\end{tabular}

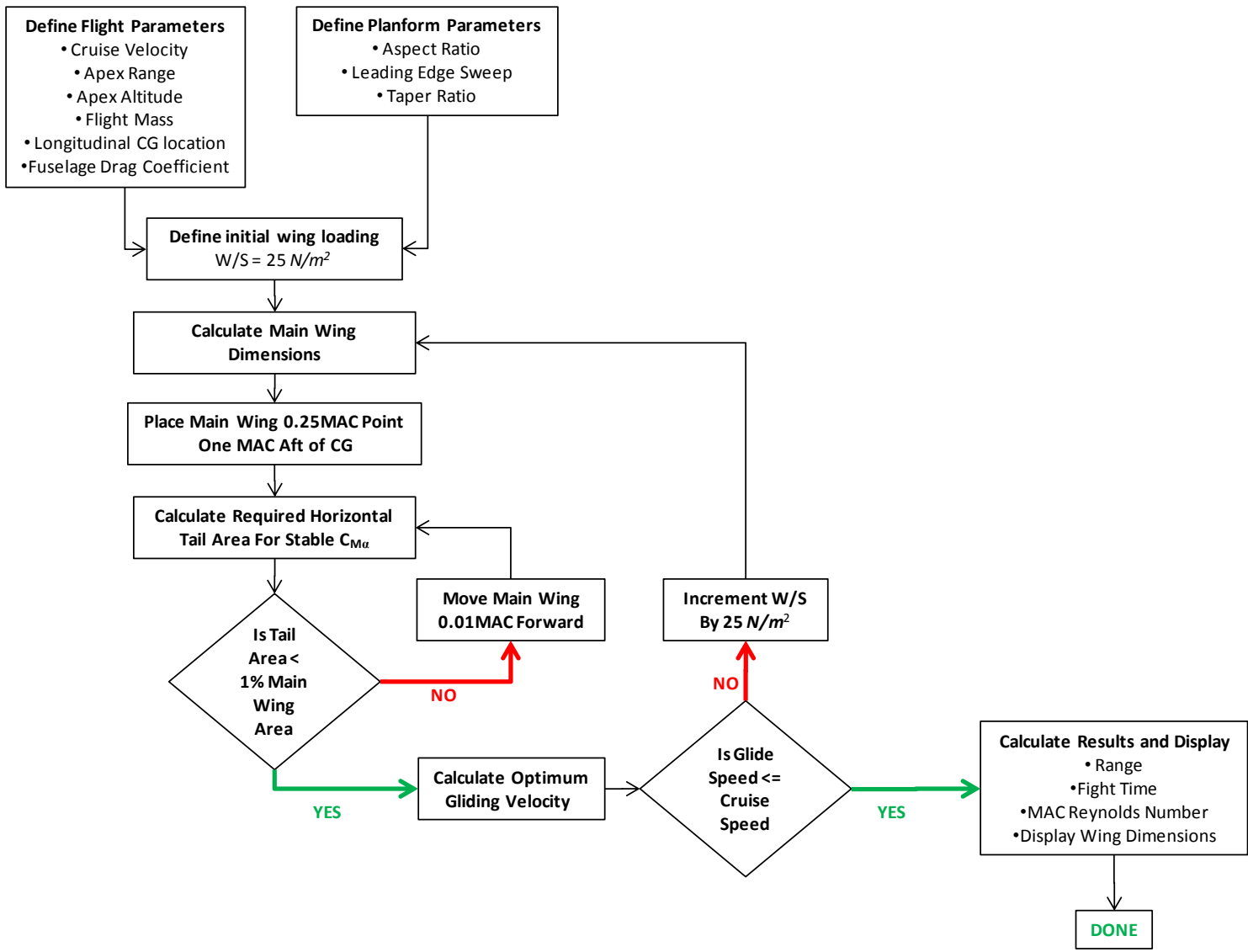

Figure 6-2: Optimization Code Flowchart 
Figure 6-3 presents the most important results from this process, clearly illustrating the significant range extensions possible with increased lift-to-drag ratio from greater launch angles. The increased efficiency possible with larger wings at lower velocities coupled with the greater initial glide start was far more important to maximum range than obtaining the maximum down-field distance at apex.

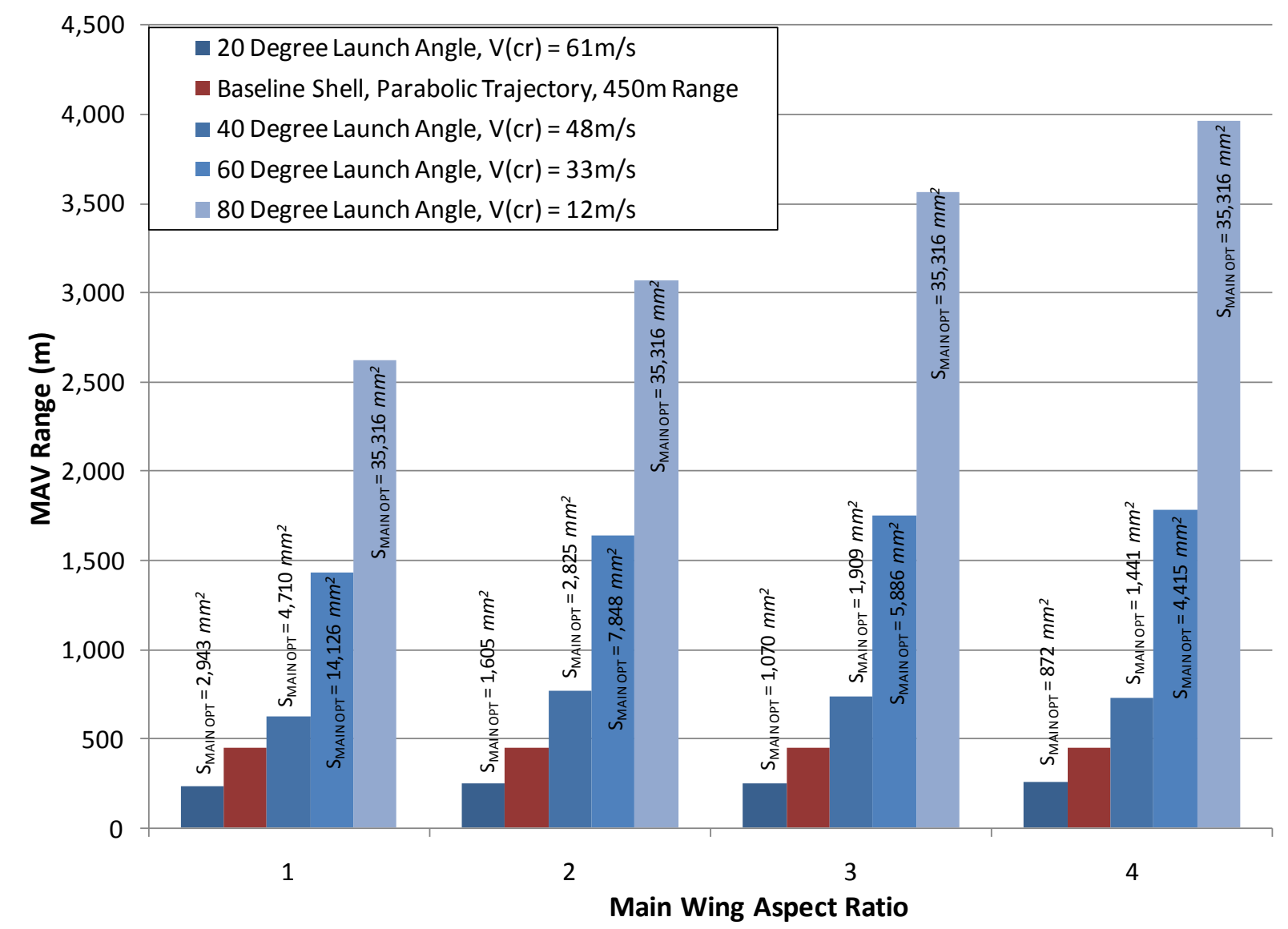

Figure 6-3: Comparison of High Speed, Low Angle Launch and Low Speed, High Angle Launch Missions

Based on the results from Figure 6-3 the idea of two divergent mission plans was developed. The simplest route was to achieve the minor range extension originally specified from a $45^{\circ}$ launch angle with high cruise speed and very small wings. Alternately, and more difficult, a high $60^{\circ}$ to $80^{\circ}$ launch angle would produce ranges on the order of 2,000 $\mathrm{m}$ and extremely long flight times when coupled with large wings. Figure 6-4 compares the two mission profiles and Figure 6-5 shows the wing areas required to accomplish them, along with the stowed geometry as a size reference. 

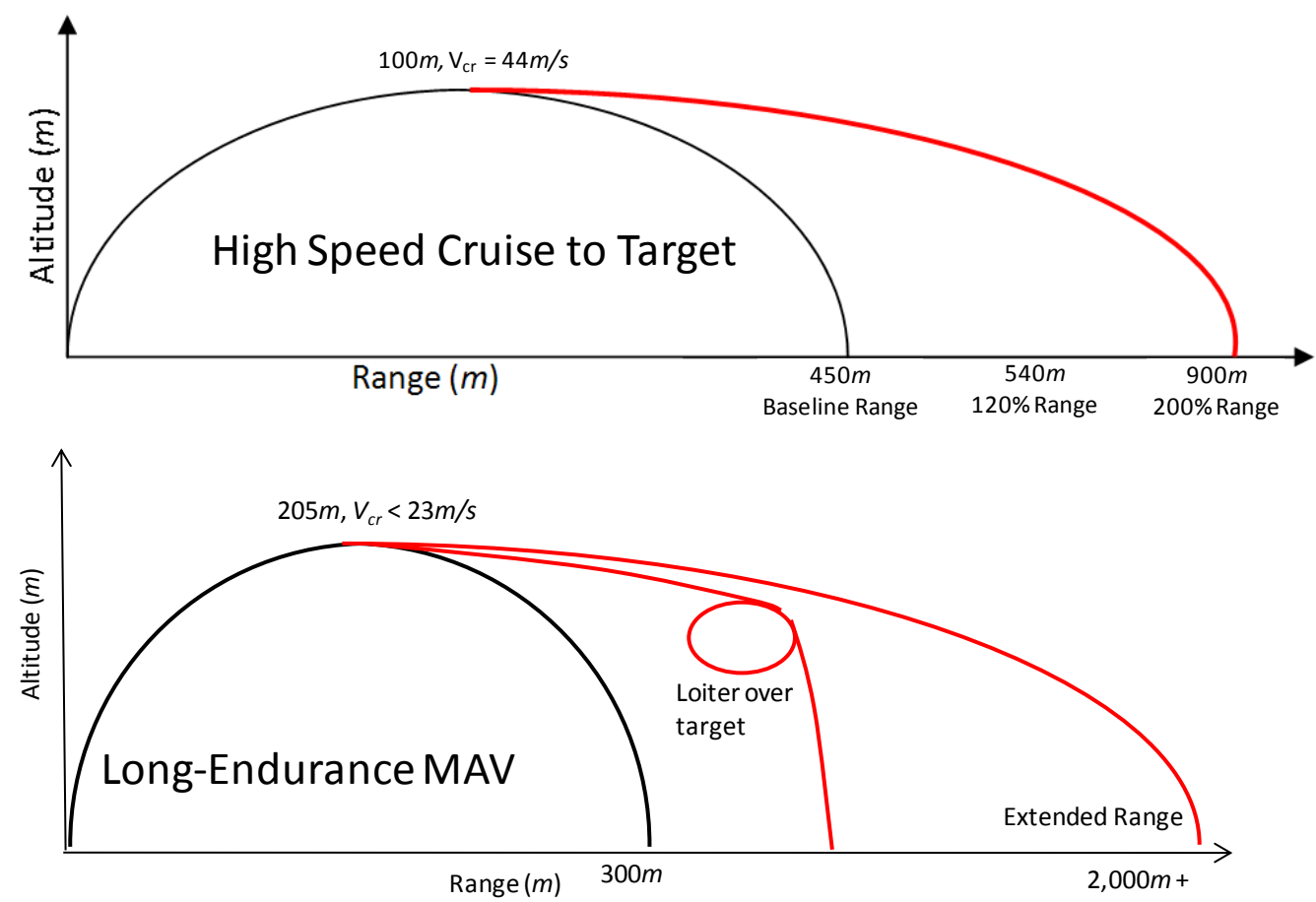

Figure 6-4: Comparison of Alternate Mission Plan Required Wing Areas, Dimensions in $\mathbf{m m}$

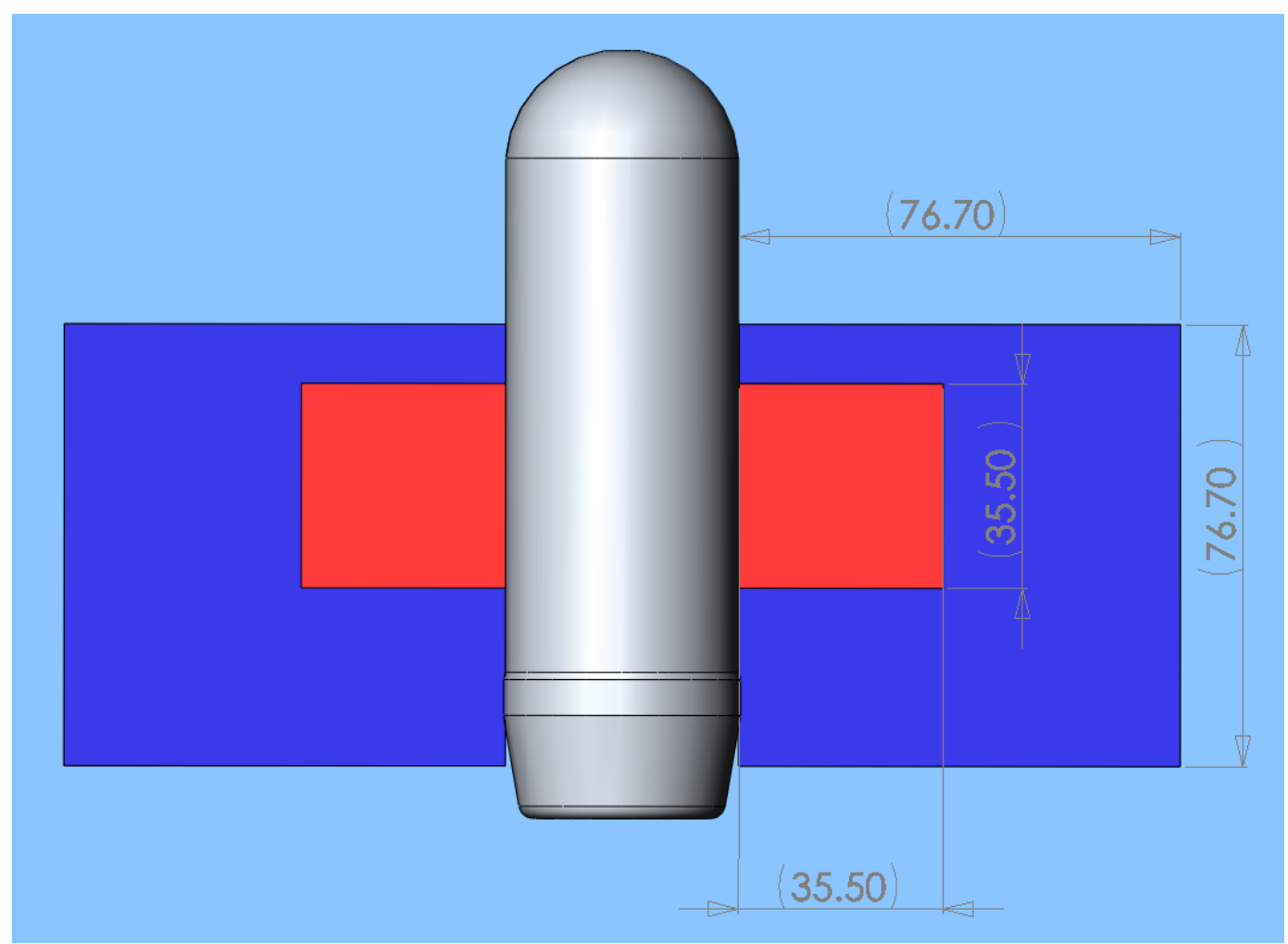

Figure 6-5: Comparison of Required Wing Area for High-Speed Cruise ( Wing Loading $(W / S)=700 \mathrm{~N} / \mathrm{m}^{2}, V_{c r}$ $=48 \mathrm{~m} / \mathrm{s}, S=2,523 \mathrm{~mm}^{2}$ ) and Long Endurance Missions (Wing Loading $(W / S)=150 \mathrm{~N} / \mathrm{m}^{2}, V_{c r}=20 \mathrm{~m} / \mathrm{s}, S=$ $11,772 \mathrm{~mm}^{2}$ ) Relative to Stowed Geometry 
The low flight speed option would be best suited to a surveillance role while the high speed variant would provide rapid, maneuverable, extended delivery. A compromise design would be a poor choice since it would require a more complex wing system than the high-speed variant and would fly much too fast for surveillance with insufficient duration. MAVs for surveillance tend to operate between $10 \mathrm{~m} / \mathrm{s}$ and $20 \mathrm{~m} / \mathrm{s}$ to provide useful time-on-target without having to frequently re-orient the viewpoint. ${ }^{23}$

With the decision to pursue two alternate missions the comparison to current MAV and UAV designs was re-considered. Figure 6-6 presents a modified version of Figure 2-3 with the two missions indicated. Neither is within the normal regime, and the high-speed version is not similar to any other current designs.

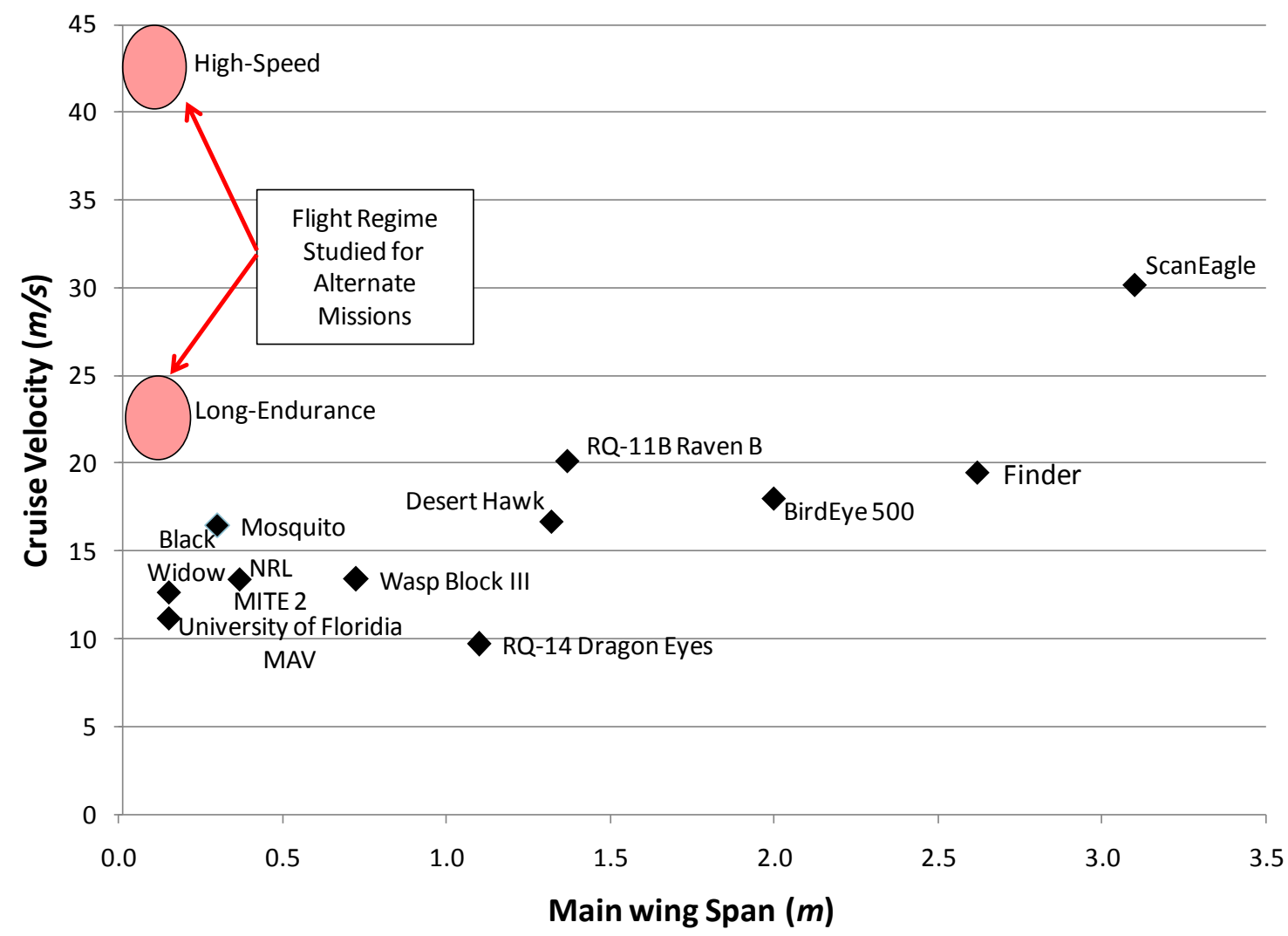

Figure 6-6: Comparison of WVU Stowable UAV Flight Regimes for High-Speed and Long-Endurance Missions to Current UAV and MAV aircraft

${ }^{23}$ (Davis, Kosicki, Boroson, \& Kostishack, 1996) 
Fuselage drag effects on range were also considered. Since the fuselage drag coefficient was a single specified value in the code it was trivial to vary between 0.2 , based on fuselage frontal area, a worst-case scenario for a fuselage generating more drag than the stowed geometry, and 0.05 for an impossibly low drag configuration. Resulting ranges were predicted for both large and small wing designs as shown in Figure 6-7. As expected the percent increase in range from a lower fuselage drag coefficient was greater with the larger wing. This was due to the increased flight time over which the drag had an effect. In both cases the reduction of fuselage drag coefficient would be limited by required fuselage volume. The optimum range-volume selection cannot be made until a much more complete systems design is available.

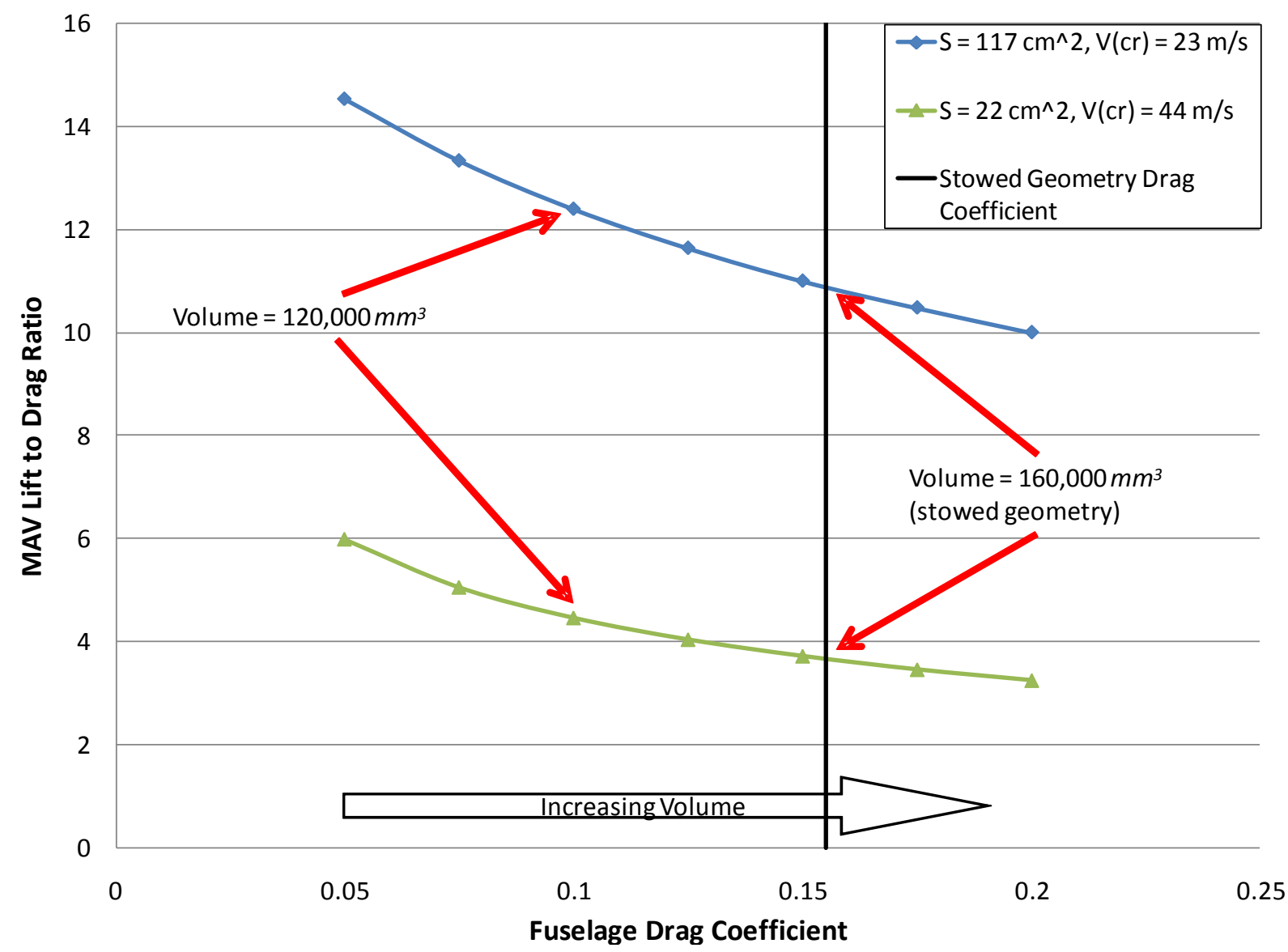

Figure 6-7: Lift-to-drag Ratio Sensitivity to Fuselage Drag Coefficient 


\section{Chapter 7 Component CFD Analysis}

To simplify the parametric numerical analysis the aircraft was broken down into sub-components. Fortunately this could be reduced to a pair of major segments, the fuselage and a wing which, over a range of Reynolds numbers and with a symmetric airfoil, would provide data for both the main wing and vertical tail. Mesh independence analyses for each of the sub-components were conducted to provide starting points for full MAV studies to be conducted in the future. This also allowed a more in-depth exploration of Fluent's ability to predict low Reynolds number airfoil performance. A detailed summary of the Fluent solver settings used in this work is provided in Appendix D.

\subsection{Fuselage Analysis}

From the classical aerodynamics work presented in Chapter 6 it was apparent that the fuselage was the largest drag contributor. Therefore any possible fuselage drag reductions would have large effects on overall MAV performance. As illustrated in Figure 7-1 a pair of Ogive tail cones were "carved" from the stowed baseline geometry. The Ogive geometries are referenced by the corresponding length of straight cylinder: 30 and $45 \mathrm{~mm}$. Mesh and solver settings identical to those used for the stowed geometry, presented in Figure 5-2 and Table 5-1were applied. Streamlining the fuselage in this manner cost 35,000 $\mathrm{mm}^{3}$ with the $45 \mathrm{~mm}$ long body and $45,000 \mathrm{~mm}^{3}$ with the $30 \mathrm{~mm}$ body.

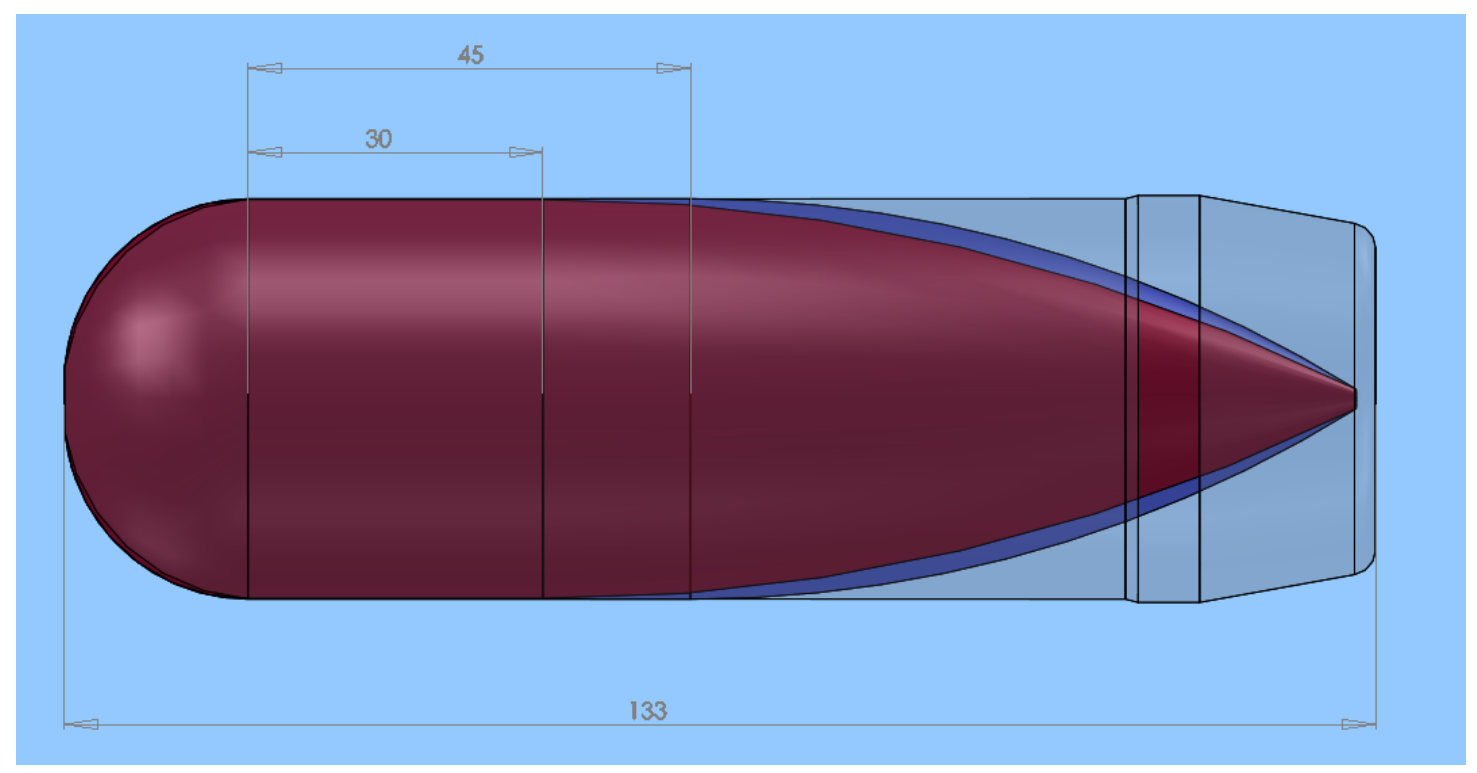

Figure 7-1: Various Ogive Tail Cones Applied to Stowed Geometry for Fuselage Study, Dimensions in $\mathbf{m m}$ 
Grid independence was obtained on the $45 \mathrm{~mm}$ long central body version ( middle outline in Figure 7-1). Specific details on mesh sizing are provided in Appendix B. Figure 7-2 shows that a meshindependent solution was reached at $7.5 \times 10^{5}$ cells in the domain. The entire mesh was generated with triangular prisms on the body and tetrahedral cells in the main volume. Body cells were restricted to 2.0 $\mathrm{mm}$ on a side with a first cell height of $1.05 \mathrm{~mm}$. A sample domain including local refinement regions and prismatic boundary layer is presented in Figure 7-3.

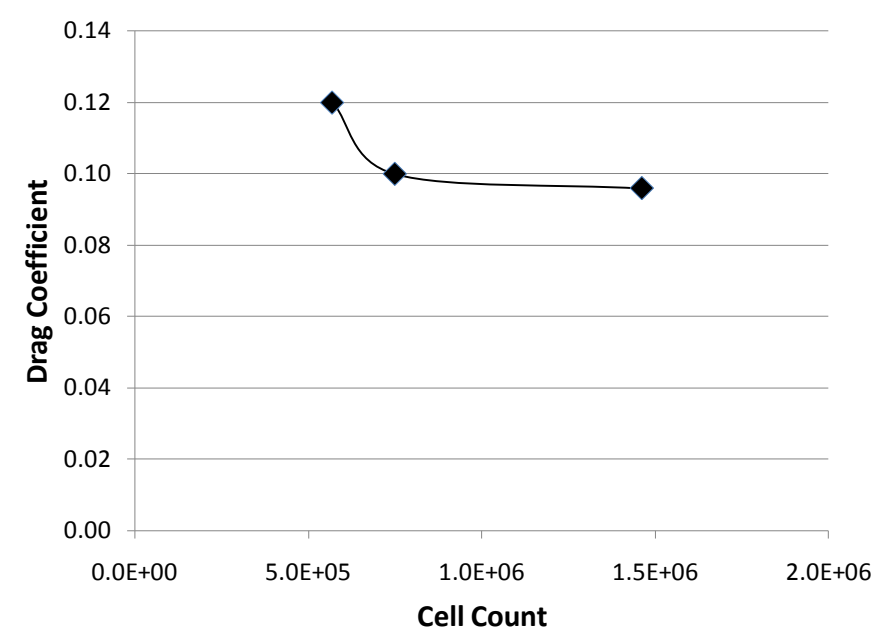

Figure 7-2: Mesh Independence Study for $45 \mathrm{~mm}$ Center Body Fuselage
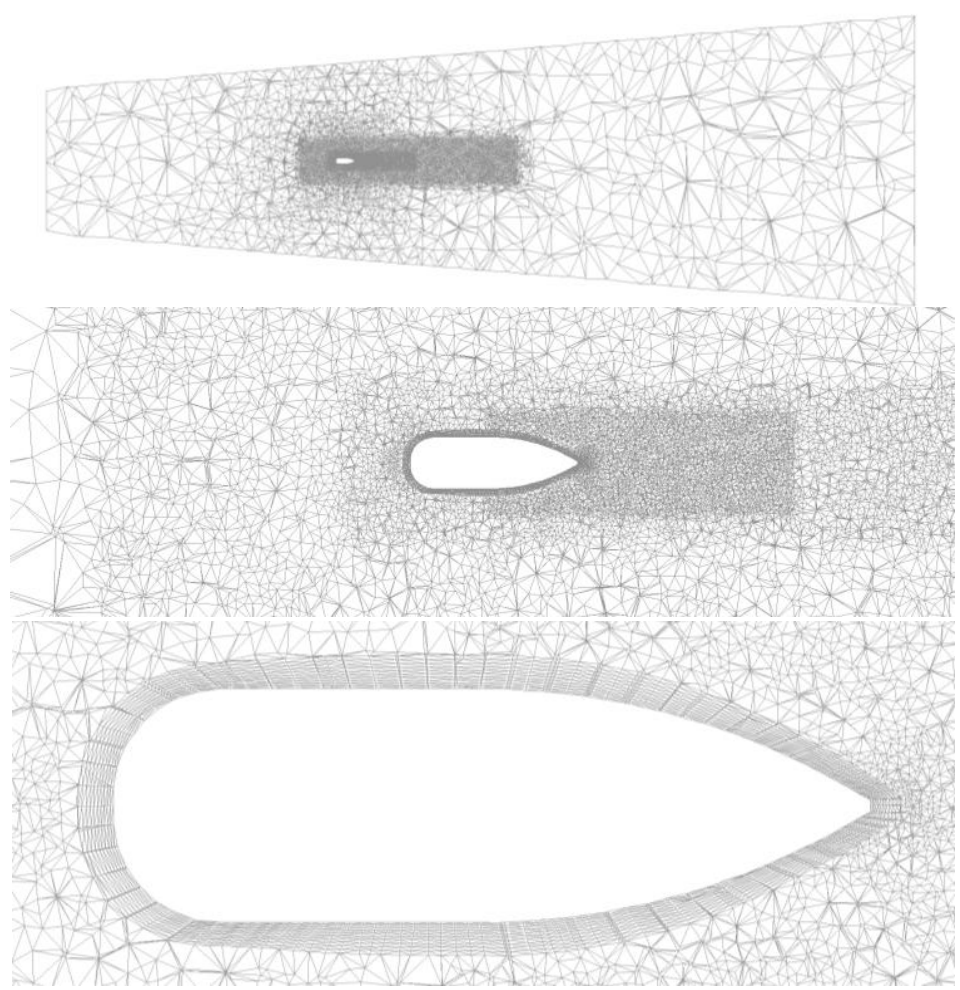

Figure 7-3: Component Mesh For Fuselage Analysis, 45 mm Center Body 
With drag data collected and plotted in Figure 7-4 it was apparent that no peak "optimum" existed. Instead a case of diminishing returns was encountered. Maximum drag reductions of approximately $30 \%$ were possible, but significant fuselage volume was sacrificed. Since the case of diminishing returns in the drag-volume correlation was gradual it appeared that fuselage volume should first be dictated by mission payload, sensors, and controls. Only after the internal design is completed could the appropriate streamlining be selected.

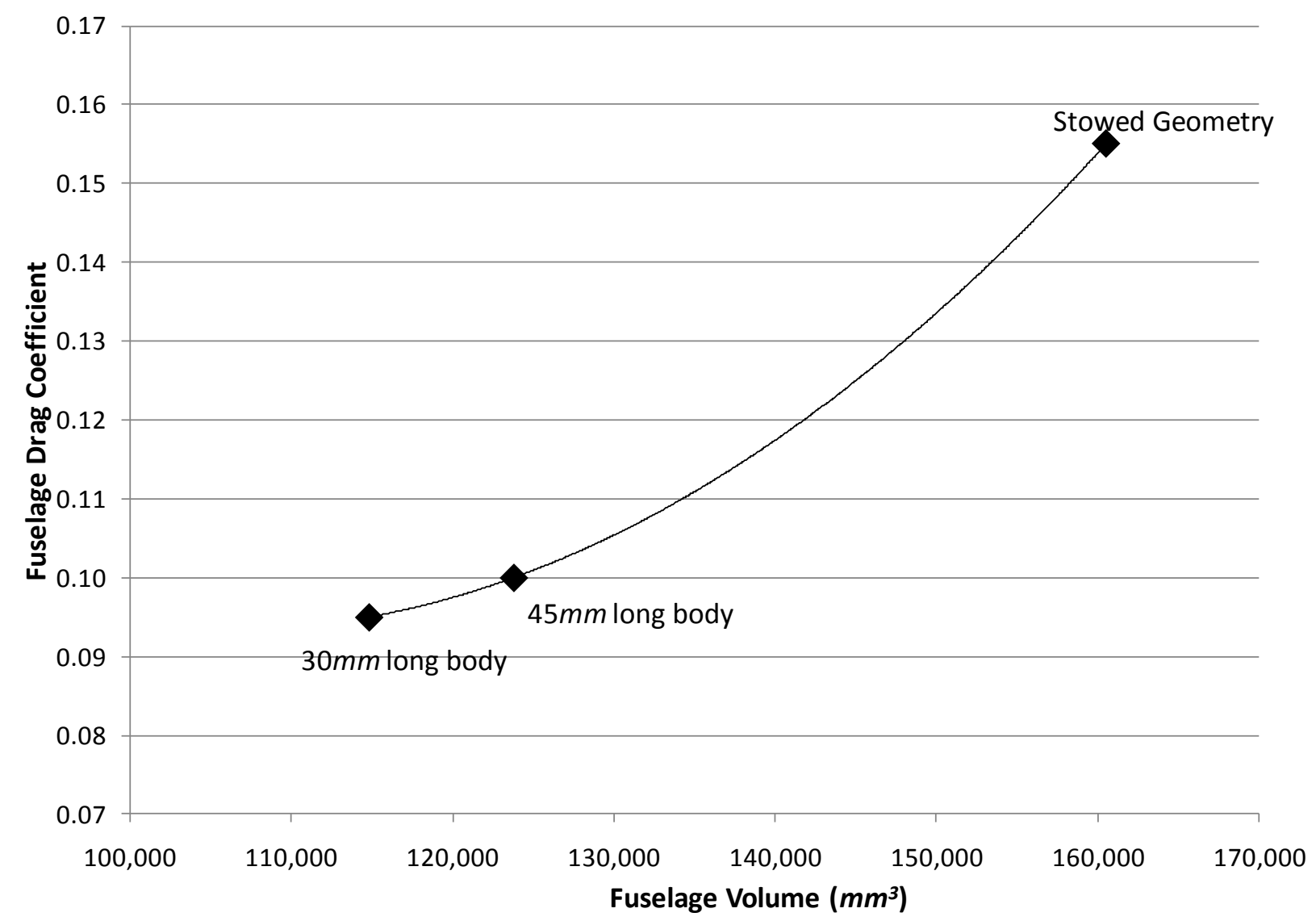

Figure 7-4: Correlation Between Fuselage Volume and Fuselage Drag Coefficient, Stowed Geometry is Far Right Value, Length of Tail Cone Increases to Left

\subsection{Two Dimensional Low Reynolds Number Airfoil Analysis}

As mentioned briefly in Section 2.3.1 flow over a two dimensional airfoil at low Reynolds numbers becomes extremely complex. The combination of laminar and turbulent regimes with possible flow separation and recirculating pockets, as shown in Figure 7-5, pushed the limits of commercial CFD software. 


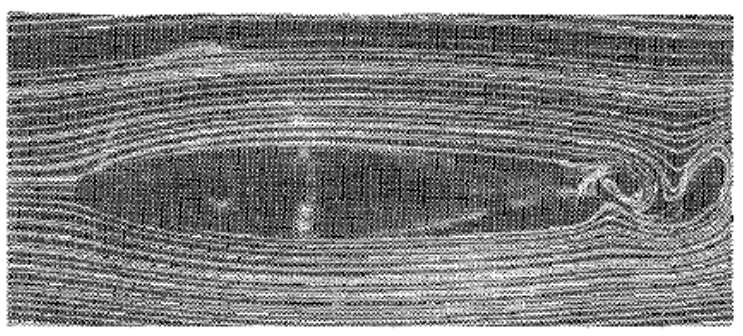

a) $\alpha=0 \mathrm{deg}$

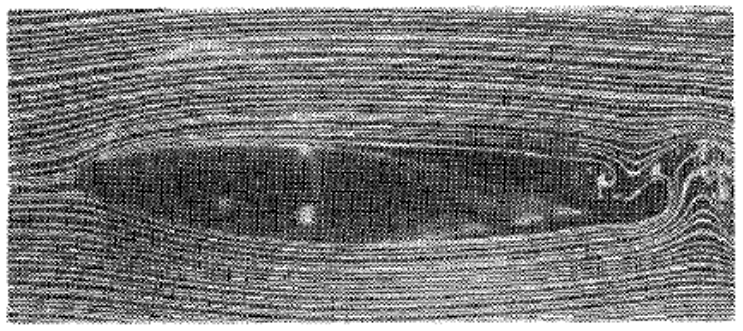

b) $\alpha=4$ deg

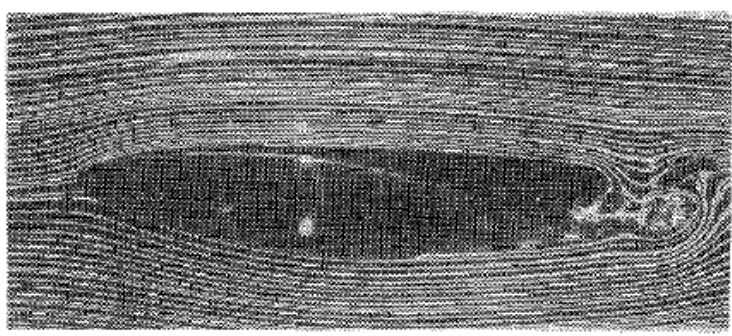

c) $\alpha=6 \mathrm{deg}$

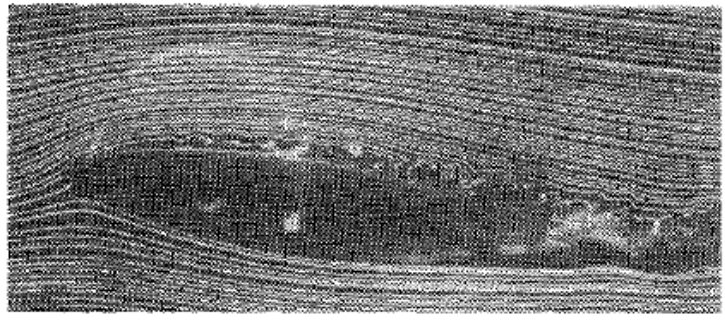

d) $\alpha=8 \mathrm{deg}$

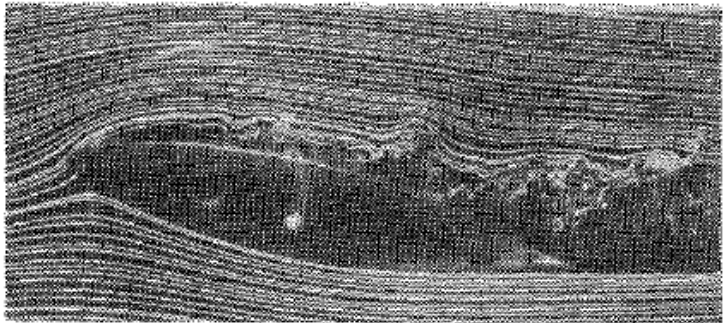

e) $\alpha=12 \mathrm{deg}$

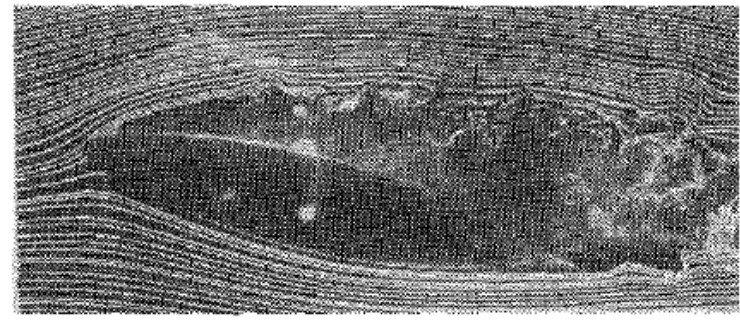

f) $\alpha=14 \mathrm{deg}$

Figure 7-5: Smoke Visualization of Transition Bubble on a Smooth Airfoil at Re - 40,000 (Mueller \& Batill, 1982)

To begin this analysis a survey of other low Reynolds number airfoil simulations was conducted. All prior work appeared to use fully orthogonal structured meshes with customized codes and transition models. ${ }^{24}$ While useful for expanding theoretical knowledge and improving turbulence transition models these codes are not useful for full three dimensional MAV design and optimization studies. To conduct this project a very flexible set of mesh specifications was required along with solver settings which functioned over a broad range of aircraft geometries.

${ }^{24}$ (Lian \& Shyy, 2007) 
Work done by Kim, et al. in 2009 showed the complex turbulent behavior over a lifting airfoil at low Reynolds number in detail from experiment. As seen in Figure 7-6 the turbulent and recirculation regions of the boundary layer can extend up to 0.06 chord lengths from the airfoil surface at very low Reynolds numbers. Initially it was hoped that the same mesh settings used to simulate the Ogive tailed fuselage geometries would work with minor changes to maximum surface cell edge lengths. Unfortunately the separation, recirculation, and reattachment was not correctly captured modeled by the $y+>30$ mesh settings generated for the stowed geometry and fuselage analysis as illustrated by the extremely poor lift and drag prediction in Figure 7-7. At most five grid points would have been located in the unusually complex boundary layer. Therefore a $y+<1$ high resolution mesh was generated with 10 to 20 nodes in the boundary layer depending on chord location. Specifics of this process are discussed in the following section.

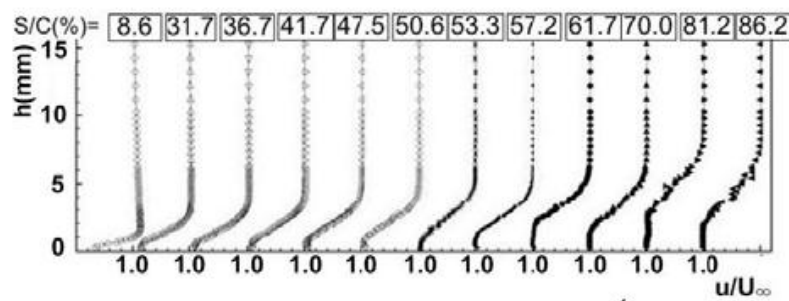

(a) Mean velocity $\left(\mathrm{Re}_{\mathrm{c}}=2.3 \times 10^{4}\right)$

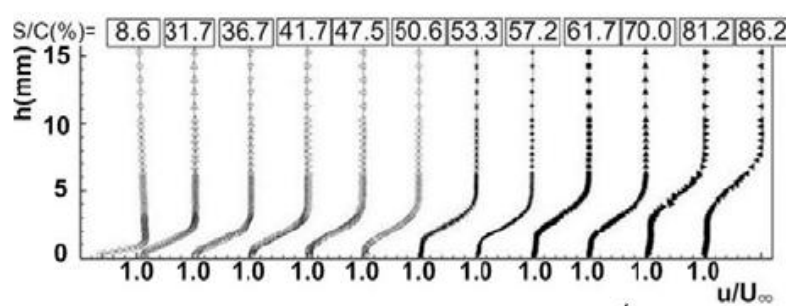

(b) Mean velocity $\left(\operatorname{Re}_{c}=3.3 \times 10^{4}\right)$

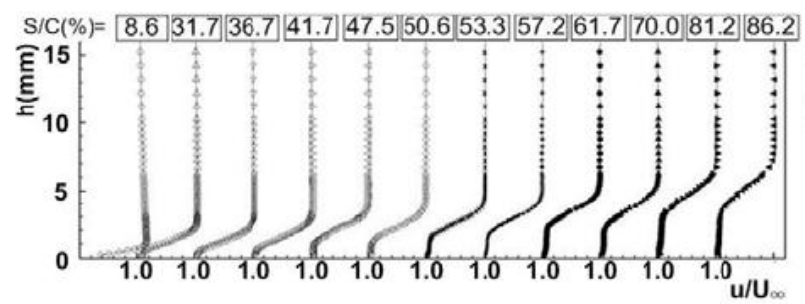

(c) Mean velocity $\left(\mathrm{Re}_{\mathrm{c}}=4.8 \times 10^{4}\right)$

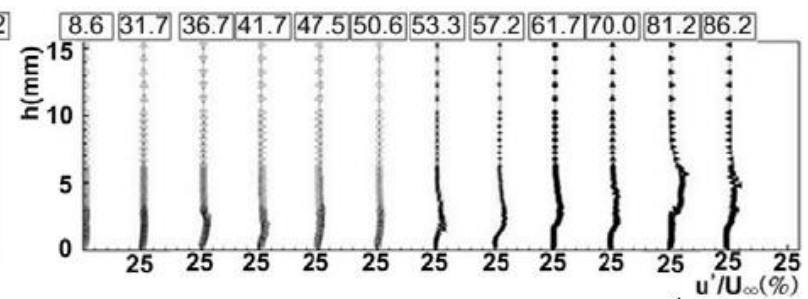

(d) Turbulence intensity $\left(\operatorname{Re}_{c}=2.3 \times 10^{4}\right)$

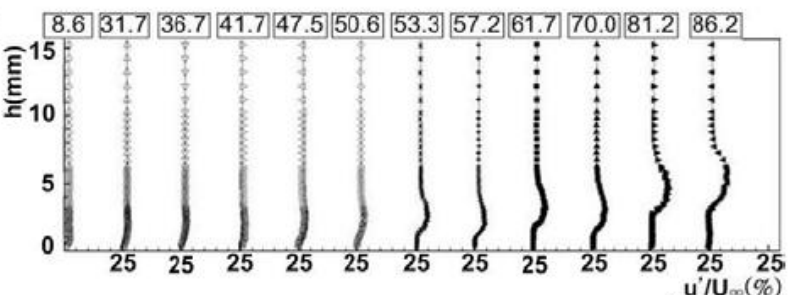

(e) Turbulence intensity $\left(\operatorname{Re}_{\mathrm{c}}=3.3 \times 10^{4}\right)$

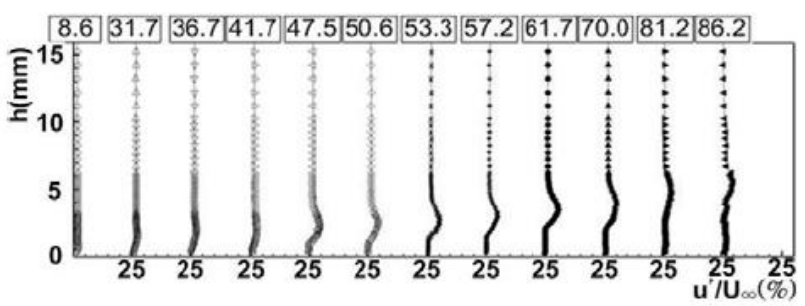

(f) Turbulence intensity $\left(\mathrm{Re}_{\mathrm{c}}=4.8 \times 10^{4}\right)$

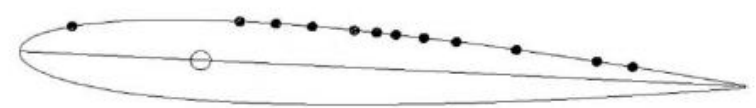

(g) Boundary layer measurement positions

Figure 7-6: Turbulent Boundary Layer Measurements at Reynolds Numbers Under 0.5x10 ${ }^{5}$, Airfoil Chord = $180 \mathrm{~mm}, \alpha=3^{\circ}$ (Kim, Yang, Chang, \& Chung, 2009) 


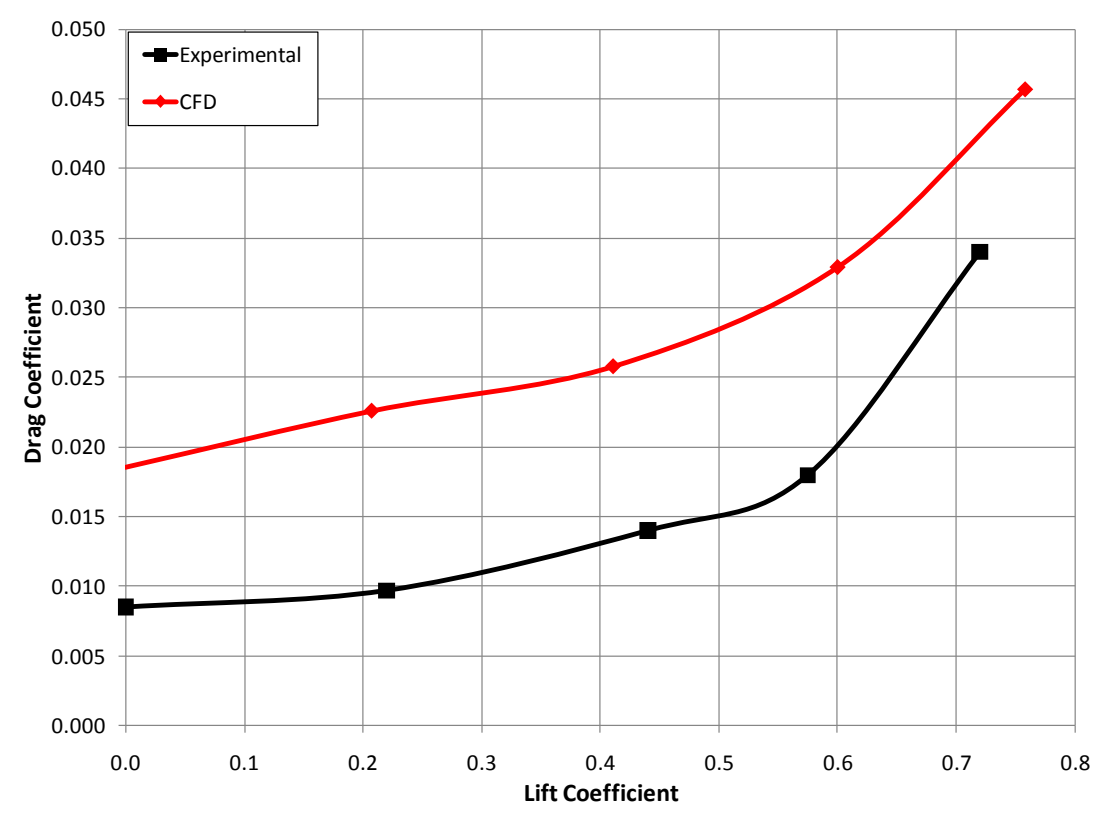

Figure 7-7: Comparison Between y+>30 Mesh Results and Experimental Data for a NACA 0009 Airfoil at $\operatorname{Re}=1.5 \times 10^{5}$. NACA 0009 Experimental Data, (Selig, Donovan, \& Fraser, 1989)

\subsubsection{NACA 0009 Validation}

Two dimensional data required validation for both mesh independence and turbulence model selection. The simple NACA 0009 airfoil was chosen for mesh and solver validation due to the wealth of experimental data available. Low Reynolds number data for the NACA 0009, reported by Selig, et al., (1989) has been used for all validation studies. Many other airfoils were studied by Selig's group; a small subset is discussed later in this document.

\subsubsection{Mesh Independence}

Figure 7-8 presents the mesh regions on which the values in Table 7-1 were specified. Settings vary from the coarsest, Mesh 5, to the finest, Mesh 1. Results from these grids at a Reynolds number of $3 \times 10^{5}$ for both the lift and drag coefficients, as well as the lift-to-drag ratio, were used to check for grid independence as shown in Figure 7-9. This demonstrates that even Mesh 4 with its 8,480 cells would have been sufficient to obtain reasonable results. However, since the two dimensional solutions took minimal computational time, "Mesh 3 Mod", incorporating a thicker prismatic layer and a more detailed local refinement region, was used to improve accuracy. Results, presented in Figure 7-9, show that while no mesh completely matches the experimental lift curve, and all over-predict the drag curve, grid independence was achieved with Mesh 4. Lift matched well for all meshes, but there was an increase in predicted drag from all finer meshes to an angle of ten degrees where the fine meshes predicted lower drag. 


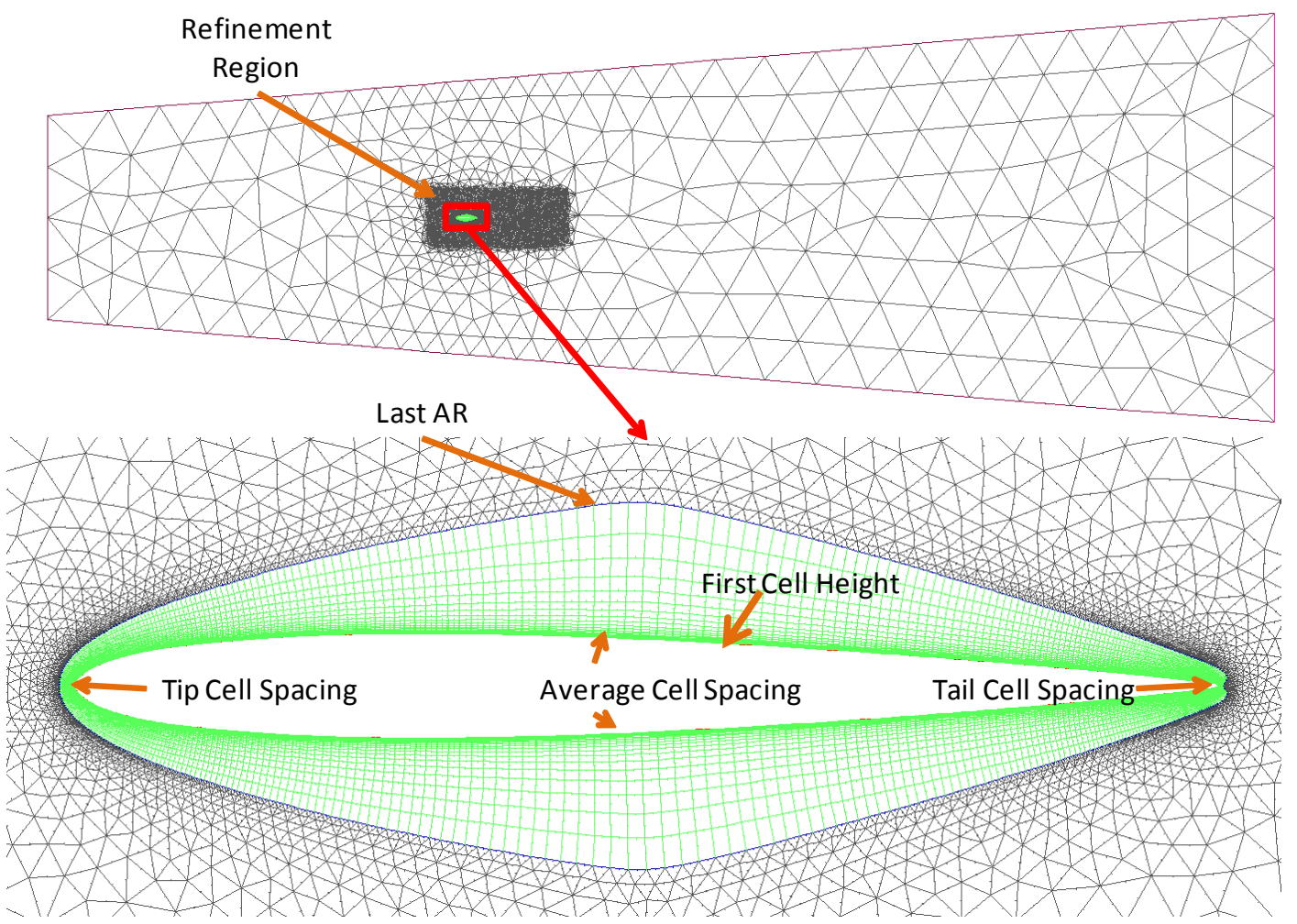

Figure 7-8: Mesh Regions for 2D Airfoil Studies, Labels as in Table 7-1

Table 7-1 Mesh Region Specifications for Figure 7-8, C=Chord Length, $0.1 \mathrm{~m}$ for this Study

\begin{tabular}{|r|c|c|c|c|c|c|}
\hline Surface Mesh & Mesh 5 & Mesh 4 & Mesh 3 & $\begin{array}{c}\text { Mesh 3 } \\
\text { MOD }\end{array}$ & Mesh 2 & Mesh 1 \\
\hline Tip \& Tail Spacing & $\begin{array}{c}0.004 \mathrm{C} \\
(0.002 \mathrm{C}\end{array}$ & $0.002 \mathrm{C}$ & $0.001 \mathrm{C}$ & $\begin{array}{c}0.001 \mathrm{C} \\
(0.00033 \mathrm{C}\end{array}$ & $0.0005 \mathrm{C}$ & $0.00025 \mathrm{C}$ \\
\hline Average Cell Spacing & $0.02 \mathrm{C}$ & $.01 \mathrm{C}$ & $.005 \mathrm{C}$ & $.005 \mathrm{C}$ & $.0025 \mathrm{C}$ & $.00125 \mathrm{C}$ \\
\hline Prismatic Layer & Last AR & Last AR & Last AR & Last AR & Last AR & Last AR \\
\hline First Cell Height & $0.00005 \mathrm{C}$ & $0.00005 \mathrm{C}$ & $0.00005 \mathrm{C}$ & $0.00005 \mathrm{C}$ & $0.00005 \mathrm{C}$ & $0.00005 \mathrm{C}$ \\
\hline Number of Layers & 25 & 25 & 25 & 25 & 40 & 40 \\
\hline Aspect / Growth Rate & $50 \%$ & $50 \%$ & $50 \%$ & $200 \%$ & $50 \%$ & $50 \%$ \\
\hline Tetrahedral Domain & \multicolumn{7}{|l|}{} & & & \\
\hline Domain Growth Rate & 1.3 & 1.3 & 1.3 & 1.3 & 1.3 & 1.3 \\
\hline Refine Growth Rate & 1.01 & 1.01 & 1.01 & 1.005 & 1.01 & 1.01 \\
\hline Refine $\mathrm{X}_{\text {center }}$ & $2 \mathrm{C}$ & $2 \mathrm{C}$ & $2 \mathrm{C}$ & $2 \mathrm{C}$ & $2 \mathrm{C}$ & $2 \mathrm{C}$ \\
\hline Refine $\mathrm{X}_{\text {length }}$ & $7 \mathrm{C}$ & $7 \mathrm{C}$ & $7 \mathrm{C}$ & $7 \mathrm{C}$ & $7 \mathrm{C}$ & $7 \mathrm{C}$ \\
\hline Refine $\mathrm{Y}_{\text {length }}$ & $3 \mathrm{C}$ & $3 \mathrm{C}$ & $3 \mathrm{C}$ & $3 \mathrm{C}$ & $3 \mathrm{C}$ & $3 \mathrm{C}$ \\
\hline Refine Vol & 400 & 200 & 100 & 50 & 100 & 100 \\
\hline Skewness & 0.78 & 0.71 & 0.72 & 0.74 & 0.77 & 0.75 \\
\hline Mesh Statistics & Last AR & Last AR & Last AR & Last AR & Last AR & Last AR \\
\hline Average Volume & 1,709 & 1,061 & 509 & 358 & 263 & 98 \\
\hline Number of Cells & 5,266 & 8,480 & 17,664 & 25,110 & 34,176 & 91,634 \\
\hline
\end{tabular}




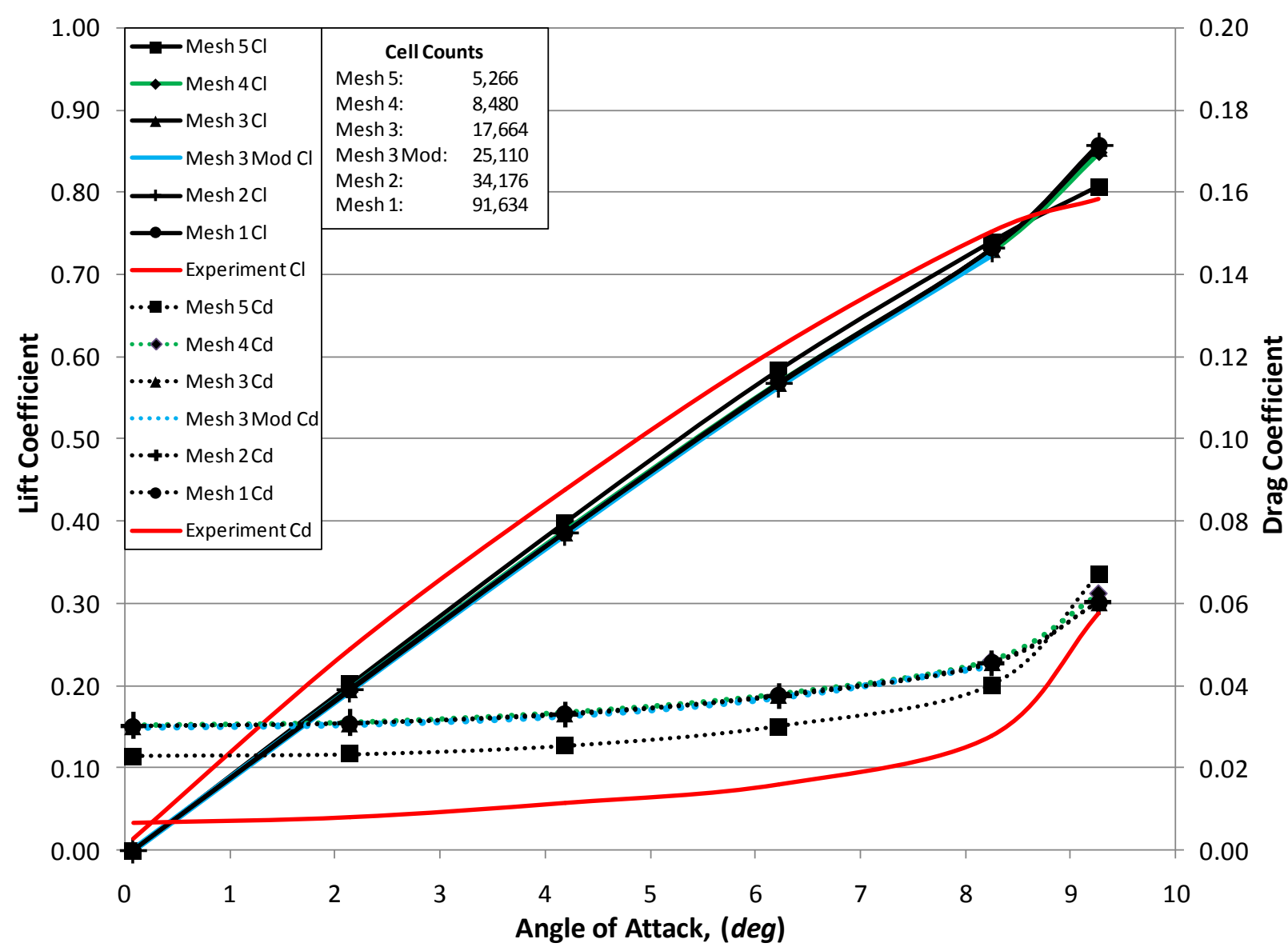

Figure 7-9: Lift and Drag Coefficient Plot Showing Mesh Independence for NACA 0009 2D Airfoil, Standard k- $\omega$ Turbulence Model

One geometric modification was made to the NACA 0009 and all other airfoils studied. As shown in Figure 7-10 the trailing edge of the airfoil was blunted. This was done by rotating the upper and lower surfaces about the leading edge by $0.1^{\circ}$ away from one another. To verify that this change had minimal effects Mesh 3 was compared to results generated by a sharp trailing edge geometry with the same upper and lower surface mesh settings. 


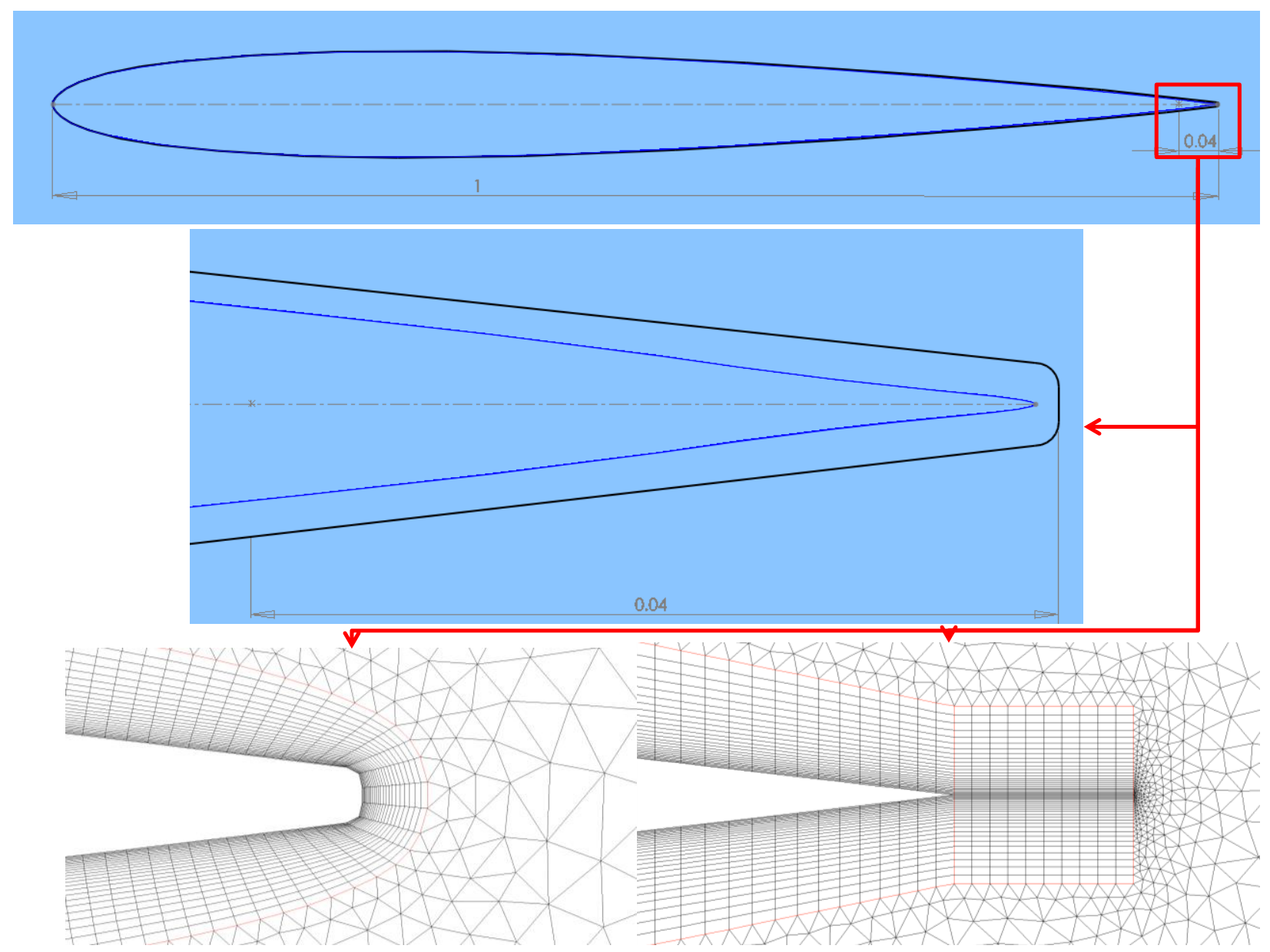

Figure 7-10: Comparison of Blunt and Sharp Trailing Edge Mesh Geometries, Dimensions in $m$

Figure 7-11 shows that the lift and drag coefficients returned by the blunted geometry were nearly identical to those calculated for the sharp training edge. Lift and drag coefficients for this study were not expected to match experimental data at this point. Errors at this stage were likely due to imperfect transition and turbulence modeling with the current settings. Following sections discuss the process used to select an appropriate turbulence model for these Reynolds numbers. This geometric modification allowed a single "last AR" prismatic layer to be grown from the surface of the airfoil which greatly simplified mesh generation for both two and three dimensional cases. A "last AR" prismatic layer creates a set of prism cells with the final layer having a specified ratio between the cell height normal to the surface and the cell length along the surface. Prismatic layers specified in this manner are more flexible and easier to generate around complex geometries but deal poorly with sharp edges. In this project it was easier to eliminate sharp edges by going back to the geometric model an inserting fillets and chamfers rather than developing a more complex and more tightly structured mesh. This blunted geometry is also likely more representative of any physical model which would be created. Even if the effort were invested to create a perfect sharp trailing edge it would likely be blunted in use. 


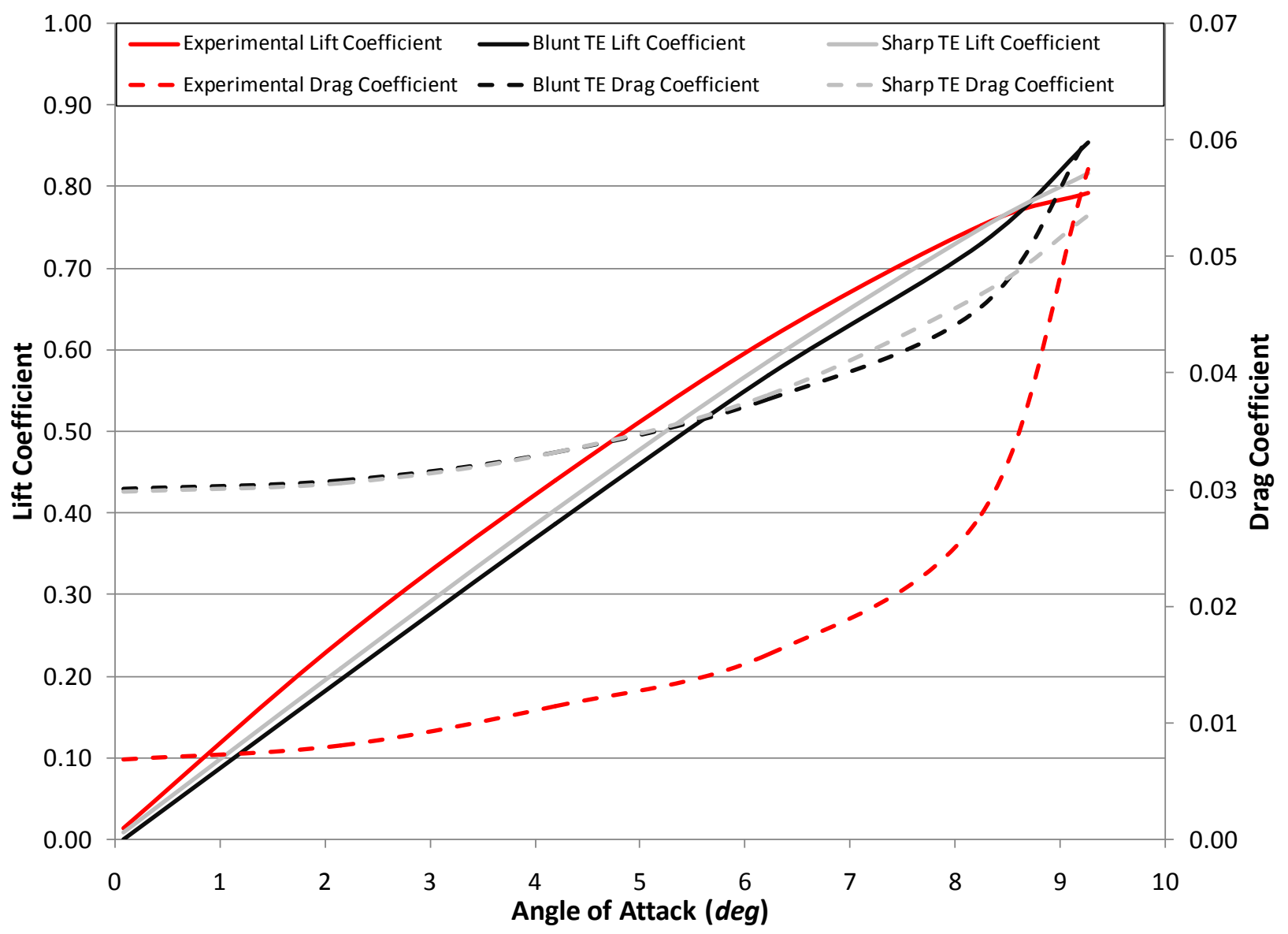

Figure 7-11: Comparison of Blunt and Sharp Trailing Edge Mesh Results, Standard k- $\omega$ Turbulence Model

\subsubsection{Turbulence Model Selection}

As seen in Figure 7-7, the standard k- $\omega$ turbulence model produced extremely poor results. As this research program was focused on design work it was not practical to write a custom turbulence model for this flow regime. A model sufficient to produce conservative first-cut engineering estimates was required. To this end the full suite of turbulence models and settings available in Fluent 12 was examined on Mesh 3 Mod at an angle of attack of $6^{\circ}$ and a Reynolds number of $3 \times 10^{5}$. Table 7-2 presents a summary of all turbulence models, some general comments, and their performance in this case. Laminar solutions were also attempted in both steady-state and transient formulations. Neither configuration returned useful results and have been omitted here. Laminar solvers failed to capture the leading edge separation, circulation bubble, and reattachment and returned a fully-stalled solution as soon as leading edge separation occurred. Only those models which predicted both lift and drag coefficients, and lift-todrag ratio, within were selected for further study. The Reynolds Stress models have been omitted due to the number of options to be displayed, and the fact that these seven equation models performed poorly and ran slowly in later testing. 
Table 7-2: Summary of Fluent 12 Turbulence Models Applied to NACA 0009 at $6^{\circ}$ Angle of Attack and Reynolds Number of $3 \times 10^{5}$, Errors Less than $10 \%$ Highlighted in Green

\begin{tabular}{|c|c|c|c|c|c|}
\hline \multirow{2}{*}{ Model } & \multicolumn{4}{|c|}{ Prediction for NACA 0009 at $\alpha=6^{\circ}$} & \multirow{2}{*}{ Comments } \\
\hline & $C_{L}$ & $\%$ Error $\mathrm{C}_{\mathrm{L}}$ & $C_{D}$ & $\%$ Error $C_{D}$ & \\
\hline Laminar & Unstable & Err & Unstable & Err & $\begin{array}{l}\text { Failed due to flow detatchment at separation } \\
\text { bubble, no modeling for re-attachment }\end{array}$ \\
\hline \multicolumn{6}{|l|}{ Spalart - Allmaras } \\
\hline Vorticity - Low RE & 0.657 & $7.15 \%$ & 0.017 & $6.92 \%$ & \multirow{4}{*}{$\begin{array}{l}\text { Simple, one equation model built for the aerospace } \\
\text { industry to handle wall bounded and adverse } \\
\text { presure gradient flows }\end{array}$} \\
\hline Strain/Vorticity - Low RE & 0.655 & $6.79 \%$ & 0.017 & $5.66 \%$ & \\
\hline Strain/Vorticity & 0.062 & $-89.85 \%$ & 0.026 & $64.15 \%$ & \\
\hline Vorticity & 0.062 & $-89.87 \%$ & 0.027 & $66.67 \%$ & \\
\hline \multicolumn{5}{|l|}{ k- $\varepsilon$} & \\
\hline Standard-Standard & 0.592 & $-3.46 \%$ & 0.041 & $155.35 \%$ & \multirow{4}{*}{$\begin{array}{l}\text { Simple two equation model based on turbulent } \\
\text { kinetic energy and turbulent dissipation rate }\end{array}$} \\
\hline Standard- NWF & 0.563 & $-8.14 \%$ & 0.053 & $230.82 \%$ & \\
\hline Standard - Enh Wall & 0.612 & $-0.20 \%$ & 0.038 & $135.85 \%$ & \\
\hline Standard - Enh Wall - Press Grad & 0.612 & $-0.24 \%$ & 0.038 & $135.85 \%$ & \\
\hline RNG - Standard & 0.624 & $1.75 \%$ & 0.029 & $81.76 \%$ & \multirow[t]{8}{*}{ RNG model improved for high strain rates } \\
\hline RNG - NWF & 0.589 & $-3.85 \%$ & 0.041 & $159.12 \%$ & \\
\hline RNG - Enh Wall & 0.649 & $5.84 \%$ & 0.028 & $75.47 \%$ & \\
\hline RNG - Enh Wall - Press Grad & 0.649 & $5.84 \%$ & 0.023 & $43.40 \%$ & \\
\hline RNG - Standard - DVM & Unstable & Err & Unstable & Err & \\
\hline RNG - NWF - DVM & Unstable & Err & Unstable & Err & \\
\hline RNG - Enh Wall - DVM & 0.645 & $5.22 \%$ & 0.024 & $50.94 \%$ & \\
\hline RNG - Enh Wall - DVM - Press Grad & 0.645 & $5.22 \%$ & 0.240 & $1409.43 \%$ & \\
\hline Realizable - Standard & 0.622 & $1.47 \%$ & 0.027 & $68.55 \%$ & \multirow{4}{*}{$\begin{array}{l}\text { Realizable model built for planar and round jets, } \\
\text { rotation, adverse pressure, separation, and } \\
\text { recirculation }\end{array}$} \\
\hline Realizable - NWF & 0.586 & $-4.34 \%$ & 0.038 & $140.88 \%$ & \\
\hline Realizable - Enh Wall & 0.652 & $6.39 \%$ & 0.020 & $28.30 \%$ & \\
\hline Realizable - Enh Wall - Press Grad & 0.652 & $6.41 \%$ & 0.020 & $28.30 \%$ & \\
\hline \multicolumn{5}{|l|}{$k-\omega$} & \\
\hline Standard & 0.635 & $3.54 \%$ & 0.026 & $64.15 \%$ & \multirow{4}{*}{$\begin{array}{l}\text { Standard model verified for wakes, mixing layers, } \\
\text { and jets. Should be valid for wall bounded shear } \\
\text { flows }\end{array}$} \\
\hline Standard - Low Re & 0.620 & $1.14 \%$ & 0.035 & $118.24 \%$ & \\
\hline Standard - Shear & 0.631 & $2.97 \%$ & 0.025 & $55.97 \%$ & \\
\hline Standard Low Re - Shear & 0.616 & $0.52 \%$ & 0.032 & $99.37 \%$ & \\
\hline SST & 0.651 & $6.18 \%$ & 0.016 & $3.14 \%$ & \multirow{2}{*}{$\begin{array}{l}\text { SST model uses the k- } \omega \text { model in the near field and } \\
\text { the } k-\varepsilon \text { model in the far-field }\end{array}$} \\
\hline SST - Low RE & Unstable & Err & Unstable & Err & \\
\hline Transition k-kl- $\omega$ Steady & Unstable & Err & Unstable & Err & \\
\hline Transition SST Steady & Unstable & Err & Unstable & Err & \\
\hline Transition SST $\mathrm{dt}=10^{-5}$ & 0.653 & $6.56 \%$ & 0.017 & $3.77 \%$ & \\
\hline
\end{tabular}

With the first down-select complete all potential turbulence models were run at angles of attack between $0^{\circ}$ and $8^{\circ}$ at two degree increments at Reynolds numbers of $3.0 \times 10^{5}, 1.5 \times 10^{5}, 1.0 \times 10^{5}$, and $0.6 \times 10^{5}$. These Reynolds numbers were selected to correspond with Selig's published data. ${ }^{25}$ Repeated down-selects occurred each time the Reynolds number was reduced based on the closest experimental match at the current Reynolds number. Figure 7-12 shows lift-to-drag ratio data after the first downselect. All steady-state models under-predicted the lift-to-drag ratio across the range. Two transient turbulence transition models, SST and k-kl- $\omega$ were also examined. Neither performed well; both overpredicted lift and under-predicted drag and were therefore useless as conservative engineering tools, even neglecting the $10^{-5} s$ time step forcing extremely long run times and making three dimensional simulations utterly impractical.

25 (Selig, Donovan, \& Fraser, 1989) 


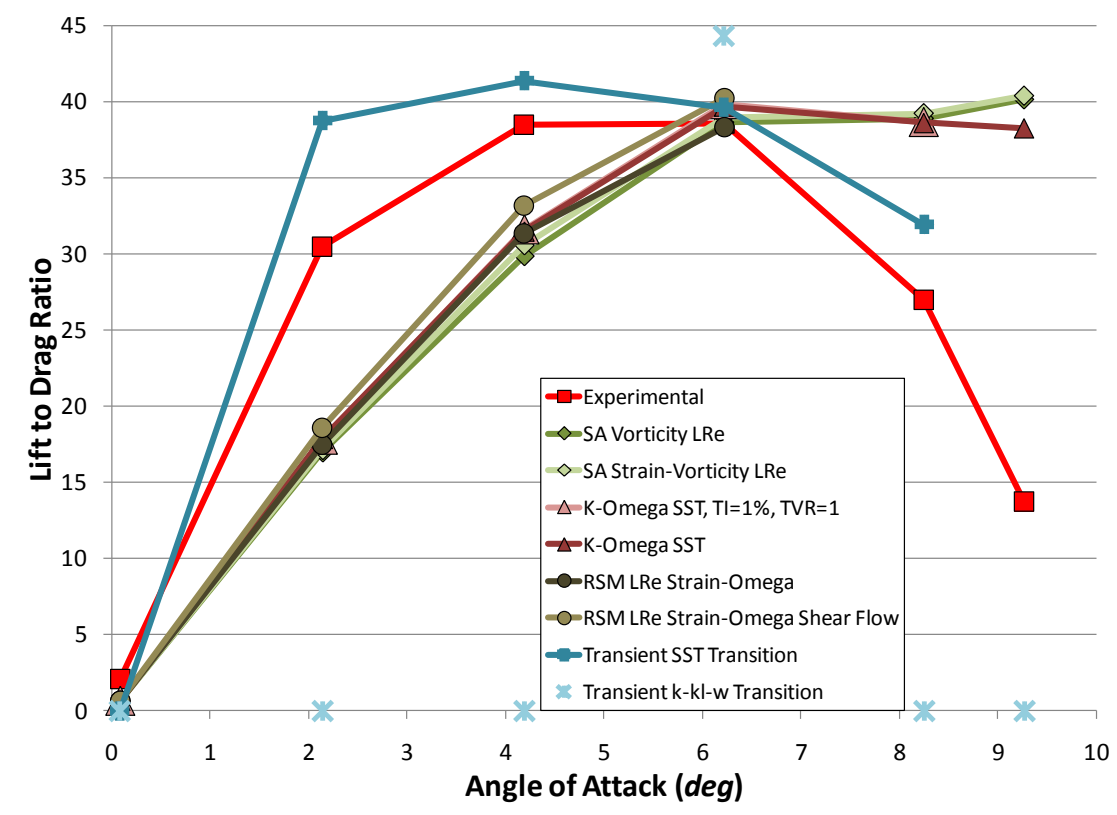

Figure 7-12: Lift-to-drag Ratios for Selected Turbulence Models at a Reynolds Number of 3x10

Continuing down-selects were conducted as the Reynolds number was reduced to $1.5 \times 10^{5}$, $1.0 \times 10^{5}$, and $0.6 \times 10^{5}$. The final lift to drag ratio plot, Figure 7-13, compares the two permutations of the Spalart-Allmaras turbulence model and a pair of k- $\omega$ model permutations. While the faster one equation Spalart-Allmaras model would have been preferable due to its reduced computational time, especially when looking forward to three dimensional modeling, the far better stall prediction of the k- $\omega$ SST model made it the clear winner.

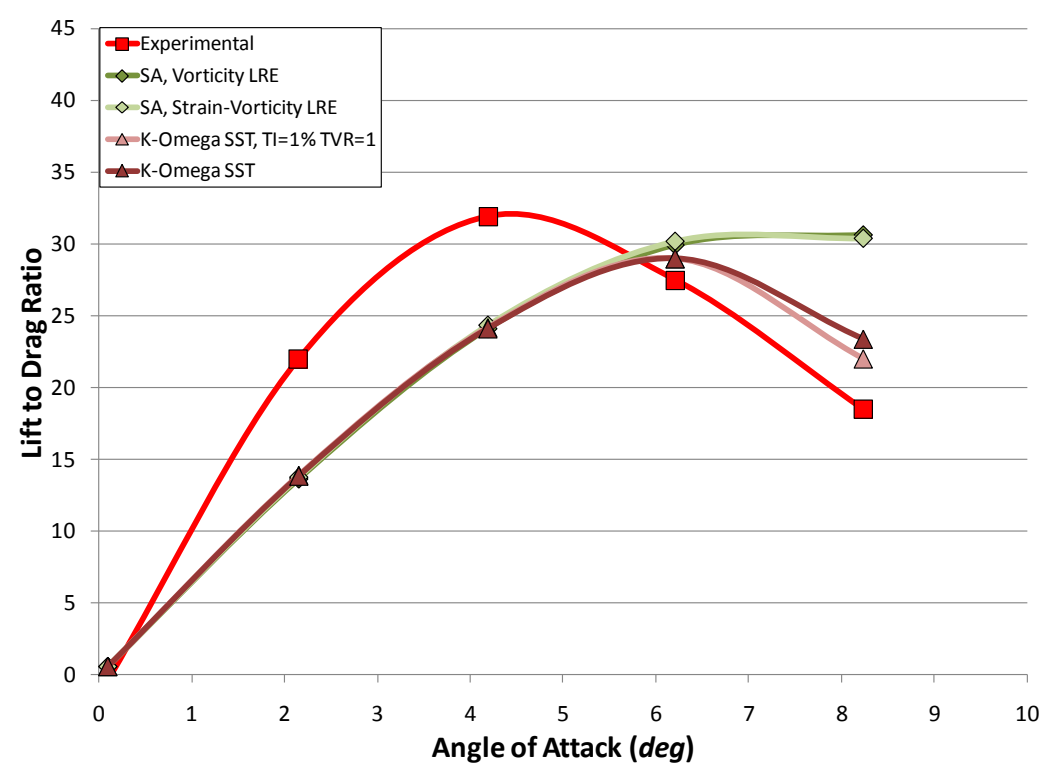

Figure 7-13: Lift-to-drag Ratios for Final Turbulence Model Down-Select at Reynolds Number of 0.6x10 
From this process the k- $\omega$ SST model was selected for its accuracy, simplicity of implementation, and short run times. Most turbulence models produced very similar results, under-predicting efficiency to $6^{\circ}$ angle of attack and over-predicting afterward. Only the transient SST Transition model seemed to predict the physical stall angle, however it significantly over-predicted efficiency across the lower angle range and was therefore not a useful engineering tool. The transient $\mathrm{k}-\mathrm{kl}-\omega$ model was only checked at $6^{\circ}$ and returned a significant over-prediction which also made it useless as a preliminary design tool. All turbulence models which produced useful results under-predicted performance at lower angles of attack, however since all were built on the assumption of fully turbulent flow stall was not predicted at the physically correct angle. The increased mixing caused by the fully turbulent boundary layer solution maintained flow attachment resulting in over-predictions of lift and under-predictions of drag past the physical stall angle of $6^{\circ}$.

Figure 7-14 through Figure 7-17 show the drag polars at each Reynolds number across the angle of attack range from zero degrees to eight degrees. Note that for these plots the experimental data was taken from tabulated lists which were not precisely at $0,2,4,6$, and 8 degrees angle of attack due to the limitations of the experimental apparatus used.

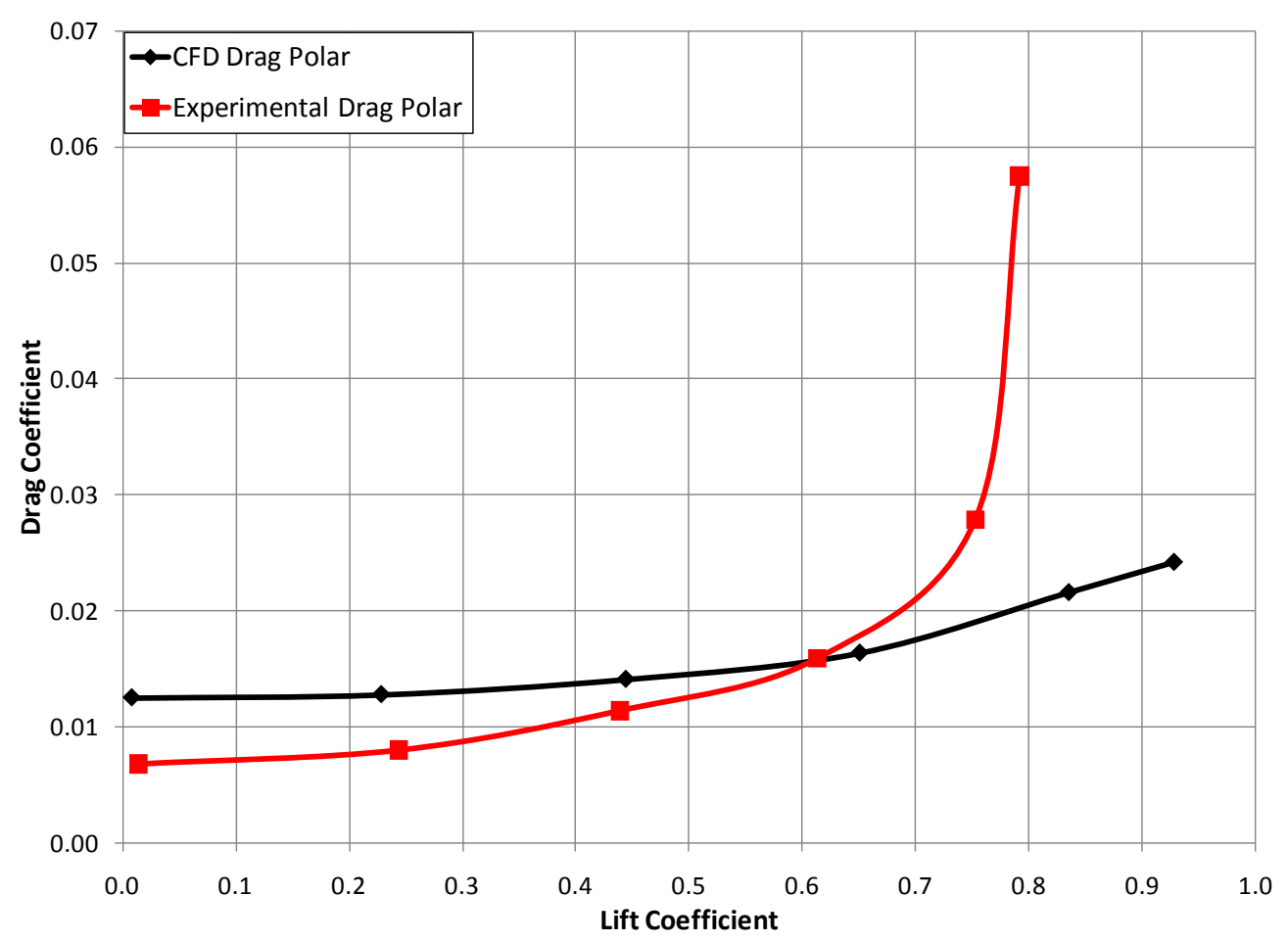

Figure 7-14: Drag Polar Using K- $\omega$ SST Turbulence Model for a NACA 0009 at a Reynolds Number of 3.0x10 ${ }^{5}$, Markers at $2^{\circ} \alpha$ Increments from $0^{\circ}$ 


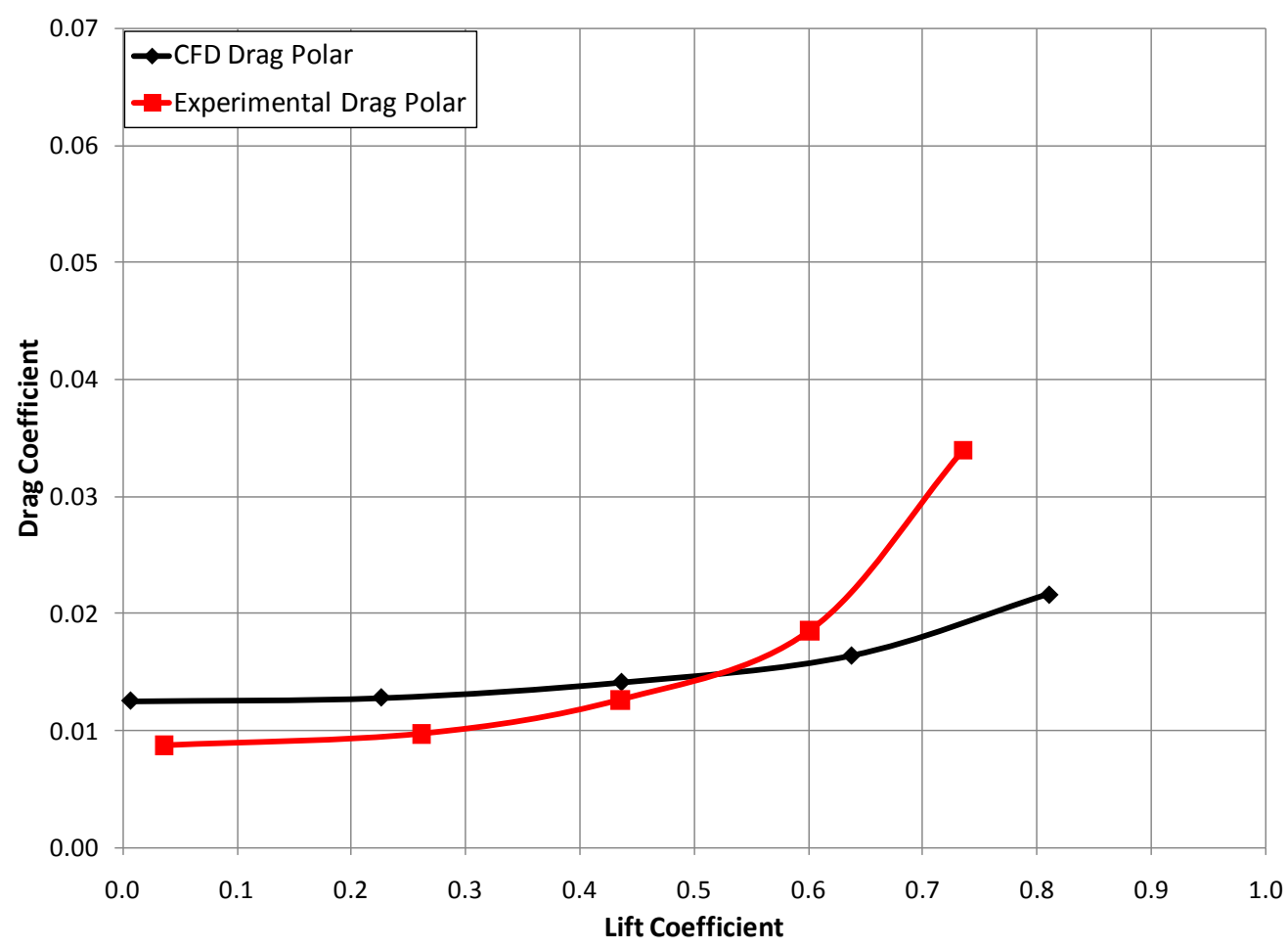

Figure 7-15: Drag Polar Using K- $\omega$ SST Turbulence Model for a NACA 0009 at a Reynolds Number of $1.5 \times 10^{5}$, Markers at $2^{\circ} \alpha$ Increments from $0^{\circ}$

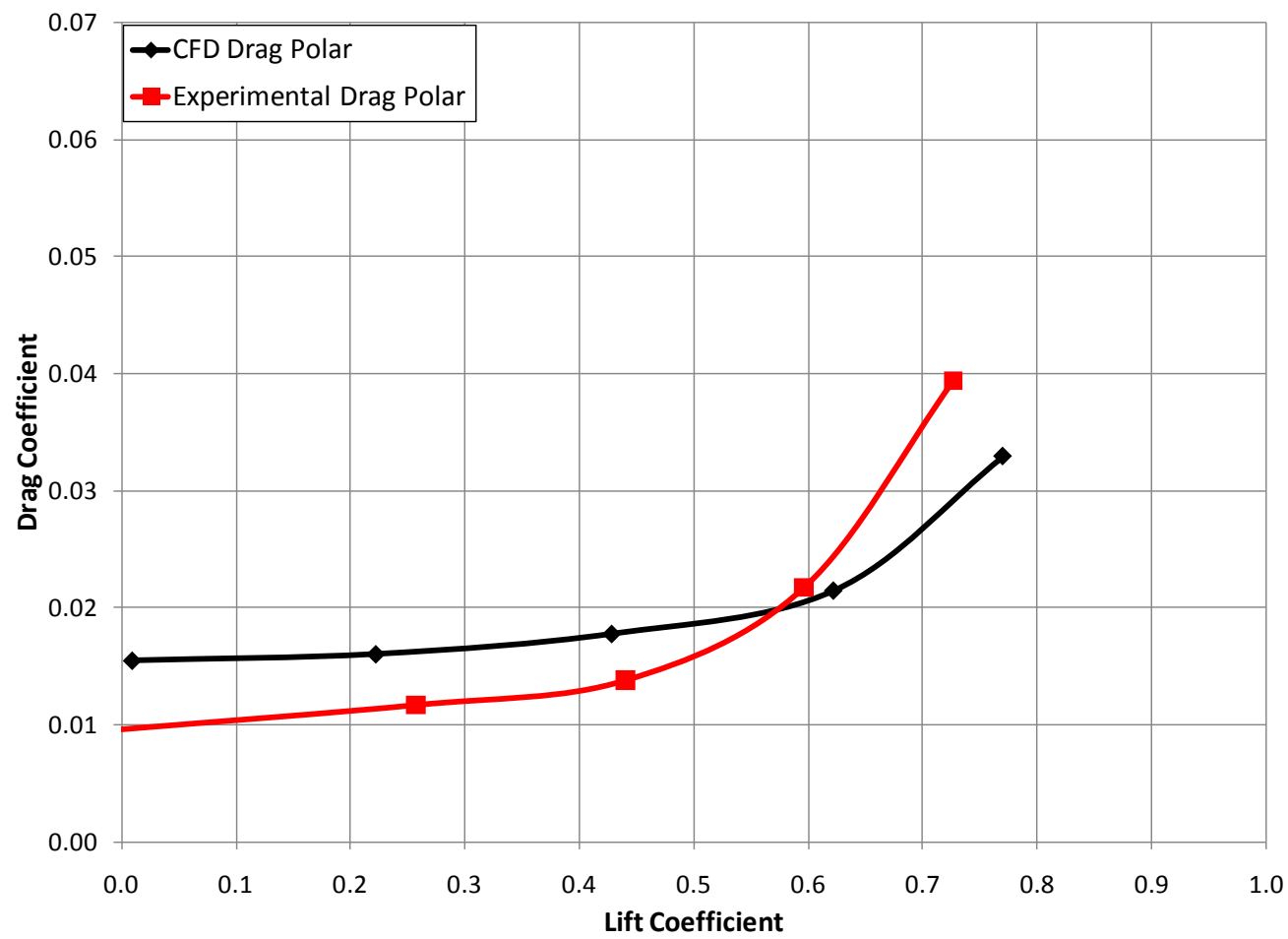

Figure 7-16: Drag Polar Using K- $\omega$ SST Turbulence Model for a NACA 0009 at a Reynolds Number of $1.0 \times 10^{5}$, Markers at $2^{\circ} \alpha$ Increments from $0^{\circ}$ 


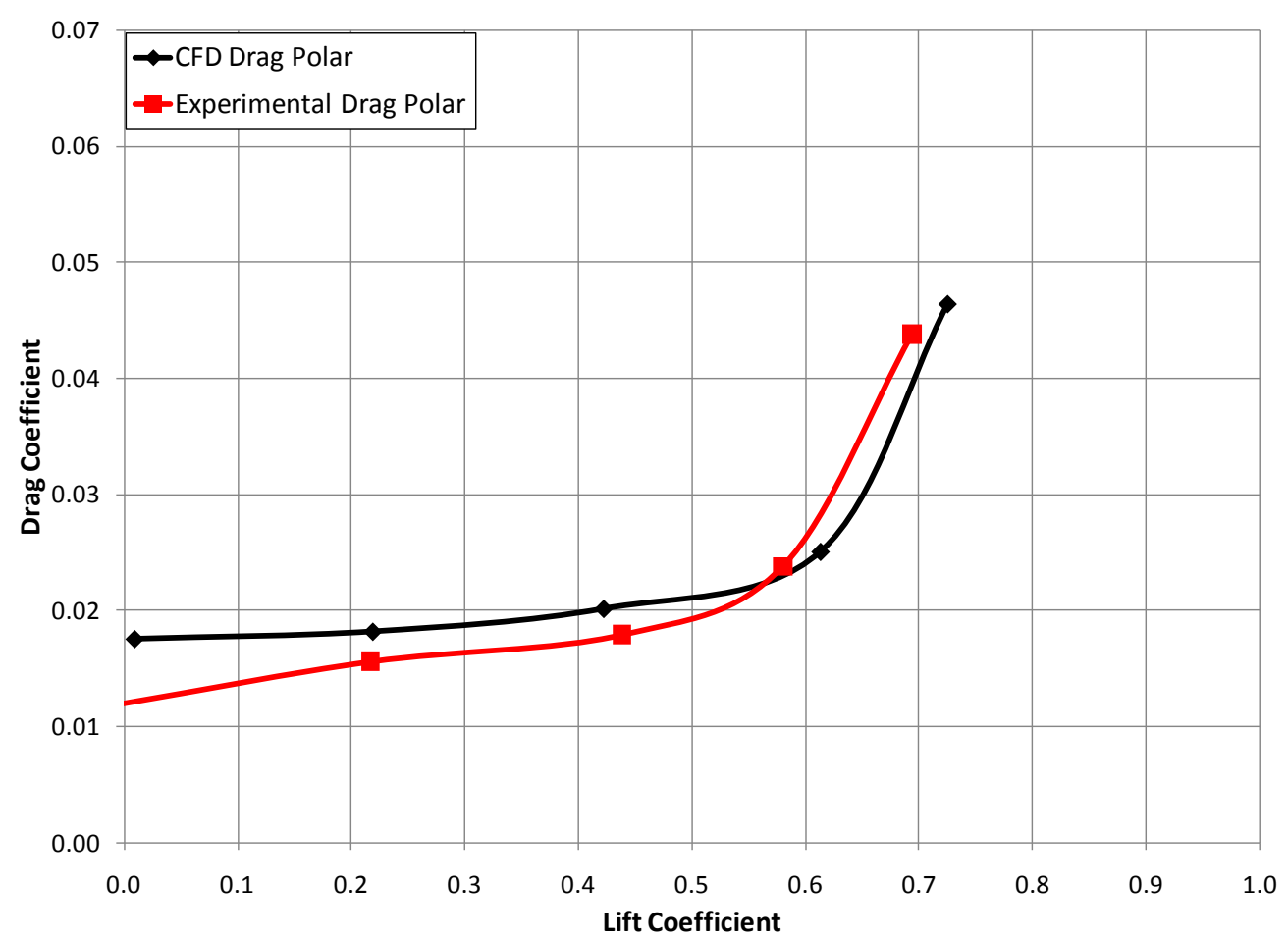

Figure 7-17: Drag Polar Using K- $\omega$ SST Turbulence Model for a NACA 0009 at a Reynolds Number of $0.6 \times 10^{5}$, Markers at $2^{\circ} \alpha$ Increments from $0^{\circ}$

While not perfect by any means the preceding results show that the k- $\omega$ SST model provided an acceptable preliminary engineering design tool, particularly at moderate angles of attack and lower Reynolds numbers. In all cases the lift was predicted with reasonable accuracy and the drag tended to be over predicted which resulted in conservative performance estimates. Wind tunnel testing would be required to verify a final design or to inform the design optimization process. Prediction was poor near zero degrees angle of attack due to the solver forcing a turbulent boundary layer around the entire airfoil. Physically large portions of the leading edge boundary layer were likely laminar in nature and therefore producing less drag. In addition, the lift coefficient, and lift-to-drag ratio was over predicted at high angles of attack. This was likely due to the turbulence model maintaining flow attachment past the point where flow separation would begin. It is interesting to note that the pre-stall prediction performance of these settings improved significantly as the Reynolds number was reduced.

Surprisingly the turbulence model did indicate the existence of a circulation bubble and reattachment region as shown in Figure 7-18 and Figure 7-19. 

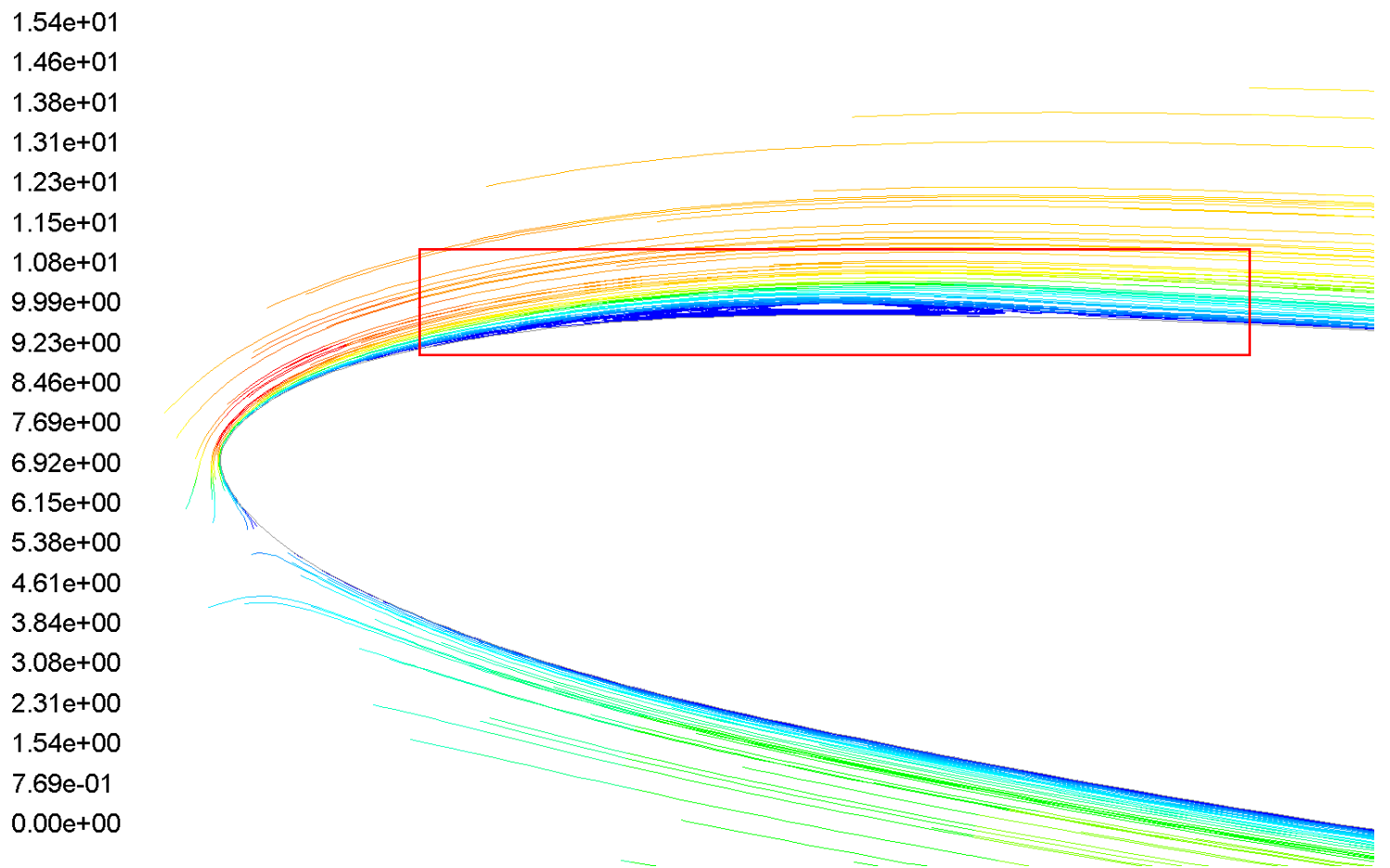

Figure 7-18: Velocity Pathlines $(\mathrm{m} / \mathrm{s})$ Showing Prediction of Recirculating Separation Bubble, $6^{0} \alpha$, $\operatorname{Re}=0.6 \times 10^{5}$

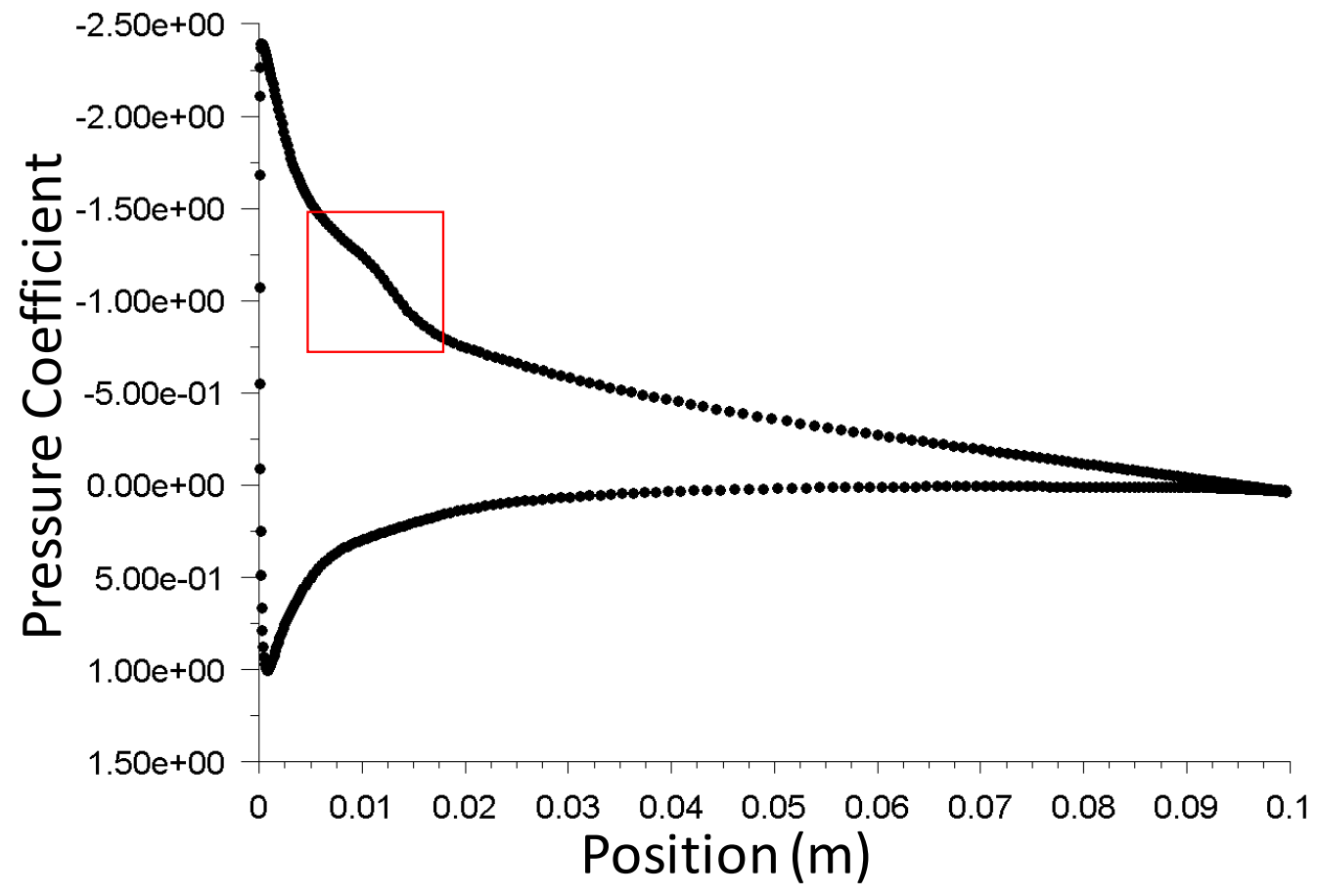

Figure 7-19: Pressure Coefficient Around NACA 0009 Showing Separation Bubble "plateau", $6^{0} \alpha$, $\operatorname{Re}=0.6 \times 10^{5}$ 
This demonstrates that, while not yet physical in magnitude and location, the field of turbulence modeling is progressing toward the ability to accurately predict low Reynolds number aerodynamics on arbitrary aircraft geometry. In fact work with the model constants in the Fluent solver could significantly increase accuracy. This was not pursued for the current project since acceptable results had already been obtained. Future work on this project could involve some experimentation with these constants to more closely match physical data.

\subsubsection{Two Dimensional Airfoil Comparison}

Table 7-3 shows the seven airfoils analyzed with the mesh and solver settings discussed previously. With the NACA 0009 already complete the other six were simulated at angles of attack from zero to eight degrees and the same set of four Reynolds numbers.

Table 7-3: Selected Airfoil Profiles and Details

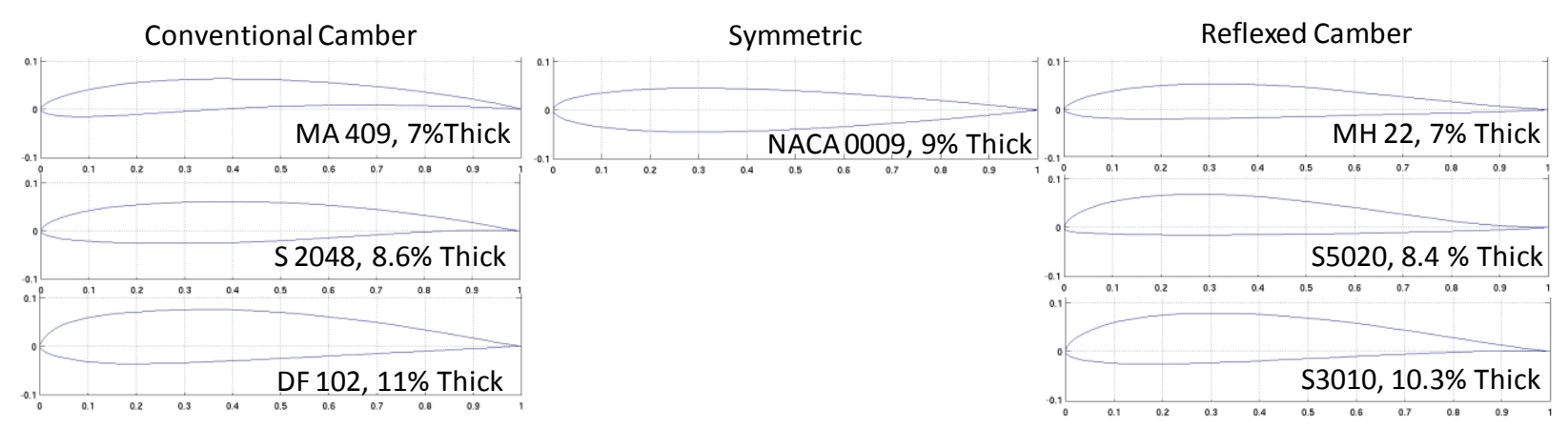

Figure 7-20 through Figure 7-26 present the drag polars for each airfoil. It is interesting to note that the quality of prediction improves as the airfoil thickness to chord ratio increases. This is likely due to the larger separation bubbles created by the sharper leading edge radius on thinner airfoils. The same trend of reasonably predicting lift and over predicting drag within the useful angle of attack range held for all but the MA 409 which had the smallest leading edge radius of all. Experimental data was unavailable for either the S5020 or S3010 airfoils. Developing this comparison with experiment was necessary to provide confidence in the ability to predict the behavior of three dimensional wings using these or other airfoils. The cost to experimentally test all airfoils, wing, and wing-body configurations would be prohibitive; therefore the current study was conducted to provide a basis for a computational optimization analysis. Future experimental work will be used to verify and improve the computational predictions. 


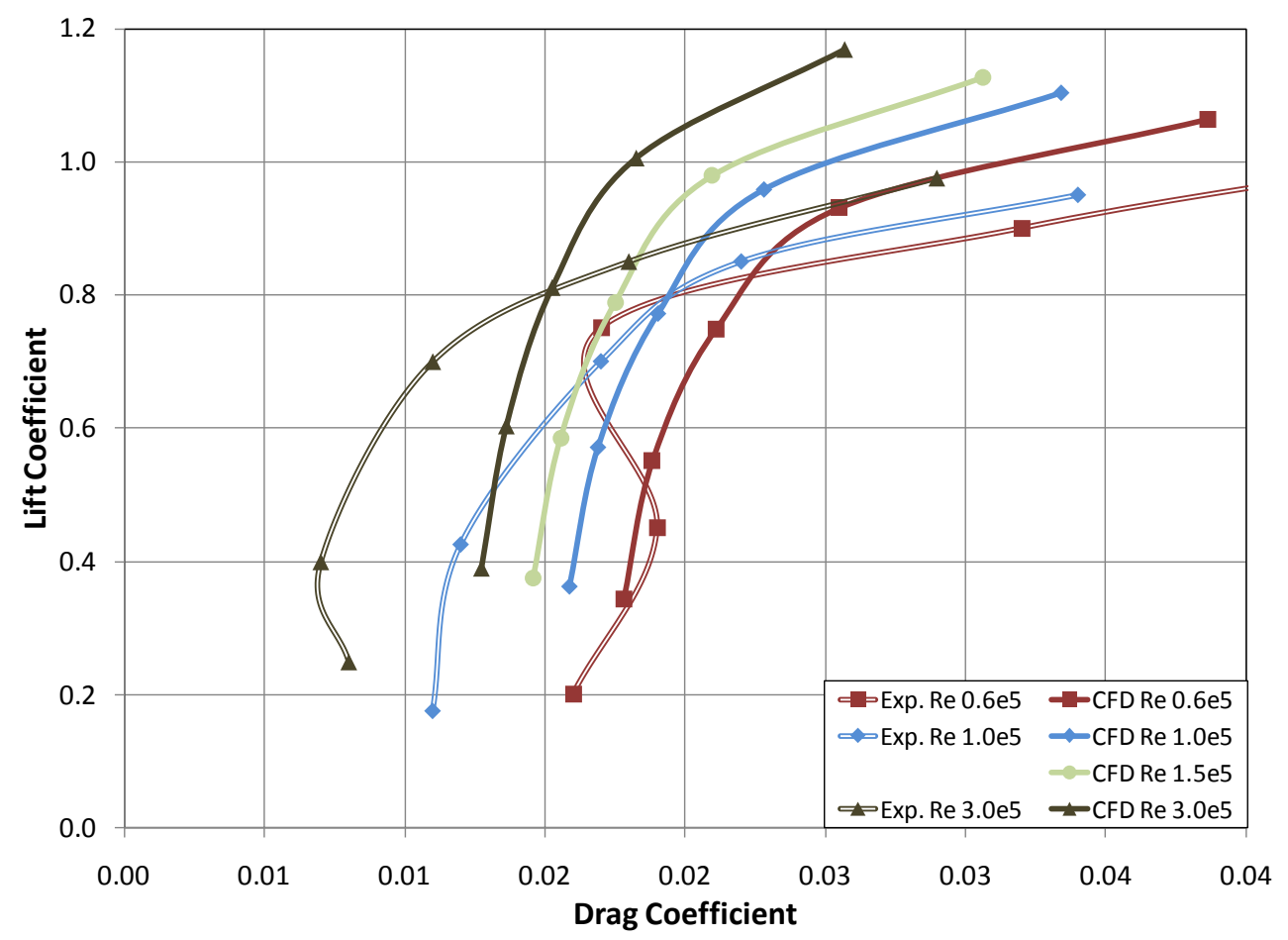

Figure 7-20: MA 409 Drag Polar with Experimental and CFD Data

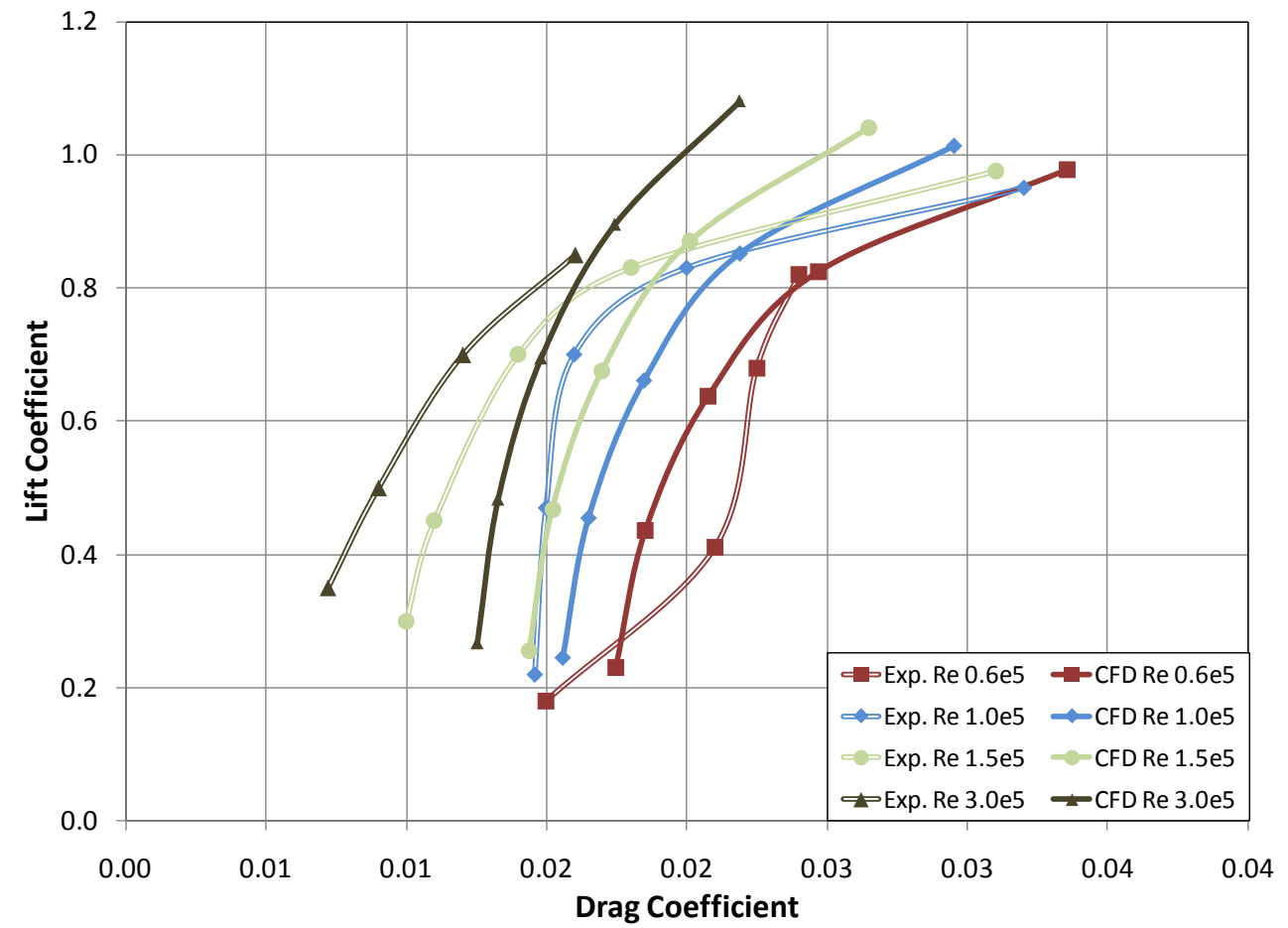

Figure 7-21: S 2048Drag Polar with Experimental and CFD Data 


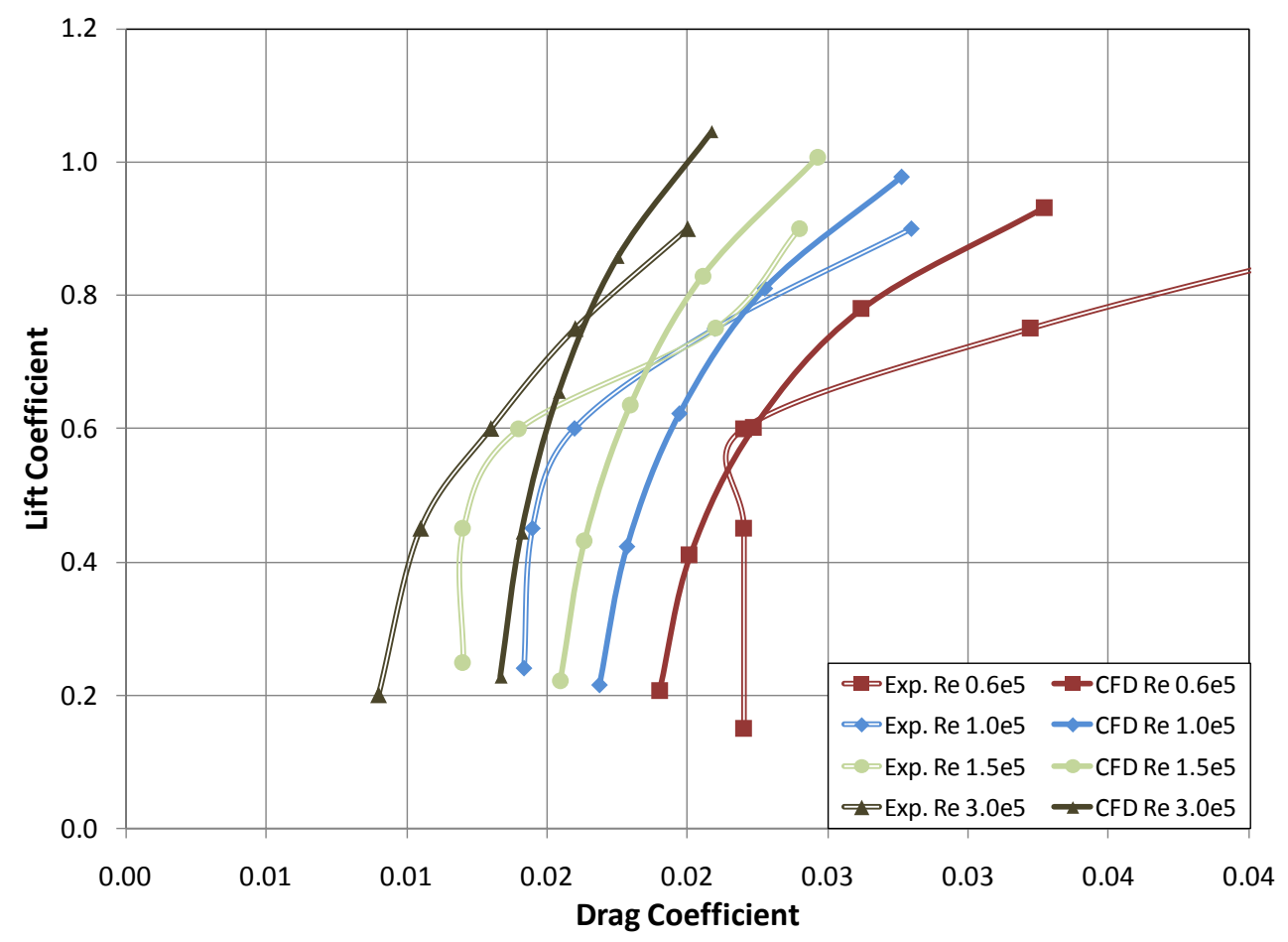

Figure 7-22: DF 102 Drag Polar with Experimental and CFD Data

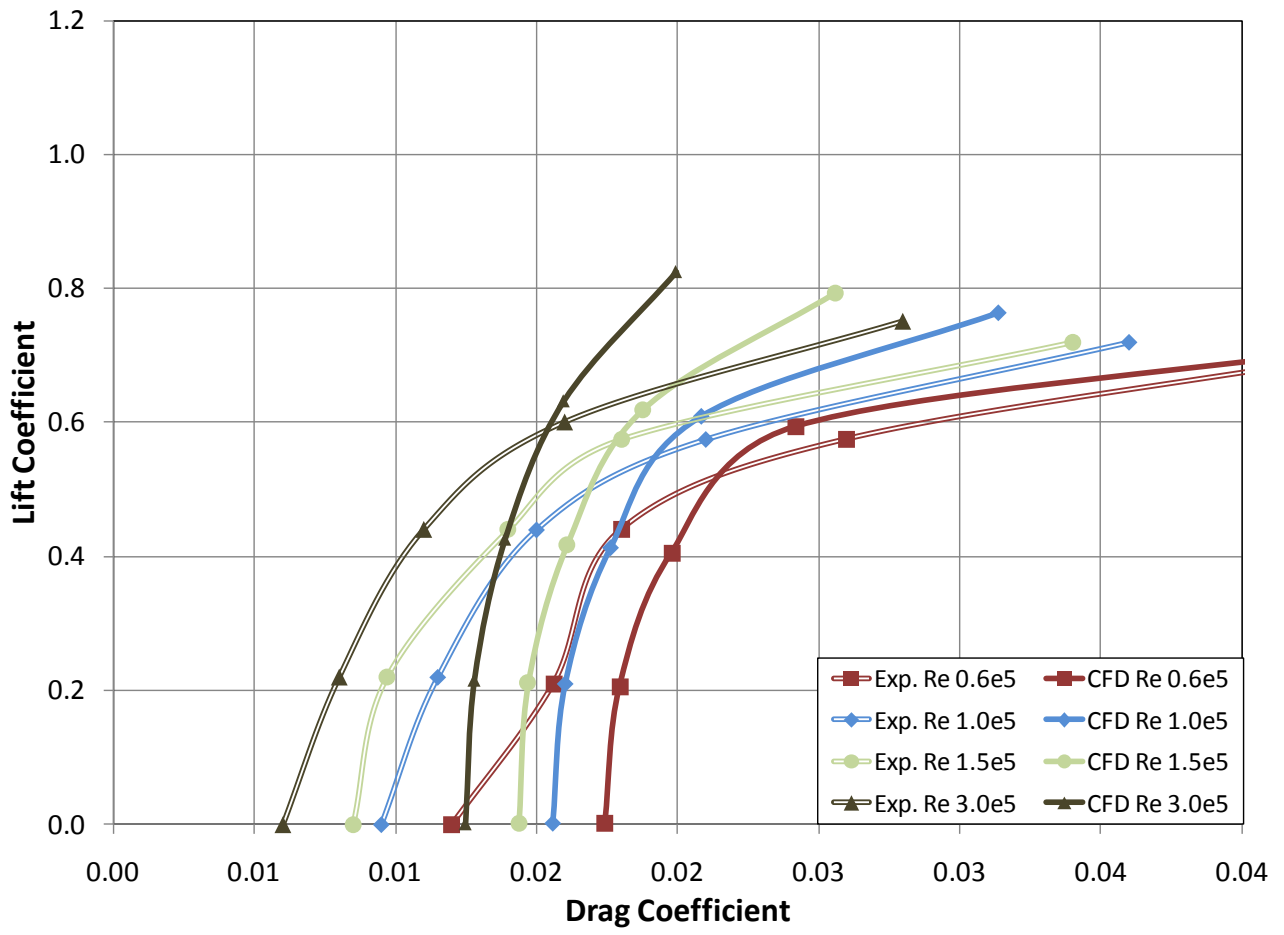

Figure 7-23: NACA 0009 Drag Polar with Experimental and CFD Data 


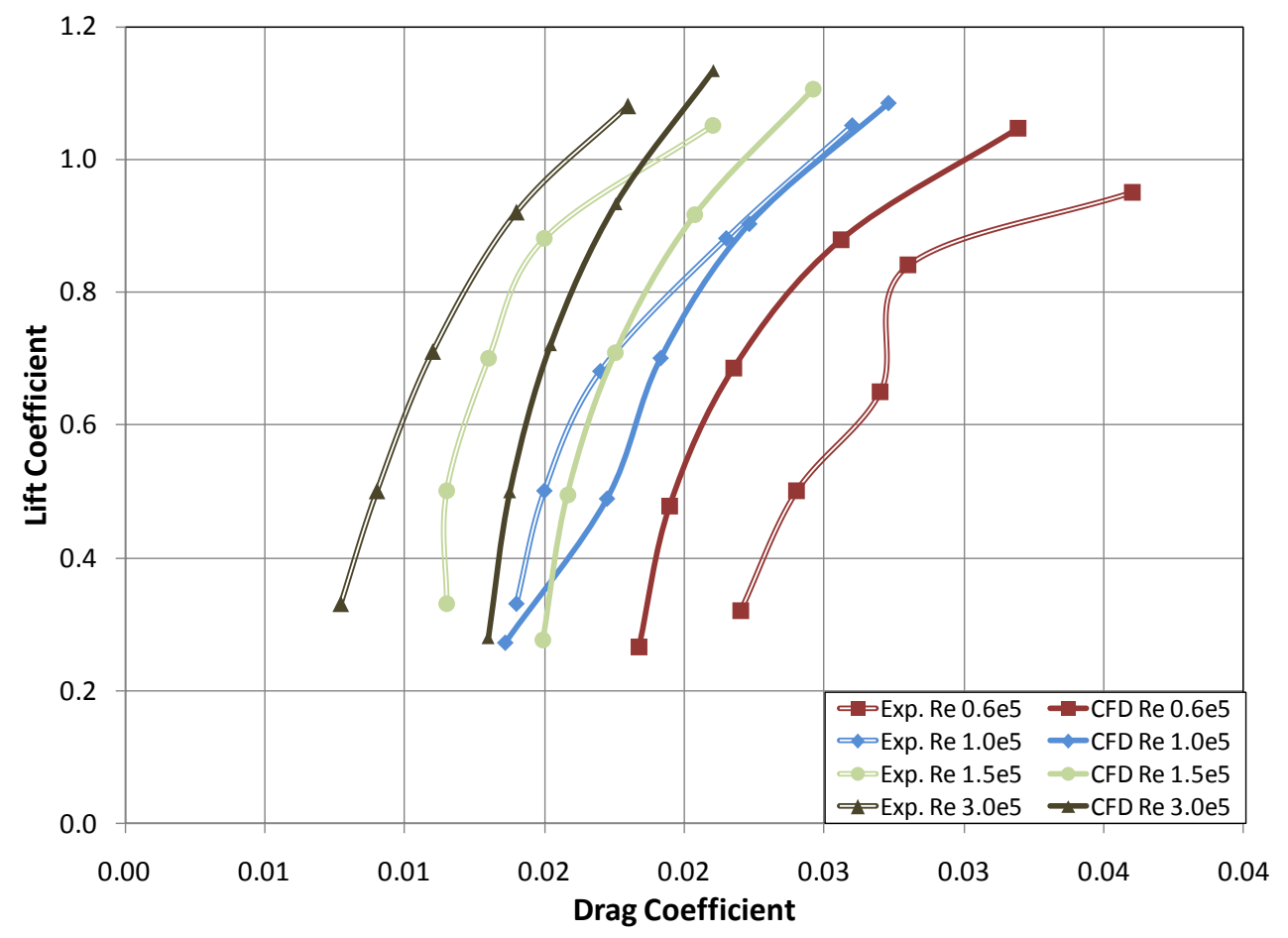

Figure 7-24: S 3010 Drag Polar with Experimental and CFD Data

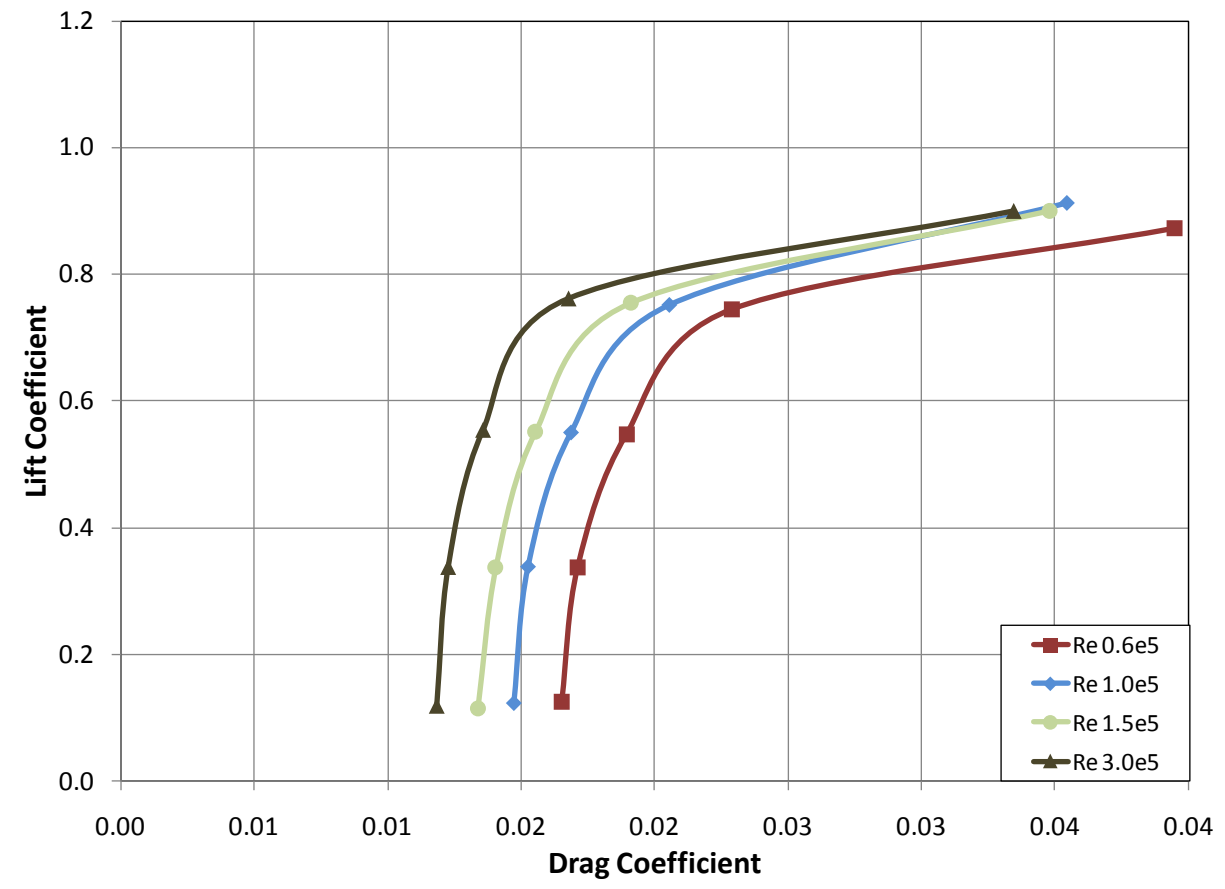

Figure 7-25: MH 22 Drag Polar 


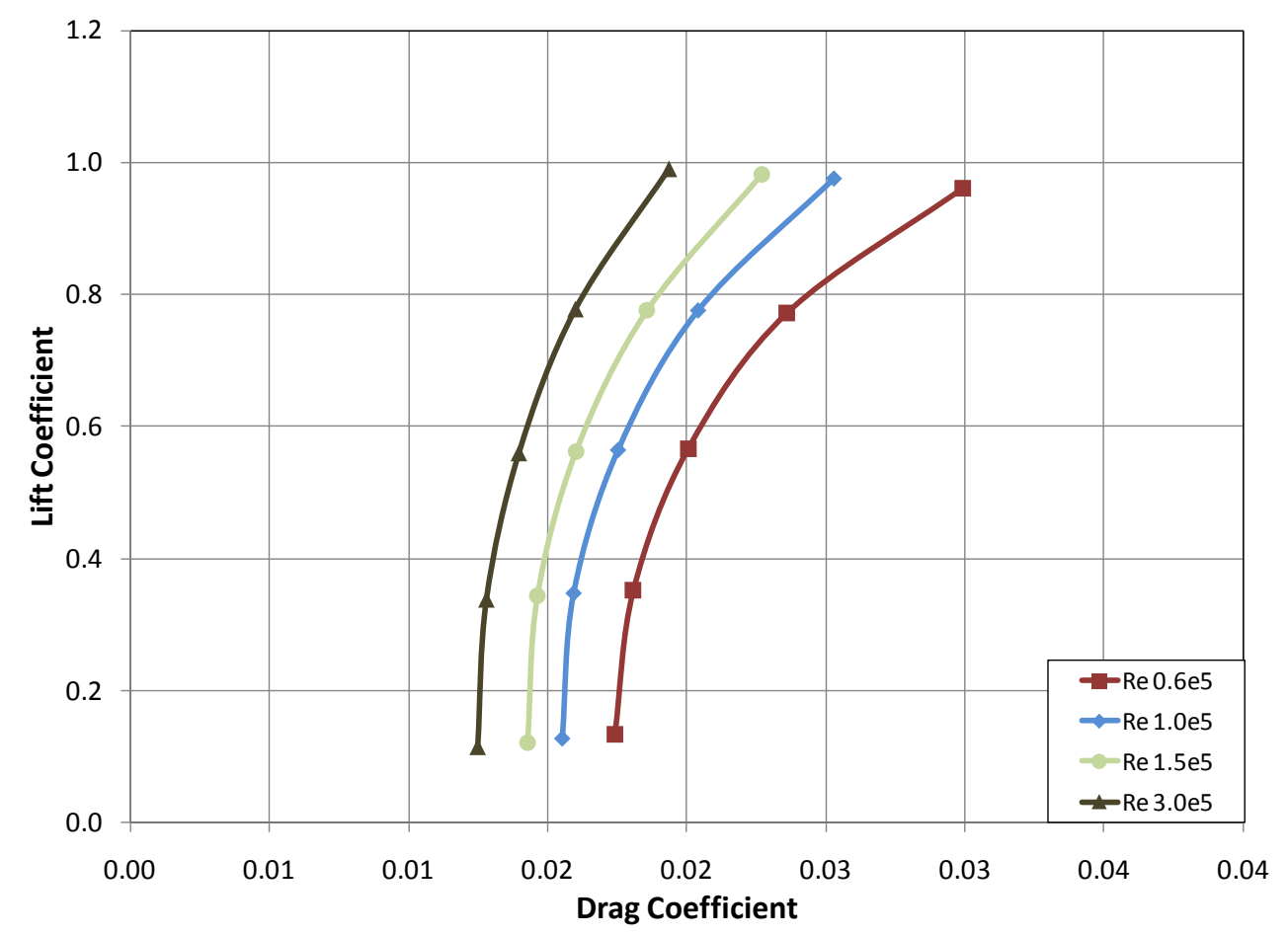

Figure 7-26: S 5020 Drag Polar

While this analysis does show some capability to predict the performance of various airfoils at low Reynolds numbers it did not seem likely that an accurate representation of their effects in three dimensions would be correctly captured. Parametric numerical studies of other airfoils would be interesting future work if coupled with a wind tunnel verification study.

\subsection{Preliminary Three Dimensional Main Wing Analysis}

Early three dimensional wing work was done prior to the two dimensional analysis discussed in Section 7.2. A DF102 airfoil was used prior to obtaining a full appreciation for simulation of flow in this regime. While the general trends of that early work, reported here, are consistent with other projects such as the work done by Mueller, et al. (2006) the specific values and exact locations of optimums are questionable ${ }^{26}$. Future work will complete a more detailed set of these analyses using mesh and solver settings expanded from Section 7.2 but the previously collected trends provided information that is worth covering as a preliminary step in this direction. The more detailed analysis will use chordwise meshes and solver models based on those developed in the $2 \mathrm{D}$ work discussed previously in this document.

${ }^{26}$ (Mueller, Torres, \& Srull, Elements of Aerodynamics, Propulsion, and Design, 2006) 
Figure 7-27 shows the primarily structured hexahedral prismatic boundary layer with triangular prism tips used for the 3D study. A detailed listing of the mesh generation parameters used is presented in Appendix B. Grid independence was reached, as illustrated by the lift and drag convergence shown in Figure 7-28, at $1.5 \times 10^{6}$ cells. Geometric and flow parameters used are presented in Table 7-4. The $33 \mathrm{~m} / \mathrm{s}$ flow velocity was selected in an attempt to split the difference between the high-speed extended range mission and the low-speed long endurance mission so that two sets of planform studies would not be required. A lift coefficient of 2.09 based on the fuselage frontal area was required to lift the $180 \mathrm{~g}$ mass MAV at $33 \mathrm{~m} / \mathrm{s}$ and all wings were incremented in angle of attack until this value was reached. Stowed geometry body diameter was used as the reference area for lift and drag coefficient calculations due to the huge variation in planform area between the high-speed and long-endurance (nearly 500\% larger) designs. A fixed reference was required to easily compare efficiencies of the competing designs. Performance data was then collected with each planform producing sufficient lift to complete the mission.

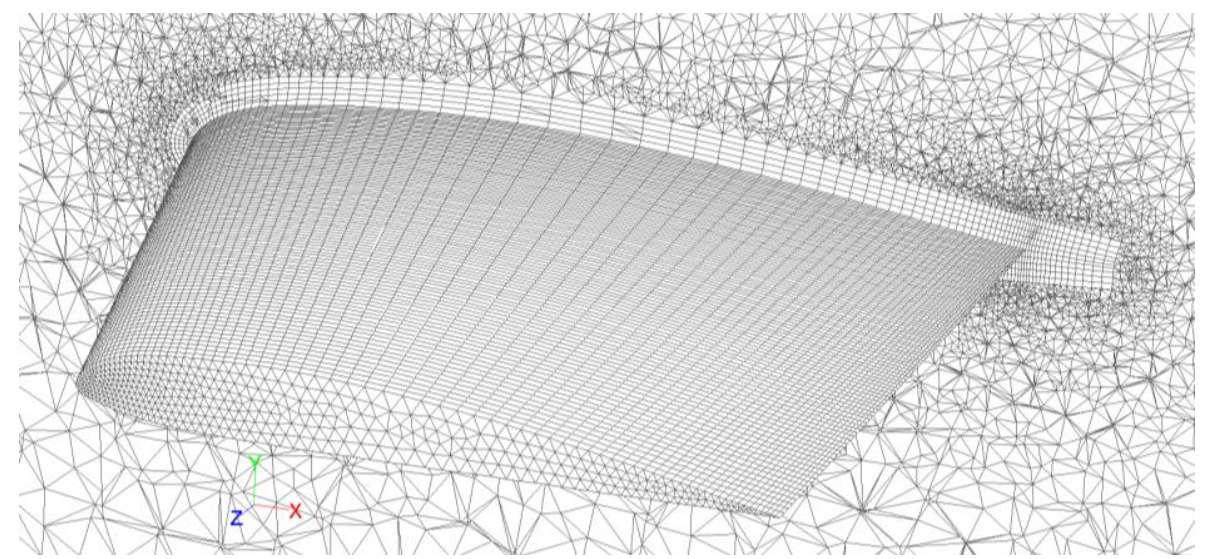

Figure 7-27: Surface and Centerline Volume Mesh for Initial 3D Wing Modeling

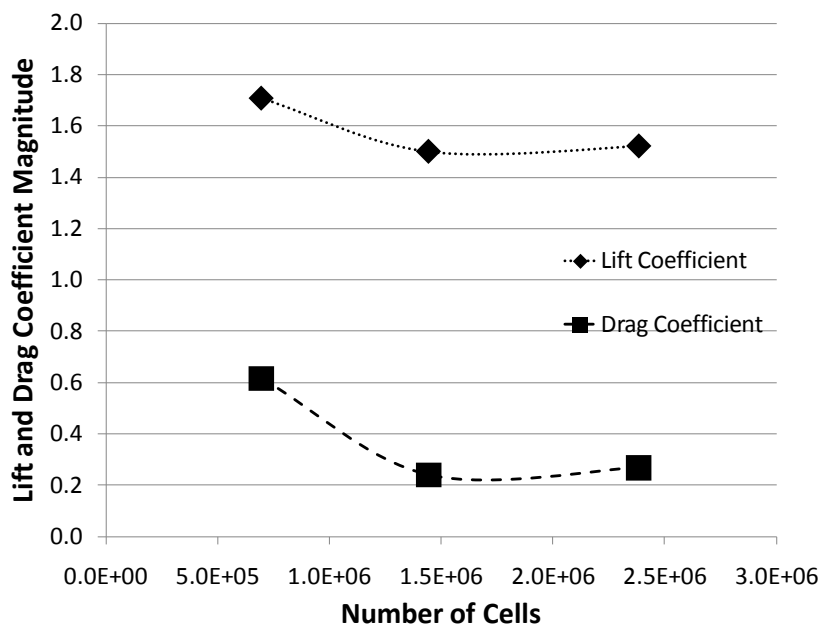

Figure 7-28: Mesh Independence Plot for Initial 3D Wing Modeling 
Table 7-4: Flow Parameters, Lift Coefficient, and Geometric Parameters Varied for Three Dimensional Planform Study

\begin{tabular}{|c|c|c|c|c|c|c|}
\hline Velocity & 33 & $\mathrm{~m} / \mathrm{s}$ & \multicolumn{3}{|c|}{$\begin{array}{l}\text { Lift Coefficient, based on } \\
\text { fuselage frontal area }\end{array}$} & 2.09 \\
\hline \multirow{2}{*}{ Airfoil } & Wing Loading & \multirow{2}{*}{$\begin{array}{c}\text { Aspect } \\
\text { Ratio }\end{array}$} & $\begin{array}{c}\text { Sweep } \\
\text { Angle }\end{array}$ & \multirow{2}{*}{$\begin{array}{l}\text { Taper } \\
\text { Ratio }\end{array}$} & Wing Area & $\mathbf{R e}_{\text {MAC }}$ \\
\hline & $\mathrm{N} / \mathrm{m}^{2}$ & & deg & & $\mathrm{cm}^{2}$ & \\
\hline \multirow{9}{*}{ DF 102} & 200 & 3 & 30 & 0.5 & 88.29 & 127,096 \\
\hline & 300 & 3 & 30 & 0.5 & 58.86 & 103,773 \\
\hline & 300 & 3 & 30 & 0.75 & 58.86 & 100,748 \\
\hline & 300 & 3 & 30 & 1 & 58.86 & 100,067 \\
\hline & 300 & 3 & 15 & 0.5 & 58.86 & 103,773 \\
\hline & 300 & 3 & 0 & 0.5 & 58.86 & 103,773 \\
\hline & 300 & 2 & 30 & 0.5 & 58.86 & 127,096 \\
\hline & 300 & 4 & 30 & 0.5 & 58.86 & 89,870 \\
\hline & 400 & 3 & 30 & 0.5 & 44.15 & 89,870 \\
\hline
\end{tabular}

As expected, Figure 7-29 shows that the classical three dimensional flow structure about a lifting wing has been captured by this simulation. The reference wing that all parameters was varied from used a DF 102 airfoil, $300 \mathrm{~N} / \mathrm{m}^{2}$ wing loading, aspect ratio of $3,30^{\circ}$ sweep angle, and a taper ratio of 0.5 .

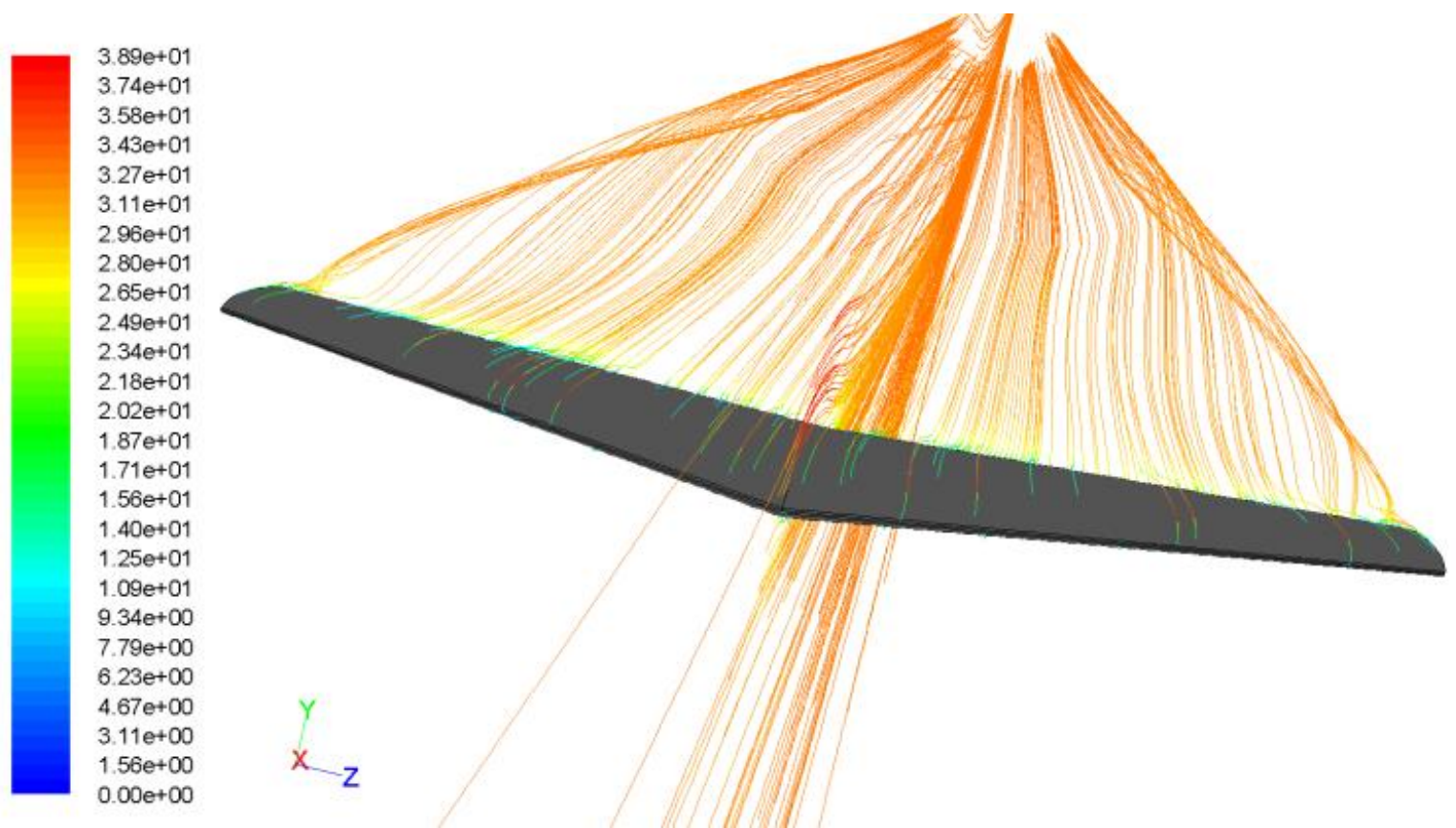

Figure 7-29: Pathlines Colored by Velocity $(\mathrm{m} / \mathrm{s})$ Around Reference Wing (Angle of Attack $=4^{\circ}$ ) 
The most interesting result of this preliminary 3D wing analysis was the inverse relationship between aspect ratio and the lift-to-drag ratio of these wings. This is entirely counter to classical aerodynamic theory which states that as aspect ratio increases efficiency also increases due to a reduction in induced drag. Figure 7-30 clearly shows nearly a $25 \%$ drop in performance as the aspect ratio was doubled from 2 to 4 . A drop of 40,000 in the Reynolds number accompanied the increased aspect ratio. This indicates that an optimum exists, which is significantly driven by the Reynolds number at the mean aerodynamic chord for aircraft at this small scale. Apparently for MAVs in certain flight regimes, with a fixed wing area, the increased efficiency of the airfoil section caused by increased mean aerodynamic chord Reynolds number can be significantly greater than the induced drag penalty incurred by reducing aspect ratio. In the more detailed study currently underway, aspect ratios of $0.5,1.0$, and 1.5 will also be examined. At some point the induced drag losses must begin to overwhelm the increased Reynolds number effects. Finding this point will be critical to optimizing the final design of these MAVs.

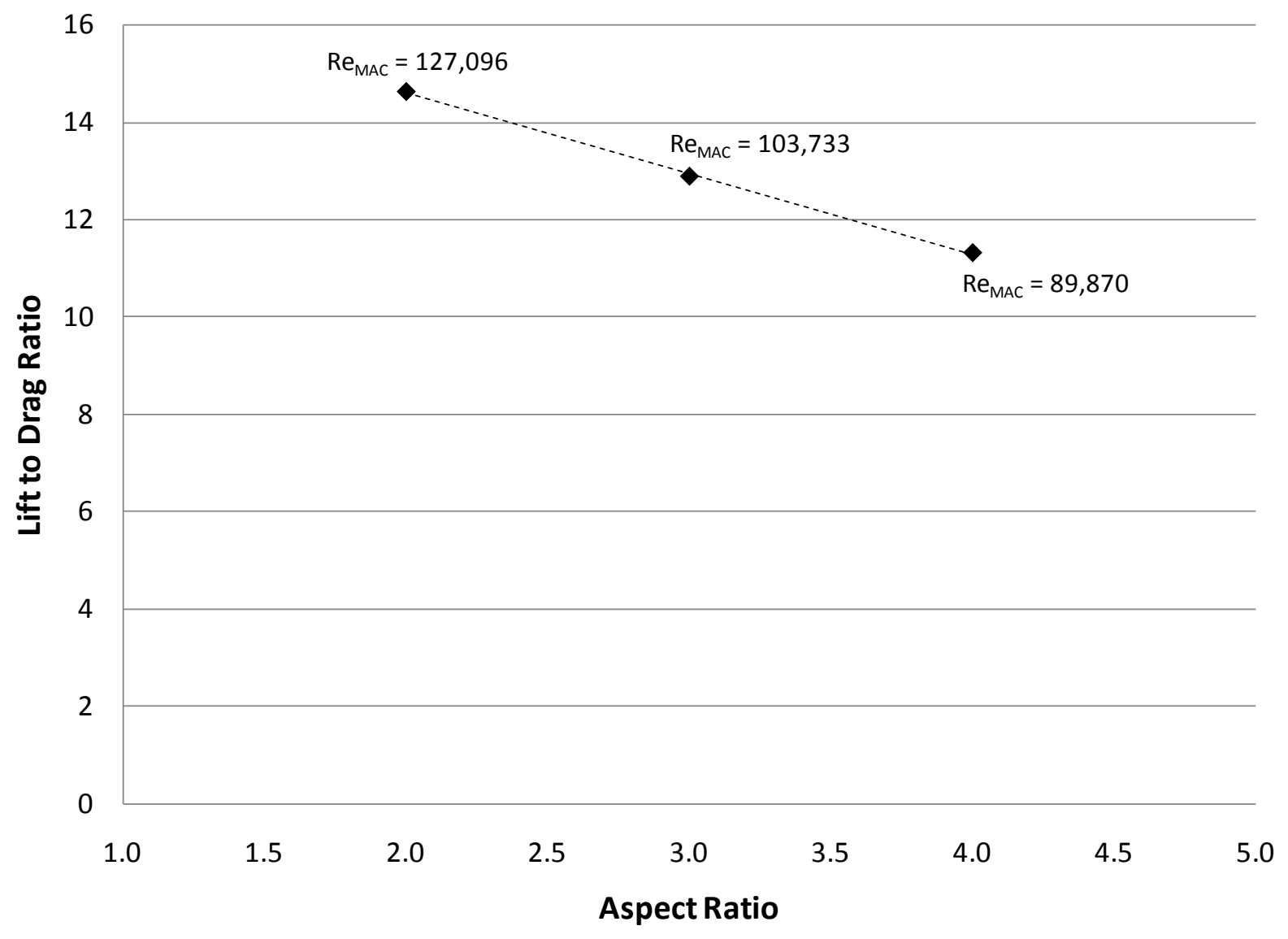

Figure 7-30: Inverse Correlation Between Aspect Ratio and Lift-to-drag Ratio and Direct Correlation Between Lift-to-drag Ratio and Mean Aerodynamic Chord Reynolds Number 
Increasing wing loading at this velocity had a positive effect on efficiency, as demonstrated in Figure 7-31. The reference $300 \mathrm{~N} / \mathrm{m}^{2}$ wing loading was the optimum calculated by the classical aerodynamics code discussed in Chapter 6 . It is apparent that this was a significant under estimate as performance improves by $11 \%$ with a $33 \%$ increase in wing loading. Finding the peak of the wing loading tradeoff will permit designs to be sized at or above this point so as to minimize wing loading and simplify the task of collapsing the wings into the stowed geometry. These trends remain qualitatively similar between the MAV scale and in classical theory, though it is possible that the curves are shifted somewhat. No judgment can be made at this time due to the previously discussed limitations with this study.

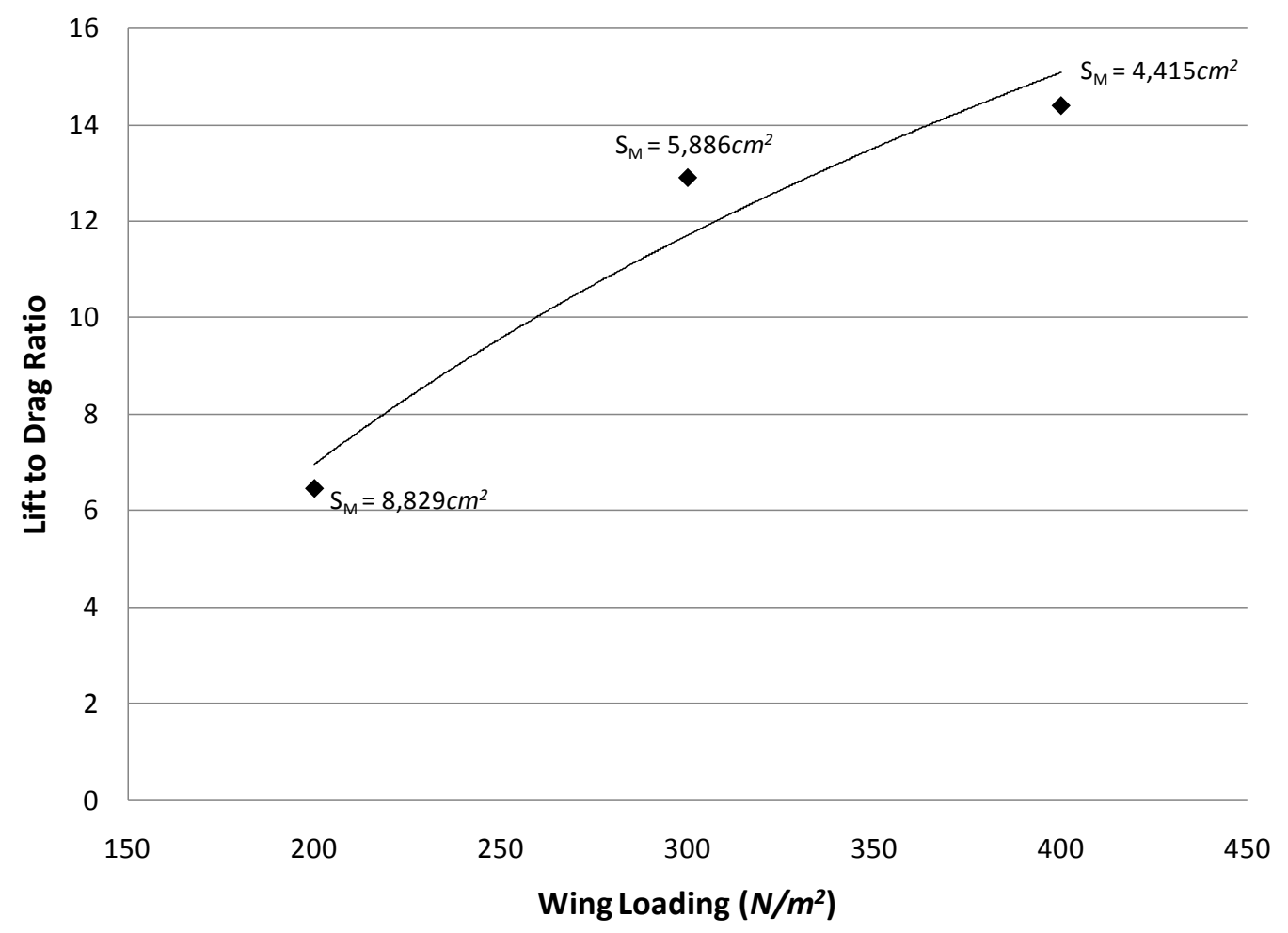

Figure 7-31: Lift-to-drag Ratio Improving Towards Optimum As Wing Loading Increases in Initial Study

Fortunately, from a parameter space perspective, varying the leading edge sweep angle had little effect on the performance of the wing as shown in Figure 7-32. Therefore leading edge sweep may be used to enhance stability by both shifting the aerodynamic center and through the dihedral effect of rear sweep angles. This agrees with classical aircraft design theory though the intensity of the effect of sweep angle on stability may be different at these scales. 


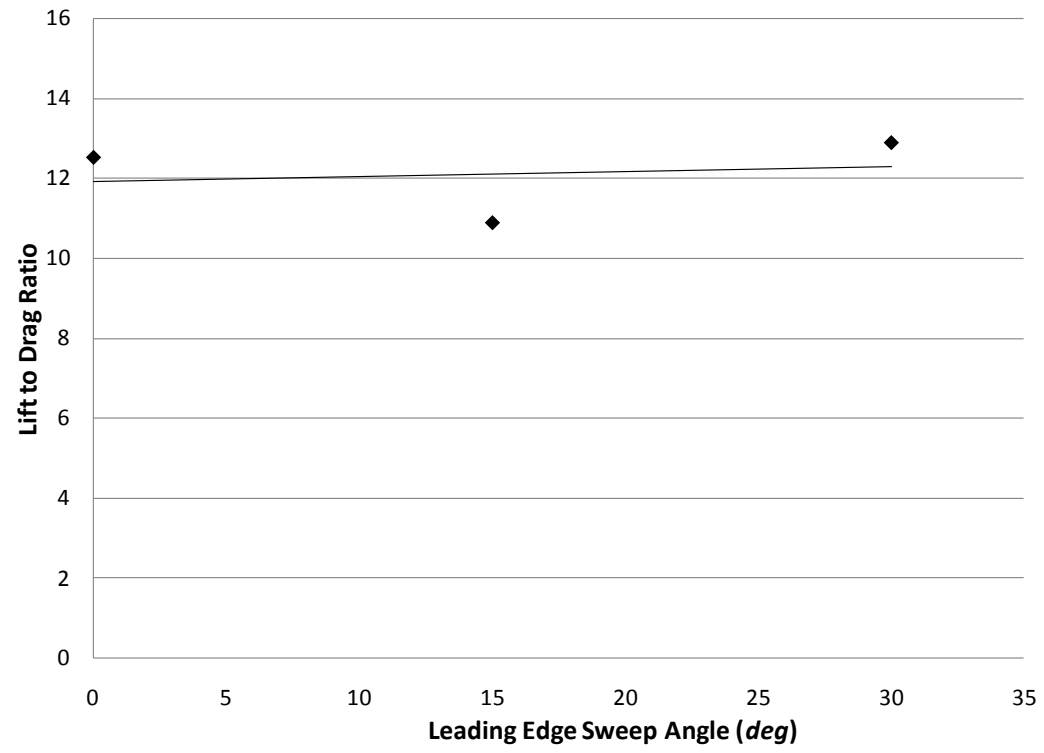

Figure 7-32: Lift-to-drag Ratio Insensitive to Leading Edge Sweep Angle

Classical aerodynamic theory agreed well with the trends observed when varying the taper ratio. Reducing the taper ratio from 1.0 to 0.5 enhanced the lift-to-drag ratio consistently as shown in Figure 7-33. It appears that the classical ideal elliptical lift distribution may well still hold at these scales.

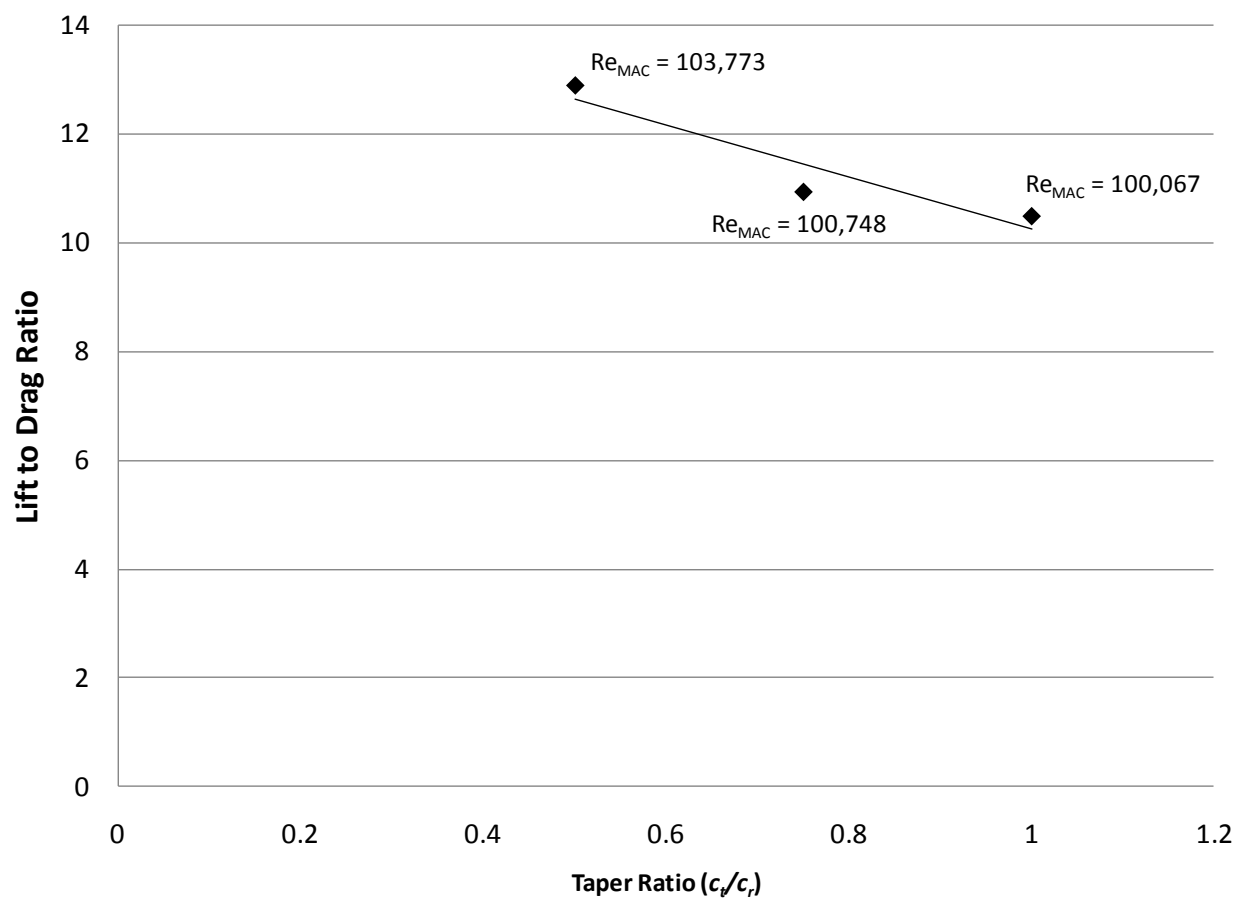

Figure 7-33: Inverse Correlation Between Taper Ratio and Lift-to-drag Ratio 


\section{Chapter 8 Recommended Preliminary Designs}

Based on this work it is possible to recommend two designs for prototyping, wind tunnel validation, and eventual flight tests. This would include the high speed cruise and long endurance configurations and both leaf spring or membrane wing structures will be experimented with. While the work presented here provides excellent starting points, true design optimization will require significant physical experimentation. Determining the complex interactions between large fuselages and low aspect ratio wings at low Reynolds numbers is only one of the problems not yet vetted. With this ground work it is now possible to implement the optimization process outlined in Figure 8-1.

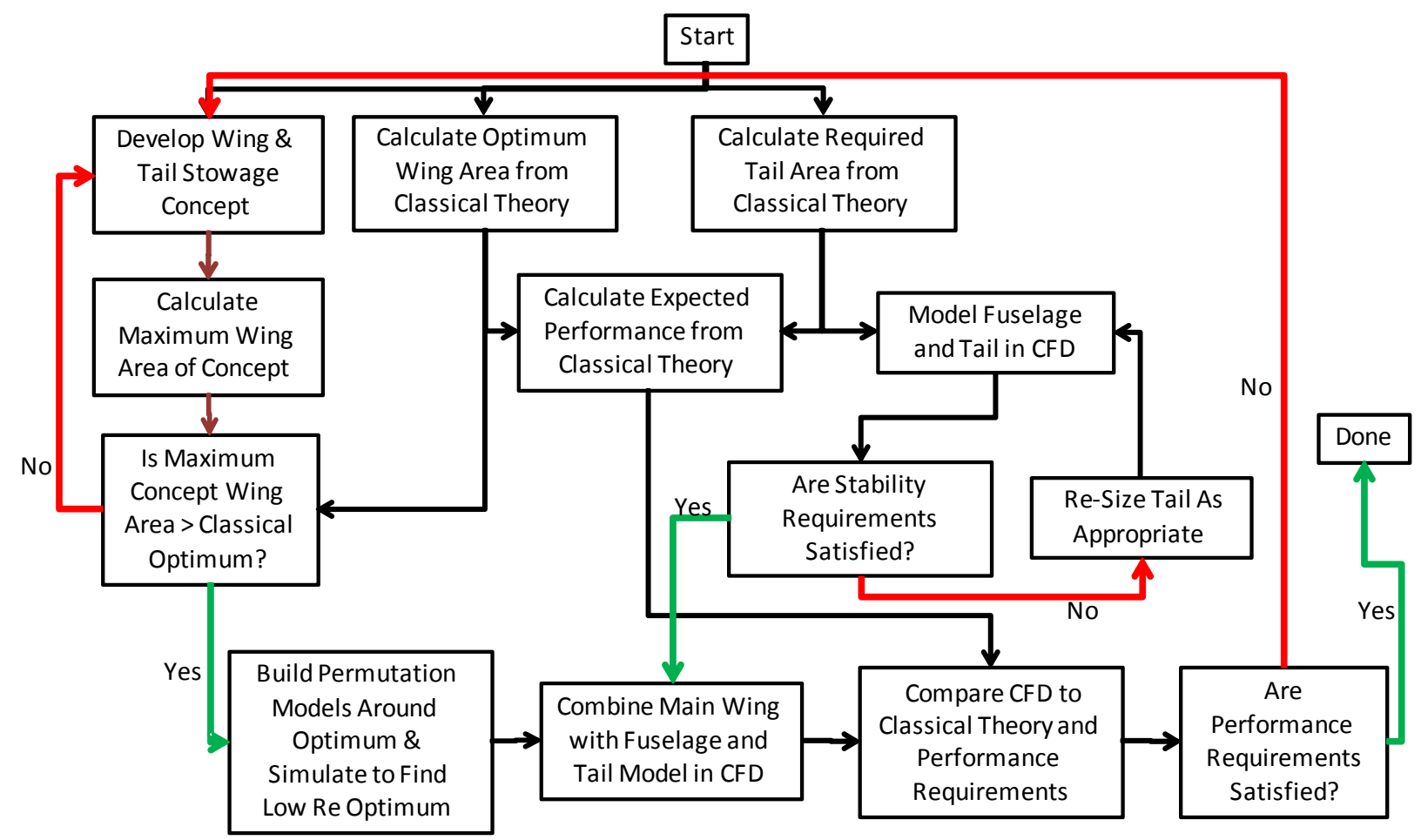

Figure 8-1: Flow Chart of Proposed Optimization Process

\subsection{High Speed Cruise Configuration}

From a mechanical perspective the high speed cruise mission would be the simplest to implement. Wing areas less than $22 \%$ of those required for the long endurance mission will be relatively easy to store. Figure 8-2 provides a simplified sketch of the design with an Ogive tail and appropriate wing areas in a cruciform layout. Figure 8-3 provides an outline of the high speed cruise mission. 


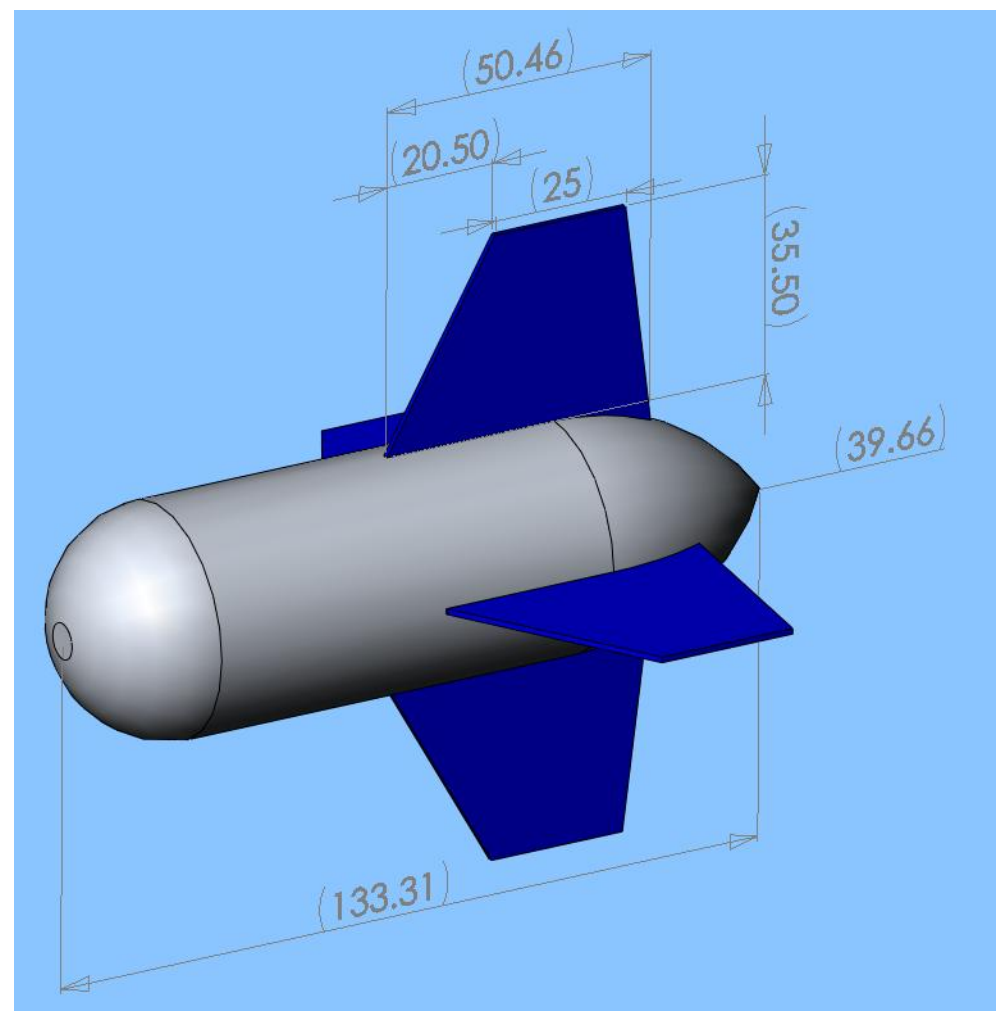

Figure 8-2: High Speed To Target Configuration, (dimensions in $\mathbf{m m}$ )

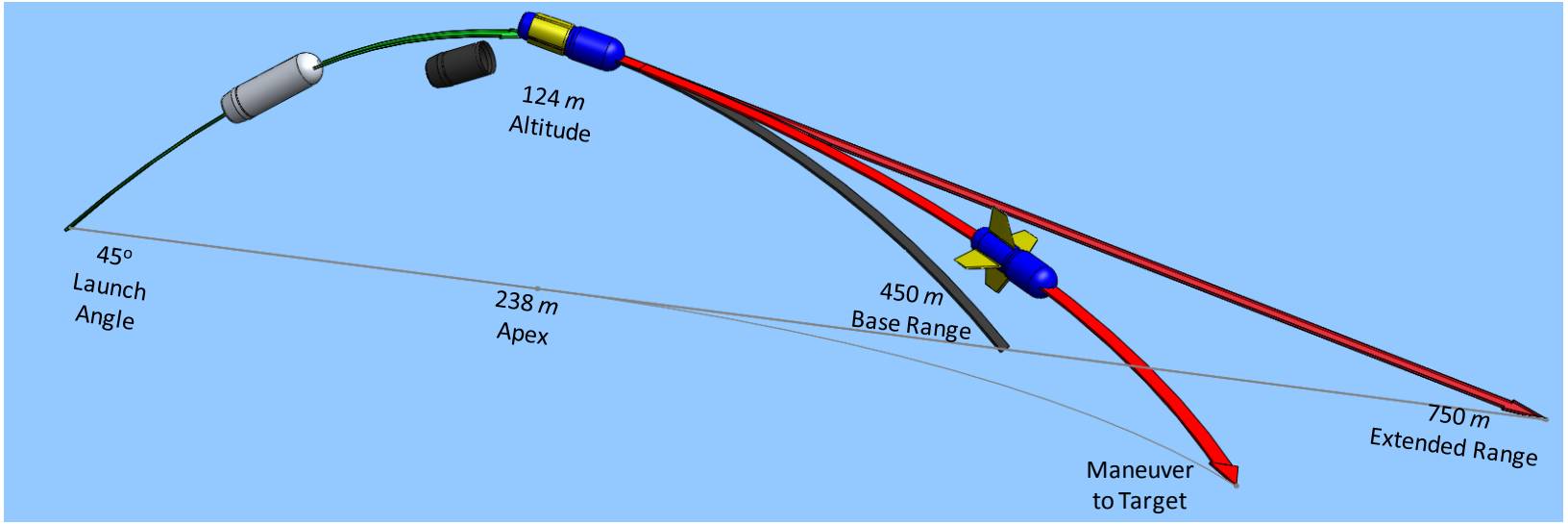

Figure 8-3: High Speed Cruise Mission Profile

At this point preliminary structural design and prototyping are ready to begin for both the membrane and leaf spring structures. Conceptual packaging designs for both are shown in Figure 8-4 and Figure 8-5. These initial models, with hemispherical tails, retain nearly $130,000 \mathrm{~mm}^{3}$ of usable fuselage volume out of the $161,000 \mathrm{~mm}^{3}$ provided by the stowed geometry, or $82 \%$. More detailed structural design work will be required to implement the designs shown. Both were created to confirm that sufficient volume was available; actuators, catches, and connectors will be designed in the next stage of the project. 

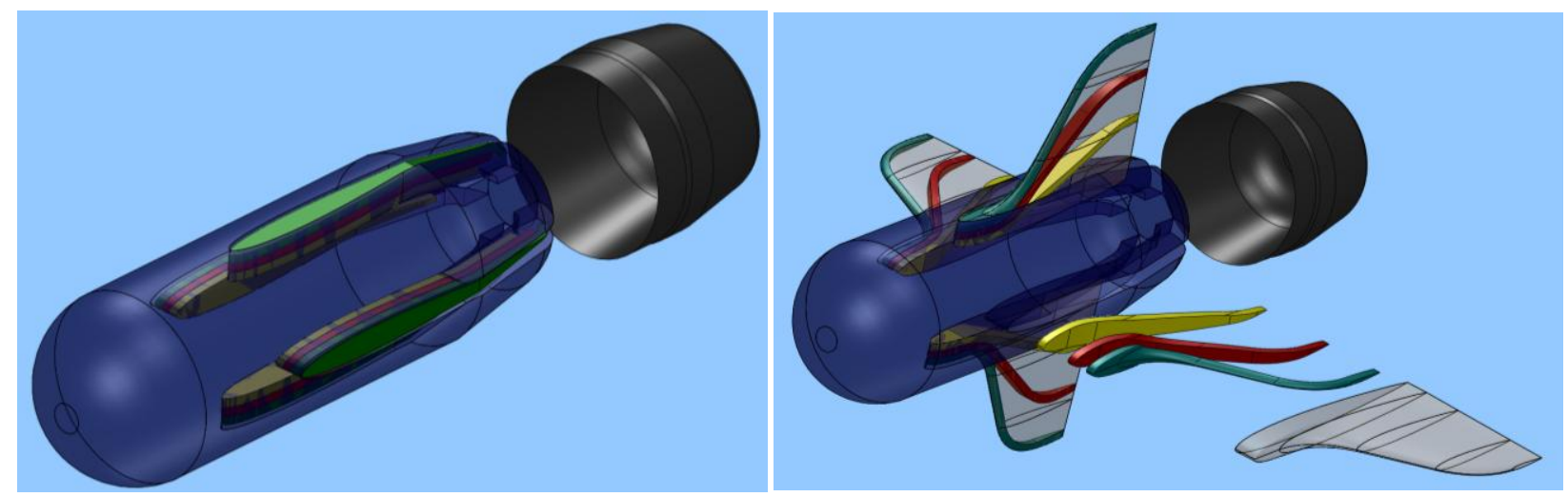

Figure 8-4: High Speed Leaf Spring Structure Concept, Partially Deployed (Left) and Fully Deployed (Right)

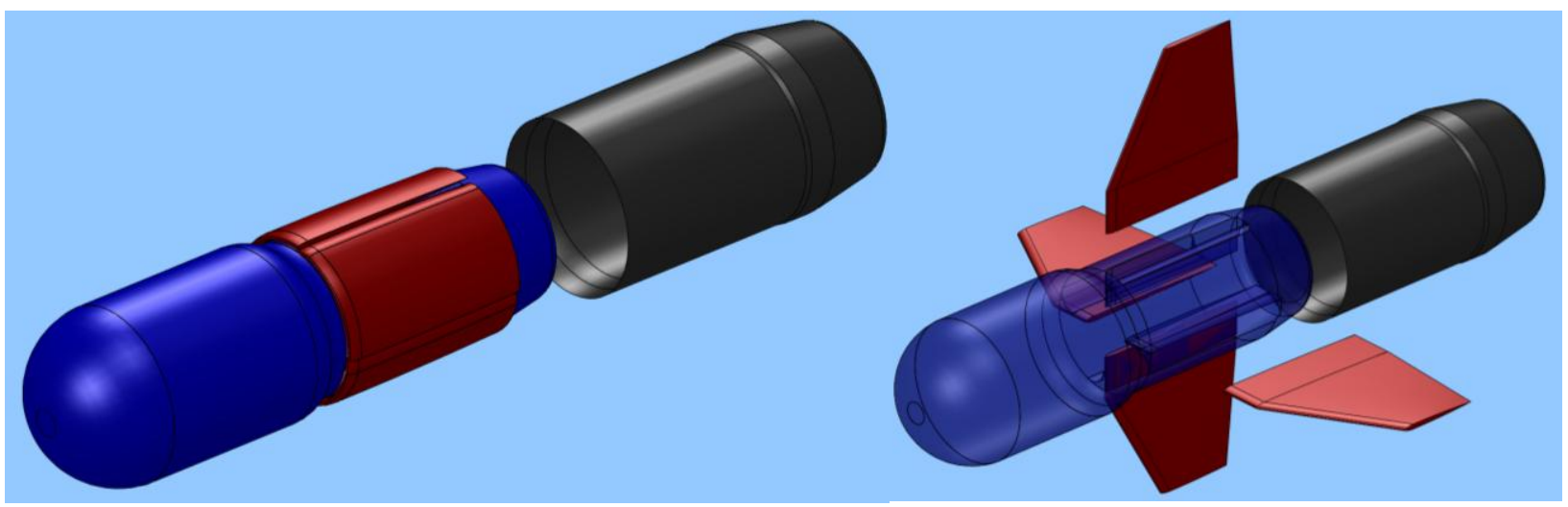

Figure 8-5: High Speed Membrane Wing Structure Concept, Partially Deployed (Left) and Fully Deployed (Right)

As discussed in Chapter 6, the high speed cruise wing area has been fixed at 2,520 $\mathrm{mm}^{2}$ through a classical aerodynamic optimization analysis. The initial location of the center of gravity will be $50 \%$ down the fuselage and coincident with the $20 \%$ mean aerodynamic chord location. This should provide a stable platform. However, complex interactions between the nonlinear positive pitching moment of an axisymmetric body and the behavior of low aspect ratio wings at these Reynolds numbers is poorly understood and may cause problems. Significant experimental work will be required.

Prototypes of both the leaf spring and membrane structures should now be created since conceptual modeling and analysis have reached their limits. Wind tunnel experimental results will be required to improve efficiency and stability.

The expected performance for the high-speed design is presented in Table 8-1. Performance was calculated for both the high-drag baseline fuselage $\left(C_{D}=0.155\right)$ and an idealized, streamlined version $\left(C_{D}\right.$ $=0.100)$. It is interesting to note that the range only increased by $88 \mathrm{~m}(13 \%)$ when the fuselage drag coefficient was dropped by $35 \%$. 
Table 8-1: Sizes and Expected Performance of High Speed MAV

\begin{tabular}{|c|c|c|c|c|c|c|c|c|c|c|c|}
\hline \multicolumn{3}{|c|}{ Launch Information } & \multicolumn{3}{|c|}{ Wing Planform Information } & \multicolumn{3}{|c|}{ Performance, $C_{\text {do Fuse }}=0.155$} & \multicolumn{3}{|c|}{ Performance, $C_{\text {do Fuse }}=0.100$} \\
\hline Launch Angle & 45 & deg & Wing Loading & 700 & $N / m^{2}$ & Main Wing $\alpha_{\mathrm{TRIM}}$ & 8.8 & $\operatorname{deg}$ & Main Wing $\alpha_{\text {TRIM }}$ & 8.8 & $\operatorname{deg}$ \\
\hline Apex Velocity & 45 & $\mathrm{~m} / \mathrm{s}$ & Wing Area & 2,523 & $\mathrm{~mm}^{2}$ & Glideslope & 16.3 & deg & Glideslope & 13.6 & deg \\
\hline Apex Altitude & 124 & $m$ & LE Location & 68.4 & $m m$ & Range & 663 & $m$ & Range & 751 & $m$ \\
\hline Apex Range & 238 & $m$ & Root Chord & 47.4 & $m m$ & Gliding Time & 9.84 & $s$ & Gliding Time & 11.7 & $\left.\right|^{S}$ \\
\hline Ballistic Time & 10 & $s$ & Tip Chord & 23.7 & $m m$ & $\mathrm{RE}_{\mathrm{MAC}}$ & 113 & 460 & $\mathrm{RE}_{\mathrm{MAC}}$ & 113, & 460 \\
\hline$C_{D \text { o Fuselage }}$ & & 155 & Span & 71 & $\mathrm{~mm}$ & $L / D$ & & 42 & $L / D$ & 4.1 & \\
\hline
\end{tabular}

\subsection{Long Endurance Configuration}

Preliminary structural designs of the long endurance configuration have been developed as well. Sections 3.1.1.3 and 3.1.3.3 showed that sufficient wing area for the long endurance mission can be compacted into the stowed geometry. However, these models are not as certain or detailed as those of the high speed configuration due to the increased wing area exacerbating any unforeseen packing problems. Packing issues should be explored first with the high speed design before continuing work on the long endurance version. Figure 8-6 provides a schematic showing dimensions of a characteristic trapezoidal planform for this variant. Several features should be noted:

- High-wing improves lateral stability characteristics

- Near total masking of fuselage by the main wing should reduce non-linear axisymmetric body pitching moment behavior but will need to be tested

- Clean transition between wing and upper fuselage should smooth air flow over the wing upper surface and increase efficiency as found by Kellog et al. (2001) in the design of the NRL MITE 2. The wing should be mounted so that the upper surface of the airfoil extends above the upper surface of the fuselage. 


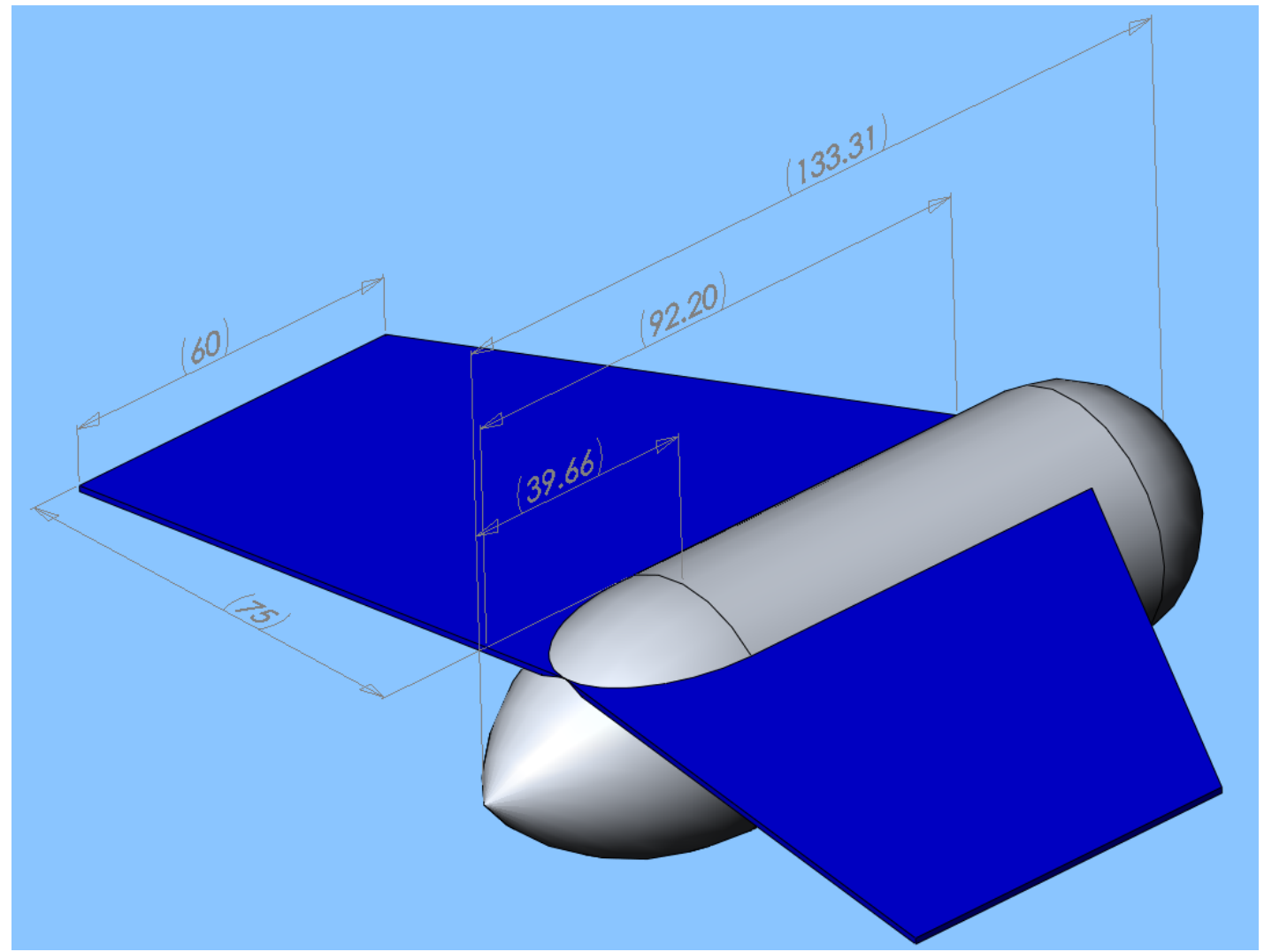

Figure 8-6: Long Endurance Concept, Dimensions in mm

Figure 8-7 and Figure 8-8 provide some detail of both the leaf spring and wrapped membrane structures for the larger wing area of this configuration. These designs are less certain as unforeseen manufacturing difficulties encountered in the prototyping of the high-speed variants will be more pronounced when applied to the larger wing. A final leaf spring system would require a thinner airfoil than the NACA 0009 used in the model presented.

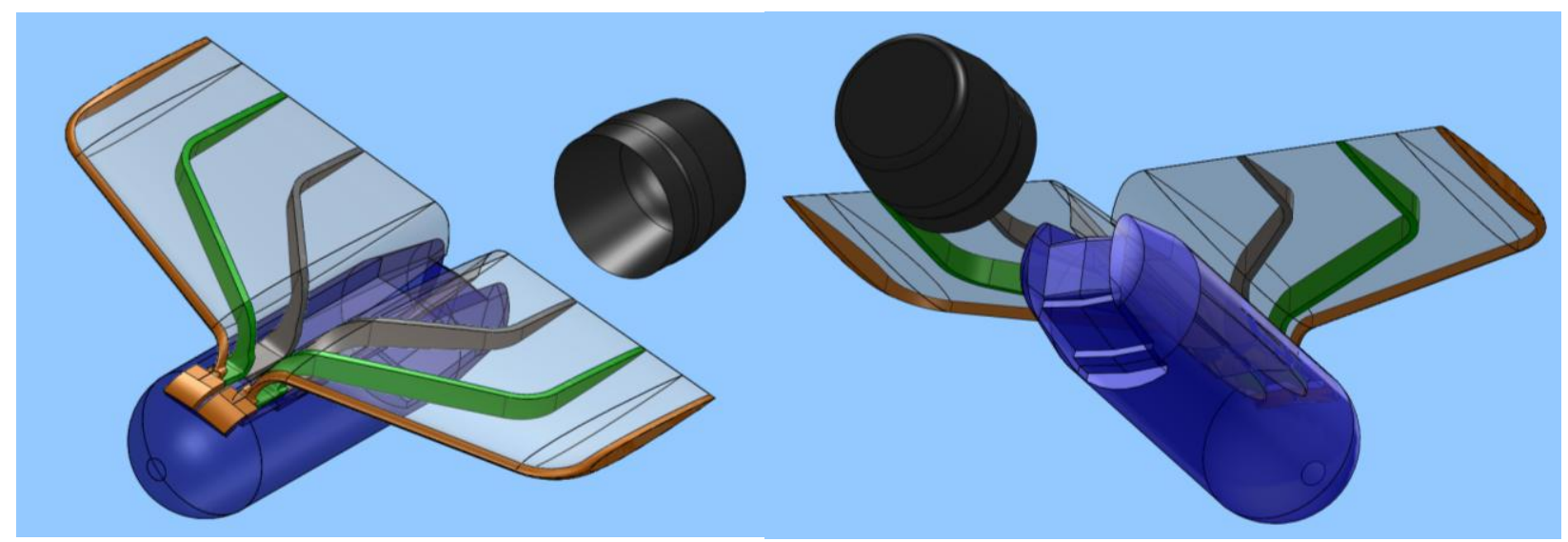

Figure 8-7: Long Endurance Configuration Leaf Spring Structure, Top Left Front Quarter (Left), Bottom Right Rear Quarter (Right) 
Major modifications, of both the leaf spring and membrane wing structures, were necessary to stow the $467 \%$ increase in wing area. Collapsing the leafs directly aft would have caused the elements to run into one another. A gull-wing arrangement mounted to the top of the fuselage allowed the leaves to wrap from the upper to lower surfaces parallel to one another without conflict as shown on the right of Figure 8-7.

Storing the membrane wing unfortunately required the addition of a pair of thin shields covering the vast majority of the fuselage (grey components in Figure 8-8). These were necessary to protect the fragile exterior surface of the membrane from the launch tube. A long rear casing, a modification of that used for the high-speed version seemed more likely to jam during deployment. Fortunately the aspect ratio 2 wing has a span sufficiently short that the slot discussed in Section 3.1.2 to enable large wing spans was not required for this design. The inner-wrapped wing ends just short of the root chord of the outer wing wrap when stowed.

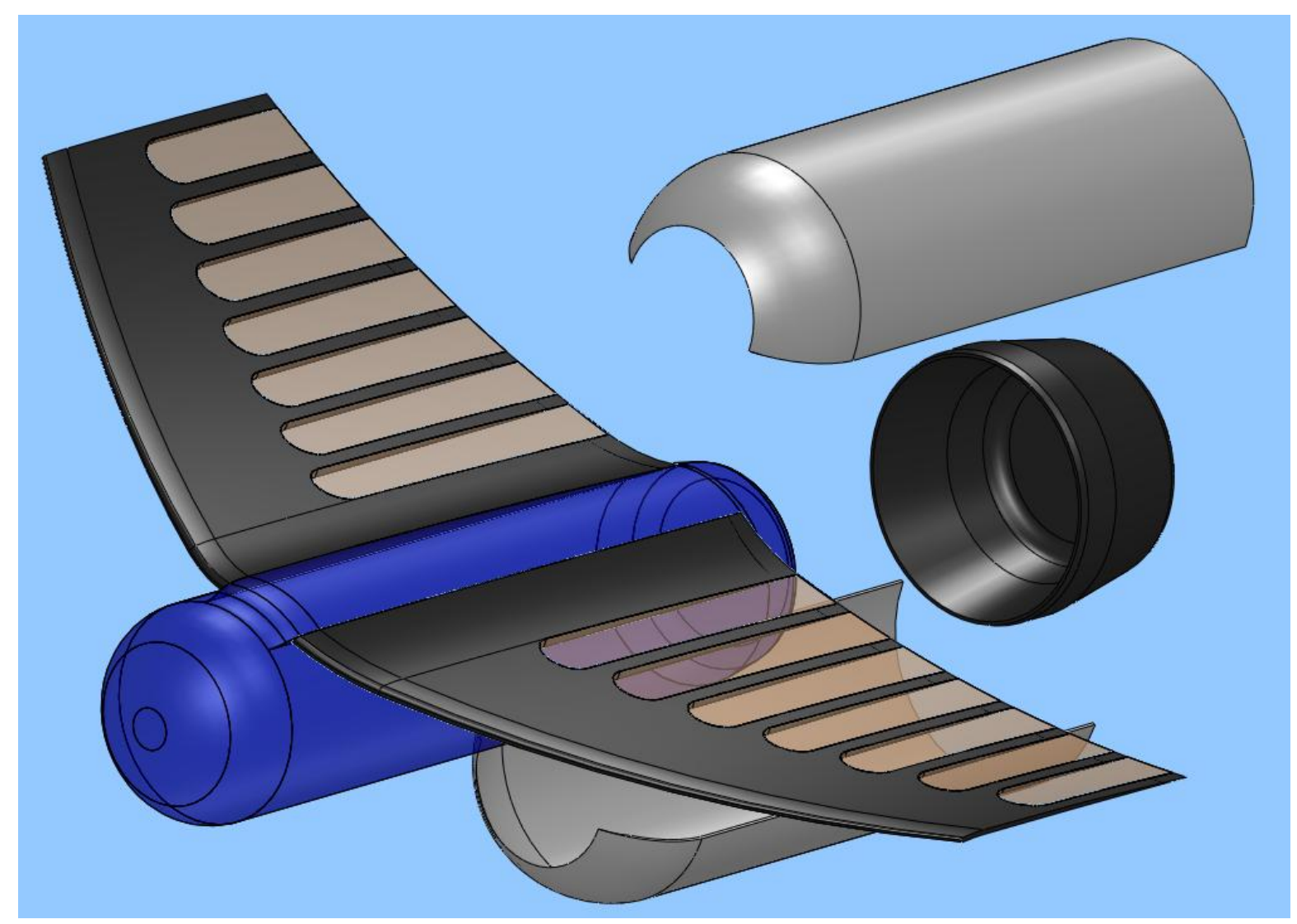

Figure 8-8: Long Endurance Configuration Wrapped Membrane Structure 
Expected performance of this configuration is presented in Table 8-2. Again note that a 35\% reduction in fuselage drag ratio only provides another $104 \mathrm{~m}$ of range, 6.6\%. Figure 8-9 presents a schematic of the low speed cruise mission profile with an emphasis on moderate endurance over-the-hill surveillance.

Table 8-2: Sizes and Expected Performance of Long Endurance MAV

\begin{tabular}{|c|c|c|c|c|c|c|c|c|c|c|c|}
\hline \multicolumn{3}{|c|}{ Launch Information } & \multicolumn{3}{|c|}{ Planform Information } & \multicolumn{3}{|c|}{ Performance, $C_{\text {do fuse }}=0.155$} & \multicolumn{3}{|c|}{ Performance, $C_{\text {do Fuse }}=0.100$} \\
\hline Launch Angle & 73 & deg & Wing Loading & 150 & $\mathrm{~N} / \mathrm{m}^{2}$ & Main Wing $\alpha_{\text {TRIM }}$ & 9.86 & deg & Main Wing $\alpha_{\text {TRIM }}$ & 9.86 & deg \\
\hline Apex Velocity & 20 & $\mathrm{~m} / \mathrm{s}$ & Wing Area & 11,772 & $m m^{2}$ & Glideslope & 8.4 & $\operatorname{deg}$ & Glideslope & 7.8 & $\operatorname{deg}$ \\
\hline Apex Altitude & 212 & $m$ & LE Location & 7.46 & $\mathrm{~mm}$ & Range & 1,576 & \begin{tabular}{|l|l}
6 & $m$
\end{tabular} & Range & 1,680 & $m$ \\
\hline Apex Range & 132 & $m$ & Root Chord & 102.3 & $\mathrm{~mm}$ & Gliding Time & 73 & $s$ & Gliding Time & 78 & $s$ \\
\hline Ballistic Time & 12.9 & & Tip Chord & 51.1 & $\mathrm{~mm}$ & $R E_{M A C}$ & & 8,930 & $\mathrm{RE}_{\mathrm{MAC}}$ & 108, & ,930 \\
\hline$C_{D \text { ofuselage }}$ & 0. & 155 & Span & \begin{tabular}{|l|l|}
153.4 \\
\end{tabular} & $\mathrm{~mm}$ & L/D & & 5.8 & L/D & & 3 \\
\hline
\end{tabular}

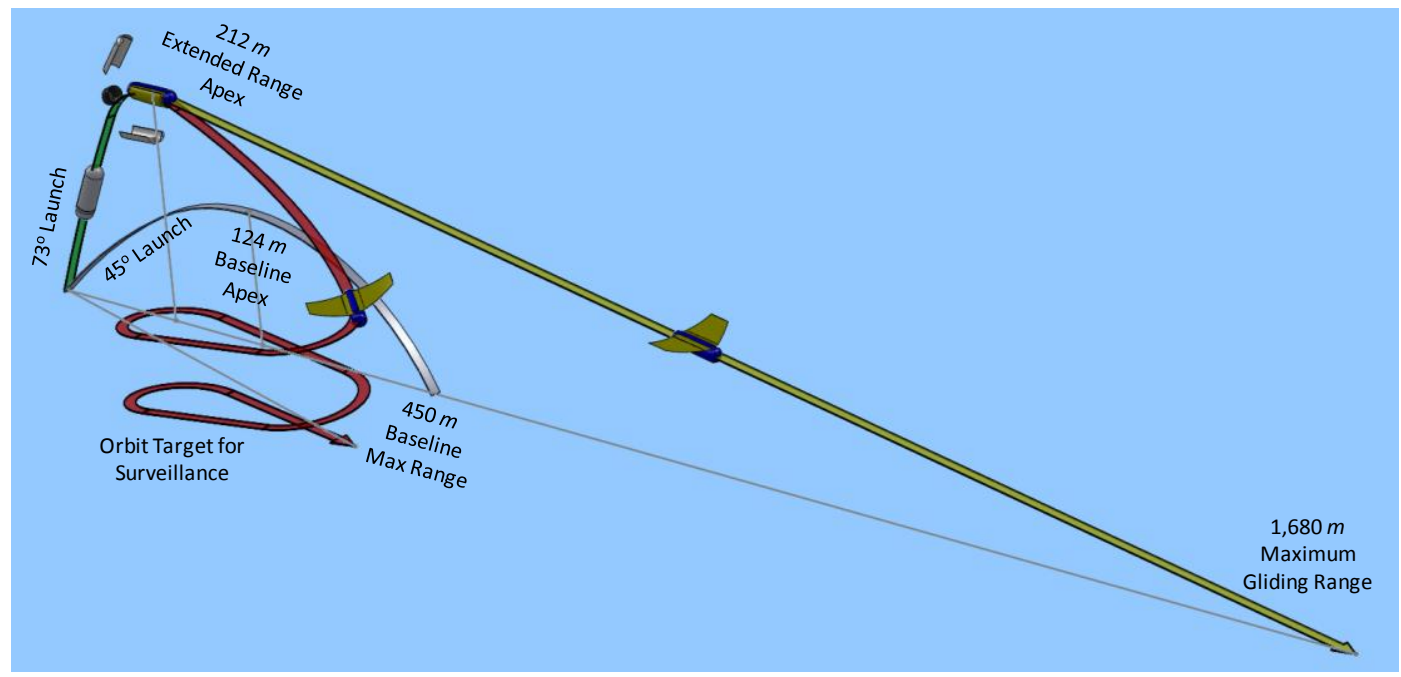

Figure 8-9: Schematic of Long Endurance Mission Profile 


\section{Chapter 9 Summary and Recommendations}

This work has shown that an effective micro air vehicle can be stowed within a small, rugged, cylindrical volume. In addition the same MAV can perform a useful mission while gliding from the apex of a ballistic arc.

A survey of prior art showed that the projected flight regime of this aircraft would be well outside the usual MAV cruise performance envelope. This survey also indicated that power supplies, communication systems, actuators, and sensors have all been miniaturized sufficiently to enable the mission concept with the provided geometric constraints. Information collected on low Reynolds number aerodynamics indicated that flow separation and laminar-turbulent transition effects would be encountered, significantly increasing the difficulty of computational modeling and pushing the limits of classical aerodynamic theory. The two primary goals were verifying volumetric feasibility and obtaining reasonable performance predictions.

Digital solid modeling of a series of wing stowage concepts lead to the development of the Leaf Spring and membrane wing structures which enabled significantly greater wing areas and provided approximately $400 \%$ more fuselage volume than the sponsor's initial designs. In addition to these two novel structures several methods of control actuation have also been developed. Refinement of the thin curved-plate membrane wings used in earlier MAVS have enabled this structure to incorporate full thick airfoil profiles.

A fundamentally new "leaf spring" structure has also been proposed. This system uses a group of contoured "leaf elements" providing the structural function of both spars and ribs in a conventional wing while collapsing into an extremely small stowed volume. A film skin of Mylar, latex, or similar material would be bonded over the leaf elements to provide the outer surface. Multiple biomimetic morphing techniques could be applied to this structure including adaptive washout and variable sweep angle, wing area, angle of attack, and camber. Continuing work should now focus on physically prototyping both structural concepts and all control actuation methods. Material choice and subtle geometric permutations will be critical in obtaining optimum function and further progress will be extremely slow without physical models.

With the volumetric feasibility verified work progressed to performance estimation and optimization. The semi-empirical Missile DATCOM code developed by the USAF was used to rapidly calculate initial estimates of required stabilizer and wing areas. Initial simulations in Fluent showed that a low aspect ratio delta planform significantly outperformed conventional high aspect ratio wing and tail layouts. 
An in-house MATLAB code was developed to calculate optimum delta wing surface areas and longitudinal positions for cruise flight conditions. These cruise conditions were the calculated apex altitude and velocity for a range of launch angles determined from launch data provided by the research sponsors. In addition to returning optimum wing areas, the in-house code calculated total range from ballistic launch, gliding range, total flight time, and gilding flight time as well as the Reynolds number at the mean aerodynamic chord.

CFD analyses of individual components was then conducted in preparation for future verification of the component build-up method at MAV scales. The tradeoff between fuselage drag and volume was determined by shaving the aft end into progressively longer Ogive conics. A 39\% reduction in fuselage drag cost $28 \%$ of the stowed volume at the approximate point that diminishing returns began to take hold.

Developing a suite of mesh and solver settings capable of providing reasonable preliminary design performance predictions for two dimensional airfoils between Reynolds numbers of 60,000 and 300,000 consumed significant time. An examination of all Fluent 12 turbulence models was conducted. This provided a small subset of the 51 studied permutations capable of predicting the lift, drag, and lift-todrag ratio of a NACA 0009 airfoil at $6^{\circ}$ angle of attack within $\pm 10 \%$. Each of these models was then used to generate entire drag polars for the 0009. Finally the k- $\omega$ SST model was selected due to its simplicity of implementation, and speed of calculation. Future computational work should initially focus on improving flow modeling performance by modifying model constants of the k- $\omega$ SST model. Should this fail to improve results alternate low Reynolds transition models may need to be examined. Once that work is completed a second three dimensional planform study should be performed with the new mesh settings and turbulence model.

A three dimensional planform study was conducted prior to realizing the intricacies of modeling this transitional flow. Despite this the general trends obtained were very strong, and while specific values are likely not accurate the qualitative information obtained was extremely useful. The effects of varying wing loading, taper ratio, and sweep angle all followed the trends shown in classical theory. This was important since wing loading has a primary effect on optimum cruise while taper ratio directly effects planform efficiency and sweep angle is critical for obtaining longitudinal stability of a delta design. However, increasing aspect ratio did not follow the classical trend. 
Over the range of aspect ratios studied: 2, 3, and 4, the lift-to-drag ratio actually fell as the aspect ratio was increased, which is contrary to classical wing theory. Calculating the mean aerodynamic chord Reynolds number for each case provided the explanation. At an aspect ratio of 2 the mean aerodynamic chord Reynolds number was 127,096 which fell to 89,870 as the aspect ratio was increased to 4 . In this critical transitional region smooth airfoils are extremely sensitive to falling Reynolds numbers. Future work should implement the revised mesh and solver settings developed for the two dimensional work and study a larger range of aspect ratios, down to 0.5 or less, to find the point at which increasing induced drag outweighs the benefits of increasing chordwise Reynolds number. It would also be interesting to examine several airfoils to determine whether the aspect ratio / Reynolds number tradeoff point is profile dependent to any significant degree. Several alternate MAV planforms such as circular, elliptical, and trochoidal layouts should also be examined. Wing-body effects between the low aspect ratio planforms and large fuselage will also need investigated.

The primary conclusion of this work is that the initial concept is entirely practicable from volumetric and aerodynamic perspectives. However, the initial performance goals were not optimal from either of those engineering design viewpoints. Proposals for two more optimal designs have been made including a high-speed cruise variant capable of a $66 \%$ range extension, and a long-endurance configuration capable of gliding times greater than $60 \mathrm{~s}$. Much physical and computational work remains to be done prior to deploying a fully functional system but the initial groundwork has been completed and is very promising. 


\section{References}

Appich, W. H., \& Wittmeyer, R. E. (2001). Aerodynamic Effects of Body Slots on a Guided Projectile with Cruciform Surfaces. Journal of Spacecraft , VOL. 17, NO. 6, 522-528.

Blake, W. B. (1998). Missile DATCOM User's Manual - 1997 FORTRAN 90 Revision. Wright-Patterson Air Force Base: Air Force Research Laboratory, Air Vehicles Directorate.

Bourlett, S. P. (1997). Patent No. 5,615,847. United States.

Carlucci, D. E., \& Jacobson, S. S. (2008). Ballistics: Theory and Design of Guns and Ammunition. Boca Raton, FL: CRC Press.

Davis, W. R., Kosicki, B. B., Boroson, D. M., \& Kostishack, D. F. (1996). Micro Aerial Vehicles for Optical Surveillance. The Lincoln Laboratory Journal, VOL. 9, NO. 2, 194-214.

Fleming, G. A., Bartram, S. M., Waszak, M. R., \& Jenkins, L. N. (2001). Projection Moire Interferometry Measurments of Micro Air Vehicle Wings. Proceedings of the SPIE International Symposium on Optical Science and Technology. San Diego, CA: SPIE.

Grabowsky, J. (2007). AeroVironment Future Solutions - ISR. Pacific Theater Operational Science and Technology Conference.

Guiler, R. W. (2007). Control of a Swept Wing tailless Aircraft Through Wing Morphing. Morgantown WV: West Virginia University.

Ifju, P. G., Ettinger, S., Jenkins, D., \& Martinez, L. (2001). Composite Materials for Micro Air Vehicles. Proceedings of the SAMPE Annual Conference (pp. 7-12). Long Beach, CA: University of Florida Mechanics and Engineering Science Department.

Kellogg, J., Bovias, C., Dahlburg, J., Foch, R., Gardner, J., Gordon, D., et al. (2001). The NRL MITE Air Vehicle. US Naval Research Laboratory.

Kemp, I. (2007, February). The Infantry's Explosive Punch: 40 mm Grenades and Launchers. Asian Military Review , pp. 17-23.

Kim, D.-H., Yang, J.-H., Chang, J.-W., \& Chung, J. (2009). Boundary Layer and Near-wake Measurments of NACA 00012 Airfoil at Low Reynolds Numbers. 47th AIAA Aerospace Sciences Meeting Including the New Horizons Forum and Aerospace Exposition. Orlando, FL: AIAA.

Krashanitsa, R., Platanits, G., \& Silin, D. (2006). Auopilot Integration into Micro Air Vehicles. In J. Schetz, Introduction to the Design of Fixed-Wing Micro Air Vehicles (pp. 109-149). Reston, VA: American Institute of Aeronautics and Astronautics, Inc.

Lian, Y., \& Shyy, W. (2007). Laminar-Turbulent Transition of a Low Reynolds Number Rigid or Flexible Airfoil. AIAA Journal, VOL. 45, NO. 7, 1501-1513.

Lissman, P. B. (1983). Low-Reynolds Number Airfoils. Annual Review of Fluid Mechanics, VOL. 15, 223-239.

Lockheed Martin. (2010). Hellfire II Missile. Retrieved April 28, 2010, from Lockheed Martin: http://www.lockheedmartin.com/products/HellfireII/index.html

Lyon, D. H. (2003). Mortar-Launched Recon-Targeting Programs. Army Research Lab, Ballistics and Weapons Concepts Division.

Martorana, R. T., Anderson, J., Spearing, S. M., Kessler, S., Appleby, B., Bergmann, E., et al. (2003). Patent No. 2003/0089820 Al. United States.

Morris, S. J. (1997). Design and Flight Test Results for Micro-Sized Fixed-Wing and VTOL Aircraft. Palo Alto, CA: MLB Company.

Morris, S. J. (2000). Design of Micro Air Vehicles and Flight Test Validation. Palo Alto, CA: MLB Company. 
Mueller, T. J. (1999). Aerodynamic Measurments at Low Reynolds Numbers for Fixed Wing Micro Air Vehicles. Development and Operation of UAVs for Military and Civil Applications. Belgium: University of Notre Dame.

Mueller, T. J., \& Batill, S. (1982). Experimental Studies of Separation on a Two-Dimensional Airfoil at Low Reyolds Numbers. AIAA Journal, VOL. 20, NO. 4, 457-463.

Mueller, T. J., Torres, G. E., \& Srull, D. W. (2006). Elements of Aerodynamics, Propulsion, and Design. In J. A. Schetz, Introduction to the Design of Fixed-Wing Micro Air Vehicles (pp. 39-107). Reston, VA: American Institute of Aeronautics and Astronautics, Inc.

Ott, J., \& Biezad, D. (2004). Design of a Tube-Launched UAV. Proceedings of the AIAA 3rd Unmanned Unlimited Conference (pp. 540-550). Chicago, IL: AIAA.

Palmer, M. R. (2001). Patent No. 6,260,797. United States.

Pepper, W. B., \& Fellerhoff, R. D. (1969). Parachute System to Recover Spinning Shell Subjected to 20,000 g's. Journal of Spacecraft , VOL. 6, NO. 3, 344-346.

Pornsin-sirirak, T. N., Tai, Y. C., \& Ho, C. M. (2001). Titanium-alloy MEMS wing technology for a micro air vehicle aplication. Sensors and Actuators, VOL. A 89, 95-103.

Raymer, D. P. (2006). Aircraft Design: A Conceptual Approach, Fourth Edition. Reston, VA: American Institute of Aeronautics and Astronautics.

Raythoeon Corporation. (2009). Raytheon Excalibur Datasheet. Raytheon Corporation.

Roberts, W. B. (1980). Calculation of Laminar Separation Bubbles and Their Effect on Airfoil Performance. AIAA Journal, VOL. 18, NO. 1, 25-31.

Ruffier, F., Viollet, S., Amic, S., \& Franeschini, N. (2003). Bio-Inspired Optical Flow Circuits for the Visual Guidance of Micro Air Vehciles. Proceedings of the IEEE Symposium on Circuits and Systems (pp. 846-849). Bangkok, Thiland: IEEE.

Sachs, G. (2007). Why Birds and Miniscale Airplanes Need No Vertical Tail. Journal of Aircraft, VOL. 44, NO. 4, 1159-1167.

Selig, M. S., Donovan, J. F., \& Fraser, D. B. (1989). Airfoils at Low Speeds. Virginia Beach, VA: H. A. Stokely Publishing.

Shyy, W., Ifju, P., \& Vieru, D. (2005). Membrane Wing-based Micro Air Vehicles. Applied Mechanics Reviews , 283-301.

Shyy, W., Lian, Y., Tang, J., Viieru, D., \& Liu, H. (2008). Aerodynamics of Low Reynolds Number Flyers. New York, NY: Cambridge University Press.

Silton, S. I. (2005). Navier-Stokes Computations for a Spinning Projectile from Subsonic to Supersonic Speeds. Journal of Spacecraft and Rockets, VOL. 42, NO. 2, 223-231.

Silton, S. I., \& Dinavahi, S. P. (2008). Base Drag Considerations on a 0.50-caliber Spinning Projectile. Proceedings of the 26th AIAA Applied Aerodynamics Conference. Honolulu, HI: AIAA.

Simons, M. (1999). Model Aircraft Aerodynamics; Fourth Edition. Poole, Dorset, UK: Special Interest Model Books Ltd.

Stanford, B., Abdulrahim, M., Lind, R., \& Ifju, P. (2007). Investigation of Membrane Actuation for Roll Control of a Micro Air Vehicle. Journal of Aircraft, VOL. 44, NO. 3, 741-749.

Torres, G., \& Mueller, T. J. (2001). Micro Aerial Vehicla Development: Design, Components, Fabrication, and Flight Testing. Notre Dame: University of Notre Dame.

US Army Armament Ballistic Research Laboratory. (1984). Flight Data on Liquid-Filled Shell for SipinUp Instabilities. US Army Armament Ballistic Research Laboratory.

Woodland, R. L. (2000). Patent No. 6,056,237. United States. 


\section{Appendix A Missile DATCOM Input and Output Files}

\section{Missile DATCOM Input File: Comments preceded by "<"}

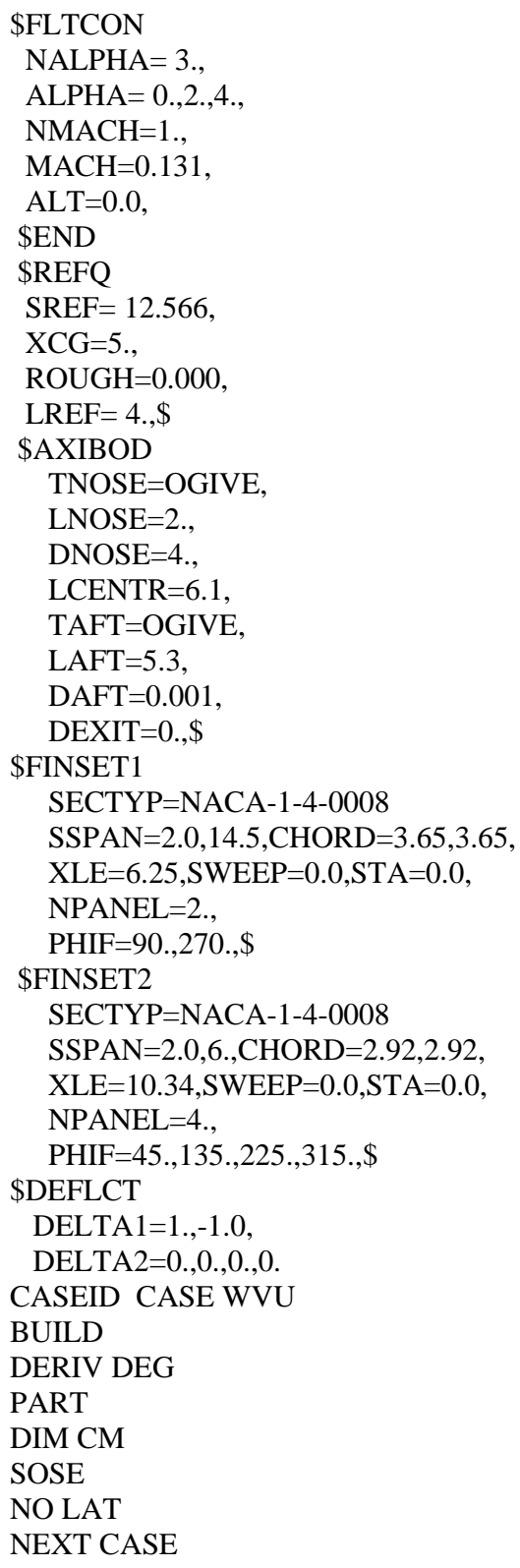

$<$ Begin specifying flight conditions

$<$ Number of angles of attack to be analyzed

$<$ Angles of attack in degrees

$<$ Number of Mach numbers to be analyzed

$<$ Mach numbers to be analyzed

$<$ Altitude to run analysis in meters

$<$ End flight condition specification

$<$ Specify reference quantities

$<$ Reference Area in square centimeters

$<$ Center of gravity location

$<$ Surface roughness characteristic length

$<$ Length

$<$ Define axisymmetric body (fuselage)

$<$ Type of nose $=$ Ogive

$<$ Length of nose $=2 \mathrm{~cm}$

$<$ Diameter of nose $=4 \mathrm{~cm}$

$<$ Length of cylindrical center body $=6.1 \mathrm{~cm}$

$<$ Type of tail cone $=$ Ogive

$<$ Length of tail cone $=5.3 \mathrm{~cm}$

$<$ Diameter of aft end of tail cone $=0.001 \mathrm{~cm}$

$<$ Close diameter $=0$

$<$ First fin set in the axial direction

$<$ Airfoil section = NACA 0008

$<$ Semi-Span from axis and chord at specified locations

$<$ Leading edge location, sweep angle,

$<$ Number of fins

$<$ Angle of fins around body from vertical

$<$ Second fin set

$<$ Airfoil section = NACA 0008

$<$ Semi span from axis and chord at semi-span locations

$<$ Leading edge location and sweep angle

$<$ Number of fins

$<$ Angle of fins around body from vertical

$<$ Fin deflection Angles

$<$ Main wings set to 1 degree angle of attack

$<$ Tails set to no angle of attack

$<$ Case name

$<$ Build data

$<$ Report derivatives in degrees instead of radians 


\section{Missile DATCOM Output File, Important quantities in bold}

$1 \quad * * * * *$ THE USAF AUTOMATED MISSILE DATCOM * REV 07/07 ****** AERODYNAMIC METHODS FOR MISSILE CONFIGURATIONS

CONERR - INPUT ERROR CHECKING

ERROR CODES - N* DENOTES THE NUMBER OF OCCURENCES OF EACH ERROR A - UNKNOWN VARIABLE NAME

B - MISSING EQUAL SIGN FOLLOWING VARIABLE NAME

C - NON-ARRAY VARIABLE HAS AN ARRAY ELEMENT DESIGNATION - $(\mathrm{N})$

D - NON-ARRAY VARIABLE HAS MULTIPLE VALUES ASSIGNED

E - ASSIGNED VALUES EXCEED ARRAY DIMENSION

F - SYNTAX ERROR

$* * * * * * * * * * * * * * * * * * * * * * * * * \operatorname{INPUT} \mathrm{DATA}$ CARDS $* * * * * * * * * * * * * * * * * * * * * * * * *$

1 \$FLTCON

2 NALPHA $=3$.,

3 ALPHA= 0.,2.,4.,

$4 \mathrm{NMACH}=1$.,

$5 \mathrm{MACH}=0.131$,

6 ALT $=0.0$,

7 \$END

8 \$REFQ

$9 \mathrm{SREF}=12.566$,

$10 \mathrm{XCG}=6.65$,

11 ROUGH $=0.000$,

12 LREF $=4 . \$$

13 \$AXIBOD

14 TNOSE=OGIVE,

** SUBSTITUTING NUMERIC FOR NAME OGIVE

15 LNOSE $=2$.,

16 DNOSE $=4$.,

17 LCENTR=6.1,

18 TAFT=OGIVE,

** SUBSTITUTING NUMERIC FOR NAME OGIVE

19 LAFT $=5.3$,

20 DAFT $=0.001$,

21 DEXIT $=0 ., \$$

22 CASEID CASE WVU

23 BUILD

24 DERIV RAD

25 PART

26 DIM CM

27 SOSE

28 NO LAT

29 NEXT CASE

$30 * *$ BLANK CARD - IGNORED

$1 \quad * * * * *$ THE USAF AUTOMATED MISSILE DATCOM * REV 07/07 ***** CASE 1 AERODYNAMIC METHODS FOR MISSILE CONFIGURATIONS PAGE 1

CASE INPUTS

FOLLOWING ARE THE CARDS INPUT FOR THIS CASE

\$FLTCON

NALPHA $=3$.,

ALPHA= 0.,2.,4.,

$\mathrm{NMACH}=1$.,

$\mathrm{MACH}=0.131$,

ALT $=0.0$, 


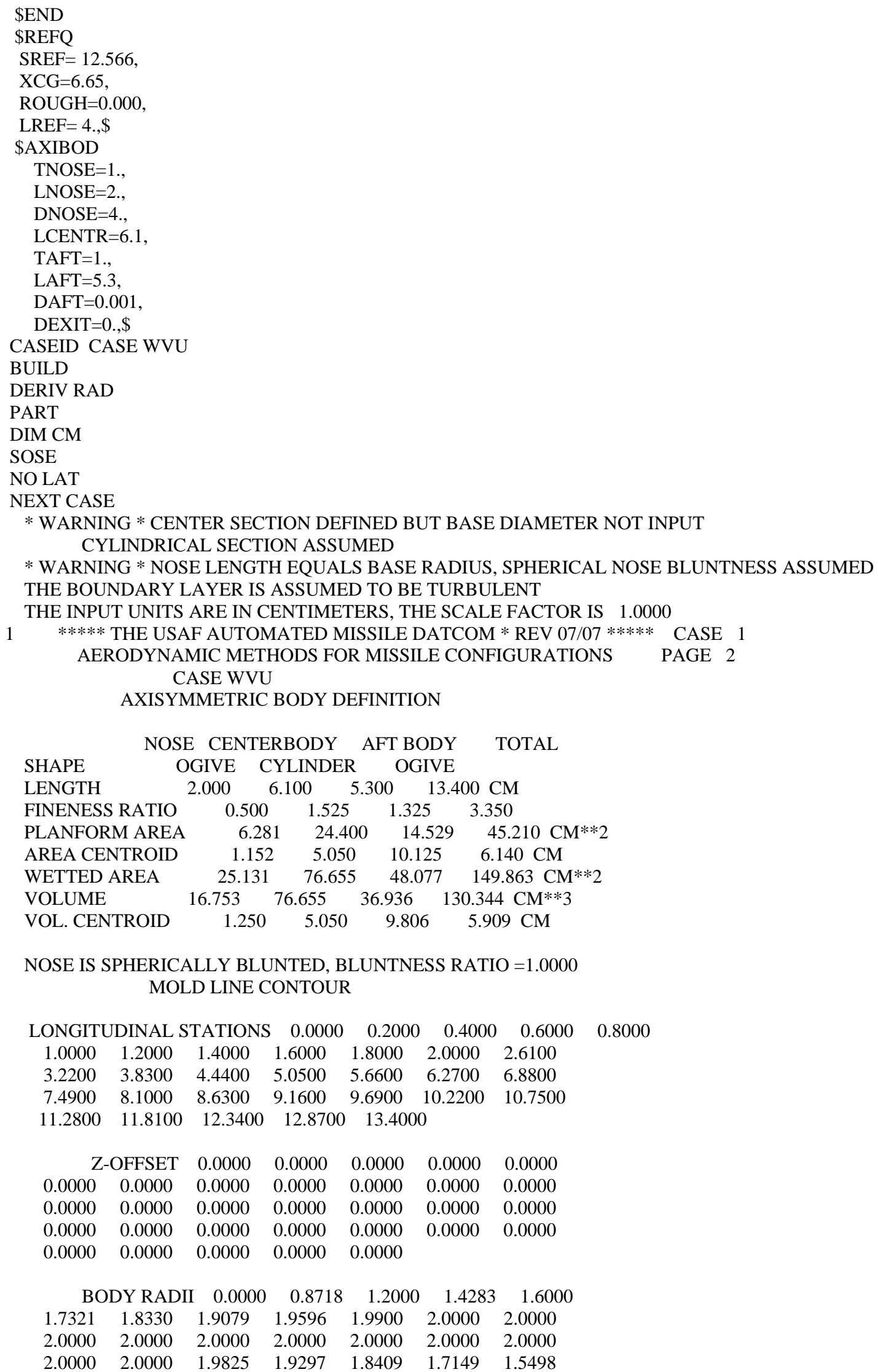




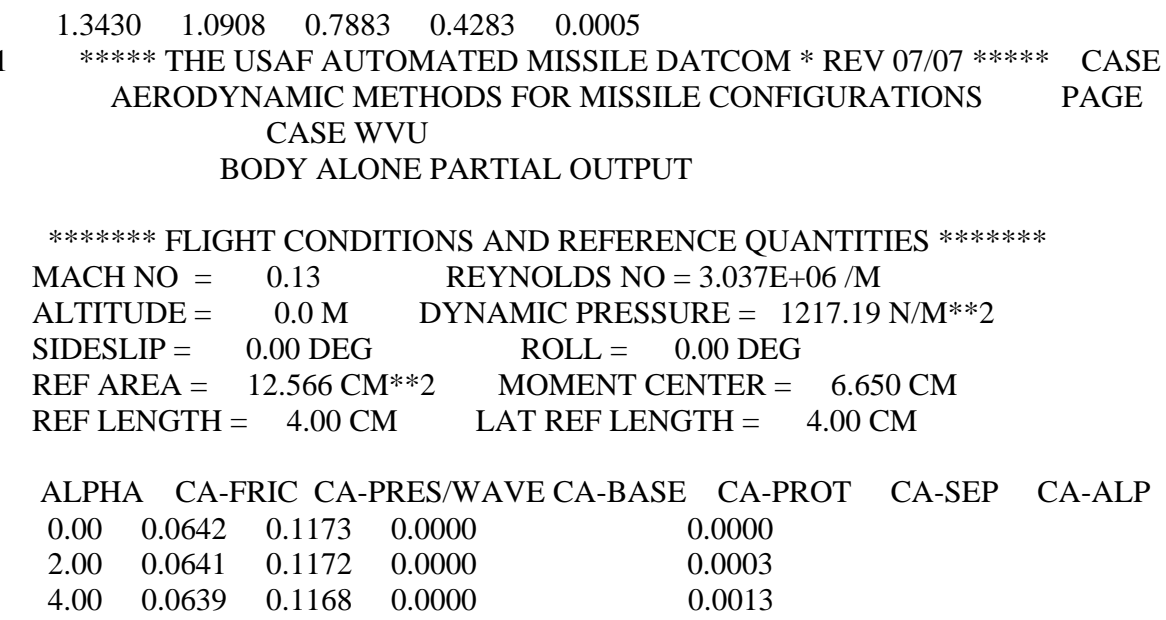

CROSS FLOW DRAG PROPORTIONALITY FACTOR = 0.61239

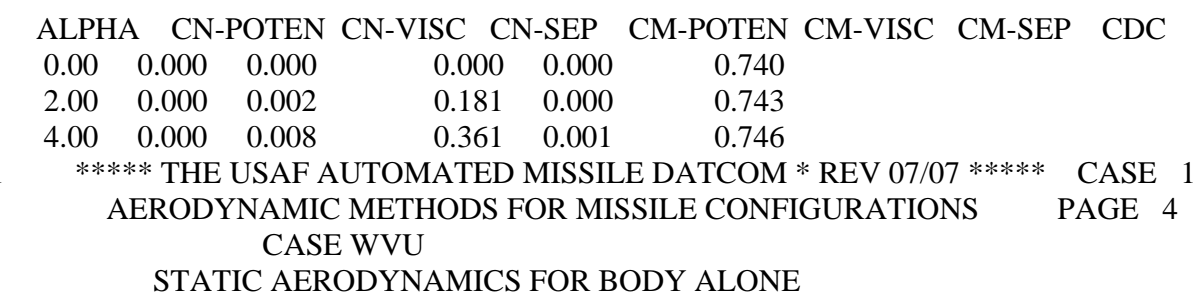

******** FLIGHT CONDITIONS AND REFERENCE QUANTITIES $* * * * * * * *$

MACH NO $=0.13 \quad$ REYNOLDS NO $=3.037 \mathrm{E}+06 / \mathrm{M}$

ALTITUDE $=\quad 0.0 \mathrm{M} \quad$ DYNAMIC PRESSURE $=1217.19 \mathrm{~N} / \mathrm{M} * 2$

SIDESLIP $=\quad 0.00$ DEG ROLL $=$ 0.00 DEG

REF AREA $=\quad 12.566 \mathrm{CM} * 2 \quad$ MOMENT CENTER $=6.650 \mathrm{CM}$

REF LENGTH $=\quad 4.00 \mathrm{CM}$ LAT REF LENGTH $=\quad 4.00 \mathrm{CM}$

\begin{tabular}{|c|c|c|c|c|c|c|}
\hline \multicolumn{5}{|c|}{---- LONGITUDINAL ----- } & \multicolumn{2}{|c|}{-- LATERAL DIRECTIONAL -- } \\
\hline ALPHA & CI & & & & & CLL \\
\hline 0.00 & 0.000 & 0.000 & 0.182 & 0.000 & 0.000 & $\mathbf{0 . 0 0 0}$ \\
\hline 2.00 & 0.002 & 0.181 & 0.182 & 0.000 & 0.000 & $\mathbf{0 . 0 0 0}$ \\
\hline 4.00 & 0.008 & 0.362 & 0.182 & 0.000 & 0.000 & 0.000 \\
\hline
\end{tabular}

ALPHA CL CD CL/CD X-C.P.

\begin{tabular}{rrrrr}
0.00 & $\mathbf{0 . 0 0 0}$ & $\mathbf{0 . 1 8 2}$ & \multicolumn{2}{c}{$\mathbf{0 . 0 0 0 - 1 7 9 3 1 . 4 4 3}$} \\
\hline 2.00 & $-\mathbf{0 . 0 0 4}$ & $\mathbf{0 . 1 8 2}$ & $\mathbf{- 0 . 0 2 4}$ & $\mathbf{9 0 . 8 5 8}$ \\
$\mathbf{4 . 0 0}$ & $\mathbf{- 0 . 0 0 5}$ & $\mathbf{0 . 1 8 2}$ & $\mathbf{- 0 . 0 2 6}$ & $\mathbf{4 5 . 2 4 7}$
\end{tabular}

X-C.P. MEAS. FROM MOMENT CENTER IN REF. LENGTHS, NEG. AFT OF MOMENT CENTER

$1 \quad * * * * *$ THE USAF AUTOMATED MISSILE DATCOM $*$ REV 07/07 ***** $\quad$ CASE 1 AERODYNAMIC METHODS FOR MISSILE CONFIGURATIONS PAGE 5 CASE WVU

STATIC AERODYNAMICS FOR BODY ALONE

******* FLIGHT CONDITIONS AND REFERENCE QUANTITIES $* * * * * * *$

MACH NO $=0.13 \quad$ REYNOLDS NO $=3.037 \mathrm{E}+06 / \mathrm{M}$

ALTITUDE $=0.0 \mathrm{M} \quad$ DYNAMIC PRESSURE $=1217.19 \mathrm{~N} / \mathrm{M}^{* * 2}$

SIDESLIP $=0.00$ DEG $\quad$ ROLL $=0.00$ DEG

REF AREA $=12.566 \mathrm{CM}^{* * 2} \quad$ MOMENT CENTER $=6.650 \mathrm{CM}$

REF LENGTH $=4.00 \mathrm{CM} \quad$ LAT REF LENGTH $=4.00 \mathrm{CM}$ 


\begin{tabular}{cccccc}
\multicolumn{7}{c}{$-0 .-$} & \\
ALPHA & CNA & CMA & CYB & CLNB & CLLB \\
0.00 & -0.0003 & 5.1961 & & & \\
2.00 & 0.1145 & 5.1808 & & & \\
4.00 & 0.2293 & 5.1655 & & & \\
$* * *$ END OF JOB $* * *$ & & & &
\end{tabular}




\section{Appendix B Grid Generation Details}

Fuselage Mesh Independence Settings

\begin{tabular}{|c|c|c|c|}
\hline & Mesh 1 & Mesh 2 & Mesh 3 \\
\hline \multicolumn{4}{|l|}{ Surface Mesh } \\
\hline Nodes Around Nose Cone & 6 & 12 & 20 \\
\hline Nodes Around Body & 25 & 75 & 125 \\
\hline Nodes Along Body & 10 & 20 & 40 \\
\hline Nodes Around Tailcone & 6 & 8 & 20 \\
\hline Surface Geometric Growth Rate From Tail & 1.25 & 1.1 & 1.05 \\
\hline Maximum Cell Size from Tail & 4 & 2 & 1 \\
\hline \multicolumn{4}{|l|}{ Prismatic Cells } \\
\hline First Prism Height & 1.05 & 1.05 & 1.05 \\
\hline Number of Layers & 10 & 10 & 10 \\
\hline Prism Growthrate & 1.05 & 1.05 & 1.05 \\
\hline \multicolumn{4}{|l|}{ Inner Refinement Region } \\
\hline Growth Rate & 1.01 & 1.01 & 1.01 \\
\hline$X$ center & 180 & 180 & 180 \\
\hline X length & 240 & 240 & 240 \\
\hline Ylength & 80 & 80 & 80 \\
\hline Z length & 80 & 80 & 80 \\
\hline Max Volume & 10 & 5 & 2 \\
\hline \multicolumn{4}{|l|}{ Middle Refinement Region } \\
\hline Growth Rate & 1.05 & 1.05 & 1.05 \\
\hline$X$ center & 250 & 250 & 250 \\
\hline$X$ length & 600 & 600 & 600 \\
\hline Ylength & 120 & 120 & 120 \\
\hline Z length & 120 & 120 & 120 \\
\hline Max Volume & 100 & 50 & 25 \\
\hline \multicolumn{4}{|l|}{ Outer Refinement Region } \\
\hline Growth Rate & 1.1 & 1.1 & 1.1 \\
\hline$X$ center & 500 & 500 & 500 \\
\hline$X$ length & 1500 & 1500 & 1500 \\
\hline Ylength & 300 & 300 & 300 \\
\hline Z length & 300 & 300 & 300 \\
\hline Max Volume & 1000 & 1000 & 1000 \\
\hline Volume Growth Rate & 1.2 & 1.2 & 1.2 \\
\hline Cell Count & 568,795 & 749,333 & $1,460,495$ \\
\hline Average Cell Size & 19,800 & 14,489 & 7,433 \\
\hline Cell Shrink Rate & & 0.732 & 0.513 \\
\hline Drag Coefficient & 0.12 & 0.1 & 0.096 \\
\hline$\%$ Change & & $-16.67 \%$ & $-4.00 \%$ \\
\hline
\end{tabular}


Two Dimensional NACA 0009 Mesh Independence Settings

\begin{tabular}{|c|c|c|c|c|c|c|}
\hline Surface Mesh & Mesh 5 & Mesh 4 & Mesh 3 & $\begin{array}{c}\text { Mesh } 3 \\
\text { MOD }\end{array}$ & Mesh 2 & Mesh 1 \\
\hline Tip \& Tail Spacing & $\begin{array}{c}0.004 \mathrm{C} \\
(0.002 \mathrm{C}\end{array}$ & $0.002 \mathrm{C}$ & $0.001 \mathrm{C}$ & $\begin{array}{c}0.001 C \\
(0.00033 \mathrm{C}\end{array}$ & $0.0005 C$ & $0.00025 C$ \\
\hline Average Cell Spacing & $0.02 \mathrm{C}$ & $.01 C$ & $.005 \mathrm{C}$ & $.005 \mathrm{C}$ & $.0025 \mathrm{C}$ & $.00125 \mathrm{C}$ \\
\hline Prismatic Layer & Last AR & Last AR & Last AR & Last AR & Last AR & Last AR \\
\hline First Cell Height & $0.00005 \mathrm{C}$ & $0.00005 \mathrm{C}$ & $0.00005 \mathrm{C}$ & $0.00005 \mathrm{C}$ & $0.00005 \mathrm{C}$ & $0.00005 \mathrm{C}$ \\
\hline Number of Layers & 25 & 25 & 25 & 25 & 40 & 40 \\
\hline Aspect / Growth Rate & $50 \%$ & $50 \%$ & $50 \%$ & $200 \%$ & $50 \%$ & $50 \%$ \\
\hline \multicolumn{7}{|l|}{ Tetrahedral Domain } \\
\hline Domain Growth Rate & 1.3 & 1.3 & 1.3 & 1.3 & 1.3 & 1.3 \\
\hline Refine Growth Rate & 1.01 & 1.01 & 1.01 & 1.005 & 1.01 & 1.01 \\
\hline Refine $X_{\text {center }}$ & $2 \mathrm{C}$ & $2 \mathrm{C}$ & $2 \mathrm{C}$ & $2 \mathrm{C}$ & $2 \mathrm{C}$ & $2 \mathrm{C}$ \\
\hline Refine $X_{\text {length }}$ & $7 C$ & $7 C$ & $7 C$ & $7 C$ & $7 C$ & $7 C$ \\
\hline Refine $Y_{\text {length }}$ & $3 C$ & $3 C$ & $3 C$ & $3 C$ & $3 C$ & $3 C$ \\
\hline Refine $\mathrm{Vol}_{\max }$ & 400 & 200 & 100 & 50 & 100 & 100 \\
\hline Mesh Statistics & Last AR & Last AR & Last AR & Last AR & Last AR & Last AR \\
\hline Skewness & 0.78 & 0.71 & 0.72 & 0.74 & 0.77 & 0.75 \\
\hline Average Volume & 1,709 & 1,061 & 509 & 358 & 263 & 98 \\
\hline Number of Cells & 5,266 & 8,480 & 17,664 & 25,110 & 34,176 & 91,634 \\
\hline \multicolumn{7}{|l|}{ Results } \\
\hline Angle of Attack & \multicolumn{6}{|c|}{0.08} \\
\hline$C_{L}$ & 0.0000 & 0.0000 & 0.0000 & 0.0000 & 0.0000 & 0.0000 \\
\hline$C_{D}$ & 0.0228 & 0.0303 & 0.0301 & 0.0298 & 0.0301 & 0.0301 \\
\hline L/D & 0.00 & 0.00 & 0.00 & 0.00 & 0.00 & 0.00 \\
\hline Angle of Attack & \multicolumn{2}{|c|}{2.14} & & & & \\
\hline $\mathrm{C}_{\mathrm{L}}$ & 0.2021 & 0.1956 & 0.1955 & 0.1951 & 0.1958 & 0.1949 \\
\hline$C_{D}$ & 0.0234 & 0.0310 & 0.0308 & 0.0306 & 0.0308 & 0.0308 \\
\hline L/D & 8.65 & 6.31 & 6.35 & 6.38 & 6.36 & 6.32 \\
\hline Angle of Attack & \multicolumn{6}{|c|}{4.19} \\
\hline$C_{L}$ & 0.3990 & 0.3872 & 0.3866 & 0.3856 & 0.3866 & 0.3864 \\
\hline$C_{D}$ & 0.0255 & 0.0335 & 0.0332 & 0.0328 & 0.0332 & 0.0332 \\
\hline L/D & 15.64 & 11.55 & 11.65 & 11.75 & 11.65 & 11.63 \\
\hline Angle of Attack & \multicolumn{6}{|c|}{6.22} \\
\hline$C_{L}$ & 0.5837 & 0.5683 & 0.5680 & 0.5651 & 0.5680 & 0.5691 \\
\hline$C_{D}$ & 0.0302 & 0.0379 & 0.0377 & 0.0372 & 0.0376 & 0.0377 \\
\hline L/D & 19.34 & 14.98 & 15.06 & 15.21 & 15.09 & 15.10 \\
\hline Angle of Attack & \multicolumn{6}{|c|}{8.25} \\
\hline$C_{L}$ & 0.7402 & 0.7292 & 0.7312 & 0.7255 & 0.7320 & 0.7322 \\
\hline$C_{D}$ & 0.0403 & 0.0462 & 0.0457 & 0.0449 & 0.0456 & 0.0456 \\
\hline L/D & 18.38 & 15.78 & 16.01 & 16.14 & 16.04 & 16.04 \\
\hline
\end{tabular}


Three Dimensional Main Wing Mesh Independence Settings

\begin{tabular}{|c|c|c|c|}
\hline \multirow{2}{*}{\begin{tabular}{|l|} 
Mesh Settings \\
Surface Mesh
\end{tabular}} & \multirow{2}{*}{ Mesh 1} & \multirow{2}{*}{ Mesh 2} & \multirow{2}{*}{ Mesh 3} \\
\hline & & & \\
\hline LE Cell Spacing & 1.35 & 0.84 & 0.65 \\
\hline TE Cell Spacing & 1.35 & 0.84 & 0.65 \\
\hline Tip Cell Count & 40 & 60 & 75 \\
\hline Tip First Length & 0.2 & 0.2 & 0.2 \\
\hline Tip Last Length & 0.2 & 0.2 & 0.2 \\
\hline \multicolumn{4}{|l|}{ LE / Te Surface Step Down } \\
\hline First Row & - & - & - \\
\hline Growt Rate & - & - & - \\
\hline Layers & - & - & - \\
\hline Transition Pattern & - & - & - \\
\hline \multicolumn{4}{|l|}{ Prismatic Layer } \\
\hline First Cell Height & 0.6 & 0.6 & 0.6 \\
\hline Number of Layers & 5 & 5 & 5 \\
\hline Geometric Growth Rate & 1 & 1 & 1 \\
\hline \multicolumn{4}{|l|}{ Pyramid Layer } \\
\hline Option & Skewness & Skewness & Skewness \\
\hline Fill Cap & Yes & Yes & Yes \\
\hline Face Angle & 120 & 120 & 120 \\
\hline \multicolumn{4}{|l|}{ Tetrahedral } \\
\hline Refinement Growth Rate & 1.01 & 1.01 & 1.01 \\
\hline $\mathrm{Xc}$ & 200 & 200 & 200 \\
\hline $\mathrm{XL}$ & 600 & 600 & 600 \\
\hline $\mathrm{YL}$ & 150 & 150 & 150 \\
\hline ZL & 300 & 300 & 300 \\
\hline Vmax & 250 & 100 & 50 \\
\hline Outer Region Growth Rate & 1.2 & 1.2 & 1.2 \\
\hline Cell Count & 694,639 & $1,442,986$ & $2,384,412$ \\
\hline Max Skewness & 0.884 & 0.869 & 0.882 \\
\hline $\mathrm{Cl}$ & 1.708 & 1.501 & 1.522 \\
\hline$\%$ Change $\mathrm{CL}$ & - & $12.11 \%$ & $1.40 \%$ \\
\hline Cd & 0.616 & 0.239 & 0.268 \\
\hline$\%$ Change CD & - & $61.18 \%$ & $12.13 \%$ \\
\hline L/D & 2.774 & 6.280 & 5.679 \\
\hline$\%$ Change L/D & - & $126.38 \%$ & $9.57 \%$ \\
\hline
\end{tabular}




\section{Appendix C Analysis Program Code}

Code used to calculate trajectory based on back-calculated launch velocity, drag coefficient, and mass:

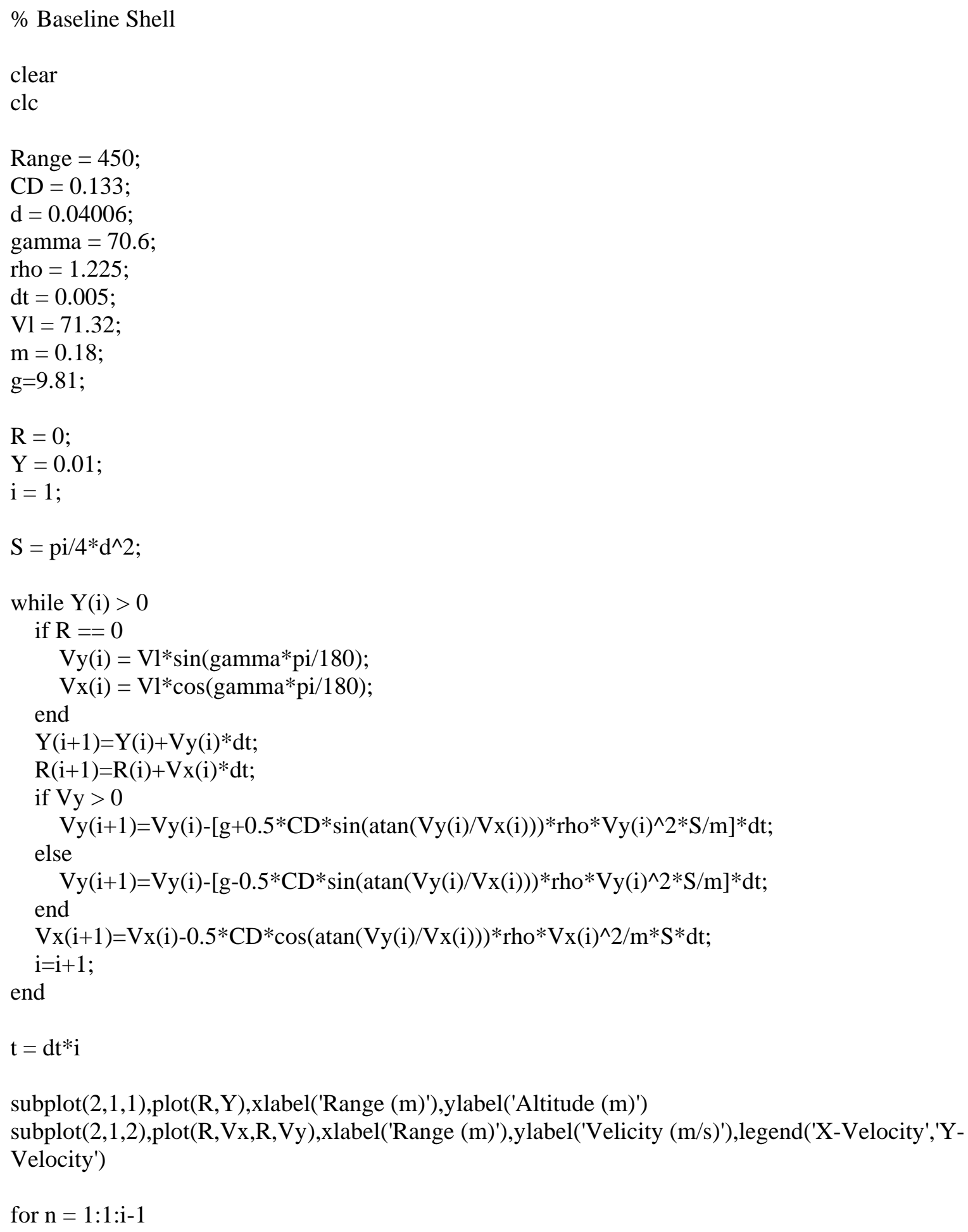




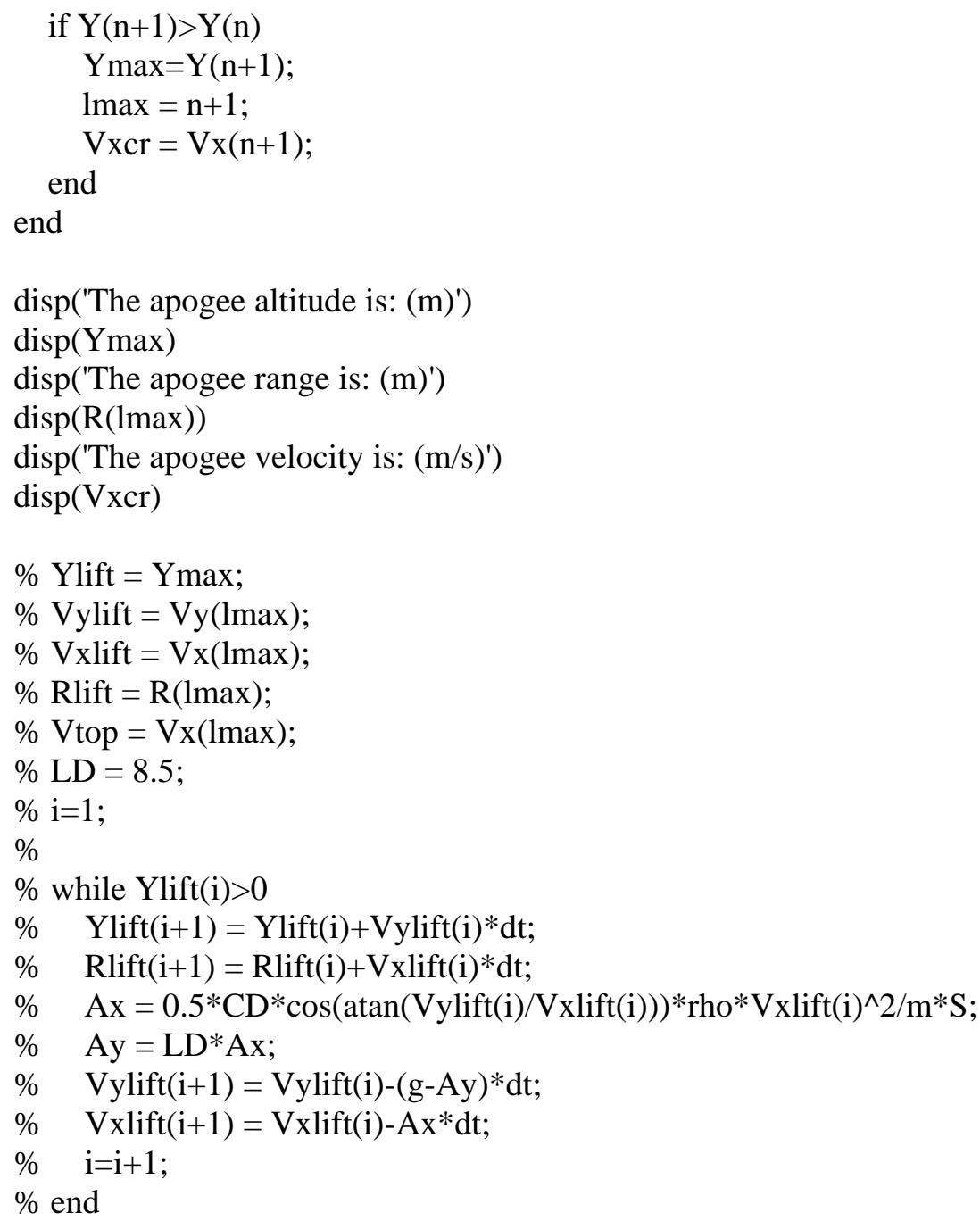




\section{Classical Aerodynamics Optimization Code}

\section{Program Integration Portion:}

$\%$ Hybrid Projectile Performance Analysis

$\%$ Sub-program: Program Integration

$\%$ By: Shanti Hamburg, 5/27/2009, for Ruggedized Stowable MAV Design Study

$\%$

$\%$ Clear variables and command window

clear

clc

$\%$ Call atmospheric and performance input data

Atmosphere_and_Performance_Input

$\mathrm{AR}=[2.5]$

ARcount $=1$;

while ARcount $<=\max (\operatorname{size}(\mathrm{AR}))$

AR_M = AR(ARcount);

Vopt $=1$

count $=0$;

$\mathrm{WS}=25$;

while Vopt $<$ Vcr \& \& count $<100000$

$\mathrm{WS}=\mathrm{WS}+25$;

$\%$ Call main wing input data

Main_Wing_Input

if count $>=1$

CbarCG = CbarCG_old;

end

$\mathrm{S} \_\mathrm{H}=-0.0001$;

count $2=0$

while S_H/S_M $<0.005 \& \&$ count $2<100000000$

$\%$ Call horizontal tail input data

H_Tail_Input

$\%$ Call fuselage performance calculation

$\% \quad$ Fuselage_Performance

\% Call main wing performance calculation

Main_Wing_Performance

$\%$ Call longitudinal stability and horizontal tail sizing

Longitude_Stability

CbarCG = CbarCG-0.00001;

$\mathrm{HM}=\mathrm{S} \_\mathrm{H} / \mathrm{S} \_\mathrm{M}$; 


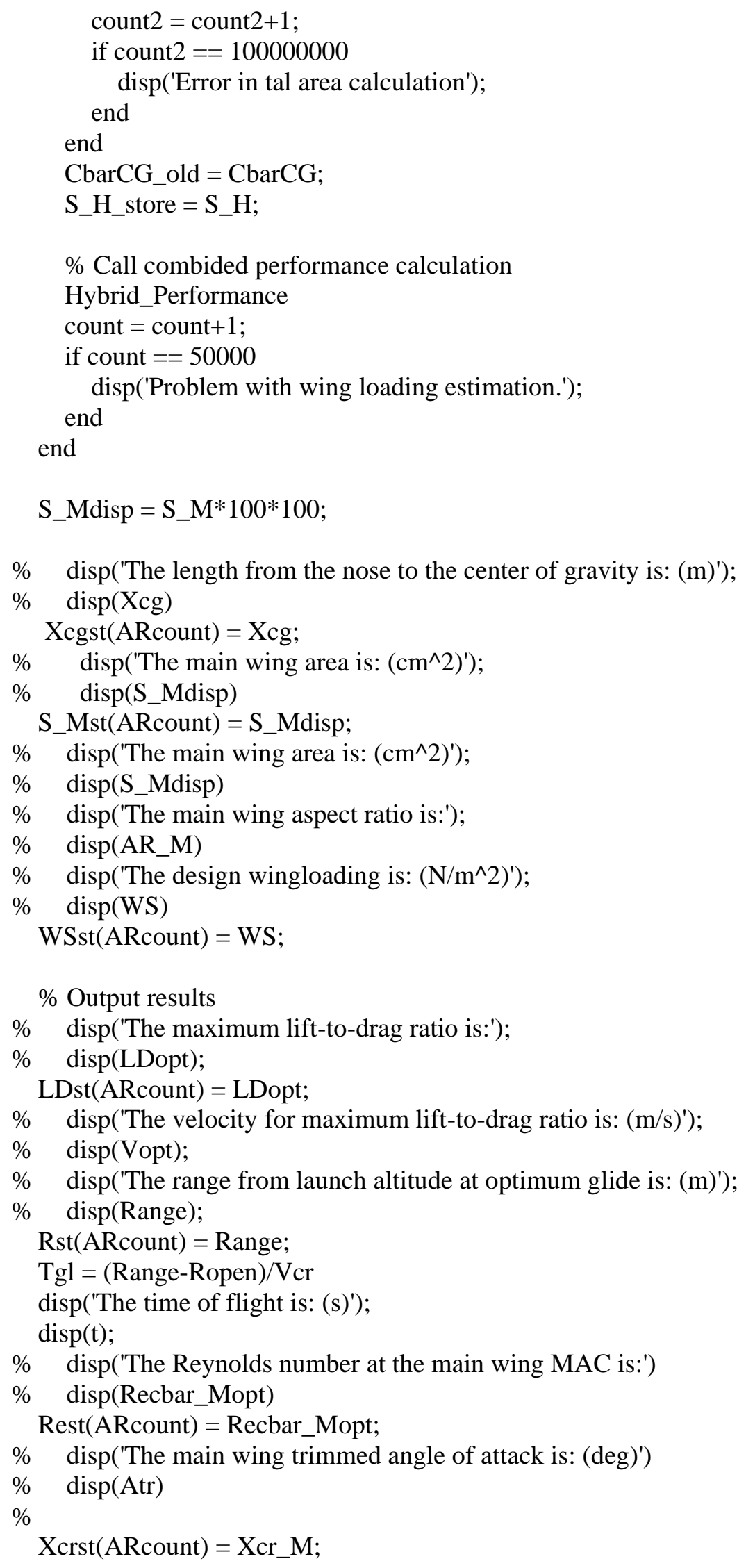




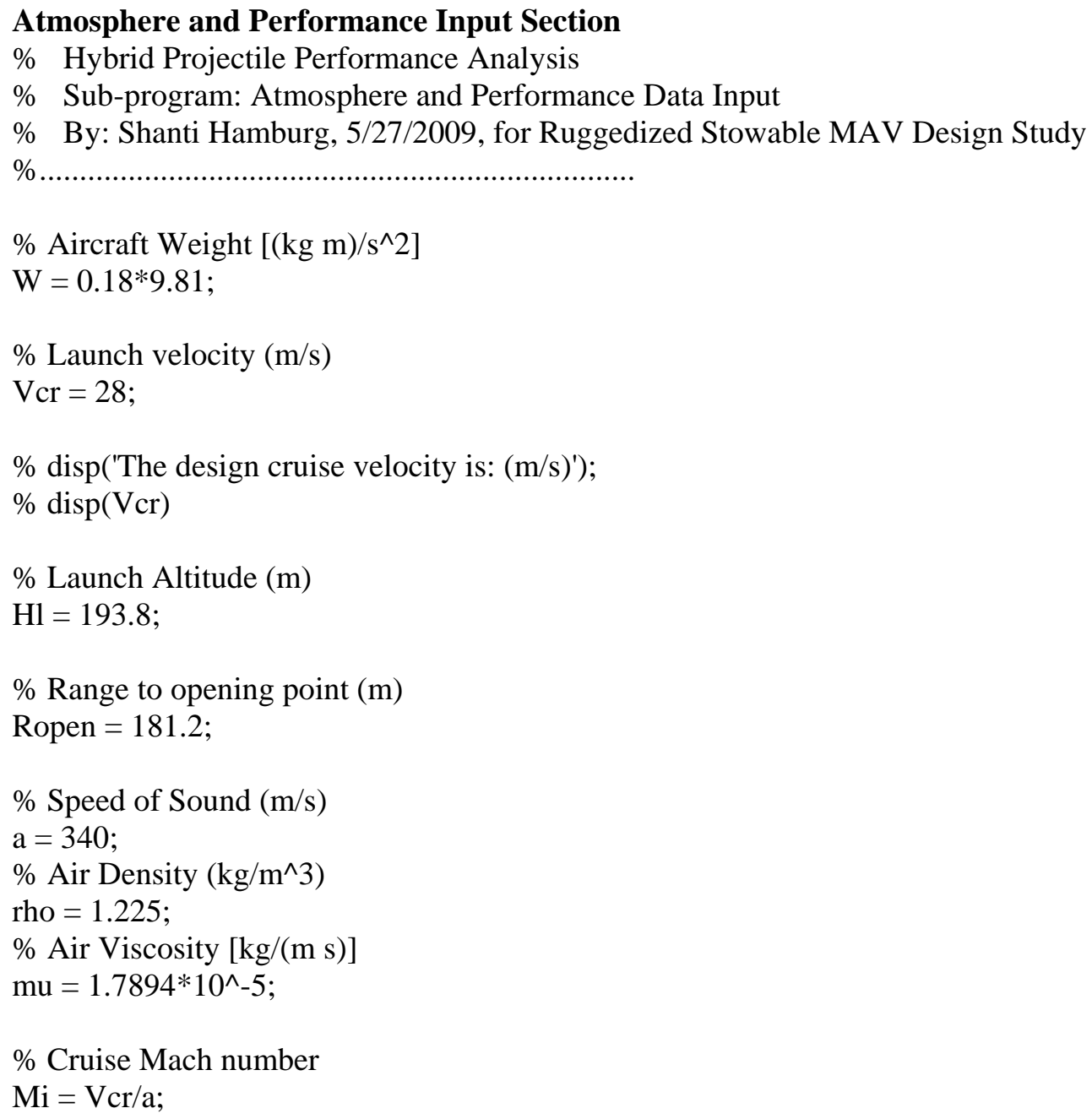




\section{Main Wing Input Section}

$\%$ Hybrid Projectile Performance Analysis

$\%$ Sub-program: Main Wing Data Input \& geometry calculation

$\%$ By: Shanti Hamburg, 5/27/2009, for Ruggedized Stowable MAV Design Study

$\%$.

$\%$ Wing loading $\left(\mathrm{N} / \mathrm{m}^{\wedge} 2\right)$

$\% \mathrm{WS}=200$

$\%$ Aspect Ratio

$\% \mathrm{AR} \_\mathrm{M}=2.5$;

$\%$ Center of gravity, distance forward of wing Xac as a ratio of mean

$\%$ aerodynamic chord

$\mathrm{CbarCG}=.4$;

$\%$ Leading edge sweep angle (deg)

GLE_M = 0;

$\%$ Taper ratio

LA_M $=1$;

$\%$ Root Chord Leading Edge Location (m)

$\% \mathrm{Xcr} \_\mathrm{M}=.05$;

$\%$ Chord location of maximum airfoil thickness (decimal of chord length)

Xtc_M = 0.4;

$\%$ Maximum airfoil thickness to chord ratio

TC_M $=0.1$;

$\%$ Zero lift angle of attack (deg)

A0L_M $=-3$;

$\% \% \% \% \% \% \% \% \% \%$ END MAIN WING INPUT DATA

\%\%\%\%\%\%\%\%\%\%\%\%\%\%\%\%\%\%\%\%\%\%\%\%\%\%\%\%\%\%\%\%\%\%\%\%\%\%\%

$\%$ Wing area $\left(\mathrm{m}^{\wedge} 2\right)$

$\mathrm{S} \_\mathrm{M}=\mathrm{W} / \mathrm{WS}$;

$\%$ Wingspan (m)

b_M $=\left(S \_M^{*} A R \_M\right)^{\wedge} 0.5$;

$\%$ Root chord (m)

cr_M $=2 * b \_M /\left(A R \_M *\left(1+L A \_M\right)\right)$;

$\%$ Tip chord length $(\mathrm{m})$

ct_M = LA_M*cr_M;

$\%$ Mean aerodynamic chord $(\mathrm{m})$ 


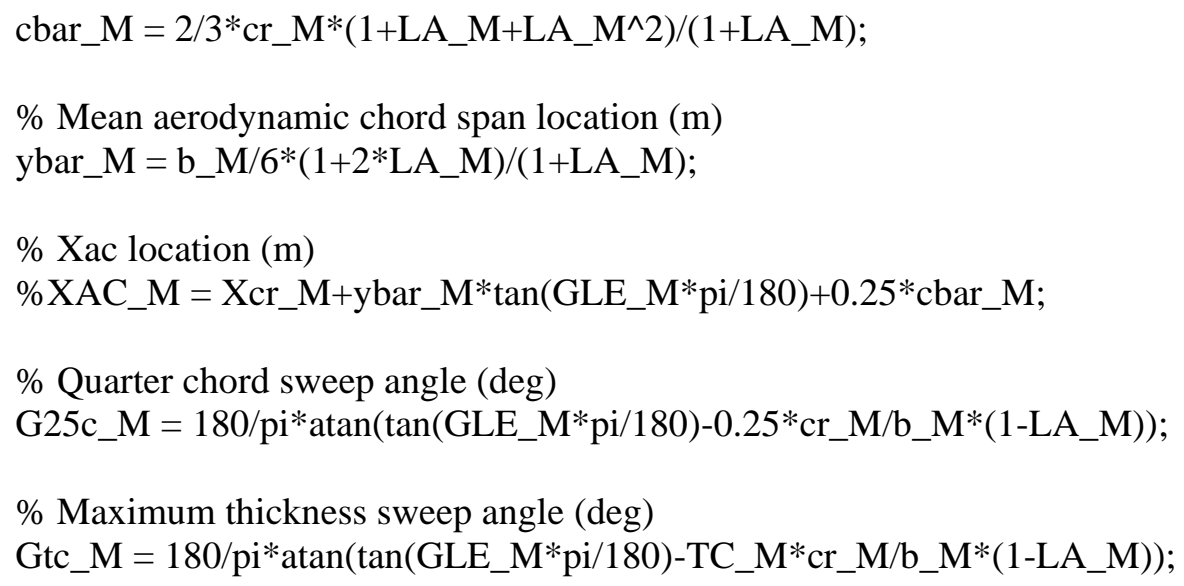




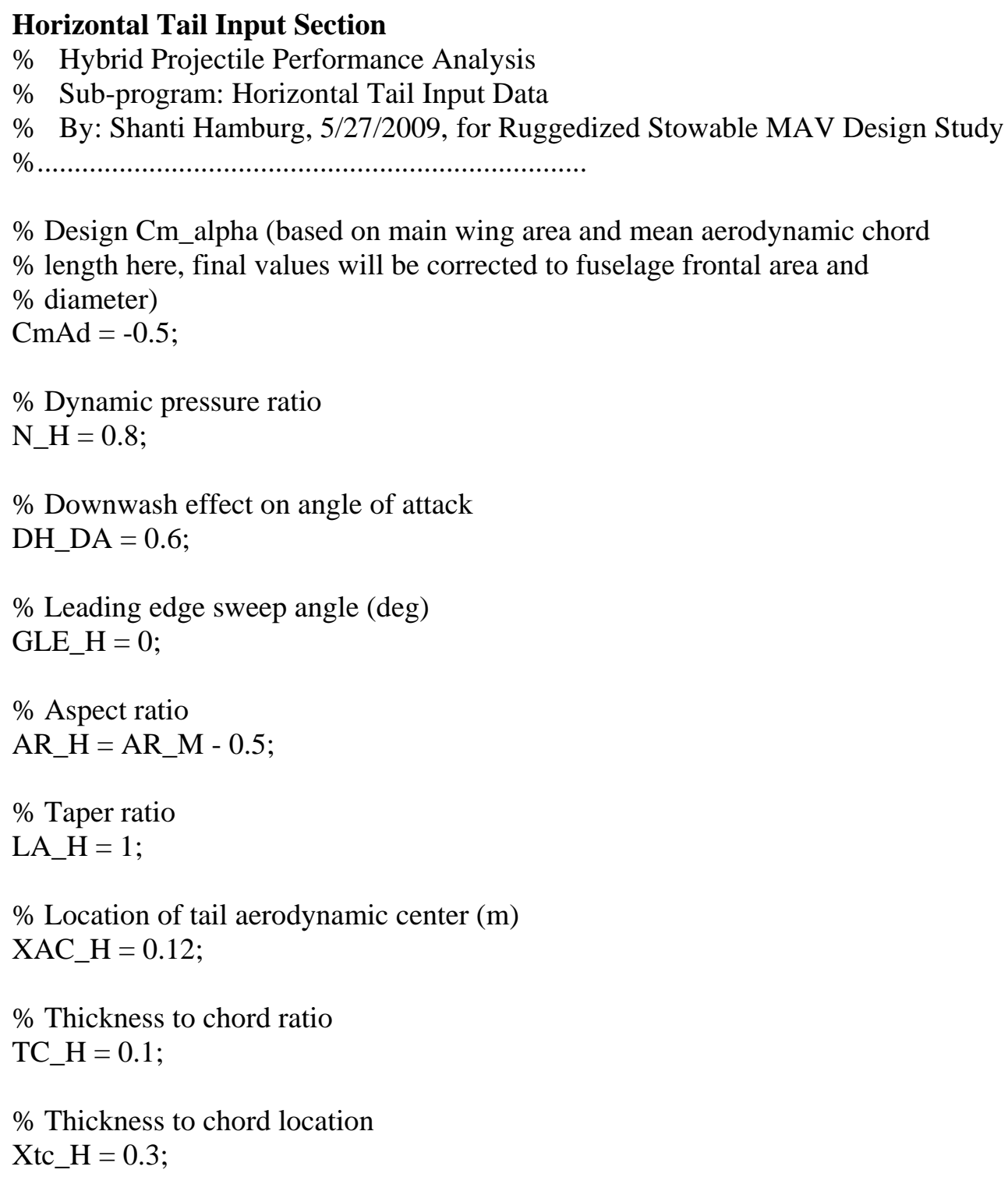




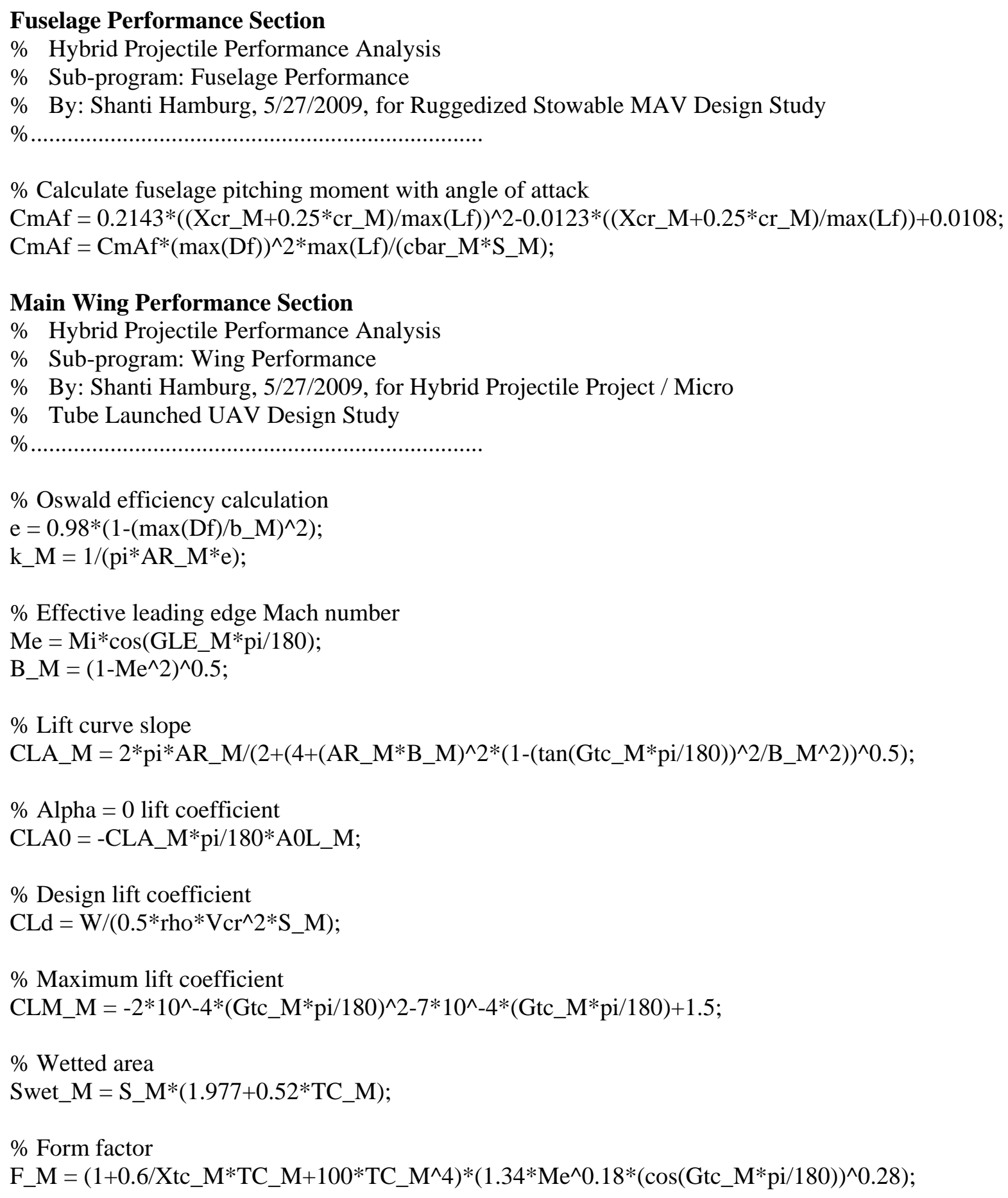

\section{Main Wing Performance Section}

$\%$ Hybrid Projectile Performance Analysis

$\%$ Sub-program: Wing Performance

$\%$ By: Shanti Hamburg, 5/27/2009, for Hybrid Projectile Project / Micro

$\%$ Tube Launched UAV Design Study

$\%$.

$\%$ Oswald efficiency calculation

$\mathrm{e}=0.98 *\left(1-\left(\max (\mathrm{Df}) / \mathrm{b} \_\mathrm{M}\right)^{\wedge} 2\right)$;

$\mathrm{k} \_\mathrm{M}=1 /\left(\mathrm{pi} * \mathrm{AR} \_\mathrm{M}^{*} \mathrm{e}\right)$;

$\%$ Effective leading edge Mach number

$\mathrm{Me}=\mathrm{Mi} * \cos \left(\mathrm{GLE} \_\mathrm{M} * \mathrm{pi} / 180\right)$;

B_M $=\left(1-\mathrm{Me}^{\wedge} 2\right)^{\wedge} 0.5$;

$\%$ Lift curve slope

CLA_M $=2 *$ pi $\left.* A R \_M /\left(2+\left(4+\left(A R \_M * B \_M\right)^{\wedge} 2 *\left(1-\left(\tan \left(G t c \_M * p i / 180\right)\right)\right)^{\wedge} 2 / B \_M^{\wedge} 2\right)\right)^{\wedge} 0.5\right)$;

$\%$ Alpha $=0$ lift coefficient

CLA0 = -CLA_M*pi/180*A0L_M;

$\%$ Design lift coefficient

$\mathrm{CLd}=\mathrm{W} /\left(0.5 * \mathrm{rho}^{*} \mathrm{Vcr}^{\wedge} 2 * \mathrm{~S} \_\mathrm{M}\right)$;

$\%$ Maximum lift coefficient

CLM_M $=-2 * 10^{\wedge}-4 *\left(\mathrm{Gtc} \_\mathrm{M} * \mathrm{pi} / 180\right)^{\wedge} 2-7^{*} 10^{\wedge}-4 *\left(\mathrm{Gtc} \_\mathrm{M} * \mathrm{pi} / 180\right)+1.5$;

$\%$ Wetted area

Swet_M = S_M*(1.977+0.52*TC_M);

$\%$ Form factor

$\mathrm{F} \_\mathrm{M}=\left(1+0.6 / \mathrm{Xtc} \_\mathrm{M} * \mathrm{TC} \_\mathrm{M}+100 * \mathrm{TC} \_\mathrm{M}^{\wedge} 4\right) *\left(1.34 * \mathrm{Me}^{\wedge} 0.18 *\left(\cos \left(\mathrm{Gtc} \_\mathrm{M} * \mathrm{pi} / 180\right)\right)^{\wedge} 0.28\right)$; 


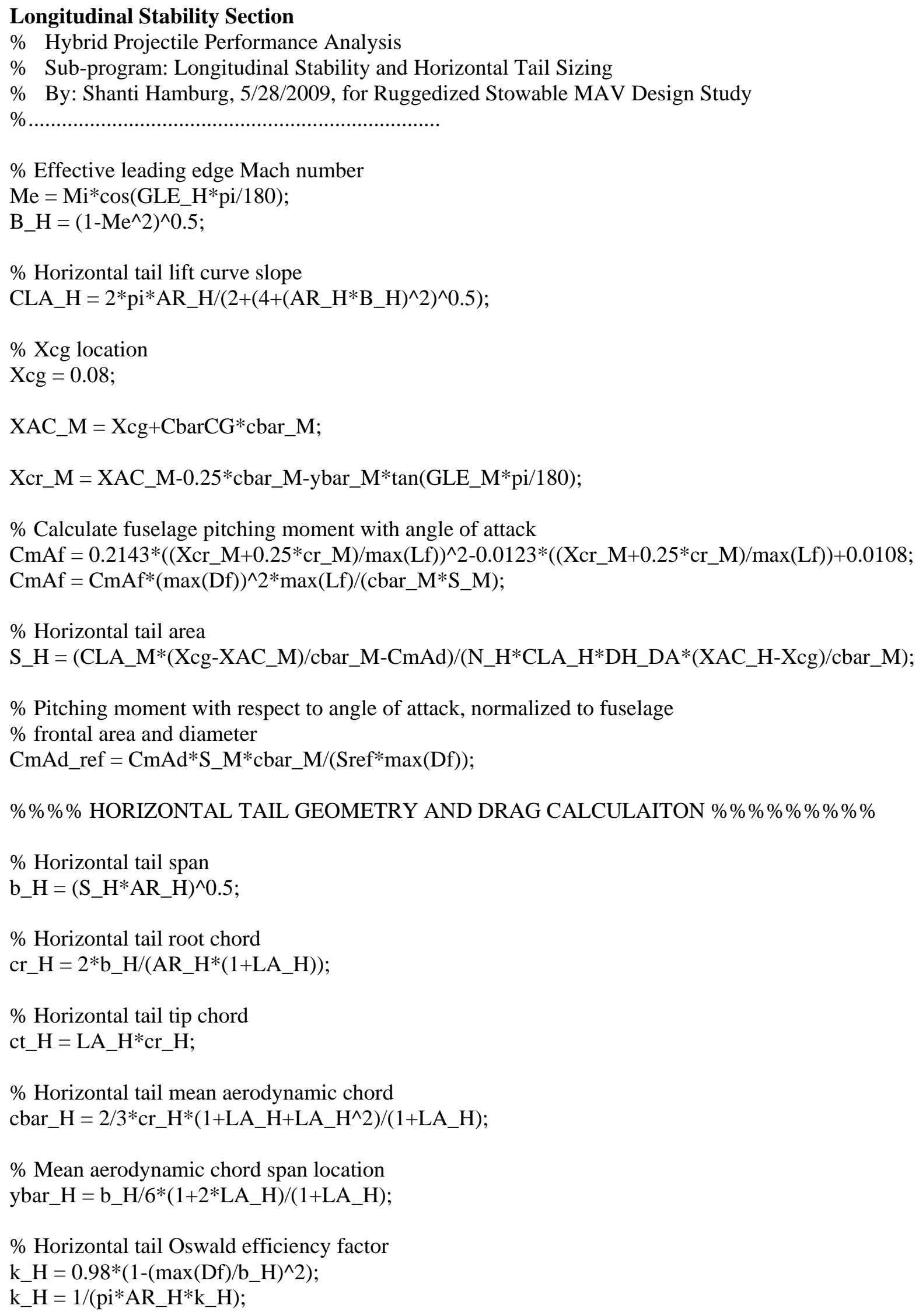


$\%$ Wetted area

Swet_H $=$ S_H*(1.977+0.52*TC_H);

$\%$ Form factor (assumes that Xtc sweep angle $=0$ )

$\mathrm{F} \_\mathrm{H}=\left(1+0.6 / \mathrm{Xtc} \_\mathrm{H} * \mathrm{TC} \_\mathrm{H}+100 * \mathrm{TC} \_\mathrm{H}^{\wedge} 4\right) *\left(1.34 * \mathrm{Me}^{\wedge} 0.18^{*} 1^{\wedge} 0.28\right)$; 


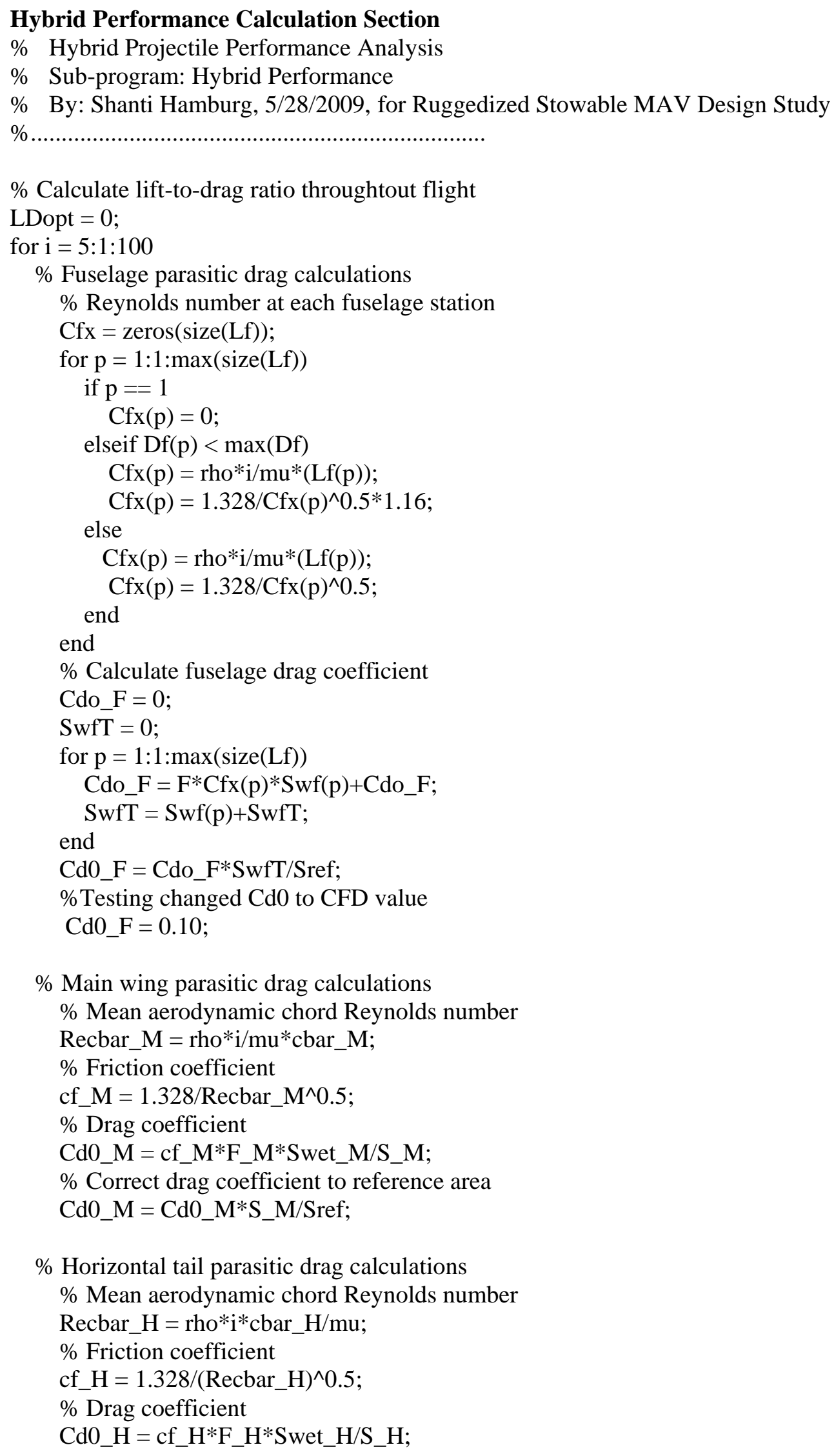


$\%$ Correct drag coefficient to reference area

Cd0_H = Cd0_H*S_H/Sref;

$\% \quad \%$ Vertical tail parasitic drag calculations

$\% \quad \%$ Mean aerodynamic chord Reynolds number

$\% \quad$ Recbar_V $=$ rho*i*cbar_V/mu;

$\% \quad \%$ Friction coefficient

$\% \quad$ cf_V $=1.328 /(\text { Recbar_V })^{\wedge} 0.5$

$\% \quad \%$ Drag coefficient

$\% \quad \mathrm{Cd} 0 \_\mathrm{V}=\mathrm{cf} \_\mathrm{V} * \mathrm{~F} \_\mathrm{V} * \mathrm{Swet}$-V/S_V ;

$\% \quad \%$ Correct drag coefficient to reference area

$\% \quad \mathrm{Cd} 0 \_\mathrm{V}=\mathrm{Cd} 0 \_\mathrm{V} * \mathrm{~S} \_\mathrm{V} / \mathrm{Sref}$;

$\mathrm{Cd} 0=\mathrm{Cd} 0 \_\mathrm{F}+\mathrm{Cd} 0 \_\mathrm{M}+\mathrm{Cd} 0 \_\mathrm{H} ; \%+\mathrm{Cd} 0 \_\mathrm{V}$;

$\mathrm{CL}(\mathrm{i})=\mathrm{W} /\left(0.5 * \mathrm{rho}^{*} \mathrm{i}^{\wedge} 2 * \mathrm{~S} \_\mathrm{M}\right)$;

$\mathrm{DI}(\mathrm{i})=\mathrm{k} \_\mathrm{M} * \mathrm{CL}(\mathrm{i})^{\wedge} 2 * \mathrm{~S} \_\mathrm{M} * 0.5 * \mathrm{rho}^{*} \mathrm{i}^{\wedge} 2$;

$\mathrm{DP}(\mathrm{i})=\mathrm{Cd} 0 * 0.5 *$ rho $* \mathrm{i}^{\wedge} 2 * \mathrm{Sref}$;

$\mathrm{V}(\mathrm{i})=\mathrm{i}$;

$\mathrm{L}(\mathrm{i})=\mathrm{W}$;

$\mathrm{D}(\mathrm{i})=\mathrm{DP}(\mathrm{i})+\mathrm{DI}(\mathrm{i})$;

$\mathrm{CD}(\mathrm{i})=\mathrm{D}(\mathrm{i}) /\left(\right.$ Sref* $* .5 *$ rho $\left.^{*} \mathrm{i}^{\wedge} 2\right)$;

$\mathrm{LD}(\mathrm{i})=\mathrm{L}(\mathrm{i}) / \mathrm{D}(\mathrm{i})$;

$\mathrm{GS}(\mathrm{i})=\operatorname{atan}(1 / \mathrm{LD}(\mathrm{i}))$;

$\operatorname{Lg}(\mathrm{i})=\mathrm{D}(\mathrm{i}) * \sin (\mathrm{GS}(\mathrm{i}))+\mathrm{W}^{*} \cos (\mathrm{GS}(\mathrm{i}))$;

$\operatorname{Tg}(\mathrm{i})=\mathrm{W}^{*} \sin (\mathrm{GS}(\mathrm{i}))-\mathrm{D}(\mathrm{i}) * \cos (\mathrm{GS}(\mathrm{i}))$;

if $i>1$

if $\mathrm{LD}(\mathrm{i})>\mathrm{LD}(\mathrm{i}-1)$

Vopt $=\mathrm{i}$;

LDopt $=$ LD(i);

Recbar_Mopt $=$ Recbar_M;

$\operatorname{Atr}=(\overline{C L}(\mathrm{i})-\mathrm{CLA}$ ) $/$ CLA_M*180/pi; end

end

if $\mathrm{i}==\mathrm{Vcr}$

$\mathrm{LDcr}=\mathrm{LD}(\mathrm{i})$;

Recbar_Mcr $=$ Recbar_M;

Atrcr $=(C L(i)-C L A 0) / C L A \_M * 180 / p i$;

CLcr $=$ CL(i)*S_M/Sref;

$\mathrm{CDcr}=\mathrm{CD}(\mathrm{i})$;

$\mathrm{CdOcr}=\mathrm{CdO} \mathbf{M}$;

GScr $=180 /$ pi*atan $(1 /$ LDcr $)$;

$\mathrm{Rcr}=\mathrm{Hl} / \tan (\mathrm{GScr} * \mathrm{pi} / 180)$;

tcr $=\mathrm{Rcr} /(\mathrm{Vcr} * \cos (\mathrm{GScr} * \mathrm{pi} / 180))$;

$\mathrm{Cd} 0 \mathrm{Fcr}=\mathrm{Cd} 0 \_\mathrm{F}$;

end

end

$\%$ Optimum glideslope

GSopt $=180 /$ pi*atan(1/LDopt $)$;

$\%$ Maximum range 
Range $=$ Hl $/ \tan (G S o p t *$ pi $/ 180)+$ Ropen;

$\%$ Time of flight

$\mathrm{t}=$ Range $/\left(\operatorname{Vopt}^{*} \cos \left(\mathrm{GSopt}{ }^{*} \mathrm{pi} / 180\right)\right) ;$ 


\section{Appendix D Fluent Configuration Details}

\begin{tabular}{|c|c|c|}
\hline \multicolumn{3}{|c|}{ Fluent 12.4.1 Launcher Settings } \\
\hline Category & Option & Setting \\
\hline Dimension & 2D / 3D & As Appropriate \\
\hline \multirow{2}{*}{ Options } & Double Precision & YES \\
\cline { 2 - 3 } & Use Job Scheduler & NO \\
\cline { 2 - 3 } & Use Remote Linux Nodes & NO \\
\hline \multirow{2}{*}{ Display Options } & Display Mesh After Reading & YES \\
\cline { 2 - 3 } & Embed Graphics Windows & NO \\
\cline { 2 - 3 } & Workbench Color Scheme & YES \\
\hline \multirow{2}{*}{ Processing Options } & Serial & NO \\
\cline { 2 - 3 } & Parallel (Local Machine) & YES \\
\cline { 2 - 3 } & Number of Processors & 4 \\
\hline Version & 12.1.4 & Default \\
\hline Parallel Settings & Interconnects & Default \\
\cline { 2 - 3 } & MPI Types & Shared on Local \\
\cline { 2 - 3 } & Run Types & \\
\cline { 2 - 3 } & &
\end{tabular}

\begin{tabular}{|c|c|}
\hline \multicolumn{2}{|c|}{ Fluent 12.4.1 Solver Settings, Problem Setup, General } \\
\hline Mesh & \\
\hline Scale & Convert milimeter mesh to meters \\
\hline Check & Check for grid problems \\
\hline Report Quality & Check skewness $<0.9$ \\
\hline \multicolumn{2}{|l|}{ Solver } \\
\hline Type & Pressure-Based \\
\hline Velocity Formulation & Absolute \\
\hline Time & As Appropriate \\
\hline Gravity & NO \\
\hline Units & Default \\
\hline
\end{tabular}

\begin{tabular}{|l|c|}
\hline \multicolumn{2}{|c|}{ Fluent 12.4.1 Solver Settings, Problem Setup, Models } \\
\hline Multiphase & Off \\
\hline Energy & Off \\
\hline Viscous & As discussed \\
\hline Radiation & Off \\
\hline Heat Exchanger & Off \\
\hline Species & Off \\
\hline Discrete Phase & Off \\
\hline Solidification \& Melting & Off \\
\hline Acoustics & Off \\
\hline
\end{tabular}




\begin{tabular}{|l|c|}
\hline \multicolumn{2}{|c|}{ Fluent 12.4.1 Solver Settings, Problem Setup, Materials } \\
\hline Fluid & Air \\
\hline Solid & Aluminum \\
\hline
\end{tabular}

\begin{tabular}{|l|c|}
\hline \multicolumn{2}{|c|}{ Fluent 12.4.1 Solver Settings, Problem Setup, Cell Zone Conditions } \\
\hline All Cells & Fluid \\
\hline Oprating Conditions \\
\hline Operating Pressure $\left(\boldsymbol{N} / \mathbf{m}^{\mathbf{2}}\right)$ & 101325 \\
\hline Reference Pressure Location & $\mathrm{X}=-0.9$ \\
\cline { 2 - 2 } & $\mathrm{Y}=0$ \\
\cline { 2 - 2 } & $\mathrm{Z}=0$ \\
\hline
\end{tabular}

\begin{tabular}{|l|c|}
\hline \multicolumn{2}{|c|}{ Fluent 12.4.1 Solver Settings, Problem Setup, Boundary Conditions } \\
\hline Inlet & Velocity Inlet \\
\hline Outlet & Pressure Outlet \\
\hline Surface & Default Wall \\
\hline Interior & Interior \\
\hline Interface & Interior \\
\hline
\end{tabular}

\begin{tabular}{|l|c|}
\hline \multicolumn{2}{|c|}{ Fluent 12.4.1 Solver Settings, Problem Setup, Reference Values } \\
\hline Area $\left(\mathrm{m}^{2}\right)$ & 0.001266 \\
\hline Density $\left(\mathrm{kg} / \mathrm{m}^{3}\right)$ & 1.225 \\
\hline Length $(\mathbf{1})$ & 1 \\
\hline Temperature $(\boldsymbol{K})$ & 288.16 \\
\hline Velocity $(\mathrm{m} / \mathrm{s})$ & As Appropriate \\
\hline Viscosity $(\mathrm{kg} /(\mathrm{m} \mathbf{s}))$ & $1.7894 \times 10^{-5}$ \\
\hline Ratio of Specific Heats & 1.4 \\
\hline
\end{tabular}

\begin{tabular}{|l|c|}
\hline \multicolumn{2}{|c|}{ Fluent 12.4.1 Solver Settings, Solution, Solution Methods } \\
\hline Scheme & SIMPLE \\
\hline Gradient & Green-Gauss node Based \\
\hline Pressure & Second Order \\
\hline All Others & Second Order Upwind \\
\hline
\end{tabular}

\begin{tabular}{|l|c|}
\hline \multicolumn{2}{|c|}{ Fluent 12.4.1 Solver Settings, Solution, Solution Controls } \\
\hline Under-Relaxation Factors & Default \\
\hline Solution Limits & Default \\
\hline
\end{tabular}




\begin{tabular}{|c|c|}
\hline \multicolumn{2}{|c|}{ Fluent 12.4.1 Solver Settings, Solution, Monitors } \\
\hline \multicolumn{2}{|l|}{ Residual Monitor } \\
\hline Print to Console & Yes \\
\hline Plot & Yes \\
\hline Convergence Criterion & None \\
\hline \multirow[t]{5}{*}{ Equations to Monitor } & Continuity \\
\hline & X-Velocity \\
\hline & Y-Velocity \\
\hline & Z-Velocity \\
\hline & Turbulence Model Parameters \\
\hline \multicolumn{2}{|l|}{ Drag Monitor } \\
\hline Print to Console & Yes \\
\hline Plot & Yes \\
\hline Force Vector & $(X=1)(Y=0)(Z=0)$ \\
\hline \multirow[t]{2}{*}{ Axis Limits } & X Axis (Auto Range) \\
\hline & Y Axis $(0.0-0.2)$ \\
\hline \multicolumn{2}{|l|}{ Drag Monitor } \\
\hline Print to Console & Yes \\
\hline Plot & Yes \\
\hline Force Vector & $(X=0)(Y=1)(Z=0)$ \\
\hline \multirow[t]{2}{*}{ Axis Limits } & X Axis (Auto Range) \\
\hline & Y Axis (0.0 - 0.2) \\
\hline
\end{tabular}

Fluent 12.4.1 Solver Settings, Solution, Solution Initialization

\begin{tabular}{|l|c|}
\hline Gauge Pressure $\left(\mathrm{N} / \mathrm{m}^{2}\right)$ & 0 \\
\hline X Velocity $(\mathrm{m} / \mathrm{s})$ & 0 \\
\hline Y Velocity $(\mathrm{m} / \mathrm{s})$ & 0 \\
\hline Z Velocity $(\mathrm{m} / \mathrm{s})$ & 0 \\
\hline Turbulence Parameters & (Problem Dependent, Defaults Used) \\
\hline
\end{tabular}

Fluent 12.4.1 Solver Settings, Solution, Calculation Activities

\begin{tabular}{|l|c|}
\hline Autosave Every (Iterations) & 500 \\
\hline When Data File Saved Save Case & If Modifified \\
\hline Retain Only Most Recent Files & YES \\
\hline Maximum Number of Data Files & 2 \\
\hline File Name & As Appropriate \\
\hline
\end{tabular}

\begin{tabular}{|l|c|}
\hline \multicolumn{2}{|c|}{ Fluent 12.4.1 Solver Settings, Solution, Run Calculation } \\
\hline Check Case & YES \\
\hline Number of Iterations & Problem Dependent \\
\hline Reporting Interval & 1 \\
\hline Profile Update Interval & 1 \\
\hline
\end{tabular}




\section{Appendix E Curriculum Vitae}

\section{Shanti D. Hamburg}

884 TREMONT ST. • MORGANTOWN, WEST VIRGINIA • 26505

(304) 290-2628•SHAMBURG@GMAIL.COM

EDUCATION

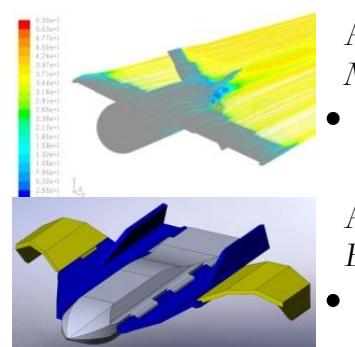

August 2007 - August 2010

MS, Aerospace Engineering

West Virginia University CEMR

Morgantown, West Virginia

- Thesis Title: Conceptual and Preliminary Design of a Ruggedized Stowable Micro Air Vehicle

August 2002 - May 2007

BS, Aerospace Engineering, BS, Mechanical Engineering

- Grade Point Average: 3.1
West Virginia University CEMR Morgantown, West Virginia

\section{RELEVANT TECHNICAL ELECTIVES}

Flight Controls • Flight Simulation • Fundamentals of Computational Fluid Dynamics $\bullet$ Guided Missile Systems - Hybrid Vehicle Design - Mechanics of Composite Materials - Professional Engineering CAD • Structural Finite Element Analysis - Turbulent Fluid Flow • Unmanned Aerial Vehicle Design

\section{WORK EXPERIENCE}

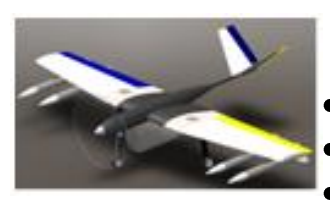

August 2006 - August 2009

Teaching Assistant for UAV Design Team

West Virginia University CEMR

- Team organization, grading, and project schedule management

- Program financial management, college, alumni, and corporate fund raising

- Instructing and aiding students in small aircraft design and composite manufacturing

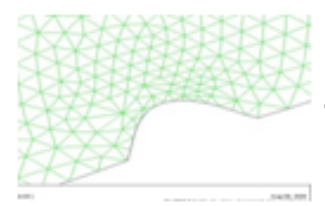

June 2008 - September 2008

West Virginia University CEMR Research Assistant

Morgantown, West Virginia

- Assisted in the design and execution of Fluent CFD models of dynamic roughness elements on airfoils at high angles of attack

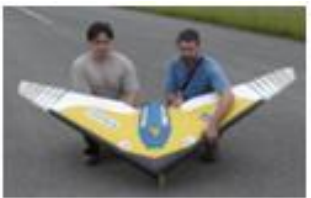

May 2007 - June 2007

West Virginia University CEMR

Research Assistant

Morgantown, West Virginia

- Assisted in the design and construction of a $7 \mathrm{ft}$ span tailless flying wing with functional morphing control surfaces

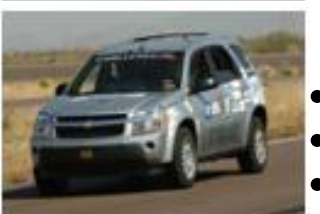

August 2006 - May 2007

Co-Capitan of Challenge X Hybrid Vebicle Design Team

West Virginia University CEMR

Morgantown, West Virginia

- Assisted with team organization and community outreach.

- Facilitated cooperation between IC engine, software controls, and hybrid system sub-teams

- Arranged component and equipment sponsorships

- Modeled hybrid system components and assemblies in Pro/Engineer 
October 2005 - January 2006

Research Assistant

- Developed structure and built wind tunnel models

- Studied the performance of small scale, low aspect ratio ground effect aircraft for personal use

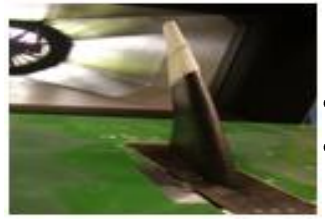

March 2005 - May 2005

Research Assistant

- Constructed wind tunnel models

- Studied the benefits of an active aeroelastic (morphing) control system compared to a conventional flapped system as applied to a Horten-type tailless flying wing

December 2002 - January 2003

Ski Instructor

Snowshoe Ski Resort Snowshoe, West Virginia

- Taught three to twelve year old children the basic techniques and safety measures involved with the sport of skiing

- Gained interpersonal skills in instruction and customer relations

EXTRACURICCULAR ACTIVITIES

- Team Leader, WVU Unmanned Aerial Vehicle Design Team, August 2005 - May 2006

- Co-Capitan of WVU Challenge X diesel-electric hybrid vehicle design \& construction team, August 2006 - May 2007

- Secretary and Public Relations Officer for WVU American Institute of Aeronautics and Astronautics student chapter, August 2004 - May 2007

- Member, WVU Habitat for Humanity student chapter, January 2004 - December 2006

- Member, WVU Unmanned Aerial Vehicle Design Team, August 2003 - May 2005

\section{RELEVANT SKILLS}

- Experience with the Fluent CFD Package

- Experience with Missile DATCOM semi-empirical projectile analysis code

- Experience with basic composite mold and component fabrication

- Experience with basic operation of D-Six and FDC flight simulator packages

- Experience with MATLAB and Simulink mathematics and control packages

- Experience with ANSYS structural analysis

- Experience with Pro/Engineer and SolidWorks solid modeling packages

- Experience with rapid 3D printer and laser cutter rapid prototyping equipment

- Experience with computer system construction, networking, and troubleshooting

- Experience with all standard digital office applications 